\title{
H-Area/ITP Geostatistical Assessment of In-Situ and Engineering Properties
}

by

D. Wyatt

Westinghouse Savannah River Company

Savannah Piver Site

Aiken, South Carolina 29808

Point of Contact, P. Casey Knapp, 2-6515

S. F. Bartlett

S. Rouhani

Y. Lin

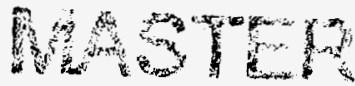

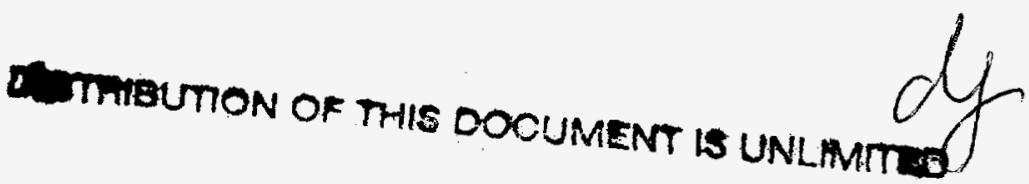

DOE Contract No. DE-AC09-96SR18500

This paper was prepared in connection with work done under the above contract number with the $U$. S.

Department of Energy. By acceptance of this paper, the publisher and/or recipient acknowledges the U. S. Government's right to retain a nonexclusive, royalty-free license in and to any copyright covering this paper, along with the right to reproduce and to authorize others to reproduce all or part of the copyrighted paper. 


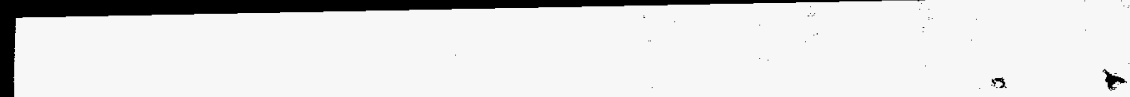




\section{DISCLAIMER}

This report was prepared as an account of work sponsored by an agency of the United States Government. Neither the United States Government nor any agency thereof, nor any of their employees, makes any warranty, express or implied, or assumes any legal liability or responsibility for the accuracy, completeness, or usefulness of any information, apparatus, product, or process disclosed, or represents that its use would not infringe privately owned rights. Reference herein to any specific commercial product, process, or service by trade name, trademark, manufacturer, or otherwise does not necessarily constitute or imply its endorsement, recommendation, or favoring by the United States Government or any agency thereof. The views and opinions of authors expressed herein do not necessarily state or reflect those of the United States Government or any agency thereof.

This report has been reproduced directly from the best available copy.

Available to DOE and DOE contractors from the Office of Scientific and Technical Information, P.O. Box 62, Oak Ridge, TN 37831; prices available from (615) 576-8401.

Available to the public from the National Technical Information Service, U.S. Department of Commerce, 5285 Port Royal Road, Springfield, VA 22161. 


\section{DISCLAIMER}

Portions of this document may be illegible electronic image products. Images are produced from the best available original document. 


$$
\text { WSRC-TR-98- } \triangle \Delta 88
$$

\title{
H-Area/ITP Geostatistical Assessment \\ of \\ In-situ and Engineering Properties
}

Final Technical Report

by:

Shahrokh Rouhani", Ph.D., P.E., Steven F. Bartlett"*, Ph.D.

Yu-Pin Lin", Ph.D., and Yong Shi*

"School of Civil and Environmental Engineering

Georgia Institute of Technology

Atlanta, Georgia 30332-0355

and

"Site Geotechnical Services Department

Westinghouse Savannah River Company (WSRC)

Aiken, SC 29802

\author{
ERDA Project Number: 93044 \\ In Response to: \\ SRS Request for Proposal Number 93044EQ \\ January 4, 1994 \\ (Revised Statement of Scope Number 93044, Revision 0, December 1, \\ 1993)
}

Sponsor Technical Representative:

S. F. Bartlett, Ph.D.

Site Geotechnical Services Department

Westinghouse Savannah River Company (WSRC)

Aiken, SC 29802

September 5, 1995 


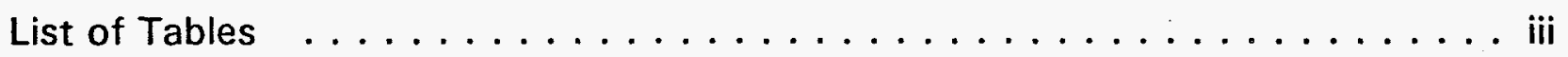

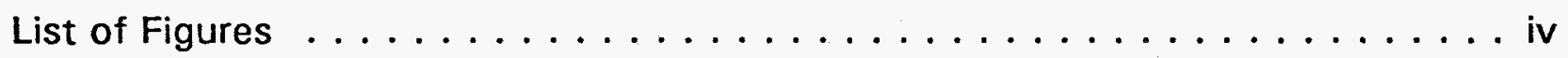

Executive Summary $\ldots \ldots \ldots \ldots \ldots \ldots \ldots \ldots \ldots \ldots \ldots \ldots \ldots \ldots$

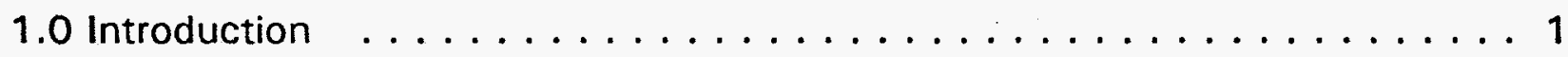

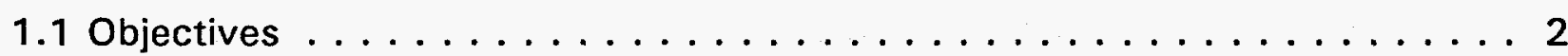

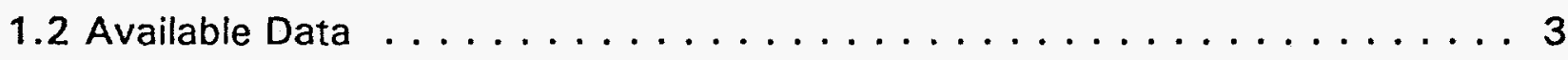

2.0 Geostatistical Methodology $\ldots \ldots \ldots \ldots \ldots \ldots \ldots \ldots \ldots$

2.1 Geostatistical Structural Analysis . . . . . . . . . . . . . 7

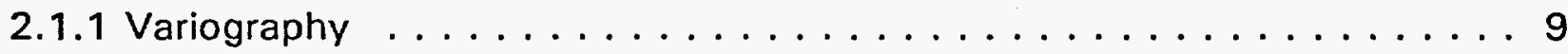

2.2 Geostatistical Estimation . . . . . . . . . . . . . . . . . 10

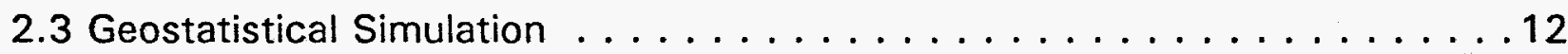

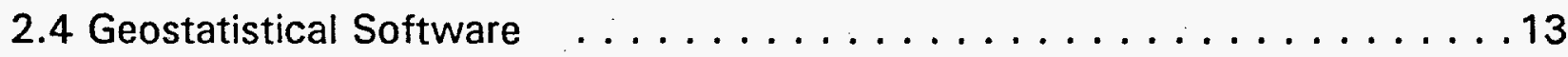

3.0 Geostatistical Analysis of CPT Data $\ldots \ldots \ldots \ldots \ldots \ldots$

3.1 Variogram Analysis of CPT Data . . . . . . . . . . . . . 17

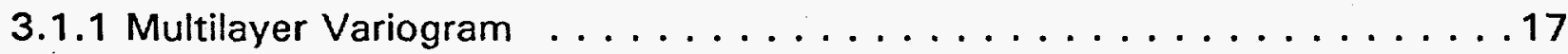

3.1.2 Soft Zones Categorical Variogram Analysis (CPT Data) $\ldots \ldots \ldots \ldots 18$

3.1.3 Soft Zones Categorical Variogram Analysis (SPT Data) . . . . . . . . . 20

3.2 CPT Estimation Results . . . . . . . . . . . . . . . . . . 20

4.0 Geostatistical Simulation of Shear Wave Data $\ldots \ldots \ldots$. . . . . . . 23

4.1 Shear Wave Simulation Results $\ldots \ldots \ldots \ldots \ldots \ldots \ldots$ 


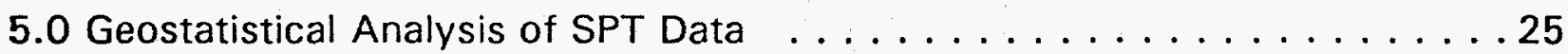

5.1 SPT Estimation and Simulation Results $\ldots \ldots \ldots \ldots \ldots \ldots \ldots$

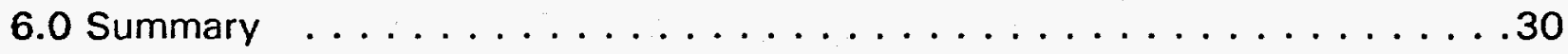

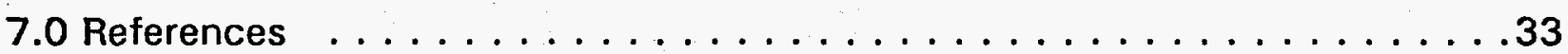

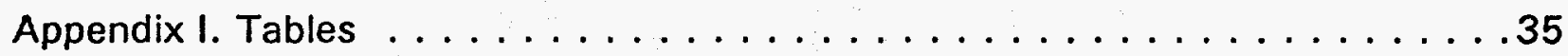

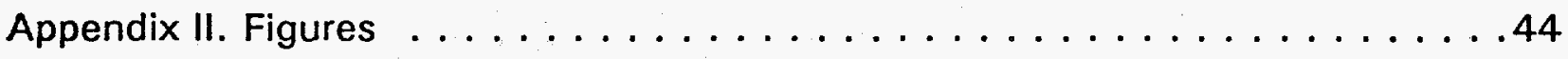

Appendix III. Preliminary Evaluation of OCR from SCPT Data by P. W. Mayne . 89

Appendix IV. List of SCPT Borehole Logs $\ldots \ldots \ldots \ldots 10 \ldots$

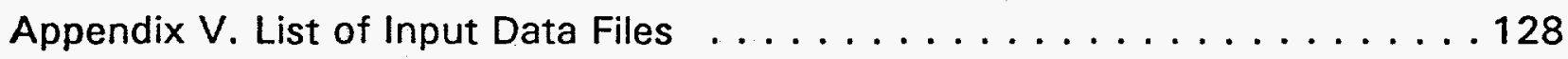

Appendix VI. Regression Analyses and Analysis of Variance . . . . . . . . 131 


\section{LIST OF TABLES}

\section{APPENDIX I}

Table 1.2.1 List of Geological Substrata at the ITP Site

Table 3.0.1 List of Investigated CPT Borehole Data

Table 3.0.2 List of Removed Negative Friction Ratio Data

Table 3.0.3 Measurements with Slightly Negative Tip Resistances

Table 3.0.4 List of Removed Spurious Data in the Fill Layer

Table 3.0.5 List of Removed High Friction Ratio Data

Table 3.1.1 Parameters of Fitted Multi-Layer Variograms of Tip Resistances

Table 5.0.1 Parameters of Fitted Multi-Layer Normal Score Variograms of $\left(N_{1}\right)_{60}$ Values 


\section{LIST OF FIGURES \\ APPENDIX II}

Figure 1.2.1 Savannah River Site H Area In-Take Precipitation (ITP) Exploration Plan

Figure 3.1.1 Lateral and Vertical Variogram of Tip Resistance (Fill Layer)

Figure 3.1.2 Lateral and Vertical Variogram of Tip Resistance (TR1 Layer)

Figure 3.1.3 Lateral and Vertical Variogram of Tip Resistance (TR2 Layer)

Figure 3.1.4 Lateral and Vertical Variogram of Tip Resistance (TR3 Layer)

Figure 3.1.5 Lateral and Vertical Variogram of Tip Resistance (TR4 Layer)

Figure 3.1.6 Lateral and Vertical Variogram of Tip Resistance (DB1 Layer)

Figure 3.1.7 Lateral and Vertical Variogram of Tip Resistance (DB2 Layer)

Figure 3.1.8 Lateral and Vertical Variogram of Tip Resistance (DB3/DB4 Layer)

Figure 3.1.9 Lateral and Vertical Variogram of Tip Resistance (DB5 Layer)

Figure 3.1.10 Lateral and Vertical Variogram of Tip Resistance (Santee Layer)

Figure 3.1.11 Lateral and Vertical Variogram of Tip Resistance (Soft Soil)

Figure 3.1.12 Lateral and Vertical Variogram of Tip Resistance (Intermediate Soil)

Figure 3.1.13 Lateral and Vertical Variogram of Tip Resistance (Stiff Soil)

Figure 3.1.14 Vertical and Directional Lateral Variogram of Tip Resistance along Angle $30^{\circ}$ (Soft Soil)

Figure 3.1.15 Vertical and Directional Lateral Variogram of Tip Resistance along Angle $45^{\circ}$ (Soft Soil)

Figure 3.1.16 Vertical and Directional Lateral Variogram of Tip Resistance along Angle $60^{\circ}$ (Soft Soil)

Figure 3.1.17 Vertical and Directional Lateral Variogram of Tip Resistance along Angle $30^{\circ}$ (Intermediate Soil)

Figure 3.1.18 Vertical and Directional Lateral Variogram of Tip Resistance along Angle $45^{\circ}$ (Intermediate Soil)

Figure 3.1.19 Vertical and Directional Lateral Variogram of Tip Resistance 
along Angle $60^{\circ}$ (Intermediate Soil)

Figure 3.1.20 Vertical and Directional Lateral Variogram of Tip Resistance along Angle $30^{\circ}$ (Stiff Soil)

Figure 3.1.21 Vertical and Directional Lateral Variogram of Tip Resistance along Angle $45^{\circ}$ (Stiff Soil)

Figure 3.1.22 Vertical and Directional Lateral Variogram of Tip Resistance along Angle $60^{\circ}$ (Stiff Soil)

Figure 3.1.23 Lateral and Vertical Variogram (Indicator \#1)

Figure 3.1.24 Lateral and Vertical Variogram (Indicator \#2)

Figure 3.2.1 Kriging Map of Tip Resistance along Cross-Section A-A'

Figure 3.2.2 Kriging Map of Tip Resistance along Cross-Section B-B'

Figure 3.2.3 Cross-Validation Results at SCPT1 (Using within-layer-elevation)

Figure 3.2.4 Cross-Validation Results at SCPT6B (Using within-layer-elevation)

Figure 3.2.5 Cross-Validation Results at SCPT1 (Using within-layer-depth)

Figure 3.2.6 Cross-Validation Results at SCPT6B (Using within-layer-depth)

Figure 4.0.1 Locations of Investigated CPT Boreholes

Figure 4.0.2 Omni-Directional Lateral Variogram of Shear Wave Data

Figure 4.0.3 Omni-Directional Vertical Variogram of Shear Wave Data

Figure 4.1.1 Simulated Shear Wave Velocity Profile using Seed \#1 at $\left(62618^{\prime}, 70825^{\prime}\right)$

Figure 4.1.2 Simulated Shear Wave Velocity Profile using Seed \#1 at $\left(62750^{\prime}, 70825^{\prime}\right)$

Figure 4.1.3 Simulated Shear Wave Velocity Profile using Seed \#1 at $\left(62618^{\prime}, 70952^{\prime}\right)$

Figure 4.1.4 Simulated Shear Wave Velocity Profile using Seed \#1 at $\left(62750^{\prime}, 70952^{\prime}\right)$

Figure 4.1.5 ITP Shear Wave Velocity from SCPT 
Figure 5.0.1 Locations of Combined SPT and CPT-Based Boreholes

Figure 5.1.1 Kriging Map along the East-West Cross-Section at Northing $=70590^{\prime}$

Figure 5.1.2 Kriging Map along a Lateral Sub-Layer at DB1/DB3

Figure 5.1.3 Simulated Map along the East-West Cross-Section at Northing $=70590^{\prime}$

Figure 5.1.4 Simulated Map along a Lateral Sub-Layer at DB1/DB3

Figure 5.1.5 ITP Real and SImulated Data 


\section{EXECUTIVE SUMMARY}

Preliminary field investigations performed for the seismic qualification of the ITP facility identified two issues concerning the foundation soils: (1) potentially liquefiable soils in the upper strata, and (2) a deeper zone of apparently under-consolidated calcareous sediments in the Santee Formation. To estimate the potential amount of surface settlement resulting from a seismic event, WSRC (1995) developed a program plan which detailed further field measurements and subsequent analysis and numerical modeling. As part of developing soil-properties input to this modeling, senior peer reviewers raised questions about how to properly assess the large amount of observed soil variability and how to incorporate the scale of that variability in a manner consistent with the discretization size of the mesh.

Further, the WSRC program plan outlined a probabilistic liquefaction hazard evaluation requiring a stochastical approach to modeling and reliability. To these ends, geostatistical analyses of CPT and SPT measurements from the ITP site were conducted. The results are:

Borehole Data Structure: The borehole data structure displayed a number of distinct characteristics. First, the three-dimensional data resolution was highly imbalanced, with very tight resolution in the vertical direction and orders of magnitude wider resolutions in the lateral direction. This is typical of borehole data because sampling intervals in the vertical direction in a given borehole are on the order of inches to a few feet; whereas, horizontal spacing between boreholes usually varies on the order of tens to hundreds of feet. This imbalance makes three-dimensional estimation somewhat problematic, especially in the horizontal plane. Second, the geological formations clearly exhibited a multi-layer stratigraphy with differing features. Based on these distinct features, each borehole data were divided into a number of substrata by the geological and geotechnical staff at WSRC. Third, the preliminary stratigraphic model of the site showed evidences of faulting and other 
discontinuities in the layered structure.

Complicated Intra-layer Variations: Despite the initial grouping of the borehole data into a number of substrata, in-situ measurements within each layer displayed complicated vertical and lateral variations. These variations, however, were only partially explainable based on deterministic geological and geotechnical models. Therefore, the use of statistical methods became inevitable.

Suitable Statistical Tool: Among statistical methods, geostatistical algorithms appeared to be the most suitable due to a number of reasons. First, geostatistics recognizes the multi-layer, three-dimensional structure of the borehole data. Second, unlike classical statistical procedures, geostatistics incorporates the potential spatial (auto-correlational) structure of the collected data. Third, vertically clustered borehole measurements can be processed by geostatistical methods. Finally, geostatistics offers both estimation and simulation procedures that can be used in a variety of applications.

CPT Variography and Estimation Results: The variography along the vertical direction (i.e., down the borehole) revealed well defined structures with ranges varying between 2 to $12 \mathrm{ft}$, suggesting geological bedding on a scale of this size. The results of the omni-directional lateral variograms revealed more complicated structures than the vertical variograms. The lateral variogram range for different layers varied from 40 to $130 \mathrm{ft}$, except for the Santee Formation which exhibited a lateral pure nugget effect. This implied that the horizontal dimension of the soft zones in the Santee Formation is less than the lateral resolution of the available CPT data.

Using the appropriate vertical and lateral variograms, kriging was used to interpolate CPT tip and sleeve resistances to a FLAC mesh for liquefaction and settlement analyses. The interpolated values were done layer-by-layer to preserve the multi-layered structure at ITP. 
Soft Zone Categorical Variography in the Santee Formation: Attempts to define the lateral dimensions of the soft zones in the Santee Formation were unsuccessful using the CPT data solely. Thus, the SPT borings were also analyzed because of their denser horizontal spacing in the following manner. Measured CPT tip resistances and SPT $\left(N_{1}\right)_{60}$ values in the Santee Formation were categorized into three groups as: Soft, Intermediate, and Stiff soils. Soft soils were defined as sediments having $\left(N_{1}\right)_{60}$ values less than 5 or CPT tip stresses less than 15 tsf. Intermediate soils have $\left(N_{1}\right)_{60}$ values between 5 and 10 or CPT tip stresses between 15 and 40 tsf. Stiff soils have $\left(N_{1}\right)_{60}$ values greater than 10 to CPT tip stresses greater than 40 tsf. Results indicated that: (a) The soft soils have an average thickness of less than $4 \mathrm{ft}$. (b) The average thickness of the combined soft/intermediate soils appeared to be less than $8 \mathrm{ft}$. The combined soft/intermediate soils had a vertical variogram that was not as well-defined as the one for the soft soils). (c) Neither the soft soil, nor the combined soft/intermediate soils showed any discernable lateral correlations. (d) In the absence of lateral discernable correlation, the lateral extent of the soft soils and the combined soft/intermediate soils was approximated to be less than the average borehole spacing which is $35 \mathrm{ft}$.

Shear Wave Variography and Simulation Results: The analysis of shear wave data was initiated by dividing the soil volume in the investigated area into seven different layers: Fill, TR1, TR2, TR3/TR4, DB1/DB4, DB5, and ST. This approach, however, yielded undue discontinuities along the dividing surfaces of the various layers which produced unwanted and artificially high impedance contrasts for dynamic modeling. Therefore, in subsequent simulations the complete formation was considered as a single unit. These simulated results indicated that each simulated profile preserved the spatial variabilities exhibited by the original values.

SPT Simulation versus Estimation Results: For a liquefaction hazard, $\left(N_{1}\right)_{60}$ values were geostatistically simulated and estimated. The comparison of results indicated that: (a) estimation (kriging) results were overly smooth in sparsely sampled 
locations. (b) Conditional simulation results, on the other hand, preserved the variability of $\left(N_{1}\right)_{60}$ values in both dense and sparsely sampled locations. (c) Simulations were significantly more time consuming than estimation. However, in cases where geostatistical results are intended to be used as input into other numerical models and preservation of the stochastic variability of these inputs are critical to the study objectives, then simulation rather than estimation should be used. 


\subsection{INTRODUCTION}

The following technical report describes the results of a geostatistical investigation conducted in response to tasks and requirements set out in the SRS Request for Proposal Number 93044EO, dated January 4, 1994. The project tasks were defined in the Statement of Scope (SOS) Number 93044, Revision 0, dated December 1, 1993, developed by the Savannah River Site Geotechnical Services Department.

Foundation investigations performed as part of the ITP Geotechnical Investigation have identified two issues of concern: (1) potential liquefaction susceptibility of some strata and (2) a zone of apparently under-consolidated soil that appears to be associated with dissolutioning of calcareous sediments. Liquefaction and/or dynamic settlement of these potentially unstable soils could cause differential settlement during seismic event. If the differential settlement is larger than that which can be tolerated by the ITP tanks, loss of tank integrity could occur.

The assessment of the foundation for the ITP tanks involves a large number of parameters that exhibit complex spatial structures. The primary objectives of this investigation included: (1) identification and/or development of appropriate geostatistical tools for analysis of spatial geotechnical data; (2) geostatistical analyses of in-situ and engineering properties of interest; and (3) estimation and/or simulation of properties of interest as the required input into the engineering evaluations and models used to calculate the static and dynamic stability of the embankment and foundation soils.

The geostatistical investigation was conducted along with a number of other planned activities, including preliminary evaluation of OCR from SCPT data by Prof. P. W. Mayne at Georgia Tech. A summary report of this latter activity is included in Appendix III. 


\subsection{OBJECTIVES}

The geostatistical and statistical analyses described were conducted in order to provide input into the engineering evaluations and models used to calculate the static and dynamic stability of the embankment and foundation soils. Four types of engineering evaluations were planned: (1) dynamic soil response, (2) static and dynamic slope stability, (3) liquefaction susceptibility, and (4) static and dynamic settlement. In addition to these activities, geostatistical techniques were applied to describe the spatial distribution of the geological strata in the ITP/H-Tank Farm Area as a part of "Geologic Setting" Task of in Phase II of the H-Area/ITP Geotechnical Service Program Plan (SGS-ENG-93001).

The specific purposes of the geostatistical analyses described in this report were:

(1) Providing the best possible estimates of the mean and variance of the in-situ geotechnical measurements for a given stratum and/or location by accounting for the spatial correlations of these data;

(2) Using the above best possible estimates of the in-situ measurements to predict engineering properties for a given layer and/or location by using existing geotechnical correlations;

(3) Providing a means for the evaluation of the performance of these correlations by comparing the predicted values with field measured results;

(4) Providing the engineering modelers with the spatial distribution and probable range of predicted engineering properties, through appropriated kriging or simulation procedures by taking into account the variability within a given 
stratum, the uncertainty in interpolating the in-situ measurements to an unmeasured location, and the uncertainty associated with the correlations used to predict the engineering properties from the in-situ measurements.

\subsection{AVAILABLE DATA}

The data used in this investigation include various types of borehole measurements from within the ITP facility, hereinafter referred to as "the site." The map of the site and a number of borehole locations are shown in Figure 1.2.1.

The underlying geological formation at the site has been divided into a number of substrata as listed in Table 1.2.1. The WSRC geological and geotechnical staff used CPT data and soil samples from nearby SPT borings to corroborate the layer boundaries at twenty CPT locations, as presented in Appendix IV. The selected layer contacts show a marked change in the in-situ properties and the layers have sufficient thickness so as to be traceable across a significant portion of the site. These layer contacts were used to define sub-layer surfaces for subsequent geostatistical analyses.

The available in-situ measurements which were provided by WSRC are listed in Appendix V. These in-situ measurements can be grouped as follows:

CPT Data: Cone Penetrometer soundings (CPT) borehole data include: borehole easting, borehole northing, borehole surface elevation, measurement depth, tip resistance, $q_{c}$; sleeve friction, $f_{s}$ : friction ratio, FR; pore pressure measured behind the tip, $\mathrm{u}$; and the Soil Classification Number, SCN.

SPT Data: Standard penetration tests (SPT) data include: borehole easting, borehole northing, borehole surface elevation, measurement depth, uncorrected blow count, $\mathrm{N}$; and corrected blow count, $\left(\mathrm{N}_{1}\right)_{60}$. In addition, Dr. S. F. Bartlett provided 
predicted $\left(N_{1}\right)_{60}$ values based on site-specific correlations of CPT data with SPT data. The CPT data were converted to $\left(N_{1}\right)_{60}$ using regression analysis between available SPT and CPT data. The regression analysis and the correction of SPT $N$ values to $\left(N_{1}\right)_{60}$ values were conducted by WSRC personnel.

Shear Wave Data: This data set includes a number of downhole and cross-hole shear wave velocity measurements (i.e., $V_{s}$ ) at the site. 


\subsection{GEOSTATISTICAL METHODOLOGY}

A general introduction to geostatistics is presented herein as background to various analyses conducted in this project. Geostatistics (Matheron, 1971; Journel and Huijbregts, 1978, Isaaks and Srivastava, 1989/ are a collection of techniques for the analysis of spatially correlated data. Geostatistical techniques incorporate the spatial characteristics of actual data into statistical estimation processes. Geostatistics permit the performance of critical tasks, such as: optimization of spatial mapping for physical processes, estimating average block values, and the design of sampling and monitoring schemes. In statistical terms, geostatistics provides tools for extraction of maximum amount of information from the available data.

In-situ measurements collected at different locations within the same site usually display a wide range of variability. As a result, the magnitude of the variable under investigation at an unmeasured location cannot be predicted with certainty, even if this variable was measured at other nearby boreholes. Such erratic variations have led many to use classical (i.e., non-spatial) statistical estimation methods. These methods usually assume that the collected data to be unbiased, unclustered, and independent (i.e., devoid of any correlational structures). In practice, however, borehole data are collected in a biased fashion, are clustered in the vertical direction, and are expected to display a degree of spatial structure. Geostatistics recognizes these properties and, according to well-defined criteria, provides the statistical tools for:

(1) Calculating the most accurate estimations based on sample results and other relevant information;

(2) Quantifying the accuracy of these estimations;

(3) Generating equally-likely realizations of a random field conditional to the 
available in-situ measurements; and

(4) Selecting the variables and locations to be sampled, if necessary.

The United States Environmental Protection Agency (U.S. EPA) has taken the lead in promotion of geostatistics by producing the first public-domain software package, known as GEO-EAS (Geostatistical Environment Assessment Software) developed by Englund and Sparks (EPA/600/4-88/033a, 1988). This package was followed by another EPA package, known as GEOPACK, developed by Yates and Yates (EPA/600/8-90/004, 1990). The successful results of application of GEO-EAS prompted the U.S. EPA to recommend its use in spatial environmental data analysis, as stated in "Guidance for Data Usability in Risk Assessment" (EPA/540/G-90/008, 1990) and "Basics of Pump-and-Treat Ground-Water Remediation Technology" (EPA/600/8-90/003, 1990).

The main features of linear geostatistics to be applied are:

(1) Geostatistics provides models of the spatial continuity of data in a statistical framework. For example, within a layer, data points which are closer in a given direction are assigned a specific correlation value. These correlation values are estimated based on available data in that layer.

(2) Geostatistical point or block estimates are calculated as weighted sums of the adjacent sampled values. These weights depend on the exhibited correlation structure. For example, if data appear to be highly continuous in space, the points which are closer to the estimated points will receive higher weights than those further away. The criterion for selection of these weights is the minimization of estimation variance. In this framework, geostatistical estimates may be regarded as the most accurate estimates among linear estimators (i.e., Best Linear Unbiased Estimator), implying that the geostatistical estimation 
processes are based on well-defined criteria, and thus are superior to subjective estimation techniques.

(3) Geostatistical techniques can process sample results averaged over different volumes and sizes. In other words, depending on whether the estimation is a point or block value, geostatistics will yield different results, consistent with the geometry of the estimation domain.

(4) Geostatistics provides tools for simulation of equally-likely realizations of the investigated random fields. These simulations can respect the available measured values. Such simulated results are specially useful in cases where the preservation of the spatial variability of the investigated process is critical to the study objectives.

For a more detailed review of geostatistics, readers are referred to ASCE (1990a and 1990b).

\subsection{GEOSTATISTICAL STRUCTURAL ANALYSIS}

The first task in any geostatistical investigation is to identify the spatial structure of the investigated variable in a given area. This task is usually done by developing the sample variogram of the collected data. EPA/600/4-88/033a defines the variogram as the plot of the variance (one-half the mean squared difference) of paired sample results as a function of the distance between samples

$$
\gamma_{i j}=\frac{1}{2} E\left[Z_{i}-Z_{j}^{2}\right.
$$

where

$$
\gamma_{i j}=\left(\text { semi-) variogram between } Z_{i} \text { and } Z_{j} ;\right.
$$



$\mathrm{Z}_{\mathrm{i}} \quad=\quad$ a random variable representing investigated variable at location $\mathrm{x}_{\mathrm{i}}$; and
$\mathrm{E}=$ expected value operator.

Variograms quantify the commonly observed relationship among geo-data. Such relationships usually indicate that close-together samples will tend to have more similar values than those far apart. In this respect, the variogram can be regarded as a measure of the degree of (dis)association, as displayed by available data.

Three main parameters of a typical variogram are: (1) range, (2) sill, and (3) nugget effect. Range is the distance at which the variogram reaches its maximum value. Paired samples whose separation distance is greater than the range are uncorrelated. Therefore, the range is regarded as a measure of spatial continuity of the investigated variable. The sill is the upper limit of any variogram where the variability tends reaches a limiting value at large separation distances. The sill is a measure of the population variability of the investigated variable; the higher the sill, the greater the variability in the population. A nugget effect is exhibited by the apparent jump of the variogram at the origin, which is usually attributed to small-scale variability of the investigated data and/or to measurement errors.

Because of the three-dimensional nature of the available data at ITP a number of variograms are computed and modeled as follows:

(1) Variable-specific Vertical Variograms: These are unidirectional vertical variograms which are computed for each substratum separately.

(2) Variable-specific Lateral Variograms: These are stratum-specific variograms where lateral separation distances are measured parallel to the top and bottom surfaces of the substratum. Lateral stratum-specific variograms are specially useful when processing data from formations with non-horizontal stratigraphies 
or nearly horizontal stratigraphies that have been affected by faulting.

(3) Marker Surface Variograms: These horizontal variograms are needed for estimation of the elevation of the dividing surfaces between various substrata. The data for building such variograms are the elevation of each substratum markers. These elevations were determined by the geological and geotechnical staff at WSRC, as shown in Appendix IV.

\subsubsection{VARIOGRAPHY}

The type and parameters of the variogram model must be determined based on the available information. This process, known as variography, is conducted through the use of an appropriate geostatistical software that permits the visual fitting of acceptable variogram model(s) to the computed sample variograms. Variography is initiated by grouping the available pair-values according to their vertical or lateral separation distances into a number of lags or distance classes. Ideally, twenty or more pairs should be present in each lag. The arithmetic average of one-half of differences squared, $1 / 2\left(z_{i}-z_{j}\right)^{2}$, of all pairs in a given lag is defined as the sample variogram of that distance class. Upon computation of sample variograms, four iterative steps are taken: (1) selecting an acceptable mathematical model to fit the sample variograms, (2) visually determining a reasonable sill value for that model, (3) determining the nugget value, and (4) visually selecting a reasonable range. Using the chosen parameter values, the variogram model is superimposed on the sample variogram values. At this stage, the analyst modifies the parameter values until a satisfactory visual fit is achieved.

Because the near-origin characteristics of the fitted model have the most important influence on the estimated values, the above process is primarily controlled by near-distance sample variograms. Consequently in visual model fitting, more 
emphasis is given in closely matching the sample variograms near the origin and less emphasis is given to the far-distance sample variograms.

\subsection{GEOSTATISTICAL ESTIMATION}

Upon determination of the variogram model, the linear geostatistical estimation process known as ordinary kriging can be performed as

$$
Z_{o}^{*}=\sum_{j=1}^{n} \lambda z_{j}
$$

where,

$Z_{0}^{*}=$ Estimated point or block value centered at $x_{0}$,

$z_{i}=$ Measured value at $x_{i}$

$\lambda_{i}=$ Estimation weight of $z_{i}$.

The computation of the above estimation weights are conducted on the basis of two criteria, which are:

(1) Non-Bias Condition:

$$
\left.E Z_{0}^{*}-Z_{a}\right]=0
$$

This condition ensures that there will be an absence of systematic error. If it can be assumed that the measured values have the same mean, whose magnitude is unknown, then this condition is reduced to: 


$$
\sum_{i=1}^{n} \lambda_{i}=1
$$

(2) Minimum Variance of Estimation: This condition ensures that the estimation variance of the interpolated value, whether point or block value, to be minimum. In statistical terms, the resulting estimate is viewed as the most accurate linear estimate. The estimation variance is only a function of the variogram and the estimation weights, which can be defined as

$$
\operatorname{Var}\left(Z_{o}^{*}\right)=-\sum_{i=0}^{n} \sum_{j=0}^{n} \lambda_{i} \lambda_{j} \gamma_{j j}
$$

where,

$\gamma_{i j}=$ Variogram function between $Z_{i}$ and $Z_{j}$; and

$\lambda_{0}=-1$.

The minimization of the estimation variance subject to the non-bias condition is accomplished through the Lagrange multiplier approach, yielding the following kriging system:

$$
\left[\begin{array}{ccccc}
\gamma_{11} & \gamma_{12} & \cdots & \gamma_{1 n} & 1 \\
\vdots & \vdots & & \vdots & \vdots \\
\vdots & \vdots & & \vdots & \vdots \\
\gamma_{n 1} & \gamma_{n 2} & \cdots & \gamma_{n n} & 1 \\
1 & 1 & \cdots & 1 & 0
\end{array}\right]\left[\begin{array}{c}
\lambda_{1} \\
\vdots \\
\vdots \\
\lambda_{n} \\
\mu
\end{array}\right]=\left[\begin{array}{c}
\gamma_{01} \\
\vdots \\
\vdots \\
\gamma_{0 n} \\
1
\end{array}\right]
$$

where $\mu=$ Lagrange Multiplier. In case of block kriging, $\gamma_{0 i}$ in the right-hand-side vector must be replaced by $\gamma_{\mathrm{vi}}$, which is the average variogram between the targeted block $V$ and the measurement value located at $x_{i}$.

In this project, ordinary kriging was mainly used to perform point kriging for generating nodal estimates which were then contoured to form multi-layer or three-dimensional 
maps of various soil properties.

\subsection{GEOSTATISTICAL SIMULATIONS}

Because kriging yields weighted-average estimates, it fails to preserve the variability of the original data; instead, kriging produces interpolated results that are "smoothed." However, in stochastical modeling, the preservation of the spatial variability is specially important if the processed data are aimed to be used as inputs into other statistical or numerical models. For example, in this project, the use of kriged in-situ properties in a probabilistic liquefaction assessment (Liao, 1986; WSRC, 1995) can yield erroneous results. This problem is mainly due to the fact that the interpolated values based on kriging display a lower variation than the actual measured values. Such under-representations of the variability tend to under-estimate the number of Iow SPT $\left(N_{1}\right)_{60}$ values which control the liquefaction response and ultimately underestimate the liquefaction hazard.

To correct the above deficiency, geostatistical simulation can be used (Journel and Huijbregts, 1978). The purpose of simulation is to generate sets of equally-likely outcomes which are consistent with the observed in-situ measurements. In geostatistical simulation, this often means that the simulated values have the same mean and variogram as the original data, and in the case of conditional geostatistical simulation, the simulated values must equal the observed data at the measurement points (Journel and Huijbregts, 1978). While kriging provides an estimate of the average value of $Z(x)$, geostatistical simulation yields one of the several possible outcomes of $Z(x)$ that respects the above criteria.

Typically simulation is used to generate several different spatial sets of the property of interest in order to run a deterministic model, repeatedly in a Monte Carlo type approach. The resulting set of model outputs are treated as equally-likely 
outcomes and can then be used to define the probability distribution of the modelled response.

For the ITP probabilistic liquefaction hazard assessment, conditional simulation techniques were used (WSRC, 1995). There are a number of procedures for performing this type of simulation. An effective numerical procedure is the Sequential Gaussian Simulation. In this process, upon the gaussian transformation of the available in-situ measurements, simulation is conducted, such that each simulated value is conditioned on the original data and all previously simulated values (Deutsch and Journel, 1992).

\subsection{GEOSTATISTICAL SOFTWARE}

In this investigation three major software packages were used. These were: (1) U.S. EPA's GEO-EAS, (2) Stanford's Geostatistical Library (GSLIB), and (3) RC's ResMod. The following paragraphs provide a summary description of these software packages.

GEO-EAS: The most commonly used public domain geostatistical software is U.S. EPA's GEO-EAS (Geostatistical Environmental Assessment Software) by Englund and Sparks (1988). GEO-EAS is basically a collection of interactive tools for two dimensional geostatistical analysis of spatially distributed data. This software provides the following programs:

(a) DATAPREP for data file management;

(b) TRANS for mathematical transformations of data;

(c) STAT1 for univariate statistical computations;

(d) PREVAR and VARIO for two-dimensional variogram analyses;

(e) XVALID for cross validation of estimated results; 
(f) KRIGE for two dimensional point or block kriging;

(g) CONREC for two dimensional contour mapping;

(h) POSTPLOT for measurement locations mapping;

(i) XYGRPAH for simple linear regression computations.

GEO-EAS offers point and block kriging techniques. Kriging can perform spatial interpolation based on correlated data, spatially biased samples, anisotropic variables, and/or clustered data set. It also generates the estimated variance that can be used as a measure for the accuracy of each interpolated value.

GSLIB: GSLIB (Deutsch and Journel, 1992) is a geostatistical software library developed at Stanford University. GSLIB programs are developmental tools and sketches for custom programs, advance applications and research. These programs are a set of FORTRAN source code for various geostatistical computations. These source codes can be modified for special applications. Various computations, such as variography, kriging, and simulations, can be performed by the different programs in GSLIB. GSLIB is coded to the ANSI standard to achieve machine independence, thus, its use is not limited to a specific PC, workstation or mainframe computer. In this project, programs for: (a) three-dimensional variogram analysis, (b) threedimensional regular grid kriging, and (c) three-dimensional irregular grid kriging were used.

ResMod: This Unix-based software is developed by $(R C)^{2}$ Reservoir Characterization, Research \& Consulting, Inc. The program is divided into three subprograms: ResPrep, ResGram, and ResMod. ResPrep is a gateway for the analysis of borehole data. The borehole data include borehole ID, Easting, Northing, Elevation, Deviation of elevation, Depth Markers, Time Markers, Depth logs, and Time Logs. This program formats the data into a binary standard data format called HDF as defined by the NCSA (National Center for Supercomputing Applications). HDF allows the binary data to be completely portable across the platforms. Besides reformatting 
the data, ResPrep serves another important function of creating fast load log files in either depth and/or time. ResPrep generates following files:

(1) CATALOG_WELLS: a text file that controls the list of well files that are loaded.

(2) Well files which contains all of the depth/time markers, logs and geometric information for a given well which are created based on the input ASCII files.

(3) Fast load well log files which contain well log information.

Upon completion of ResPrep tasks, ResGram is used to compute and construct models of spatial variabilities, including variograms. In a multilayer, three-dimensional environment, different types of variograms must be defined, such as (a) vertical variograms, (b) lateral variograms, and (c) marker surface variograms.

After variogram modeling, ResMod can be used to generate three-dimensional estimated or simulated maps for visual inspections as well as assessing local and global uncertainties. The modeling algorithms are mainly geostatistical techniques based on kriging and simulation procedures. The geostatistical algorithms are based on GSLIB. Some of the GSLIB codes have been modified to make them more flexible. In addition, there are several options which are not currently available in GSLIB or any other source. In this project, ResMod was used for three dimensional, ordinary kriging and the sequential gaussian simulation. 


\subsection{GEOSTATISTICAL ANALYSIS OF CPT DATA}

The CPT data from twenty soundings were subjected to geostatistical analysis. These CPT soundings are listed in Table 3.0.1 and partially identified in Figure 1.2.1.

The review of the above CPT data revealed a number of reported values which were viewed as inconsistent with the geology of the site. To ensure the quality of the geostatistical works these erroneous values were removed. The reported corrections are grouped as follows:

Negative Friction Ratios: A few points in the CPT soundings reported negative friction ratios. Some negative values were reported where the sleeve had measured slightly negative side friction. During preliminary analyses, each borehole data was checked separately and the spurious friction ratio data were removed for this case. The removed negative friction ratio data are listed in Table 3.0.2 Also, at few locations, negative friction ratios were reported due to slightly negative tip resistances. Because these increments may represent soft zones, their corresponding tip resistances were preserved in the data set, as listed in Table 3.0.3; however, the corresponding friction ratios were removed.

Spurious Fill Data: In a letter dated March 30, 1994, Dr. S. F. Bartlett of WSRC reported that his review of kriged results revealed some spurious data in the top of the fill near the ground surface. According to him: " [t]hese data are near ground surface where the cone penetrometer was at the beginning of its push, or where the pilot hole was dug to seat the penetrometer." All measured values at these suspect depths were removed as listed in Table 3.0.4.

Large Friction Ratios: At some intervals the measured friction ratios are all positive, but are extremely high. This is due to a very low tip stress which 
approaches zero. The use of such anomalous friction ratios could adversely impact the kriging results. Therefore they were removed, as listed in Table 3.0.5. However, as before, the low tip resistances were preserved in the data set because they may represent soft zones.

Estimation of tip resistance values and friction ratio values along vertical crosssections $A-A^{\prime}$ and $B-B^{\prime}$, as shown in Figure 1.2.1, were conducted before and after the removal of the above suspect data. The kriging results after the removal of the erroneous friction ratio data showed satisfactory results.

\subsection{VARIOGRAM ANALYSIS OF CPT DATA}

Different variogram analyses of CPT data were conducted. These computations were aimed at deciphering the underlying structures of various substrata. For this purpose tip resistance data were used in both their original and transformed conditions. The following subsections provide a summary of these analyses.

\subsubsection{MULTILAYER VARIOGRAM}

The CPT data from the twenty boreholes were subjected to multilayer variogram analyses. For this purpose, the data was divided into the pre-defined sublayers as listed in Table 1.2.1.

The variography along the vertical direction revealed well defined structures with ranges varying between 2 to $12 \mathrm{ft}$, as shown in Figure 3.1.1 through Figure 3.1.10 and listed in Table 3.1.1. The sills of these vertical variograms are from 410 to $9000 \mathrm{tsf}^{2}$ as shown in Table 3.1.1. 
The lateral variography was done along the direction parallel to the dividing surfaces (i.e. marker surfaces) of each substratum. Modified GSLIB programs and ResGram were used for such (pseudo)-horizontal variographic computations. The results of the omni-directional lateral variogram revealed structure with much wider ranges than the vertical variograms. These lateral ranges varied from 40 to $130 \mathrm{ft}$, as shown in Figure 3.1.1 through Figure 3.1.10. For modeling purposes, the type of the lateral variograms were assumed to be determined by the type of their corresponding vertical models. These latter models are based on high-resolution vertical data, and thus, are reliable representation of the intra-stratum variations at small scales. The horizontal ranges, however, were fitted directly based on the lateral sample variograms. The resulting fitted variogram were three-dimensional anisotropic models. Such models are also consistent with the depositional nature of the investigated multi-layer formation. As the previous figures indicate such a modeling approach yields satisfactory results.

As shown in the above figures and Table 3.1.1, the Santee Formation exhibited a lateral pure nugget effect and a vertical variogram with a range of $6 \mathrm{ft}$ along the vertical direction.

\subsubsection{SOFT ZONES CATEGORICAL VARIOGRAM ANALYSIS (CPT DATA)}

To further explore the structure of soft zones in the Santee Formation an indicator approach was used. For this purpose, measured tip resistances in the Santee Formation were categorized into three groups as:

(1) Soft soil (tip resistances less than or equal to 15 tsf),

(2) Intermediate soil (tip resistances between 15 and $40 \mathrm{tsf}$ ), and

(3) Stiff soil (tip resistances greater than 40 tsf).

These categorical data are equivalent to two sets of indicator variables. Soft soil 
categorical data is equivalent to Indicator \#1 (soft versus non-soft soil), and Stiff soil categorical data equals Indicator \#2 (non-stiff versus stiff soil).

All the above categorical values were then subjected to variogram analyses. Initially omni-directional lateral and vertical variograms were computed and modeled, as shown in Figures 3.1.11 through 3.1.13. These variograms consistently displayed lateral spatial structures of pure nugget effect. This implies poor spatial structure or correlation in the lateral direction within the Santee Formation.

A series of directional lateral variography for the above categorical variables were conducted along the southwest-northeast "trend" in the Santee Formation. Three specific direction-angles of $30^{\circ}, 45^{\circ}$, and $60^{\circ}$ were tested, as shown in Figures 3.1.14 through 3.1.22. These angles roughly parallel the western edge of the carbonate body and the strike of an interpreted fault (WSRC, 1995). This directional variography was done to see if the soft zones have a preferred orientation that parallels these subsurface structures. If so, this might imply a causal link between faulting and the apparent dissolutioning that has produced the soft zones along the fringe of the carbonate body. None of these directions indicated the presence of any discernable lateral correlations. Along these directions, the soft soils have a lateral extent of less than $35 \mathrm{ft}$ and the lateral extent of the combined soft/intermediate soils (Indicator \#2) is less than $50 \mathrm{ft}$.

The results of the vertical and lateral variography indicate that: (a) the soft soils had an average thickness of less than $4 \mathrm{ft}$ and (b) the average thickness of the combined soft/intermediate soils appeared to be less than $8 \mathrm{ft}$. The combined soft/intermediate soils (Indicator \#2) had a vertical variogram that was not as welldefined as the one for the soft soils. (c) Neither the soft soil, nor the combined soft/intermediate soils showed any discernable lateral correlations. (d) In the absence of lateral discernable correlations, the lateral extent of the soft soils and the combined soft/intermediate soils was approximated to be less than the average borehole spacing 
which is about $35 \mathrm{ft}$. The above results were also confirmed using the SPT data in the Santee Formation, as discussed in the following section.

\subsubsection{SOFT ZONES CATEGORICAL VARIOGRAM ANALYSIS (SPT DATA)}

The available SPT data in the Santee Formation were also converted into categorical data. For this purpose measured $\left(N_{1}\right)_{60}$ values in the Santee Formation were categorized into three groups as:

(1) Soft soil $\left(\left(N_{1}\right)_{60}\right.$ values less than or equal to 5$)$,

(2) Intermediate soil $\left(\left(\mathrm{N}_{1}\right)_{60}\right.$ values between 5 and 10), and

(3) Stiff soil $\left(\left(N_{1}\right)_{60}\right.$ values greater than 10$)$.

Despite the fact that SPT data were heavily noisy, omni-directional lateral variographies were conducted for the above categorical soft soil and stiff soil variables, as shown in Figures 3.1.23 and 3.1.24. Neither variograms displayed any discernable lateral correlation structures. These results were consistent with the results of the CPT data in the Santee Formation, as described in Section 3.1.2.

\subsection{CPT ESTIMATION RESULTS}

Based on the fitted variogram models listed in Table 3.1.1, the CPT data was used to generate interpolated values along the nodes of a predefined liquefaction and FLAC model for cross-section A-A' and B-B', as shown in Figure 1.2.1. The model nodal locations were provided by Dr. F. Ostadan of Bechtel. These interpolated crosssections were subsequently used in the liquefaction and settlement analysis described in WSRC (1995). The estimated tip resistances were interpolated using a threedimensional irregular grid kriging program with layer-specific variogram models. The 
estimated tip resistance and friction ratio contour maps in section $A-A^{\prime}$ and $B-B^{\prime}$ are shown in Figures 3.2.1 and 3.2.4, respectively.

The above results reflect the multi-layer variability of the CPT tip resistance data. However, smoothing effects due to kriging are also reflected in these latter contour maps. These results also indicate that the estimated most of the low tip resistances are located in the Santee Formation, as shown Figures 3.2.1 and 3.2.2.

For assessing the reliability of kriging estimated values, two separate crossvalidations were performed. For this purpose, SCPT-1 and SCPT-6B were selected as targeted boreholes. In the cross-validation process, each measured tip resistance value from the targeted borehole were first eliminated and then estimated based on the neighboring measured values and the fitted layer-specific lateral and vertical variogram models. The estimated CPT profiles at these locations was then compared with the actual data to qualitatively judge the performance of the kriging. The results are displayed in Figures 3.2.5 through 3.2.6. In these figures, each estimated profile is accompanied by its upper and lower $95 \%$ confidence levels with its measured values. These results showed that in almost all cases, the measured values of tip resistance fall within the confidence interval of the kriging estimated values. This implies two facts:

(1) Kriging estimated values are reliable estimates of the in-situ borehole measurements, and

(2) Kriging standard deviations are adequate measures for quantifying the accuracy of the estimated values.

Cross-validation results in Figures 3.2 .5 and 3.2 .6 are based on performing kriging layer-by-layer with the depths to the top of each layer defining the control surfaces for estimation. This method proved to give the best results and is more appropriate where faulting or other vertical discontinuities may exist in the data. 
Although layer-by-layer kriging cannot predict the actual geometry of the layers, it will respect the pre-determined layering system, thus it will not use data from other layers in making point estimates and hence does not introduce any false heterogeneity or extra uncertainty into the point estimates. 


\subsection{GEOSTATISTICAL SIMULATION OF SHEAR WAVE DATA}

Available shear wave data from nineteen boreholes were geostatistically analyzed. The location of the investigated boreholes are shown in Figure 4.0.1.

The analysis of shear wave data was initially analyzed by dividing the soil volume in the investigated area into seven different layers as: Fill, TR1, TR2, TR3/TR4, DB1/DB4, DB5, and ST. However, unlike the CPT data, the shear wave velocity logs did not show strong evidences of layering and preliminary simulations yielded undue discontinuities along dividing surfaces of the various layers which ultimately produced unwanted and artificially high impedance contrasts for dynamic modeling. Therefore, in subsequent computations the entire profile was modelled as a single unit. Omni-directional lateral and vertical variograms were then computed and modeled, as shown in Figures 4.0.2 and 4.0.3. The vertical variogram displayed a particularly well defined spatial structure with a range of approximately $70 \mathrm{ft}$. Such a range is much larger than the typical 2 to $12 \mathrm{ft}$ vertical ranges of CPT tip resistance values and shows that the shear wave velocity is much more continuous and homogeneous in the vertical direction.

\subsection{SHEAR WAVE SIMULATION RESULTS}

Shear wave values were simulated using sequential Gaussian simulation (sGs). For this purpose, fitted variogram models shown in Figures 4.0.2 through 4.0.3 were utilized. As noted above, due to excessive fluctuations in the multi-layer simulated shear wave profiles, a single-layer three-dimensional simulation was used.

In this process each simulated point is generated sequentially according to its normal conditional cumulative distribution function (ccdf) which is fully characterized through kriging system. Simulated values are conditioned on all original in-situ 
measurements and all previously simulated values within their neighborhoods. In each simulation a seed number must be defined which determines the random path of the sequential simulation.

Shear wave values were simulated at centers of the four ITP tanks which are located at $\left(62618.00^{\prime}, 70825.00^{\prime}\right),\left(62750.00^{\prime}, 70825.00^{\prime}\right),\left(62618.00^{\prime}\right.$, 70925.00'), and (62750.00', 70925.00'), as shown in Figure 1.2.1. Figures 4.1.1 through 4.1.4 display samples of simulated shear wave profiles at the center of various tanks. Each profile can be viewed as an equally likely realization of the shear wave values. The comparison of these figures with Figure 4.1 .5 (i.e., the composite graph of measured shear wave velocities) clearly indicates that each simulated profile preserves the spatial variabilities exhibited by the original values. 


\subsection{GEOSTATISTICAL ANALYSIS OF SPT DATA}

The conditional probability of liquefaction model used to evaluate the liquefaction hazard at ITP (Liao, 1986; WSRC, 1995) requires the normalized SPT blow count, $\left(N_{1}\right)_{60}$, as a measure of the soil's resistance to liquefaction. Available borings and penetrations at the ITP facility include SPT borings drilled by WSRC as part of the seismic qualification of ITP and by the consulting firm of Mueser-Rutledge during the original foundation investigations (WSRC, 1995). Four SPT boreholes were continuously split - spoon sampled by WSRC: H-SPT-14, H-SPT-18, H-SPT-20, and H-BOR-23.3. However, because of numerous underground interferences, none of these recent borings were drilled in close proximity to the ITP tanks, but were instead located around the perimeter of the ITP facility (Figure 1.2.1). These WSRC boreholes were completed under a rigorous quality assurance program, which include prior measurement of the energy delivered to the SPT hammer. The hammer energy ratio measured by WSRC was approximately 60 percent of the theoretical maximum. Other SPT borings completed by Mueser include all borings beginning with a " $241-12 \mathrm{H}$ " prefix in Figure 1.2.1. Eight of these Mueser borings are located within the footprint the ITP tanks, which make the use of these data highly desirable for defining the subsurface conditions directly beneath the tanks. However, the direct use of the Mueser SPT data is not acceptable for liquefaction analyses unless some rational method is employed to adjust the $N$ values to $\left(N_{1}\right)_{60}$. Unfortunately, the hammer efficiency was not measured for the Mueser investigation, so other means had to be sought.

To incorporate the Mueser SPT N values in the hazard analysis, an estimate of the hammer efficiency was needed. A statistical review of $N$ values at ITP by WSRC showed that Mueser's SPT N values are 1.6 times greater, on average, than those of WSRC in the layer of most interest for liquefaction analysis (i.e., TR3 / TR4). This suggest that Mueser's hammer was less efficient than that of WSRC and had an hammer energy ratio of about 37.5 percent (i.e., $60 \% / 1.6=37.5$ percent). Hence 
prior to simulation, all Mueser $N$ values were divided by 1.6 to convert these $N$ to $\left(N_{1}\right)_{60}$ values. Subsequently, all $\left(N_{1}\right)_{60}$ values from Mueser and WSRC were normalized to $\left(N_{1}\right)_{60}$ to complete the liquefaction analysis.

In addition to the SPT data, several CPT penetrations are also available near the ITP tanks (Figure 1.2.1). However, the use of CPT data is also problematic, because the probabilistic liquefaction model requires $\left(N_{1}\right)_{60}$ values as input (WSRC, 1995). To convert CPT data to SPT $\left(\mathrm{N}_{1}\right)_{60}$ values, layer-specific regression analyses were performed by WSRC for paired CPT and SPT boreholes from the ITP and RTF geotechnical investigations. To pair the data, CPT data were averaged through a $2-$ foot interval starting 0.5 feet above the adjacent $11 / 2$-foot sampling interval in the adjacent SPT boring. The general form of the regression model used is:

$$
\begin{gathered}
q_{c_{1}} / N_{1}=\beta_{1} q_{q_{1}}+\beta_{2} f r+\beta_{3} p p+\beta_{4} p_{o}^{\prime}+\beta_{5} q_{q_{1}} f r+\beta_{6} q_{c_{1}} p p+\beta_{7} q_{q_{1}} p_{o}^{\prime}+ \\
\beta_{8} f r p p+\beta_{9} f r p_{o}^{\prime}+\beta_{10} p p p_{o}^{\prime}
\end{gathered}
$$

where: $\quad \mathrm{q}_{\mathrm{c} 1}=$ CPT tip resistance normalized to $1 \mathrm{tsf}$,

$\mathrm{fr}=\mathrm{CPT}$ friction ratio;

$\mathrm{pp}=\mathrm{CPT}$ pore pressure in tsf

$p_{o}^{\prime}=$ effective overburden pressure in tsf. 
The results of the regression analysis are given below.

\begin{tabular}{|l|l|l|l|l|l|l|l|l|l|l|}
\hline layer & $\beta_{1}$ & $\beta_{2}$ & $\beta_{3}$ & $\beta_{4}$ & $\beta_{5}$ & $\beta_{6}$ & $\beta_{7}$ & $\beta_{\mathrm{a}}$ & $\beta_{9}$ & $\beta_{10}$ \\
\hline TR1 & 0.0194 & 0.654 & -0.206 & 2.41 & -0.00454 & 0.00031 & 0.0103 & 0.0165 & -0.557 & 0.031 \\
\hline TR2(a) & 0.111 & 4.32 & -14.7 & 3.73 & -0.0286 & -0.0918 & -0.0929 & 6.45 & 0 & 25.7 \\
\hline TR2(b) & 0.0496 & -3.69 & -2.27 & 4.06 & 0.0215 & 0.0351 & -0.0357 & 1.04 & 1.09 & -0.397 \\
\hline TR3/TR4 & -0.0410 & 0.380 & 0.211 & 2.33 & 0.0108 & -0.0297 & 0.0423 & 0.0714 & -0.398 & -0.060 \\
\hline DB1/DB3 & 0.116 & 6.13 & -5.62 & 5.06 & -0.0071 & 0.0232 & -0.0586 & 1.34 & -3.90 & 0.809 \\
\hline DB4 & 0.0480 & 0.77 & -0.545 & 1.93 & 0.0450 & 0.00521 & -0.0206 & 0.137 & -0.899 & 0.0284 \\
\hline DB5 & 0.501 & -7.37 & 0.272 & -0.140 & -0.0670 & -0.00175 & -0.0772 & -0.0006 & 2.27 & -0.0824 \\
\hline ST & -0.0651 & 3.34 & -0.215 & 0.697 & 0.0195 & 0.00220 & 0.0196 & 0.0062 & -0.918 & 0.017 \\
\hline
\end{tabular}

$\mathrm{TR2}$ (a) = TR2 layer above the water-table

TR2(b) = TR2 layer below the water-table.

The regression analyses and analysis of variance tables are included in Appendix VI.

The above measured, corrected and regressed $\left(N_{1}\right)_{60}$ simulated $N$ values were subjected to multi-layer lateral and vertical variography. The entire process was conducted through ResMod. For three-dimensional sequential Gaussian simulation the entire data set was normally transformed. The fitted variogram parameters of the normal score data are shown in Table 5.0.1.

Given the normal transformation of data, most variograms have sill values close to unity. The ranges, however, are very similar to other investigated CPT data. The vertical ranges vary from 2 to $13 \mathrm{ft}$, while lateral ranges vary from 300 to $450 \mathrm{ft}$. Three layer groups, i.e. TR2 above water table, TR3/TR4, and the Santee Formation, display no discernable lateral correlational structure. 


\subsection{SPT ESTIMATION AND SIMULATION RESULTS}

Estimated and simulated $\left(N_{1}\right)_{60}$ values were generated using three-dimensional kriging and sequential Gaussian simulation techniques using the data described in Section 5.0. The fitted variogram models, listed in Table 5.0.1, were utilized.

The SPT data were used to generate estimated maps based on the kriging technique. As a sample, the estimation results in an east-west cross-section at Northing $=70590.00 \mathrm{ft}$, as well as one lateral cross section in sub-layers of DB1/DB3 are displayed in Figures 5.1.1 through 5.1.2.

Upon completion of the kriging exercise, the sequential Gaussian simulation of $\left(N_{1}\right)_{60}$ values was conducted. As a sample, the same cross sections as above are used to display the simulation results, as shown in Figures 5.1.3 through 5.1.4.

The comparison of the above two sets of results highlights the differences between the kriging and simulation outputs. The kriging surfaces, Figures 5.1.1 and 5.1.2, displayed a smooth characteristic. Smoothing becomes specially excessive in sparsely sampled locations, such as the southwest corners of Figure 5.1.2. The simulated surfaces, on the other hand, preserved the variability of the investigated $N$ values, as shown in Figures 5.1.3 and 5.1.4. These results indicated that as data become sparse the use of simulated results are more advantageous.

Comparison of vertical cross sections (Figures 5.1.1 and 5.1.3) also proves that simulation procedures preserve both inter- and intra-layered variabilities. Such variabilities are absent in kriging results, such as Figure 5.1.1. Also, to check if the simulation is reasonable, the simulated results at the 4 nodes nearest to the centerpoints of the ITP tanks are plotted against the nearby WSRC SPT N data (Figure 5.1.5). The simulated results show reasonable agreement with the nearby data in the zone of interest for liquefaction analyses (i.e., between elevations 275 and 230 feet 
MSL. The real and simulated data from this interval were subsequently used in the probabilistic liquefaction hazard evaluation (WSRC, 1995). 


\subsection{SUMMARY}

The geostatistical analyses of the in-situ borehole measurements from the ITP site revealed the following conclusions:

1. Borehole Data Structure: The borehole data structure displayed a number of distinct characteristics. First, the three-dimensional data resolution was highly imbalance, with very tight resolution in the vertical direction and orders of magnitude wider resolutions in the lateral direction. Second, the geological formation clearly exhibited a multi-layer stratigraphy with differing features. Based on these distinct features, each borehole data was divided into a number of substrata by the geological and geotechnical staff at WSRC. Third, the preliminary stratigraphic model of the site showed a non-horizontal, layered structure with potential faults or other vertical discontinuities.

2. Complicated Intra-layer Variations: Despite the initial grouping of the borehole data into a number of substrata, in-situ measurements within each layer displayed complicated vertical and lateral variations . These variations, however, were only partially explainable based on deterministic geological and geotechnical models. Therefore, the use of statistical methods became inevitable.

3. Suitable Statistical Tool: Among statistical methods, geostatistical algorithms appeared to be the most suitable due to a number of reasons. First, geostatistics recognizes the multi-layer, three-dimensional structure of the borehole data. Second, unlike classical statistical procedures, geostatistics incorporates the potential spatial (auto-correlational) structure of the collected data. Third, vertically clustered borehole measurements can be processed by geostatistical methods. Finally, geostatistics offers both estimation and simulation procedures that can be used in a variety of applications. 
4. CPT Variography and Estimation Results: The variography along the vertical direction revealed well defined layers or beds with ranges varying between 2 to $12 \mathrm{ft}$. The results of the omni-directional lateral variograms revealed more complicated structures than the vertical variograms. The lateral ranges of different layers varied from 40 to $130 \mathrm{ft}$. Among the exceptions was the Santee Formation that exhibited a lateral pure nugget effect. Estimated CPT results were generated for liquefaction and FLAC modeling purposes. These estimated values preserved the multi-layer structure of the investigated variables. However, in sparsely sampled locations have a tendency to generate smooth maps.

5. Soft Zone Categorical Variography in the Santee Formation: Measured tip resistances and $\mathrm{N}$ values in the Santee Formation were categorized into three groups as: Soft, Intermediate, and Stiff soils. Results indicated that: (a) The soft soils had an average thickness of less than $4 \mathrm{ft}$. (b) The average thickness of the combined soft/intermediate soils appeared to be less than $8 \mathrm{ft}$. The combined soft/intermediate soils had a vertical variogram that was not as welldefined as the one for the soft soils. (c) Neither the soft soil, nor the combined soft/intermediate soils showed any discernable lateral correlations. (d) In the absence of lateral discernable correlations, the lateral extent of the soft soils and the combined soft/intermediate soils was approximated to be less than 35 $\mathrm{ft}$.

6. Shear Wave Variography and Simulation Results: The analysis of shear wave data was initiated by dividing the soil volume in the investigated area into seven different layers as: Fill, TR1, TR2, TR3/TR4, DB1/DB4, DB5, and ST. This approach, however, yielded undue discontinuities along dividing surfaces of the various layers. Therefore, in subsequent computations the entire formation was considered as a single unit. Simulated results indicated that each simulated 
profile preserved the spatial variabilities exhibited by the original values.

7. SPT Variography Results: Geostatistically simulated and estimated $\left(N_{1}\right)_{60}$ values were generated using three-dimensional kriging and sequential Gaussian simulation techniques. The comparison of the above two sets of results indicated that: (a) the kriging surfaces display a smooth characteristic which becomes specially excessive in sparsely sampled locations, and (b) the simulation procedures preserve both inter- and intra-layered variabilities. 


\subsection{REFERENCES}

ASCE Task Committee on Geostatistical Techniques in Geohydrology (S. Rouhani, Chairman and Principle Author), 1990a, "Review of geostatistics in geohydrology, I. Basic concepts," ASCE Journal of Hydraulic Engineering, 116(5), 612-632, May.

ASCE Task Committee on Geostatistical Techniques in Geohydrology (S.Rouhani, Chairman and Principle Author), 1990b, "Review of geostatistics in geohydrology, II. Applications," ASCE Journal of Hydraulic Engineering, 116(5), 633-658, May.

Deutsch, C.V., and A.G. Journel, 1992, GSLIB: Geostatistical Software Library and User's Guide, Oxford University Press, New York, 336 p.

Englund, E., and A. Sparks, 1988, "GEO-EAS (Geostatistical Environmental Assessment Software) Use's Guide," EPA600/4-88/033, ENMSL, Environmental Protection Agency, Las Vegas.

Issaks, E.H., and R.M. Srivastava, 1989, Applied Geostatistics, Oxford University Press, $561 \mathrm{p}$.

Journel, A.G., and C.J. Huijbregts, 1978, Mining Geostatistics, Academic Press, London, $600 \mathrm{p}$.

Liao, S.S.C., 1986, "Statistical Modeling of Earthquake - Induced Liquefaction," Ph.D. Dissertation, Dept. of Civil Engineering, Massachusetts Institute of Technology. 
Mantoglou, A., and J. Wilson, 1982, "The turning bands method for simulation of random fields using line generation by a spectral method," Water Resources Research, 18(5), 1379-1394.

Matheron, G., 1971, The Theory of Regionalized Variables and Its Applications, Les Cahiers du Centre de Morphologie Mathématique de Fontainebleau, No. $5,211 \mathrm{p}$.

Ross, S.M., 1985, Introduction to Probability Models, Academic Press, Orlando.

Westinghouse Savannah River Company, 1995, "In Tank Precipitation Facility (ITP) and H-Tank Farm (HTF) Geotechnical Report," WSRC Technical Report No. WSRC-TR-95-0057, Rev. B, May 1995. 
Appendix 1

Tables 
Table 1.2.1 List of Geological Substrata at the ITP Site

\begin{tabular}{|c|c|}
\hline Layer & Description \\
\hline Fil' & Fill \\
\hline TR1 & Tobacco Road 1 \\
\hline TR2 & Tobacco Road 2 \\
\hline TR3 & Tobacco Road 3 \\
\hline TR4 & Tobacco Road 4 \\
\hline DB1 & Dry Branch 1 \\
\hline DB2 & Dry Branch 2 \\
\hline DB3 & Dry Branch 3 \\
\hline DB4 & Dry Branch 4 \\
\hline DB5 & Dry Branch 5 \\
\hline ST & Santee Formation \\
\hline
\end{tabular}


Table 3.0.1 List of Investigated CPT Borehole Data

\begin{tabular}{|c|c|c|c|}
\hline Borehole ID No. & $\begin{array}{l}\text { Easting } \\
\quad(\mathrm{ft})\end{array}$ & $\begin{array}{l}\text { Northing } \\
\text { (ft) }\end{array}$ & $\begin{array}{c}\text { Surface } \\
\text { Elevation } \\
\text { (ft) }\end{array}$ \\
\hline SCPT-01 & 62532.00 & 70843.97 & 326.38 \\
\hline SCPT-5 & 62667.40 & 70797.30 & 326.08 \\
\hline SCPT-6B & 62783.01 & 70903.41 & 328.17 \\
\hline CРT-7 & 62612.85 & 71030.17 & 328.76 \\
\hline SCPT-10 & 62554.29 & 71002.02 & 328.41 \\
\hline CPT-11 & 62767.43 & 70885.10 & 328.03 \\
\hline SCPT-14 & 62375.16 & 70935.99 & 300.09 \\
\hline СРТ-16 & 62426.06 & 70733.84 & 297.57 \\
\hline SCPT-18 & 62657.50 & 70601.00 & 298.32 \\
\hline SCPT-20 & 63059.62 & 70843.86 & 204.29 \\
\hline SCPT-20.1 & 63051.50 & 70835.00 & 294.31 \\
\hline SCPT-20.2 & 63076.50 & 70848.00 & 294.11 \\
\hline SCPT-23 & 63017.30 & 70970.68 & 296.59 \\
\hline CPT-25 & 62998.40 & 71197.74 & 296.20 \\
\hline CPT-26 & 62805.00 & 70764.00 & 326.13 \\
\hline SCPT28.2 & 62908.00 & 70611.74 & 300.42 \\
\hline CPT-28 & 62879.94 & 70611.74 & 300.56 \\
\hline СРТ-29 & 62681.30 & 71113.00 & 334.43 \\
\hline CPT-30 & 62805.00 & 70989.00 & 328.49 \\
\hline CPT-31 & 62537.00 & 70785.00 & 326.08 \\
\hline
\end{tabular}


Table 3.0.2 List of Removed Negative Friction Ratio Data

\begin{tabular}{||l|l|l|l||}
\hline Borehole & $\begin{array}{l}\text { Interval or } \\
\text { Elevation }\end{array}$ & Layer & Comment \\
\hline SCPT6B & $286.09-279.35$ & TR1 & $\begin{array}{l}\text { All negative FR } \\
\text { values }\end{array}$ \\
\hline SCPT01 & 315.07 & Fill & FR $=-473.22$ \\
\hline SCPT01 & 310.09 & Fill & FR $=-7.81$ \\
\hline SCPT01 & 271.18 & TR1 & FR $=-443.21$ \\
\hline SCPT01 & 279.60 & TR1 & FR $=-19.26$ \\
\hline SCPT14 & 254.96 & TR2 & FR $=-82.97$ \\
\hline SCPT14 & 254.95 & TR2 & FR $=-83.18$ \\
\hline SCPT14 & 254.95 & TR2 & FR $=-83.68$ \\
\hline SCPT20-1 & 286.53 & Fill & FR $=-80.54$ \\
\hline
\end{tabular}


Table 3.0.3 Locations with Sightly Negative Tip Resistances

\begin{tabular}{||l|l|l|l|l||}
\hline Borehole & Elevation & Tip resistance & $\begin{array}{l}\text { Friction } \\
\text { Ratio }\end{array}$ & Layer \\
\hline CPT-11 & 316.16 & -2.46 & -58 & Fill \\
\hline CPT-11 & 294.82 & -.6 & -376 & Fill \\
\hline SCPT05 & 312.22 & -17.74 & -18 & Fill \\
\hline SCPT05 & 300.03 & -16.97 & -9 & Fill \\
\hline SCPT10 & 313.19 & -5.18 & -25 & Fill \\
\hline SCPT10 & 313.12 & -5.05 & -25 & Fill \\
\hline SCPT10 & 313.05 & -6.41 & -20 & Fill \\
\hline SCPT10 & 312.98 & -7.27 & -20 & Fill \\
\hline SCPT10 & 312.90 & -6.41 & -30 & Fill \\
\hline SCPT10 & 305.99 & -18.46 & -23 & Fill \\
\hline SCPT10 & 304.76 & -1.66 & -92 & Fill \\
\hline SCPT10 & 304.69 & -3.62 & -43 & Fill \\
\hline SCPT10 & 304.61 & -3.62 & -49 & Fill \\
\hline SCPT10 & 299.36 & -.77 & -184 & Fill \\
\hline SCPT10 & 298.10 & -29.61 & -8.3 & Fill \\
\hline SCPT20-2 & 286.36 & -.23 & -26 & Fill \\
\hline SCPT20-2 & 286.29 & -.11 & -167 & Fill \\
\hline SCPT6B & 306.06 & -27.02 & -9.5 & Fill \\
\hline \hline
\end{tabular}


Table 3.0.4 List of Removed Spurious Data in the Fill Layer

\begin{tabular}{||l|l|l||}
\hline Borehole & Interval & Layer \\
\hline SCPT01 & $326.83-320.75$ & Fill \\
\hline SCPT05 & $326.09-320.06$ & Fill \\
\hline SCPT05 & $385.25-218.75$ & TR1 \\
\hline SCPT6B & $328.17-322.75$ & Fill \\
\hline CPT-7 & $328.76-322.80$ & Fill \\
\hline SCPT10 & $328.41-319.90$ & Fill \\
\hline CPT-11 & $327.87-321.78$ & Fill \\
\hline SCPT18 & $298.32-292.23$ & Fill \\
\hline SCPT20-1 & $294.31-288.53$ & Fill \\
\hline SCPT20-2 & $294.11-286.11$ & Fill \\
\hline SCPT23 & $296.59-289.50$ & Fill \\
\hline CPT-26 & $326.13-320.02$ & Fill \\
\hline CPT28 & $300.56-294.45$ & Fill \\
\hline SCPT28-2 & $300.42-294.25$ & Fill \\
\hline CPT-29 & $334.43-328.01$ & Fill \\
\hline CPT-30 & $328.49-322.48$ & Fill \\
\hline CPT-31 & $326.08-319.95$ & Fill \\
\hline
\end{tabular}


Table 3.0.5 List of Removed High Friction Ratio Data

\begin{tabular}{||l|l|l|l|l|l||}
\hline Borehole & Elevation & qC & fs & FR & layer \\
\hline SCPT1 & 314.82 & .8 & 1.59 & 198 & Fill \\
\hline SCPT1 & 288.59 & 3.27 & 1.58 & 48.4 & Fill \\
\hline SCPT1 & 288.51 & 1.54 & 1.53 & 99.3 & Fill \\
\hline SCPT1 & 288.43 & 1.07 & 1.39 & 130 & Fill \\
\hline SCPT1 & 288.36 & 3.07 & 1.74 & 56.7 & Fill \\
\hline SCPT05 & 315.53 & .38 & 1.21 & 315 & Fill \\
\hline SCPT10 & 312.83 & .47 & 2.32 & 490 & Fill \\
\hline SCPT10 & 304.54 & 1.61 & 2.17 & 135 & Fill \\
\hline SCPT10 & 299.50 & 2.63 & 1.92 & 72.8 & Fill \\
\hline SCPT10 & 299.43 & .62 & 1.78 & 288 & Fill \\
\hline SCPT10 & 299.29 & .11 & 1.43 & 1253 & Fill \\
\hline SCPT10 & 299.21 & 3.24 & 1.922 & 59.3 & Fill \\
\hline SCPT23 & 293.16 & 0 & 0 & 161 & Fill \\
\hline SCPT23 & 293.08 & 0 & 0 & 65.5 & Fill \\
\hline SCPT28-2 & 294.60 & .22 & .12 & 52.8 & Fill \\
\hline SCPT28-2 & 294.53 & .33 & .75 & 224 & Fill \\
\hline SCPT28-2 & 294.46 & 1.89 & 1.2 & 63.4 & Fill \\
\hline SCPT6B & 327.20 & 0 & 0 & 92.5 & Fill \\
\hline
\end{tabular}


Table 3.1.1 Parameters of Fitted Multi-Layer Variograms of Tip Resistances

\begin{tabular}{|c|c|c|c|c|c|c|}
\hline \multirow[b]{2}{*}{ Layer } & \multicolumn{3}{|c|}{ Lateral Variogram } & \multicolumn{3}{|c|}{ Vertical Variogram } \\
\hline & Nugget & Range & Sill & Nugget & Range & Sill \\
\hline Fill & $-\cdots$ & 130 & 410 & $-\cdots$ & 2 & 410 \\
\hline TR1 & 650 & 0 & 0 & -- & 2 & 650 \\
\hline TR2 & -- & 120 & 1800 & -- & 6 & 1800 \\
\hline TR3 & $\cdots$ & 120 & 500 & $\cdots$ & 6 & 500 \\
\hline TR4 & 420 & 0 & 0 & --. & 3 & 420 \\
\hline DB1 & -- & 50 & 4000 & $-\cdots$ & 12 & .4000 \\
\hline DB2 & --- & 75 & 1700 & $-\cdots$ & 4 & 1700 \\
\hline DB3 & --- & 110 & 900 & -- & 8 & 9000 \\
\hline DB4 & 100 & 0 & 0 & $-\cdots$ & 4 & 1000 \\
\hline DB5 & $\cdots$ & 40 & 1000 & $-\cdots$ & 1 & 1000 \\
\hline ST & 8000 & 0 & 0 & -- & 6 & 8000 \\
\hline
\end{tabular}


Table 5.0.1 Parameters of Fitted Multi-Layer Normal Score Variograms of N Values

\begin{tabular}{|l|c|c|c|c|c|c||}
\hline & \multicolumn{3}{|c|}{ Lateral Variogram } & \multicolumn{3}{c|}{ Vertical Variogram } \\
\hline Layer & Nugget & Range & Sill & Nugget & Range & Sill \\
\hline TR1 & --- & 400 & 1.3 & 0.022 & 13 & 0.255 \\
\hline TR2A & 1 & --- & -- & 0 & 4 & 0.7 \\
\hline TR2B & 0.5 & 450 & 0.6 & 0 & 2 & 0.42 \\
\hline TR3/TR4 & 1 & --- & -- & 0.055 & 4 & 0.07 \\
\hline DB1/DB3 & 0.7 & 400 & 0.46 & 0.050 & 4 & 0.045 \\
\hline DB4 & --- & 300 & 1.1 & 0.070 & 2 & 0.2 \\
\hline DB5 & --- & 350 & 1.1 & 0 & 5.3 & 0.4 \\
\hline ST & 1 & --- & -- & 0.320 & 5 & 0.3 \\
\hline
\end{tabular}


Appendix II

Figures 


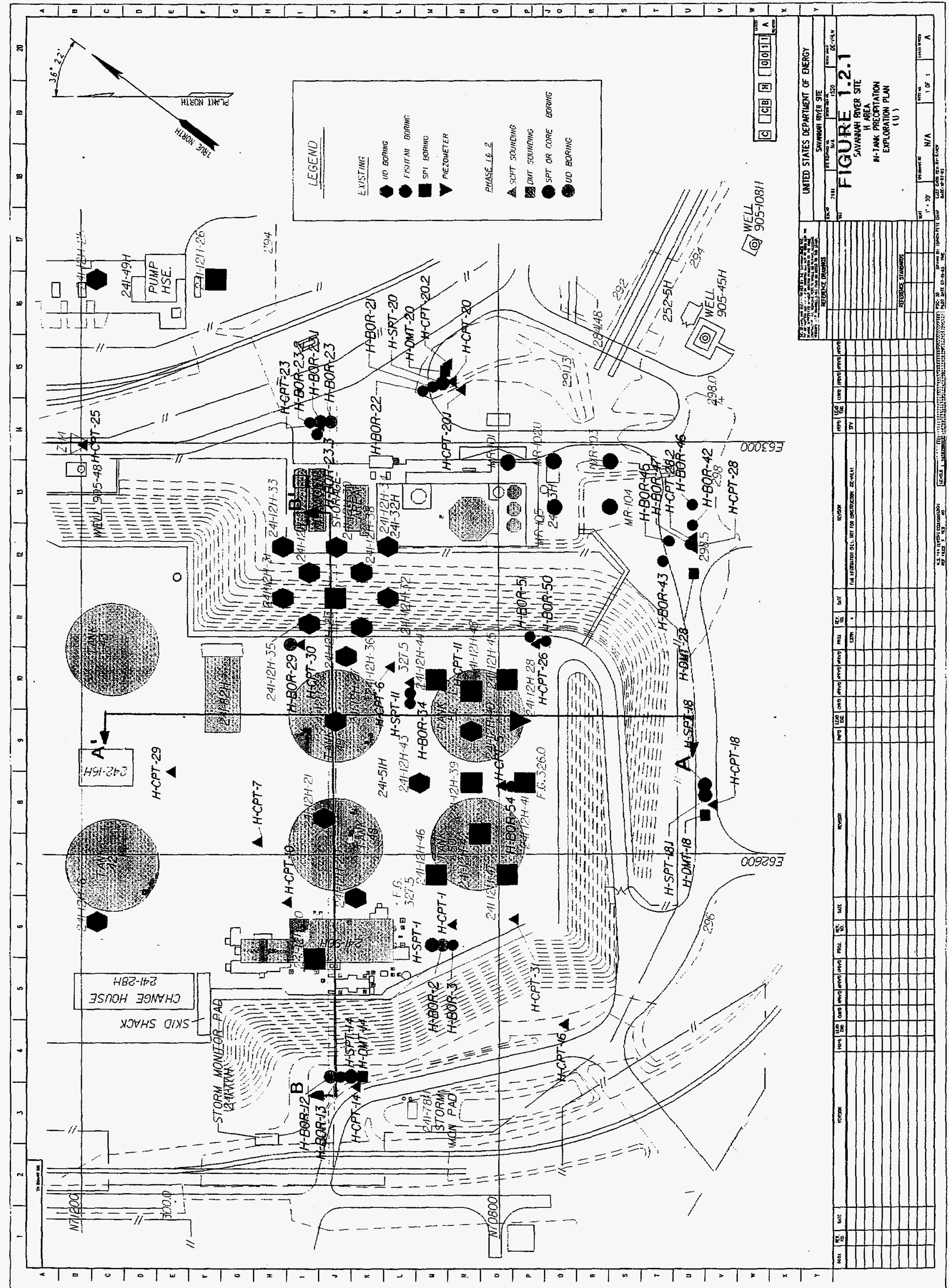


Lateral \& Vertical Variogram of Tip

Fill Layer

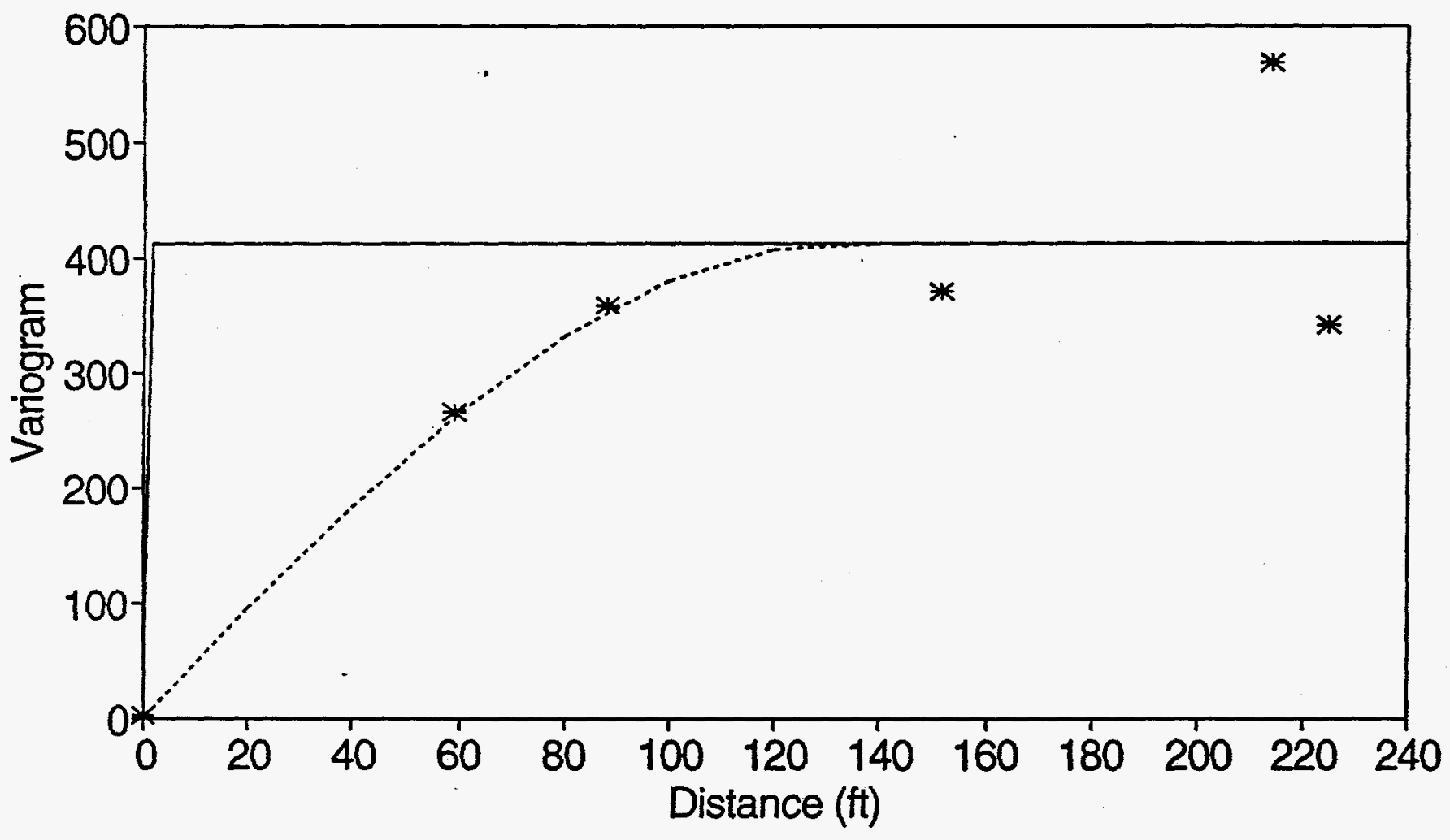

\section{-.....- Lateral variogram - Vertical Variogram}

$$
1^{*} \text { = Sample Lateral Variograms) }
$$

Figure 3.1.1 Lateral and Vertical Variogram of Tip Resistance (Fill Layer) 


\section{Lateral \& Vertical Variogram of Tip}

TR1 Layer

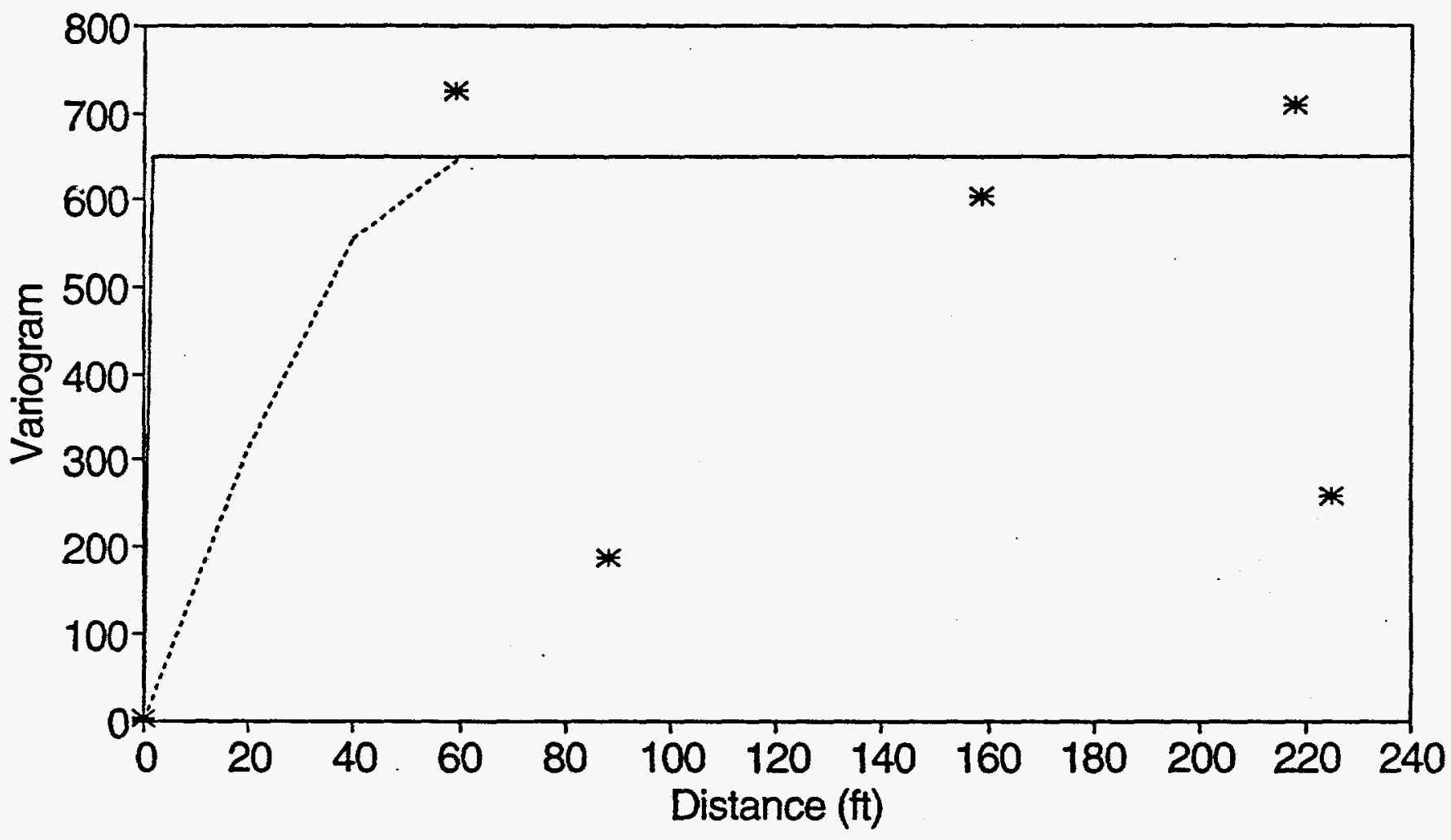

-.-.-- Lateral Variogram - Vertical Variogram

$1^{*}=$ Sample Lateral Variograms)

Figure 3.1.2 Lateral and Vertical Variogram of Tip Resistance (TR1 Layer) 


\section{Lateral \& Vertical Variogram of Tip TR2 Layer}

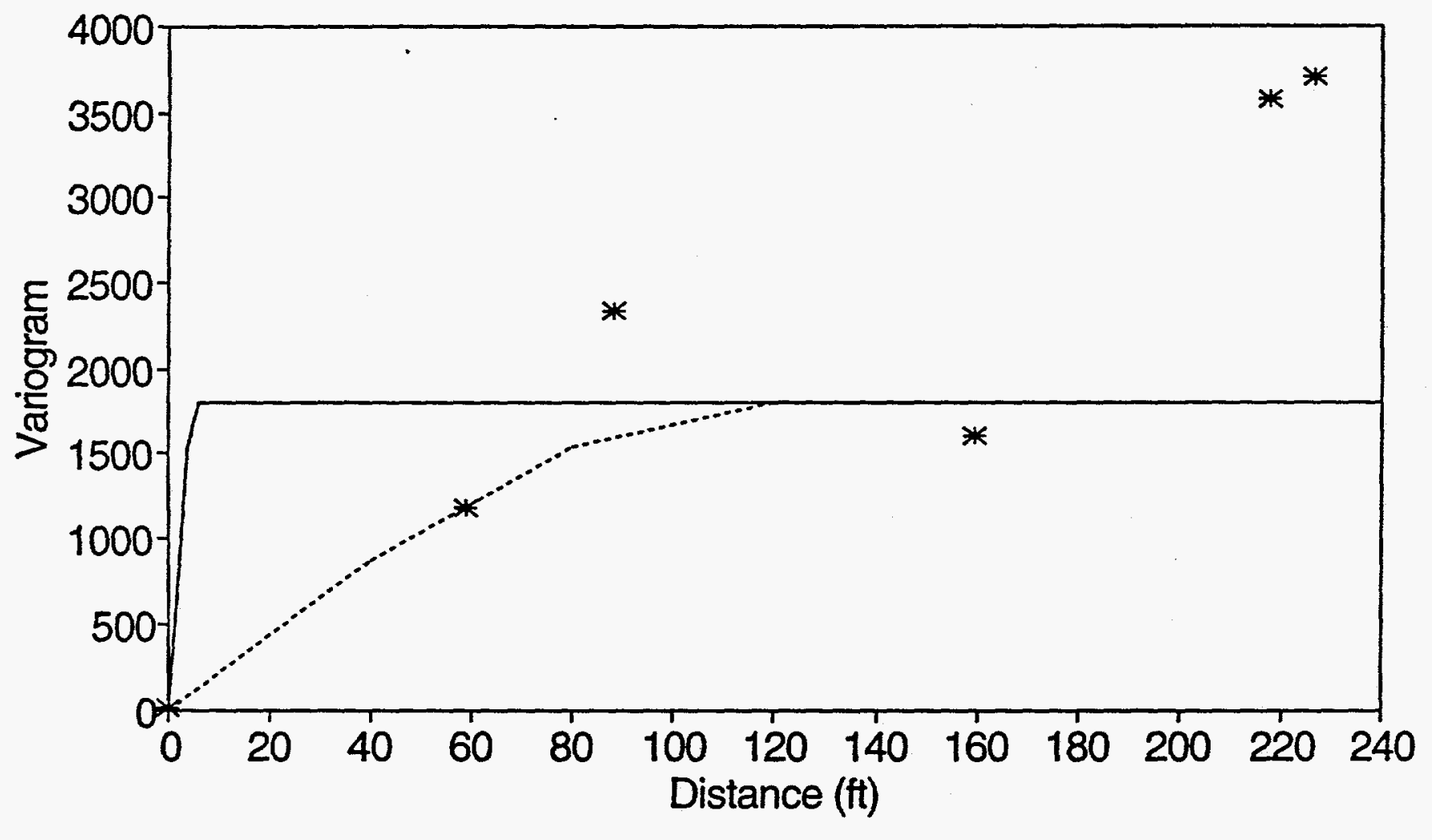

\section{...... Lateral Variogram - Lateral Variogram}

$$
\left(^{*}=\text { Sample Lateral Variograms }\right)
$$

Figure 3.1.3 Lateral and Vertical Variogram of Tip Resistance (TR2 Layer) 
Lateral \& Vertical Variogram of Tip

TR3 Layer

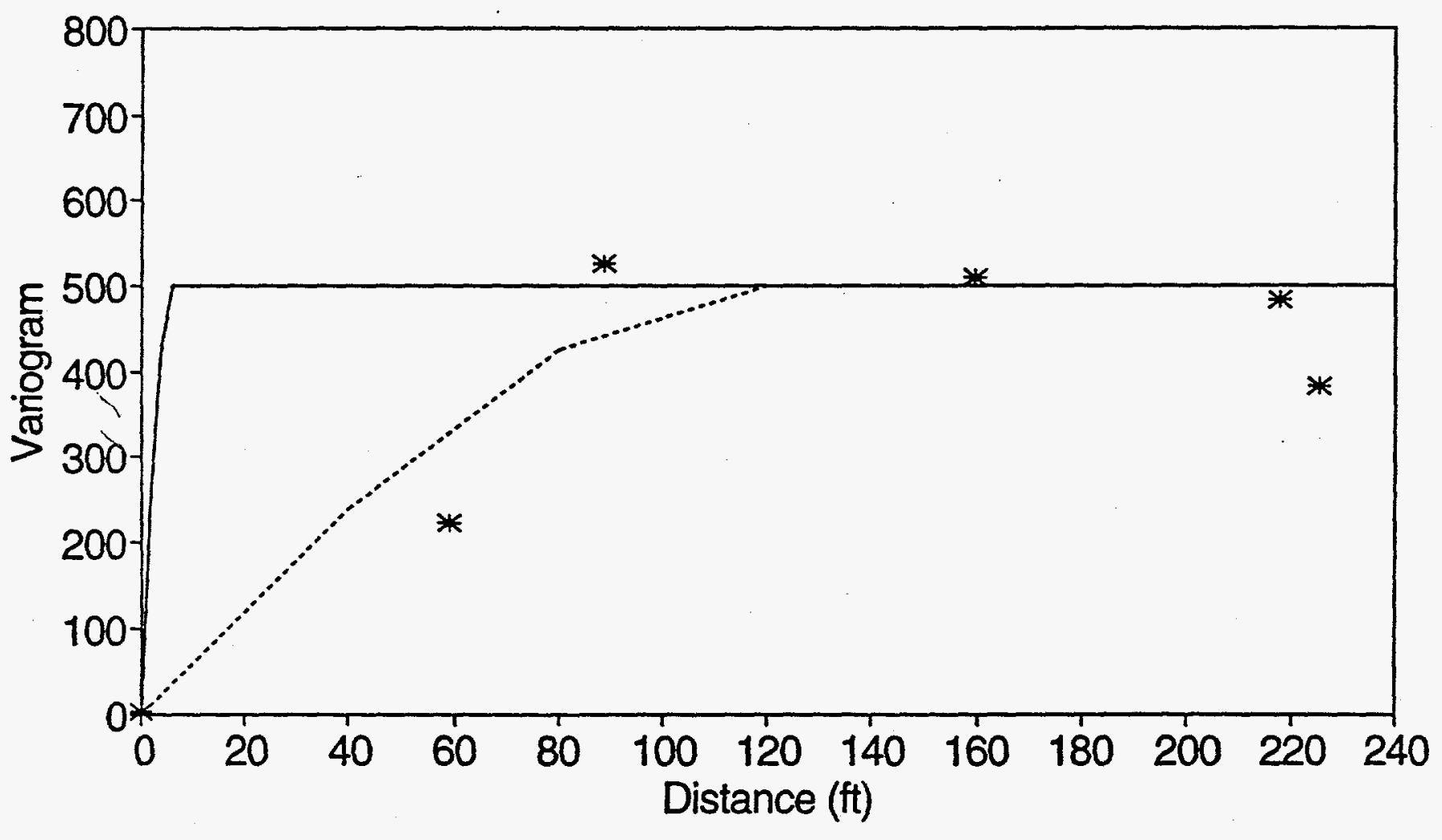

\section{......- Lateral Variogram - Vertical Variogram}

$$
1^{*} \text { = Sample Lateral Variograms) }
$$

Figure 3.1.4 Lateral and Vertical Variogram of Tip Resistance (TR3 Layer) 
Lateral \& Vertical Variogram of Tip TR4 Layer

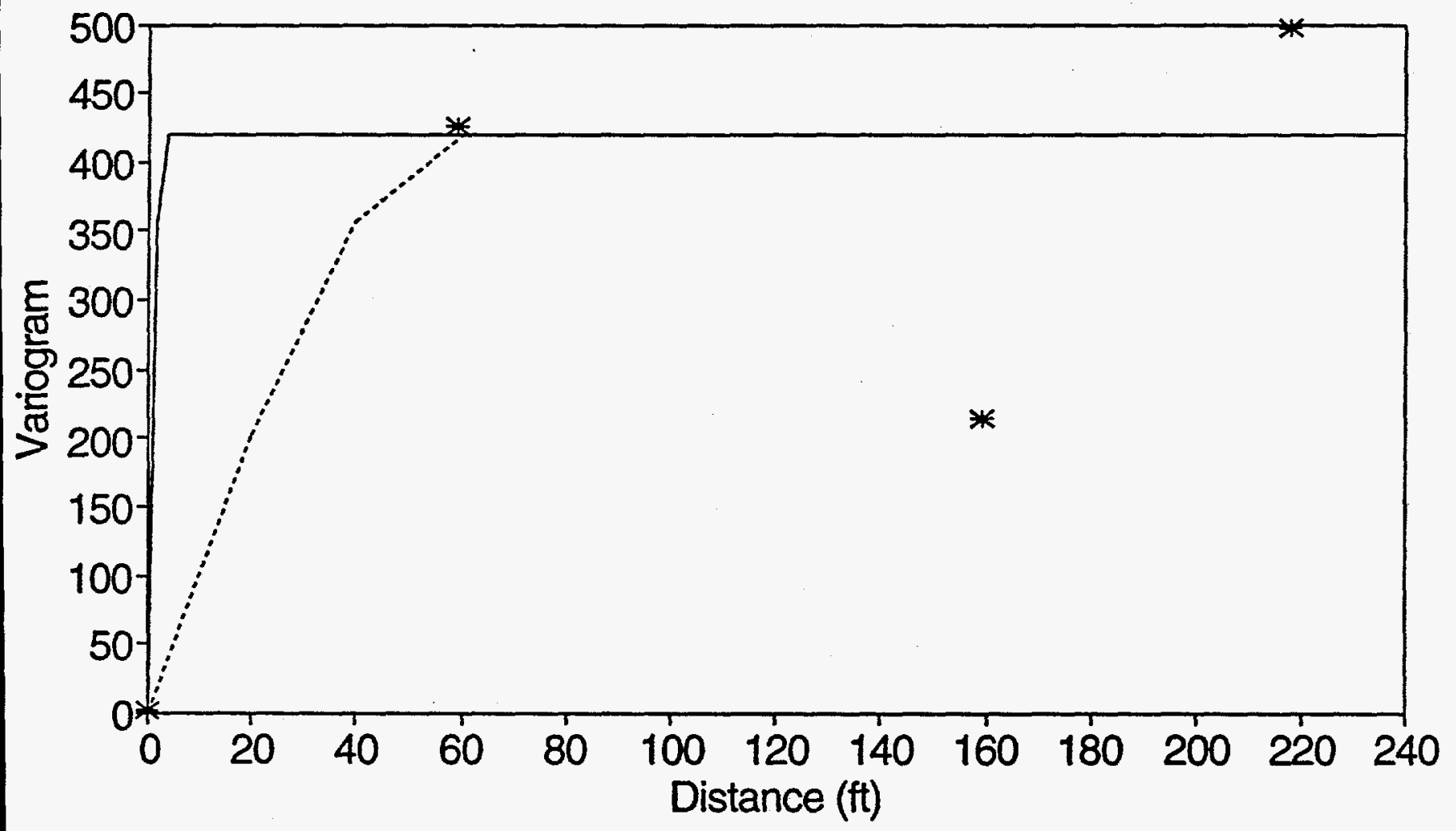

\section{-..... Lateral Variogram — Vertical Variogram}

$1^{*}$ = Sample Lateral Variograms)

Figure 3.1.5 Lateral and Vertical Variogram of Tip Resistance (TR4 Layer) 


\section{Lateral \& Vertical Variogram of Tip DB1 Layer}

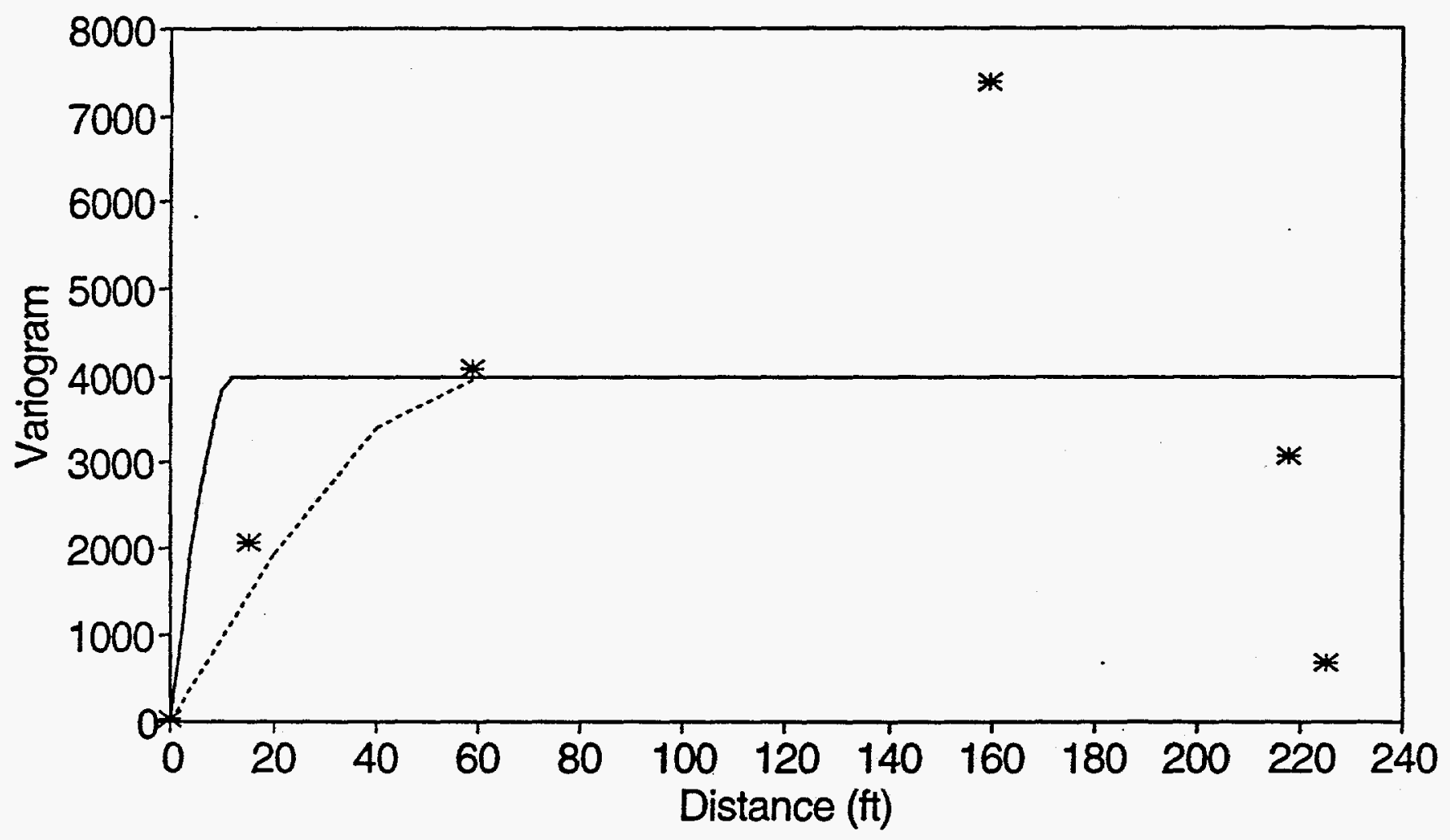

...... Lateral Variogram - Vertical Variogram

$$
1^{*} \text { = Sample Lateral Variograms) }
$$

Figure 3.1.6 Lateral and Vertical Variogram of Tip Resistance (DB1 Layer) 


\section{Lateral \& Vertical Variogram of Tip DB2 Layer}

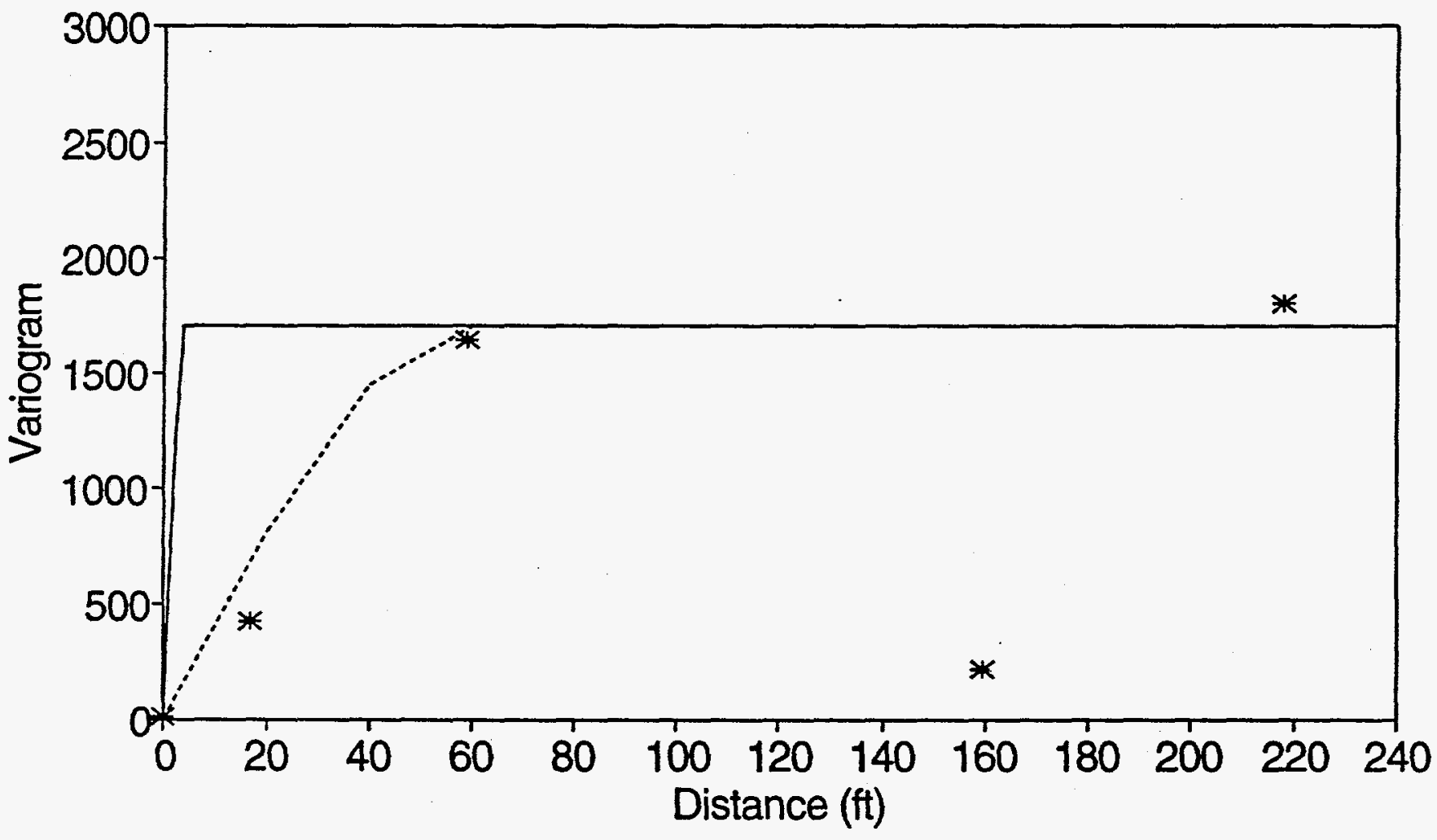

\section{-.....- Lateral Variogram - Vertical Variogram}

$$
\text { (* = Sample Lateral Variograms) }
$$

Figure 3.1.7 Lateral and Vertical Variogram of Tip Resistance (DB2 Layer) 


\section{Lateral \& Vertical Variogram of Tip DB3 Layer}

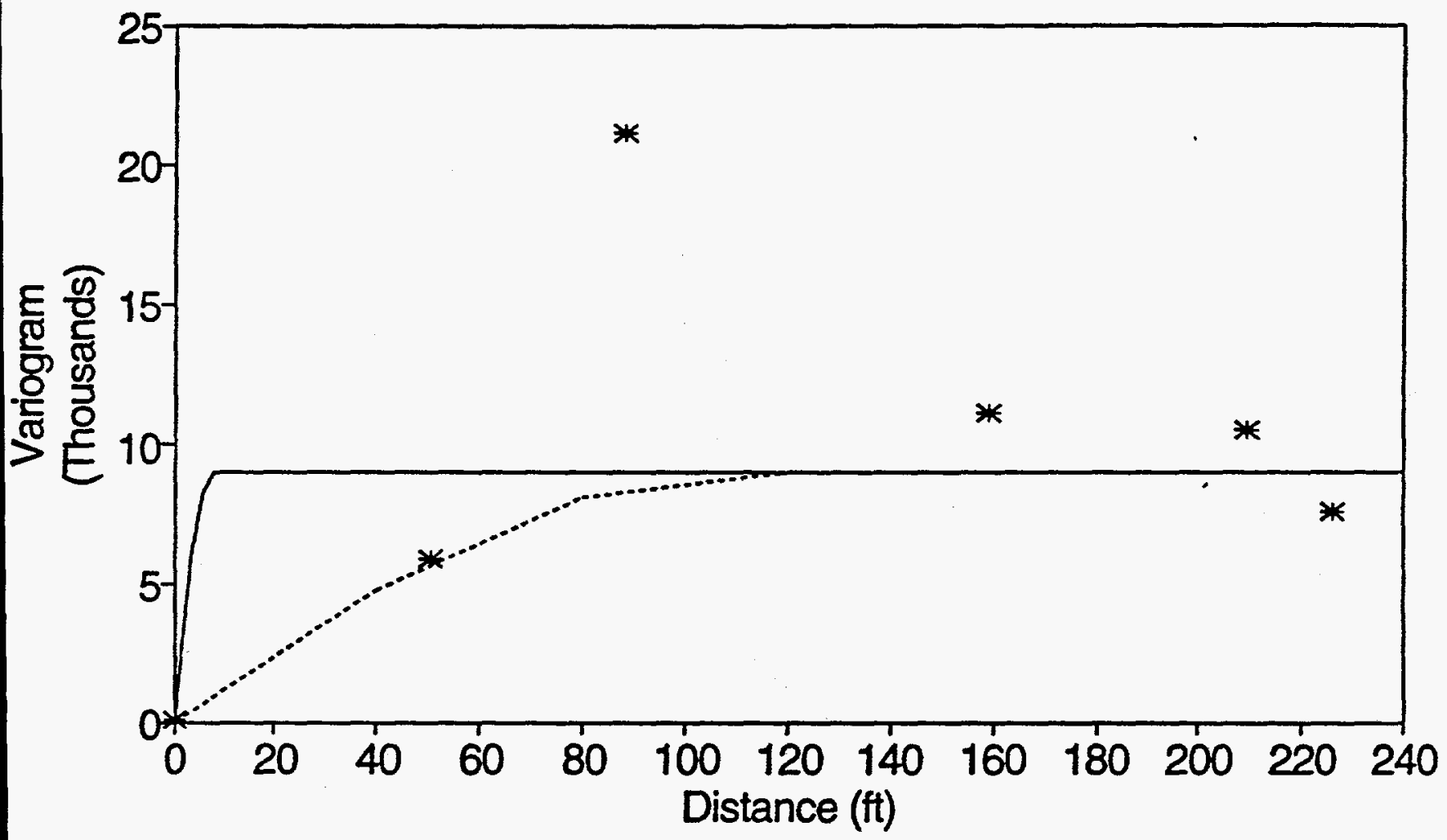

...... Lateral Variogram — Vertical Variogram

$$
1^{*}=\text { Sample Lateral Variograms) }
$$

Figure 3.1.8 Lateral and Vertical Variogram of Tip Resistance (DB3/DB4 Layer) 
Lateral \& Vertical Variogram of Tip DB5 Layer

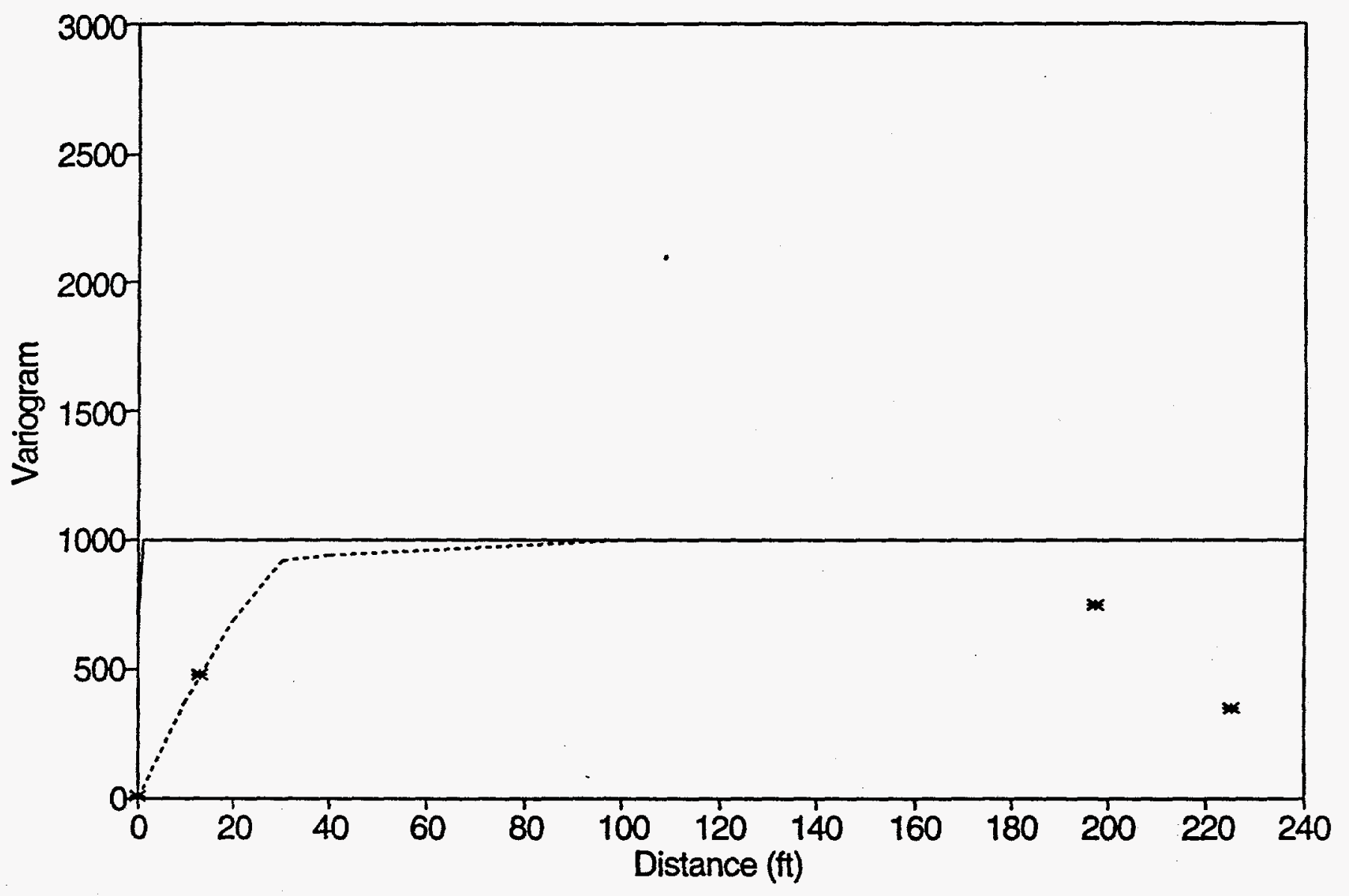

$1^{*}$ = Sample Lateral Variograms $)$

Figure 3.1.9 Lateral and Vertical Variogram of Tip Resistance (DB5 Layer) 


\section{Lateral \& Vertical Variogram of Tip Santee Layer}

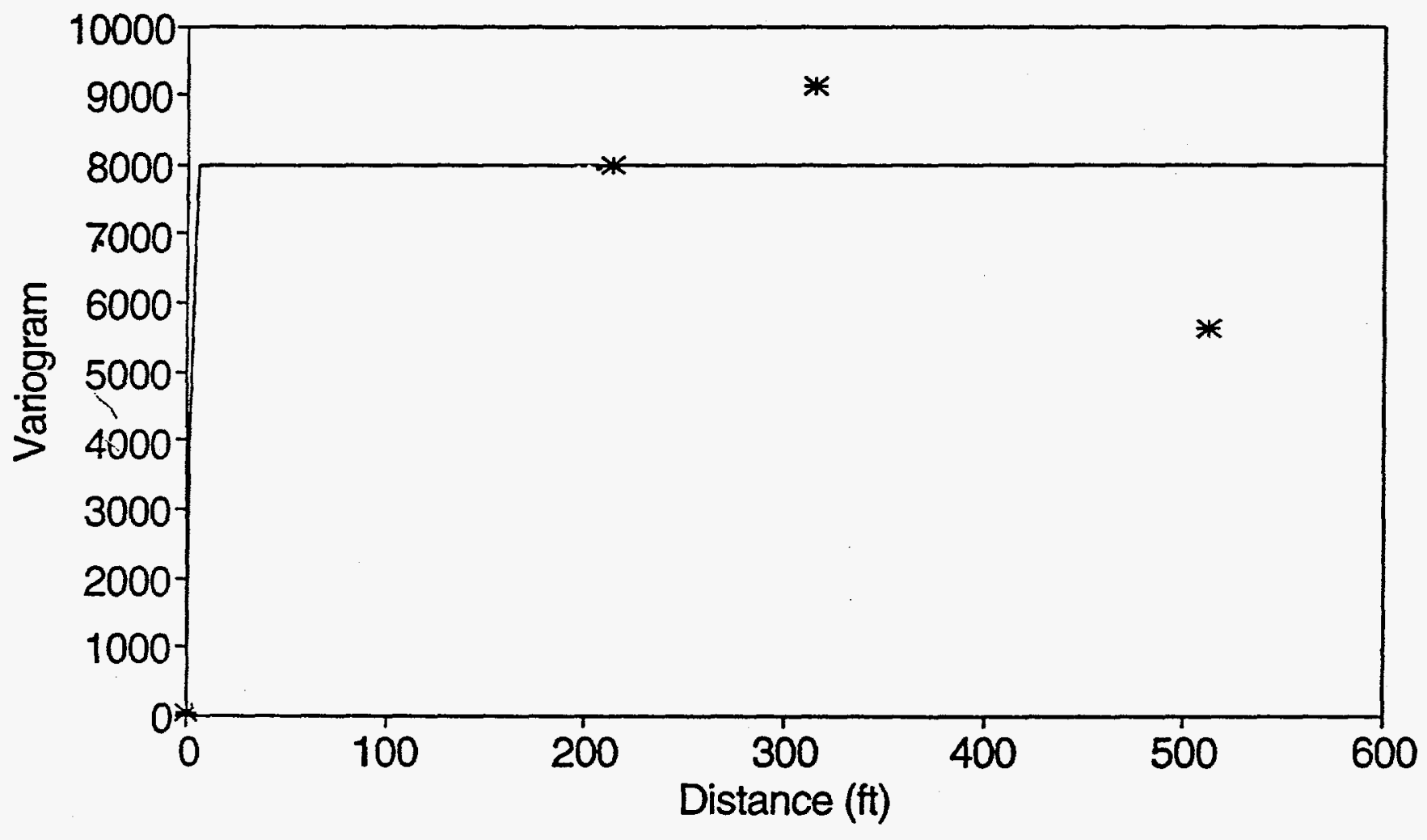

\section{…... Lateral Variogram - Vertical Variogram}

$$
\text { ( }^{*} \text { = Sample Lateral Variograms) }
$$

Figure 3.1.10 Lateral and Vertical Variogram of Tip Resistance (Santee Layer) 


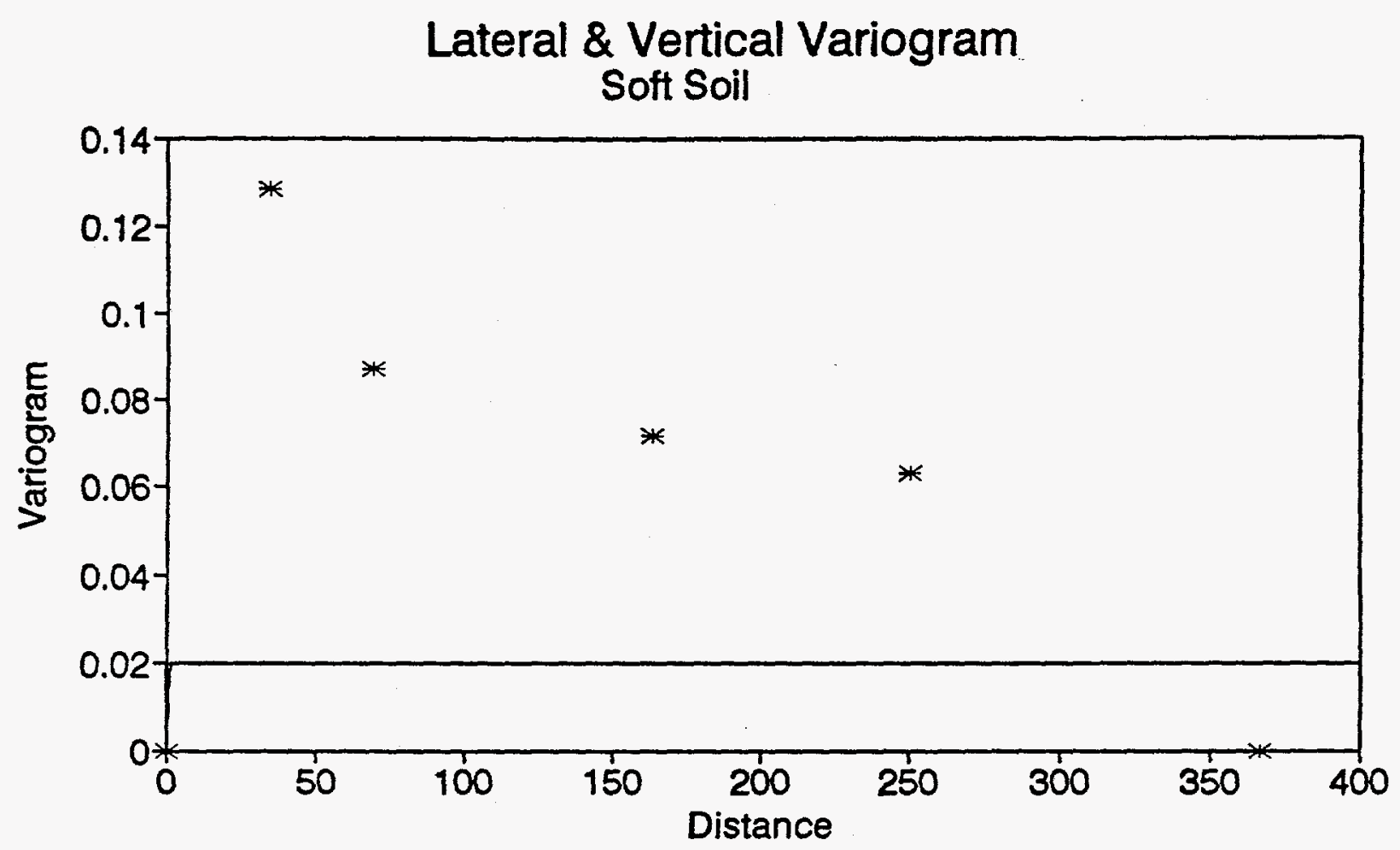

* Lateral Variogram - Vertical Variogram

Figure 3.1.11 Lateral and Vertical Variogram of Tip Resistance (Soft Soil) 


\section{Lateral \& Vertical Variogram Intermediate Soil}

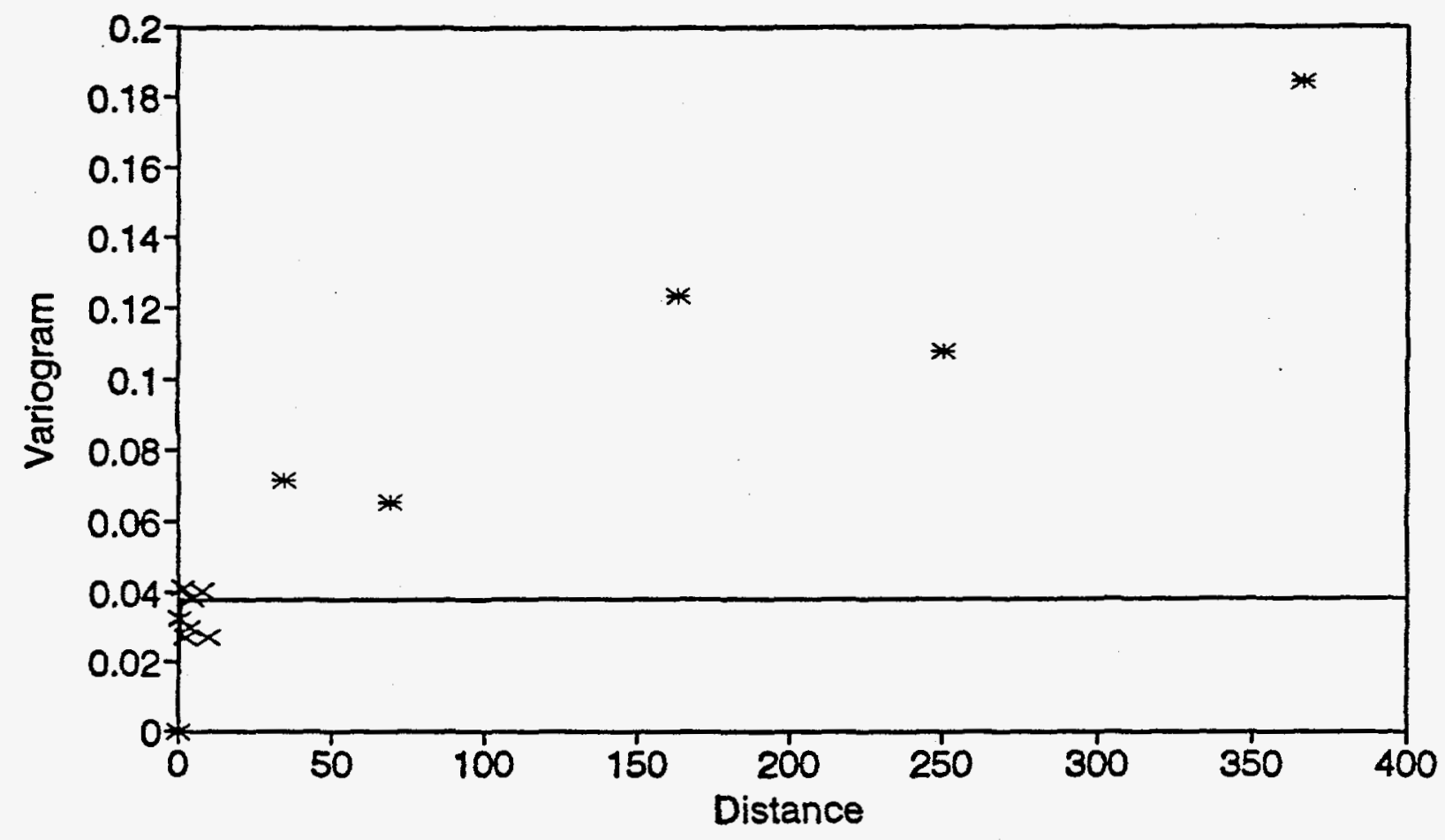

* = Sample Lateral Variograms

$\mathrm{x}=$ Sample Vertical Variograms

Figure 3.1.12 Lateral and Vertical Variogram of Tip Resistance (Intermediate Soil) 


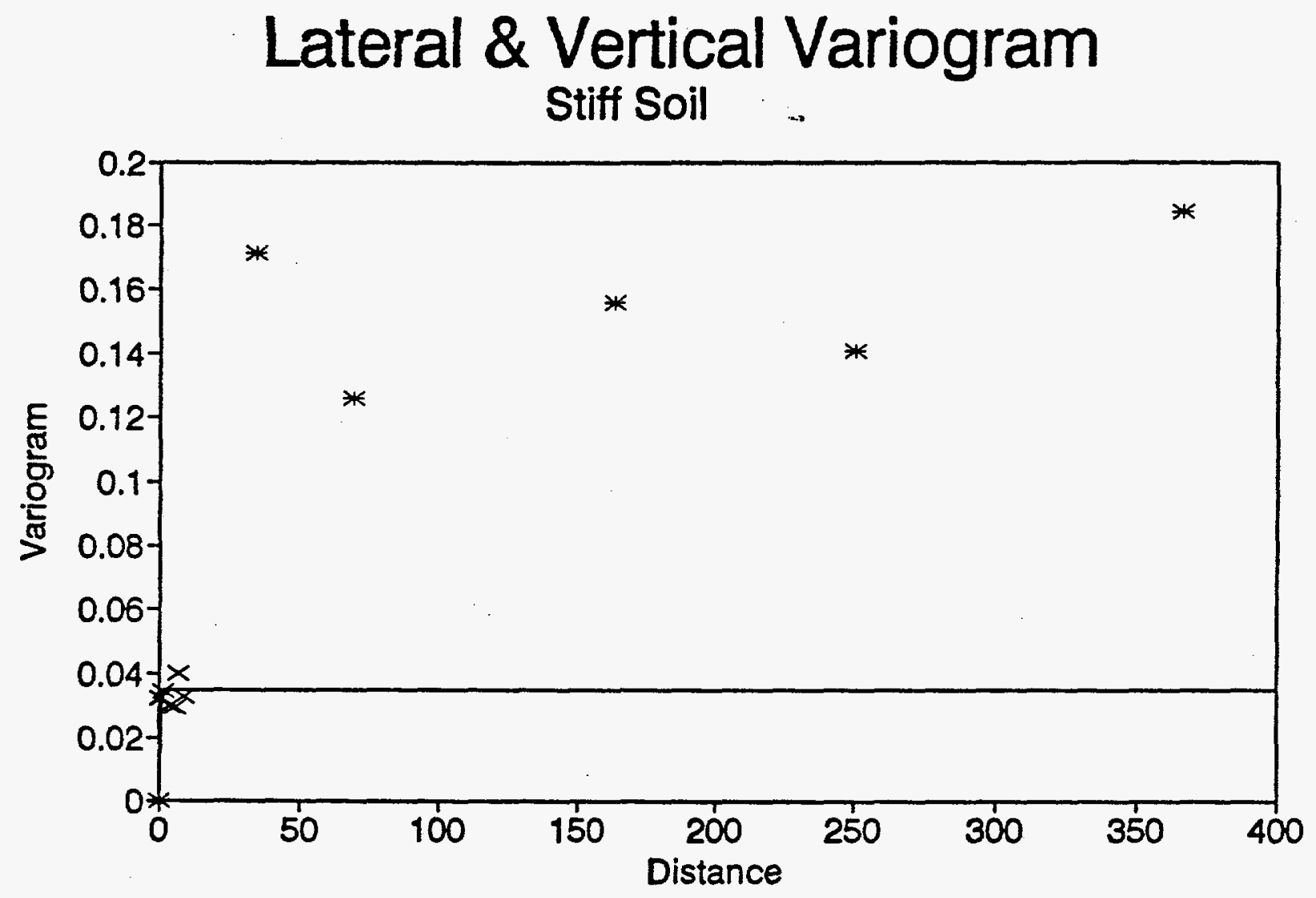

* = Sample Lateral Variograms

$\mathbf{x}=$ Sample Vertical Variograms

Figure 3.1.13 Lateral and Vertical Variogram of Tip Resistance (Stiff Soil) 
Lateral \& Vertical Variogram (30) Soft Soil

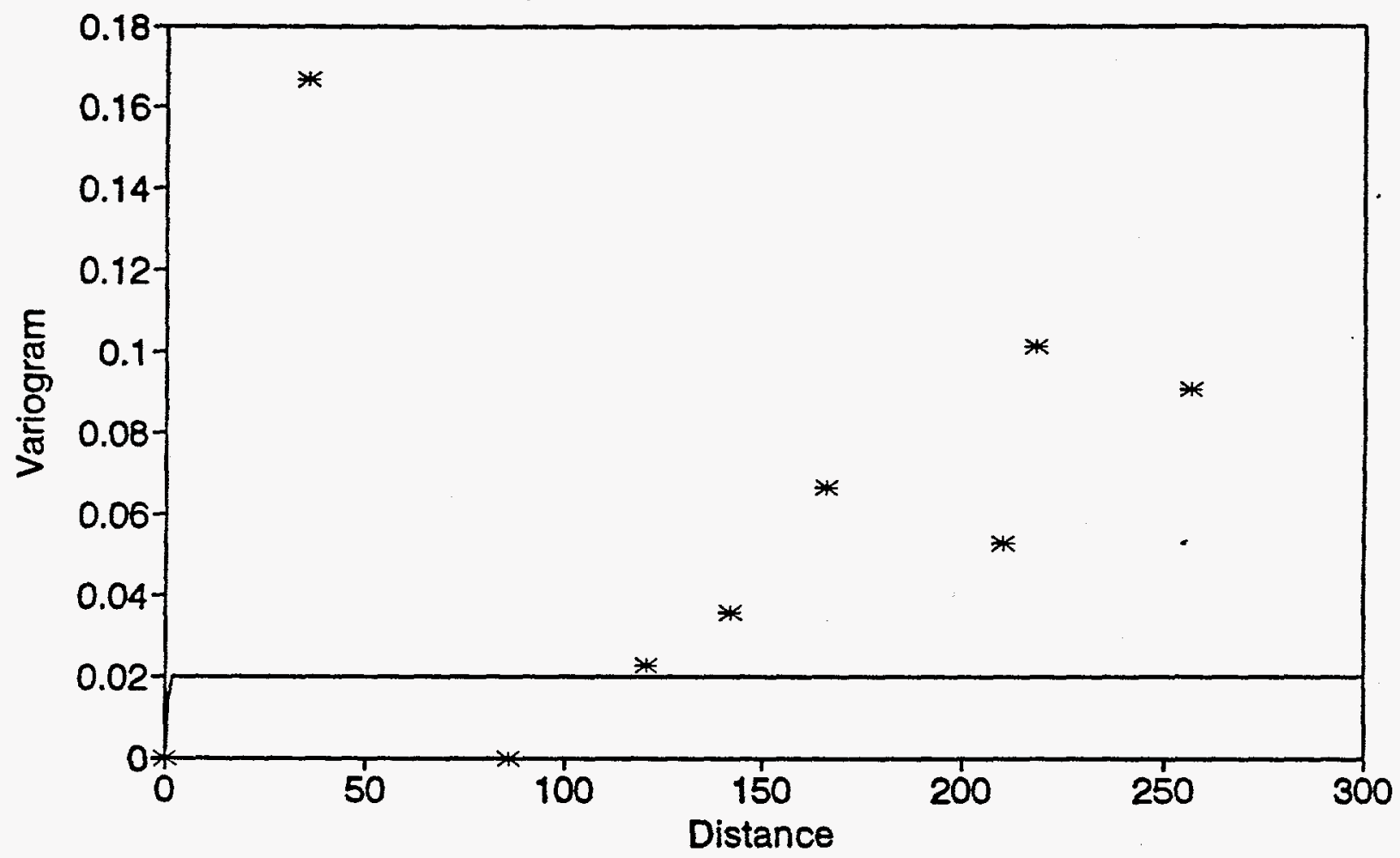

* = Sample Lateral Variograms

$x=$ Sample Vertical Variograms

Figure 3.1.14 Vertical and Directional Lateral Variogram of Tip Resistance along Angle $30^{\circ}$ (Soft Soil) 


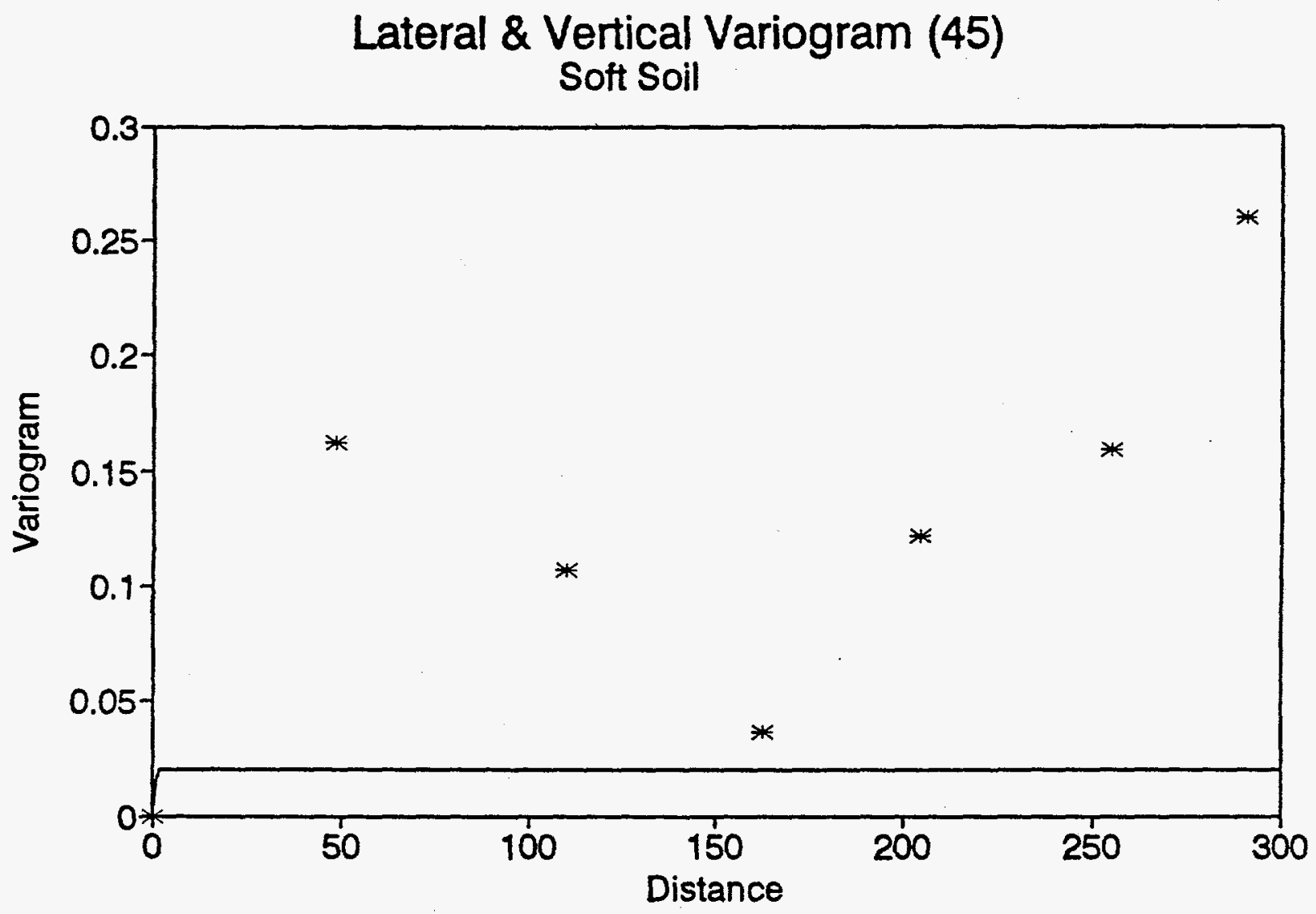

* = Sample Lateral Variograms

$x=$ Sample Vertical Variograms

Figure 3.1.15 Vertical and Directional Lateral Variogram of Tip Resistance along Angle $45^{\circ}$ (Soft Soil) 


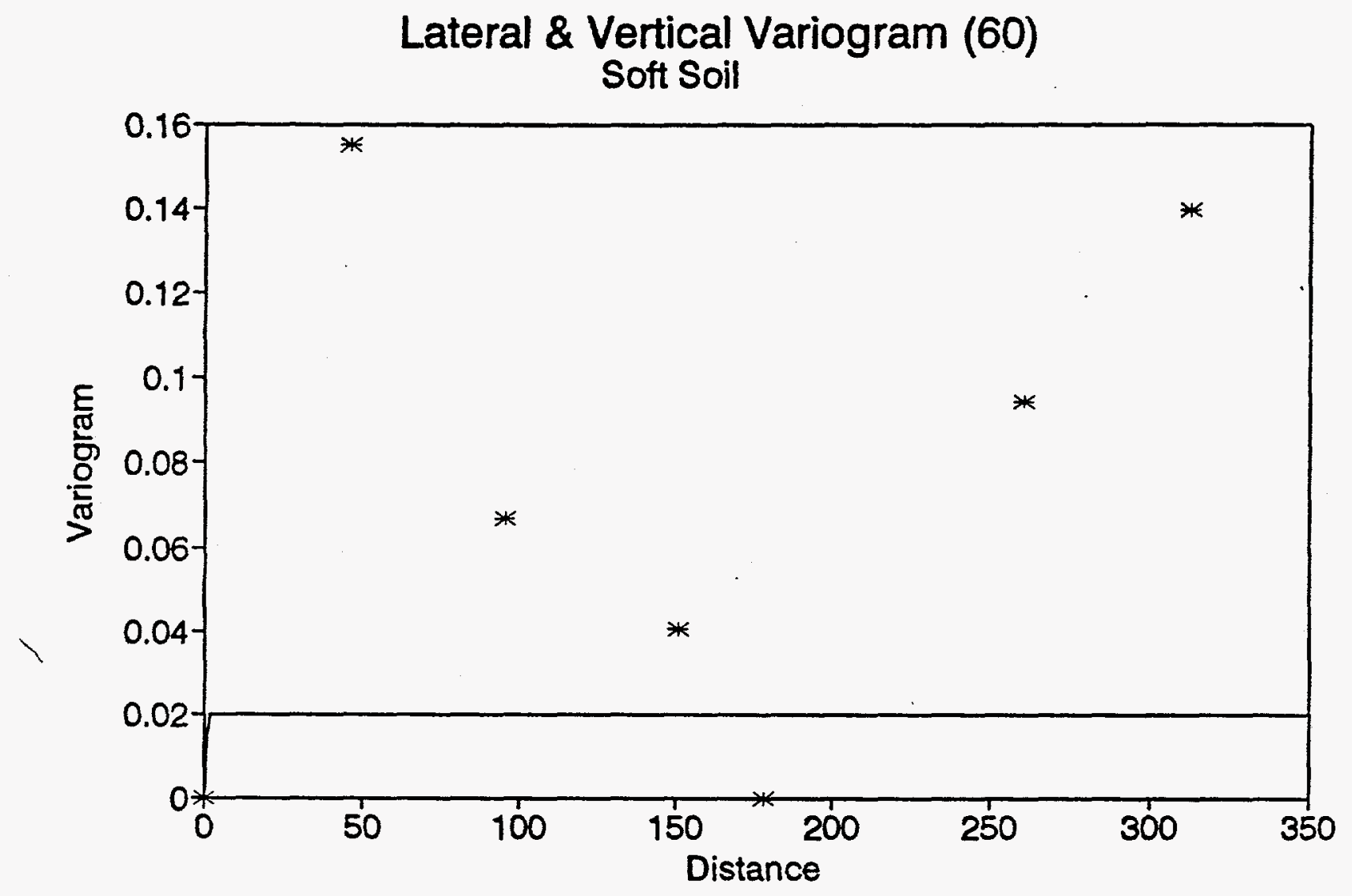

* = Sample Lateral Variograms

$x=$ Sample Vertical Variograms

Figure 3.1.16 Vertical and Directional Lateral Variogram of Tip Resistance along Angle $60^{\circ}$ (Soft Soil) 


\section{Lateral \& Vertical Variogram (30) Intermediate Soil}

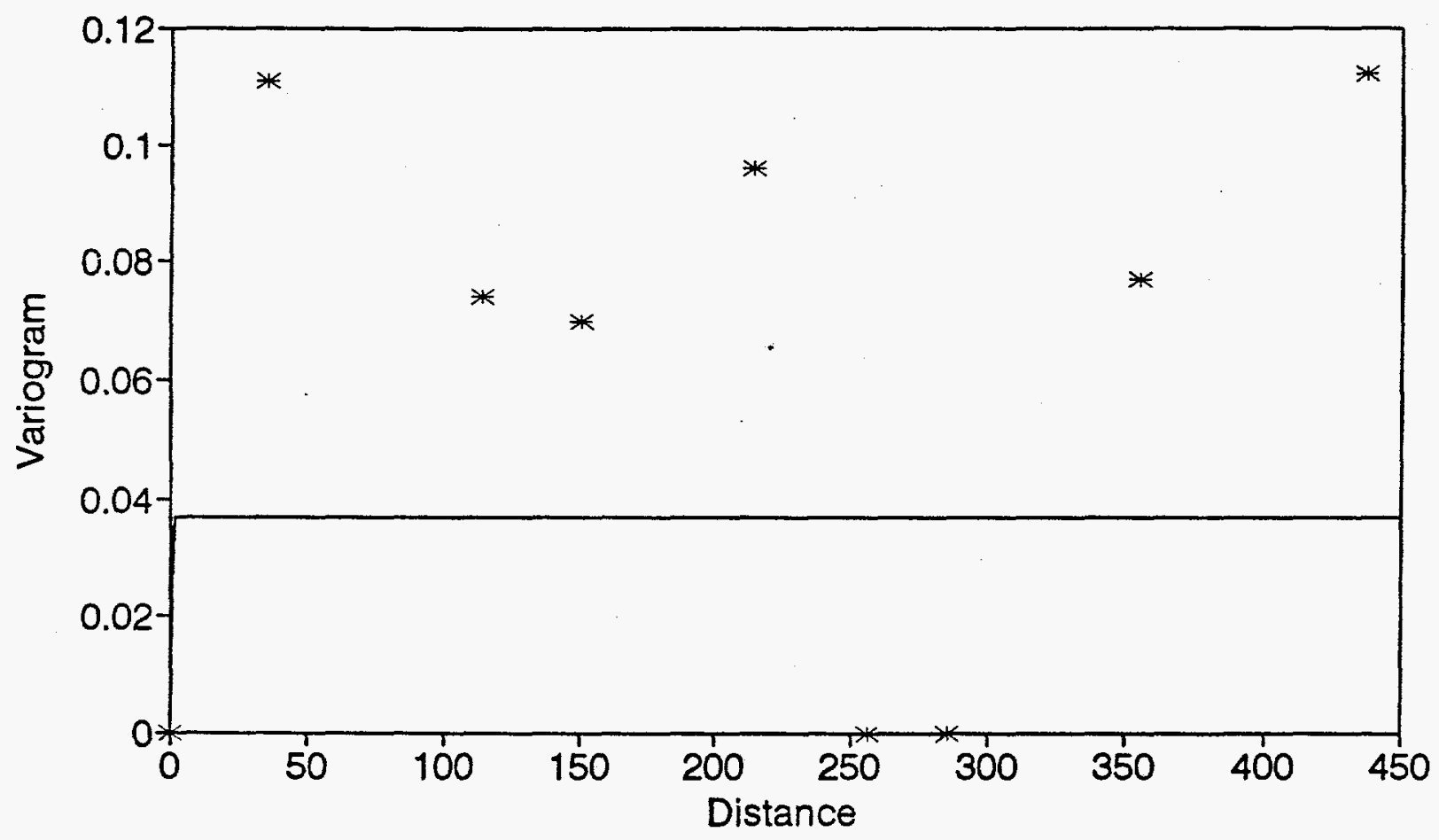

\footnotetext{
* = Sample Lateral Variograms

$x=$ Sample Vertical Variograms
}

Figure 3.1.17 Vertical and Directional Lateral Variogram of Tip Resistance along Angle $30^{\circ}$ (Intermediate Soil) 


\section{Lateral \& Vertical Variogram (45) Intermediate Soil}

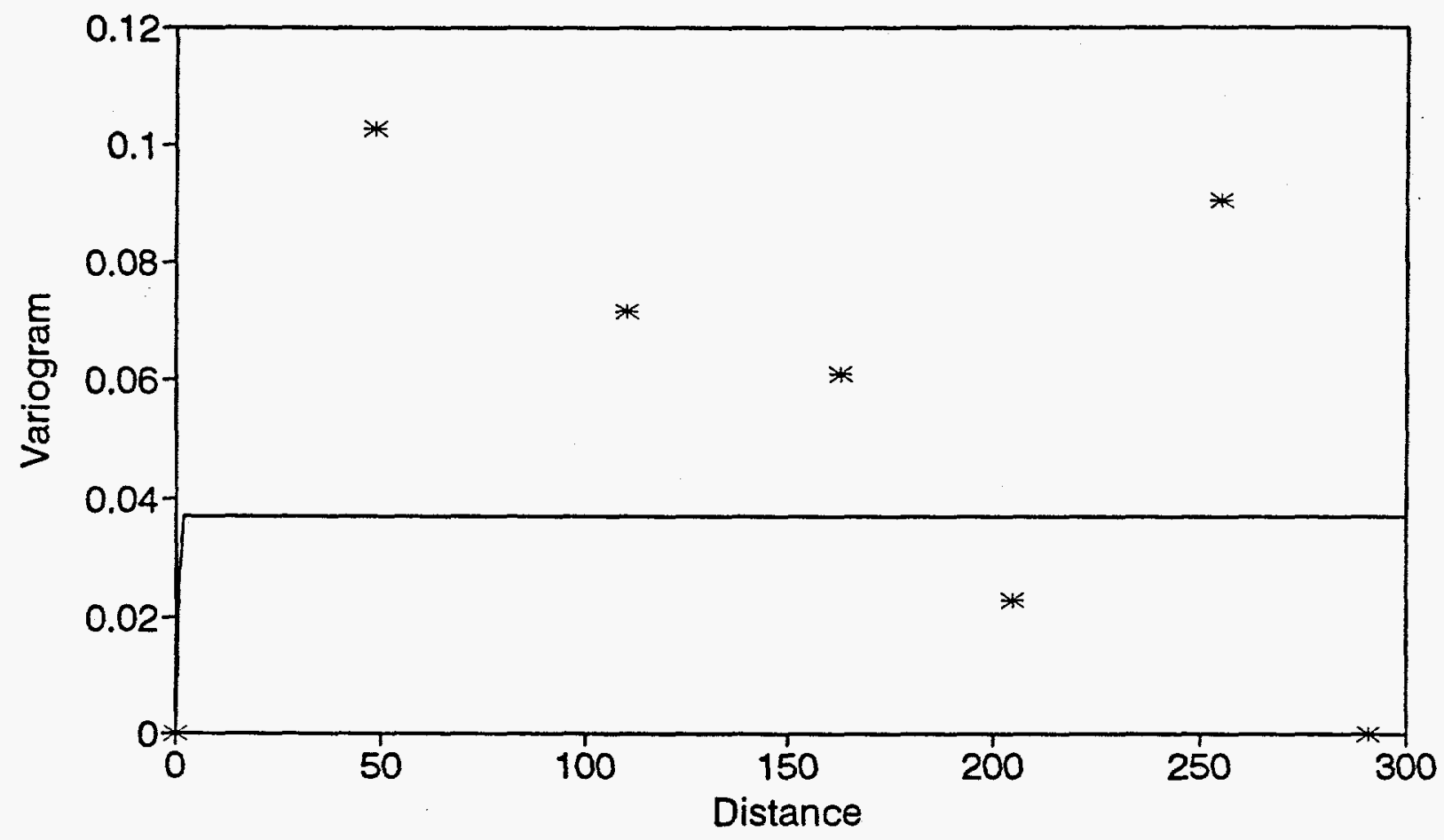

* $=$ Sample Lateral Variograms
x $=$ Sample Vertical Variograms

Figure 3.1.18 Vertical and Directional Lateral Variogram of Tip Resistance along Angle $45^{\circ}$ (Intermediate Soil) 


\section{Lateral \& Vertical Variogram (60) Intermediate Soil}

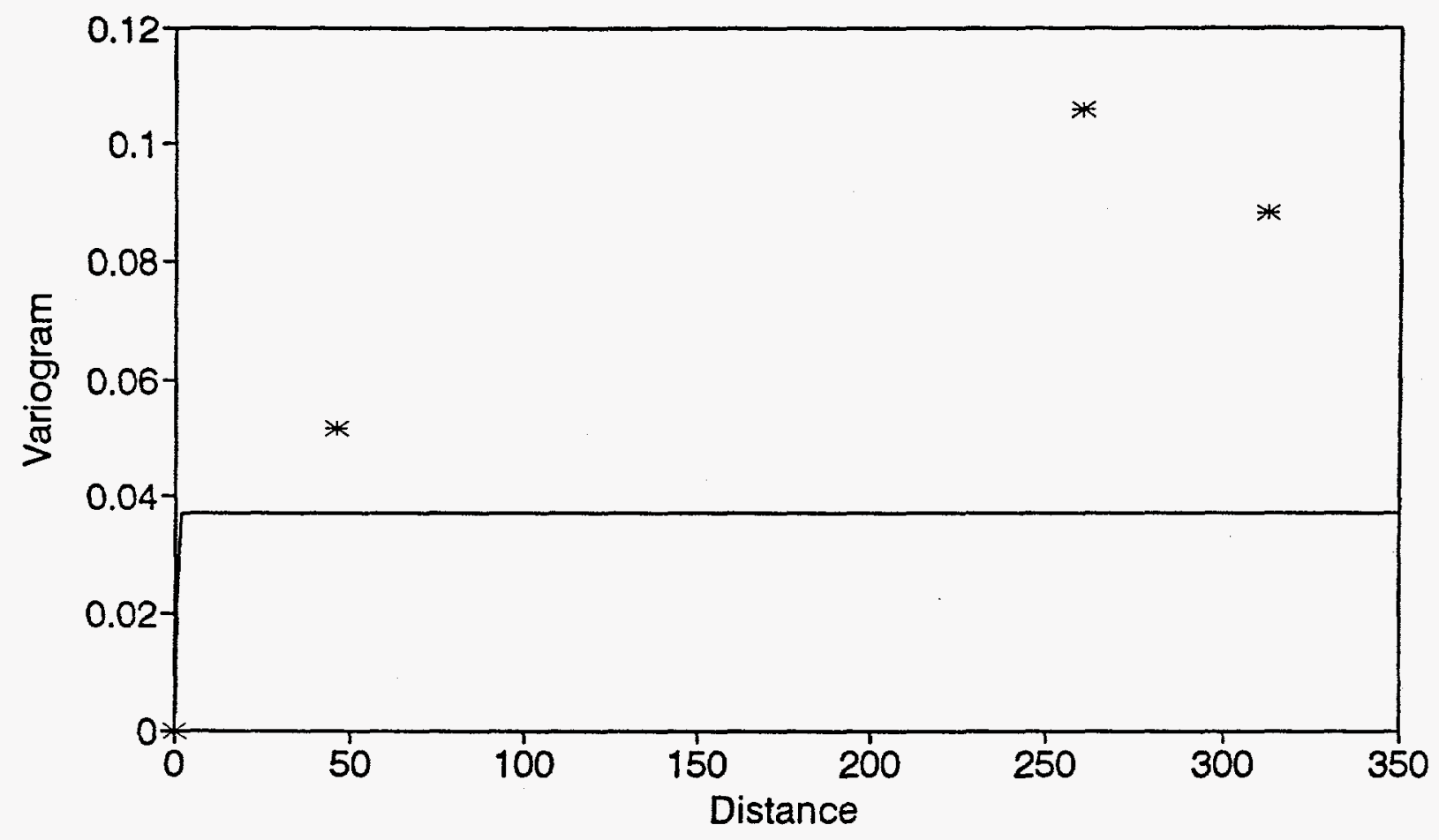

* = Sample Lateral Variograms

$x=$ Sample Vertical Variograms

Figure 3.1.19 Vertical and Directional Lateral Variogram of Tip Resistance along Angle $60^{\circ}$ (Intermediate Soil) 


\section{Lateral \& Vertical Variogram (30) Stiff Soil}

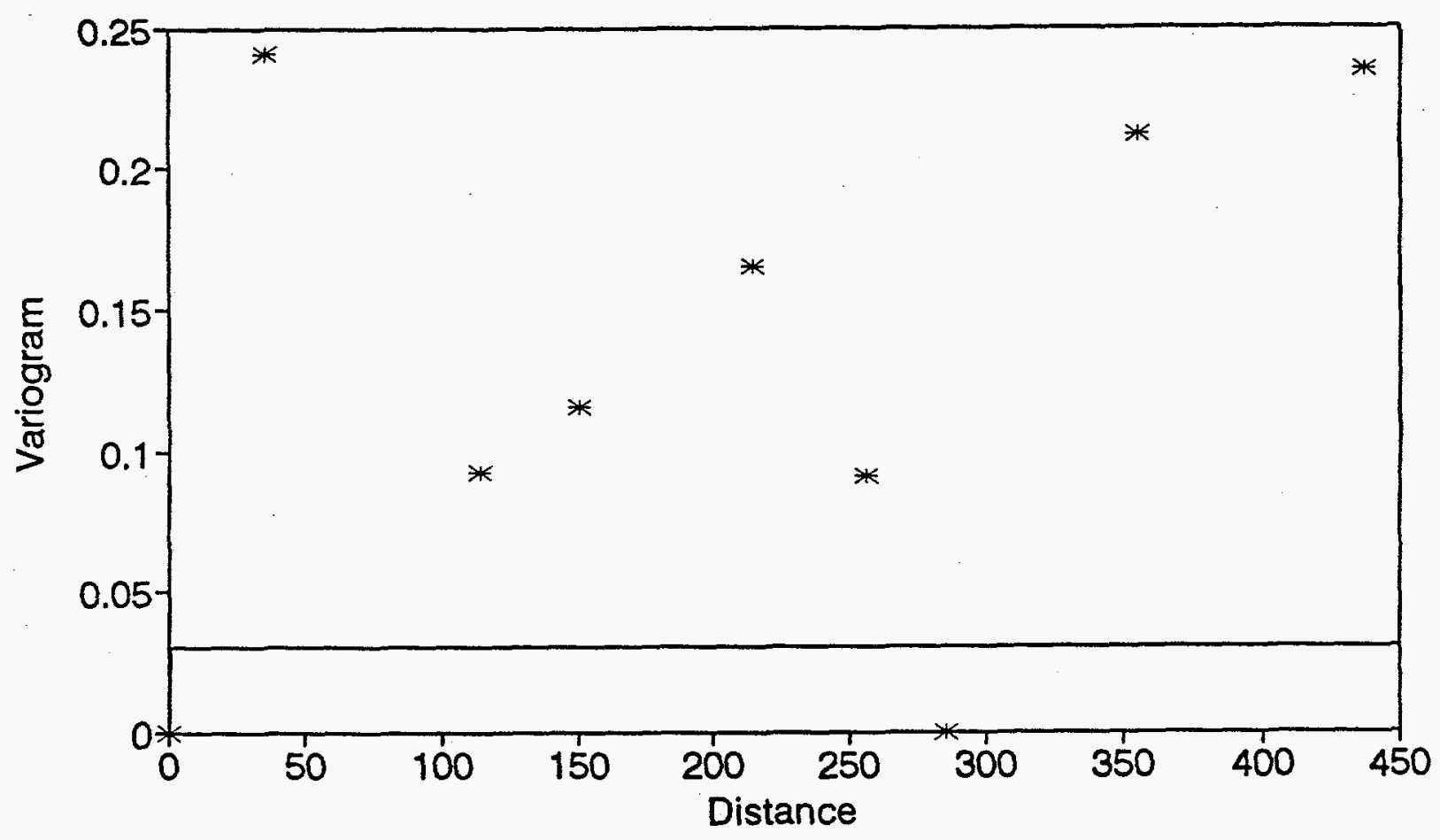

\footnotetext{
* = Sample Lateral Variograms

$x=$ Sample Vertical Variograms
}

Figure 3.1.20 Vertical and Directional Lateral Variogram of Tip Resistance along Angle $30^{\circ}$ (Stiff Soil) 


\section{Lateral \& Vertical Variogram (45)}

Stiff Soil

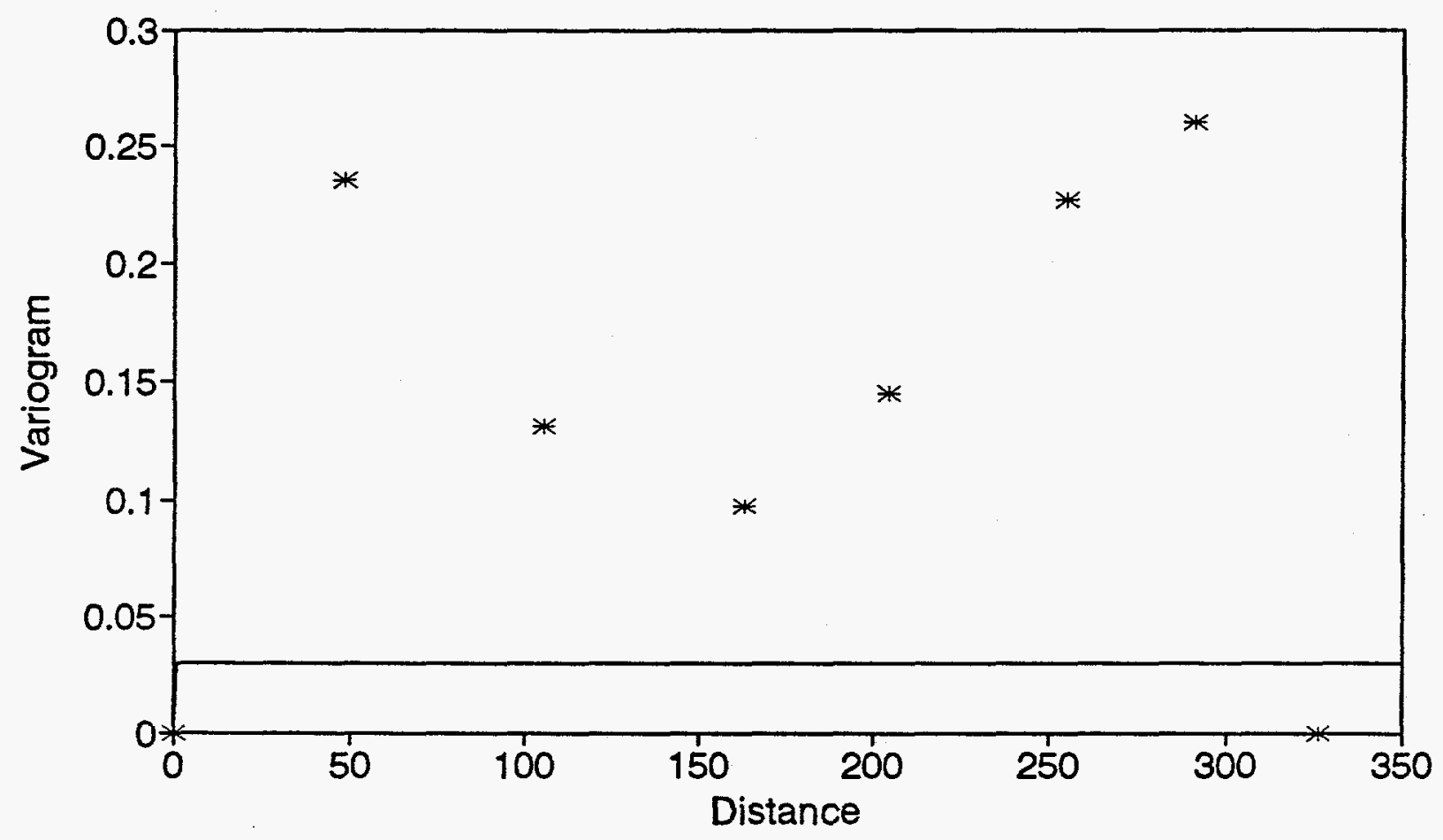

* = Sample Lateral Variograms

$x=$ Sample Vertical Variograms

Figure 3.1.21 Vertical and Directional Lateral Variogram of Tip Resistance along Angle $45^{\circ}$ (Stiff Soil) 


\section{Lateral Variogram (60 degree) Stiff Soil}

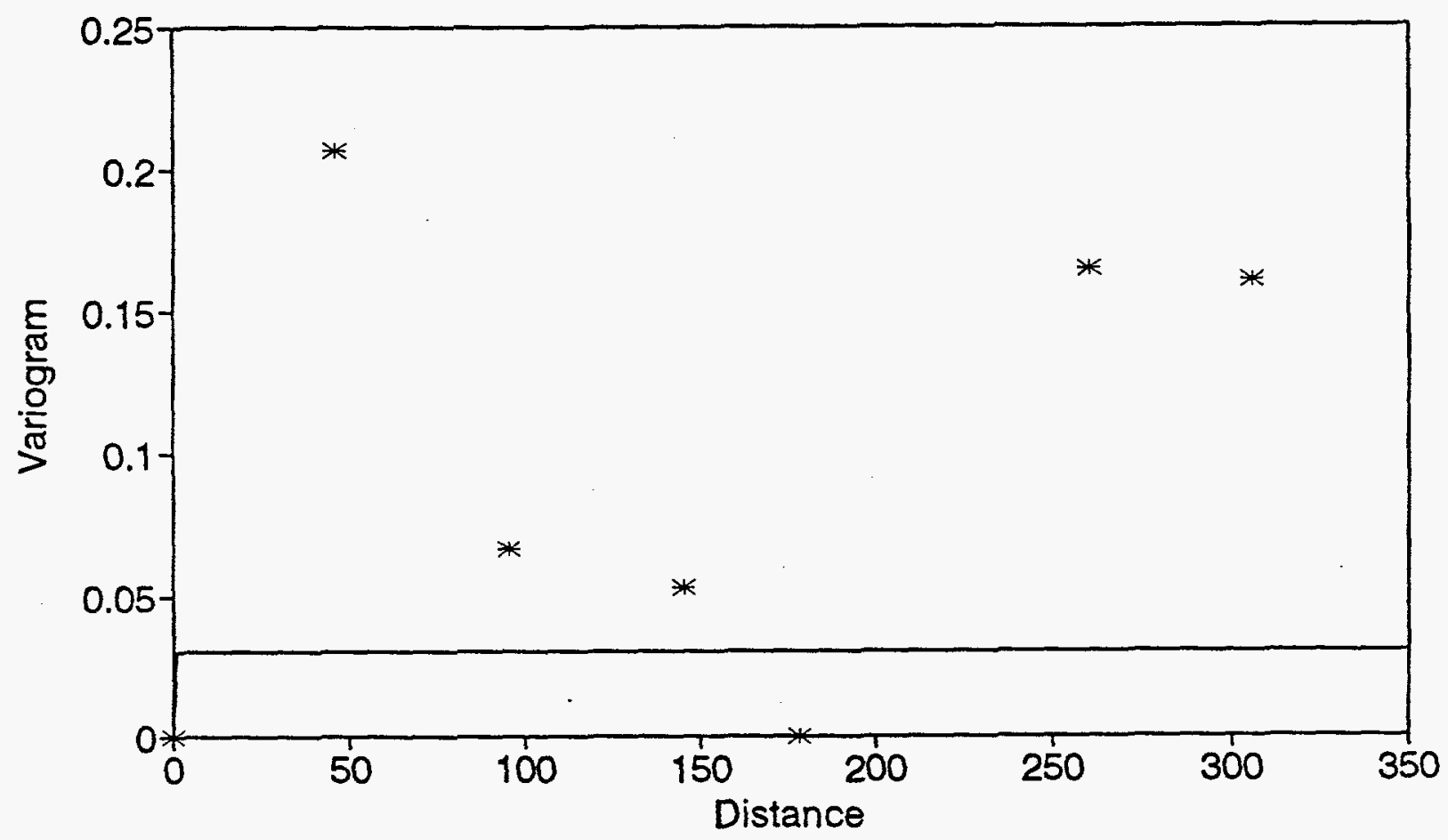

* = Sample Lateral Variograms

$x=$ Sample Vertical Variograms

Figure 3.1.22 Vertical and Directional Lateral Variogram of Tip Resistance along Angle $60^{\circ}$ (Stiff Soil) 
Lateral \& Vertical Variogram

Soft Soil

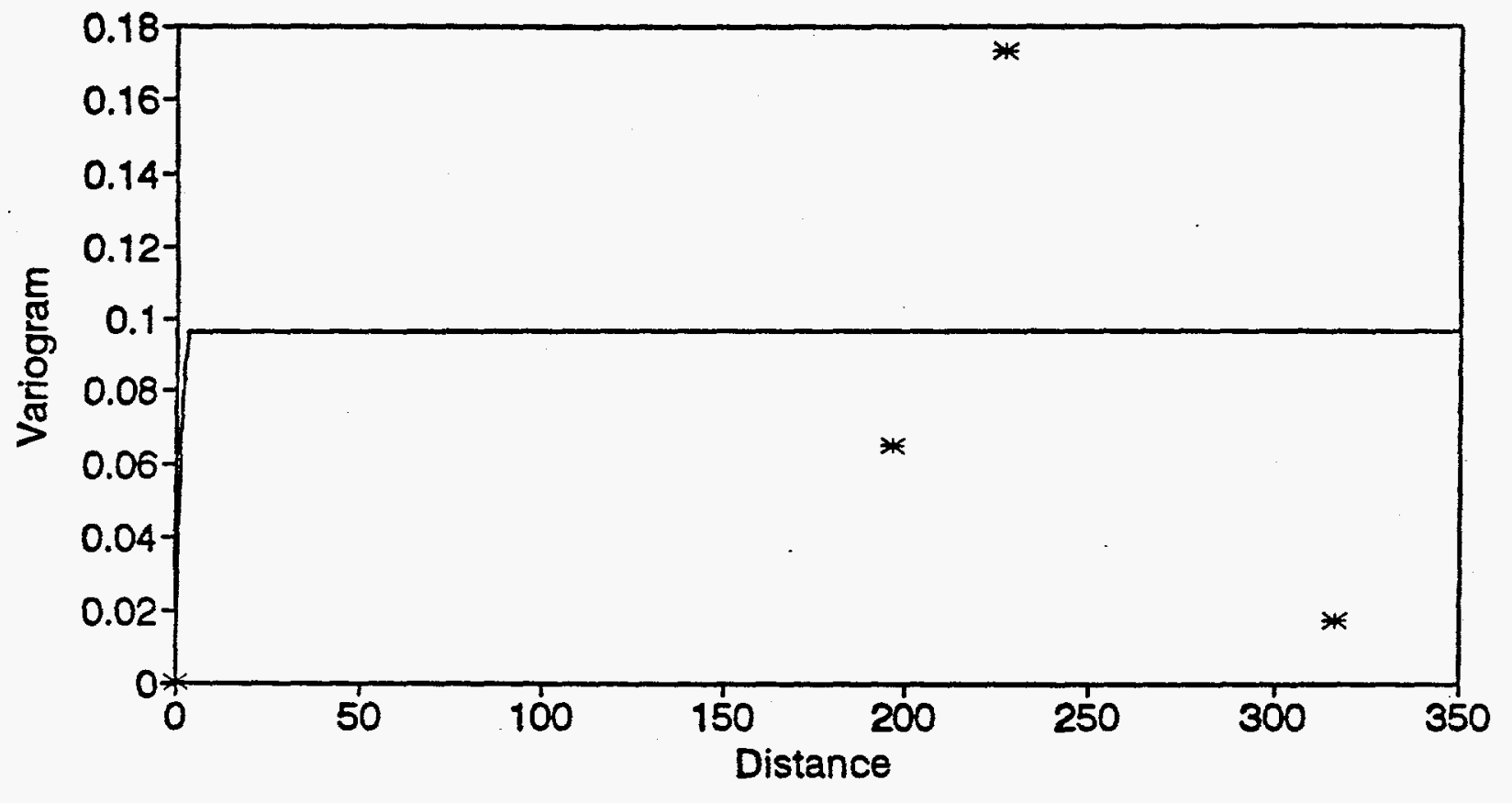

* Lateral Variogram - Vertical Variogram

* = Sample Lateral Variograms

$x=$ Sample Vertical Variograms

Figure 3.1.23 Lateral and Vertical Variogram (Indicator \#1) 


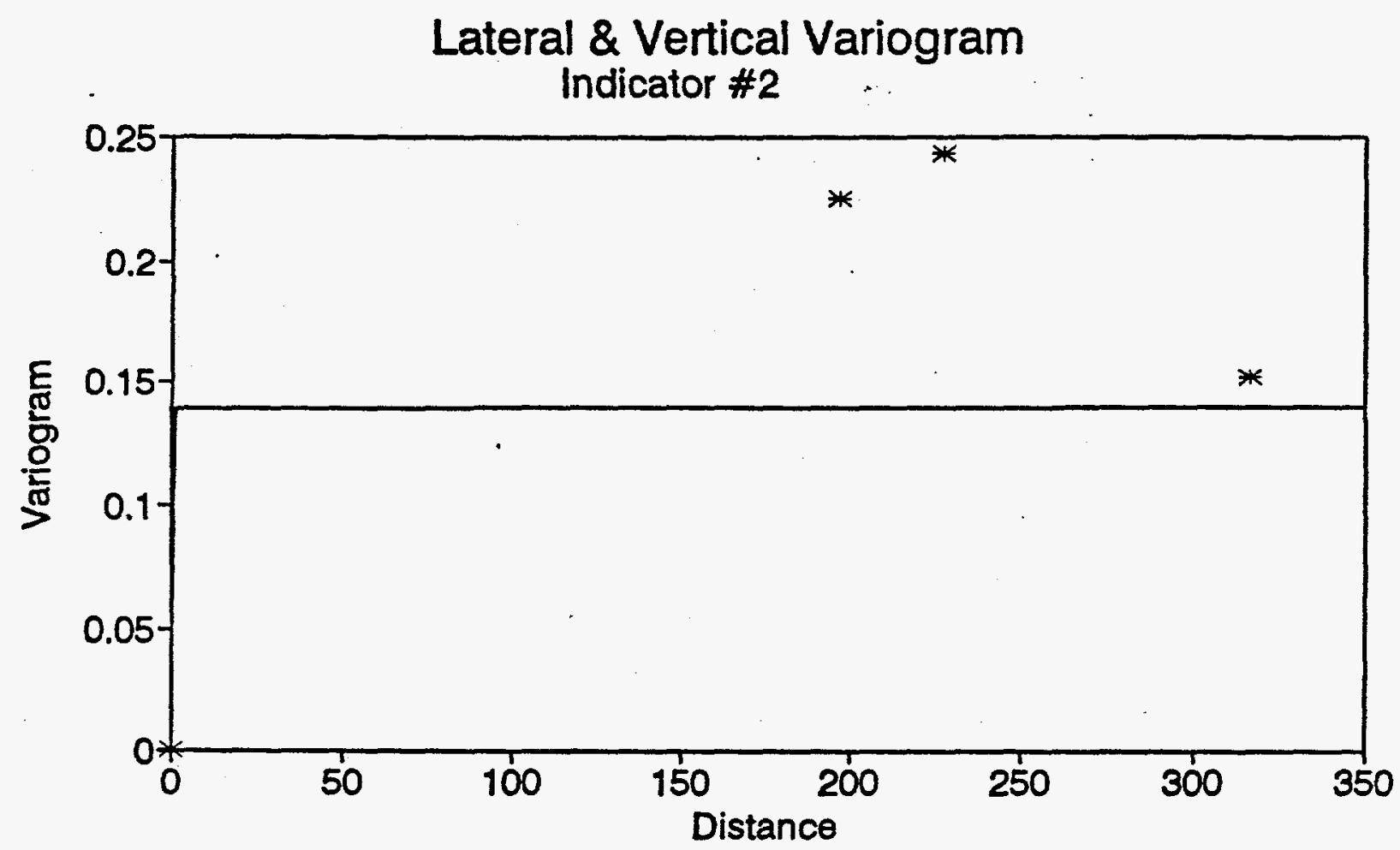

* Lateral Variogram - Vertical Variogram

* = Sample Lateral Variograms

$\mathrm{x}=$ Sample Vertical Variograms

Figure 3.1.24 Lateral and Vertical Variogram (Indicator \#2) 


\section{Contour Map of Tip Resistance Section $A-A^{\prime}$}

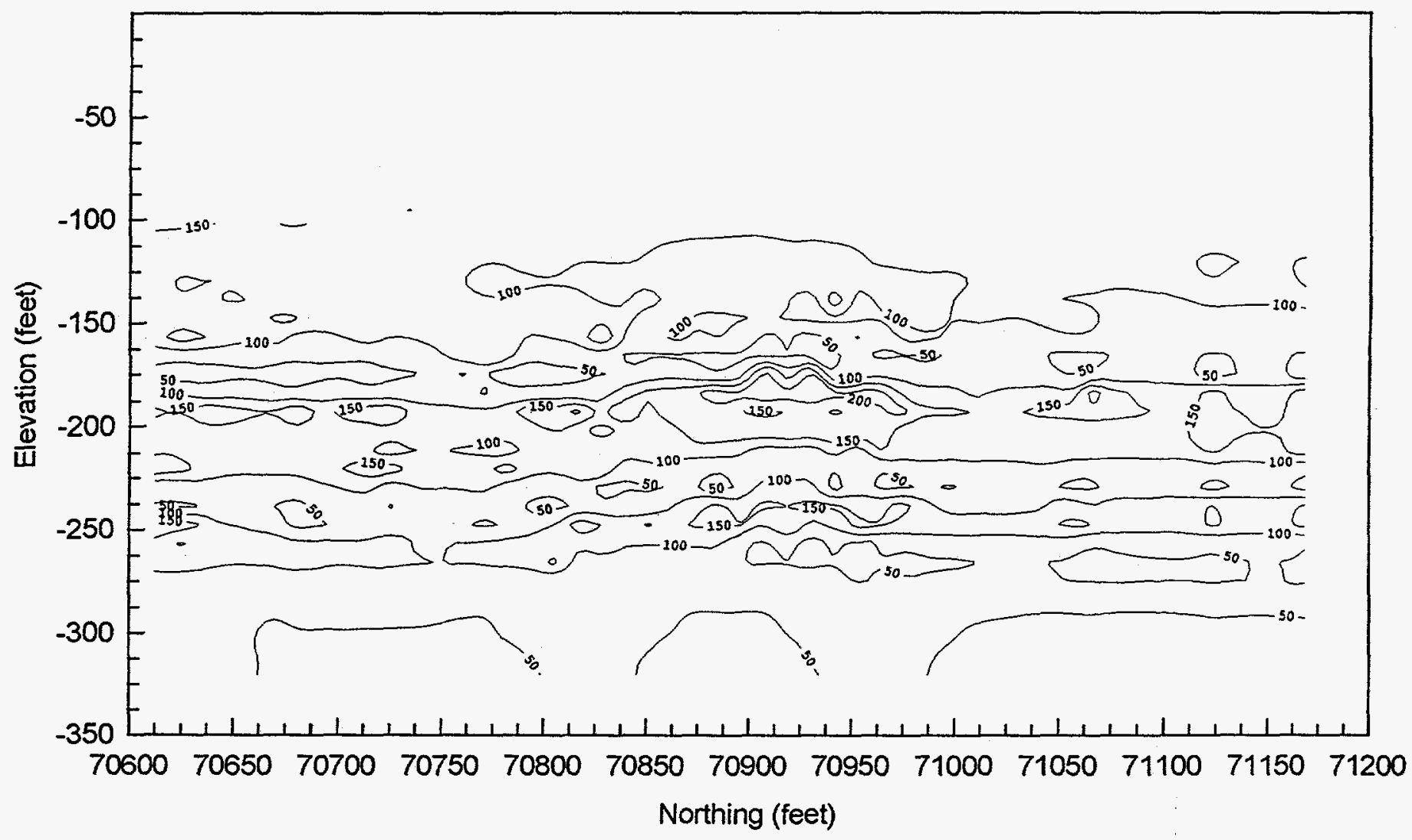

Figure 3.2.1 Kriging Map of Tip Resistance along Cross-Section A-A' 


\section{Contour Map of Tip Resistance Section B-B'}

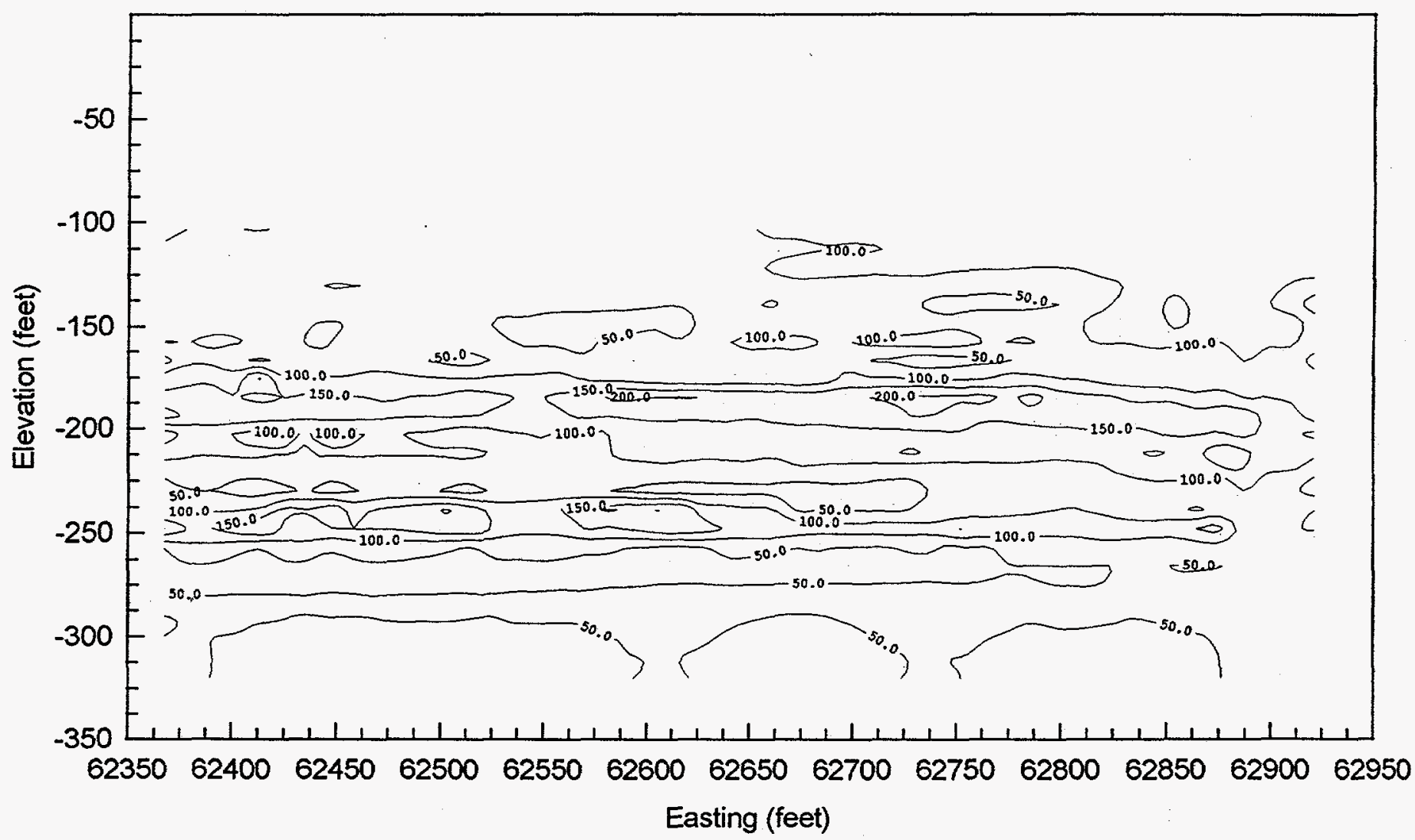

Figure 3.2.2 Kriging Map of Tip Resistance along Cross-Section B-B' 


\section{Contour Map of Fraction Ratio Section A-A'}

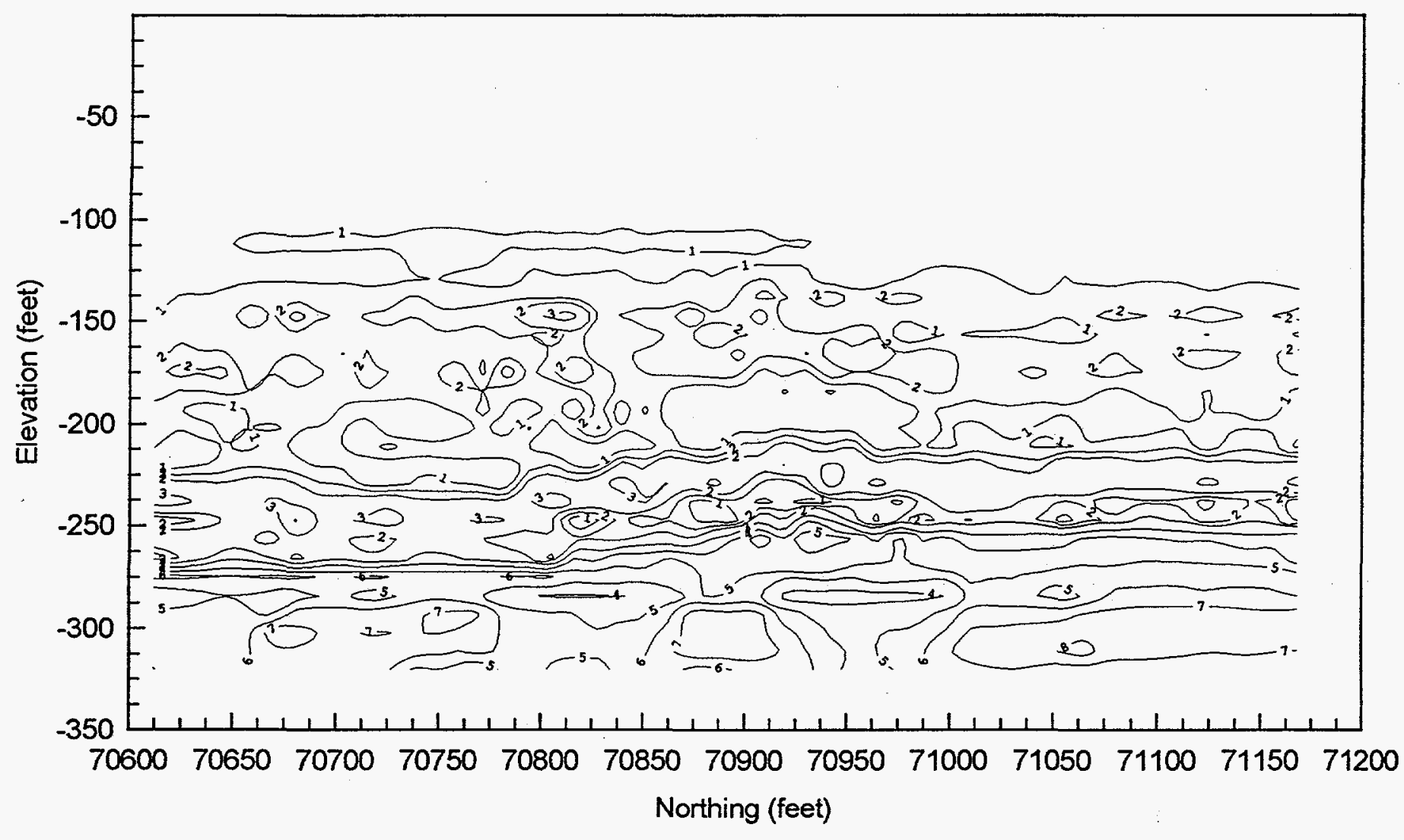

Figure 3.2.3 Kriging Map of Fraction Ratio along Cross-Section A-A' 


\section{Contour Map of Fraction Ratio Section B-B'}

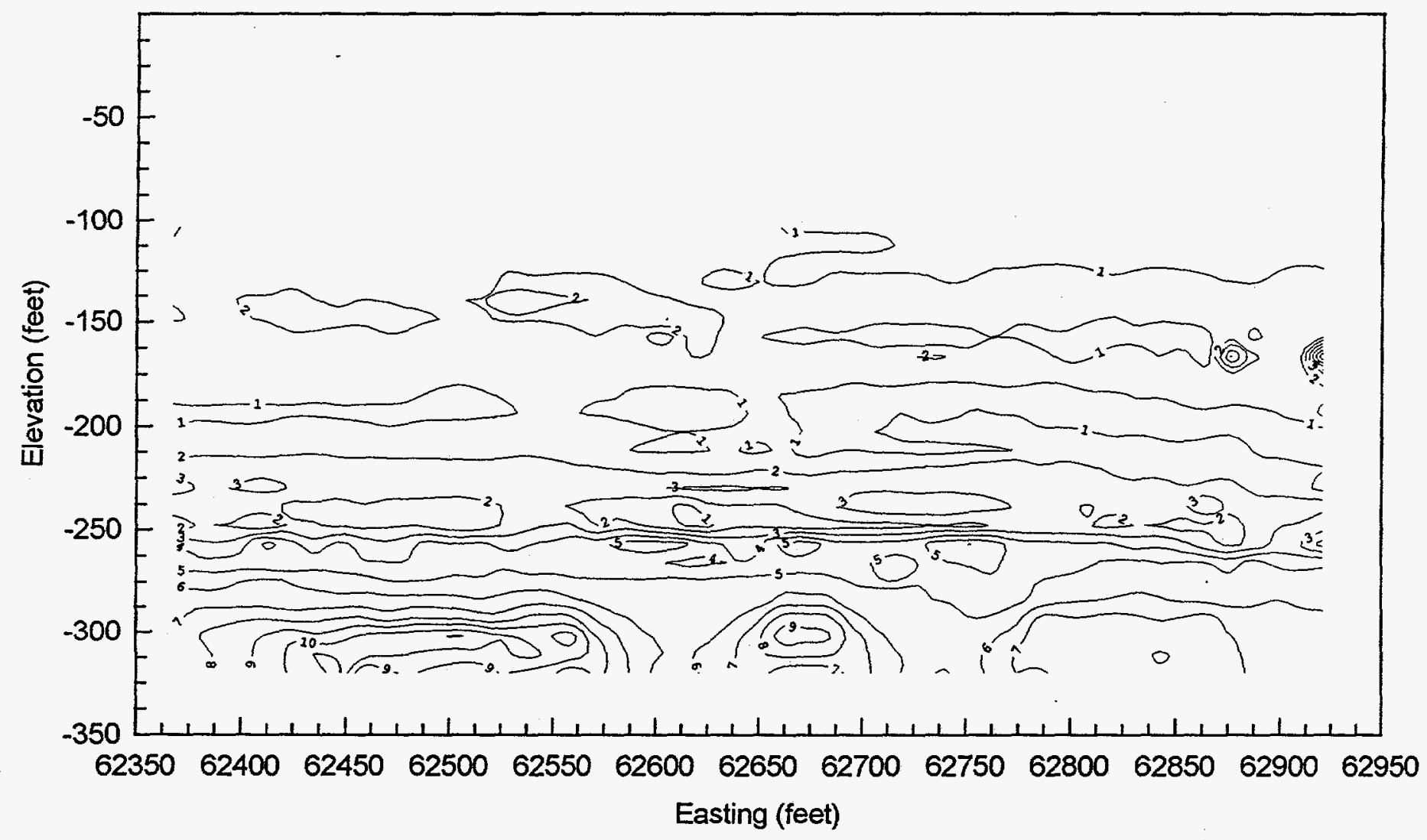

Figure 3.2.4 Kriging Map of Fraction Ratio along Cross-Section B-B' 


\section{Vertical Distribution of $q C$ at scpt1 (Cross Validation)}

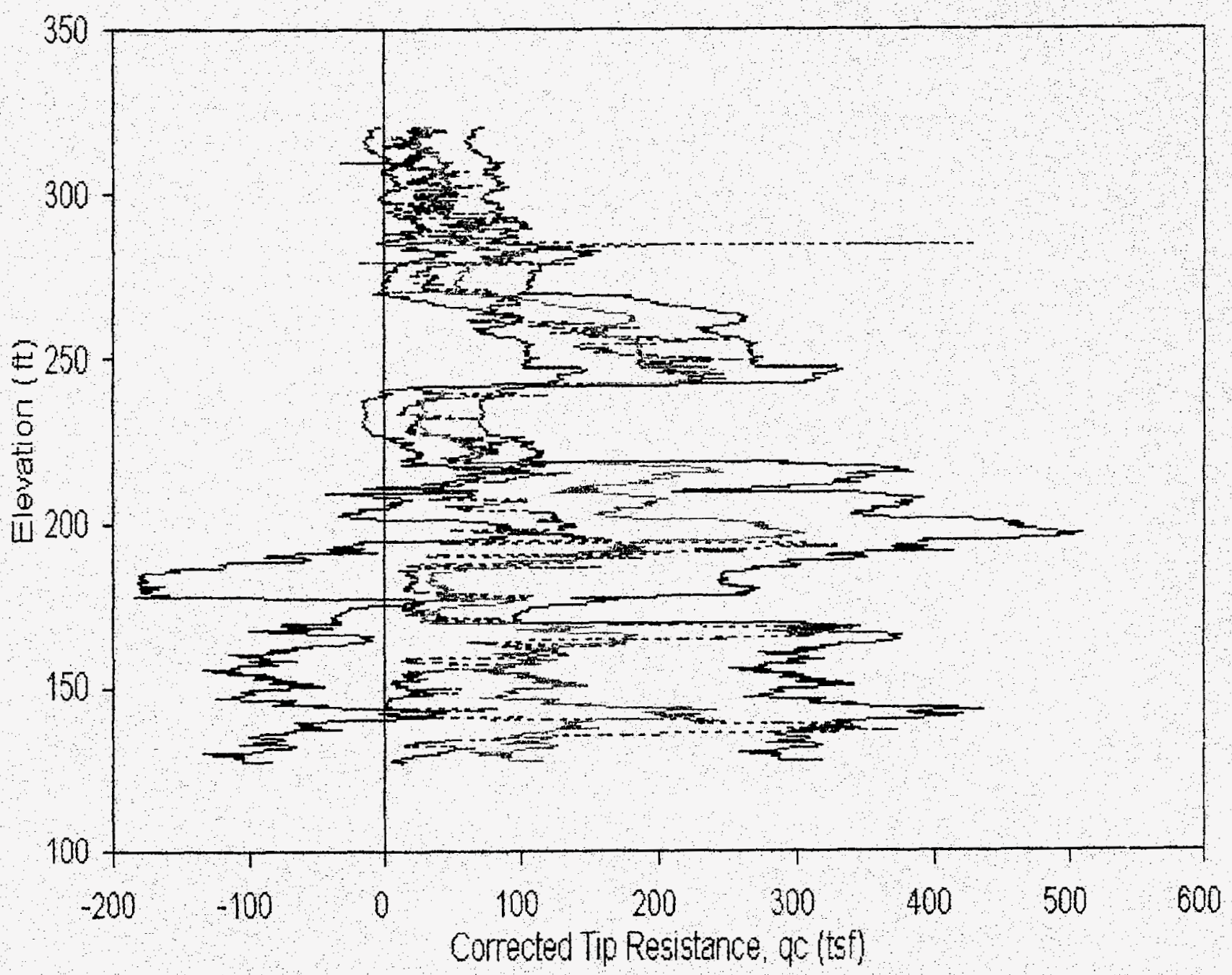

measurement value - kriged value

Figure 3.2.5 Cross-Validation Results at SCPT1 (Using within-layer-depth) 


\section{Vertical Distribution of qC \\ at scptob (Cross Validation)}

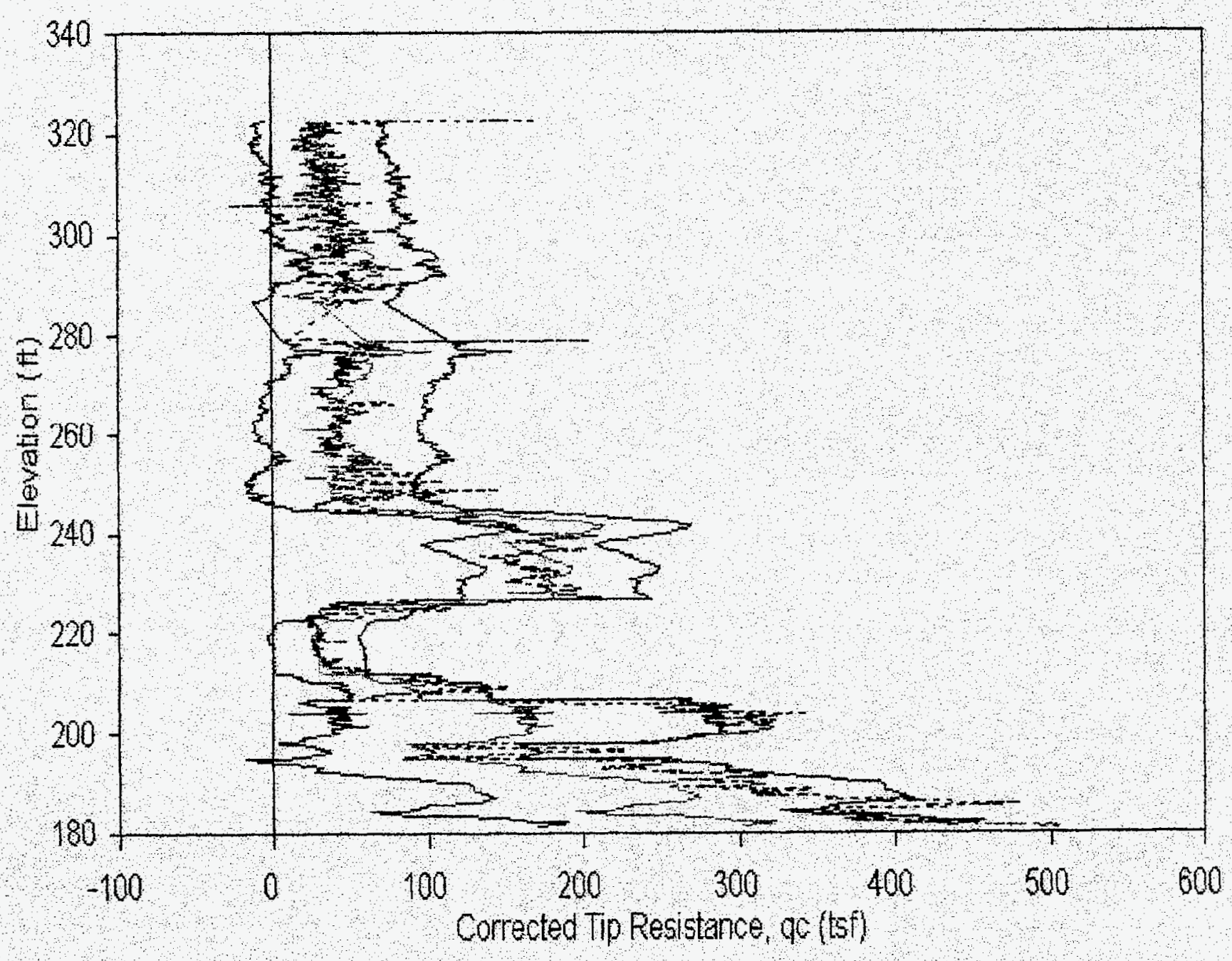

_.- measurernent value - kriged value $\quad$ - upper $95 \%$ value $\quad-$ bower $95 \%$ value

Figure 3.2.6 Cross-Validation Results at SCPT6B (Using within-layer-depth) 


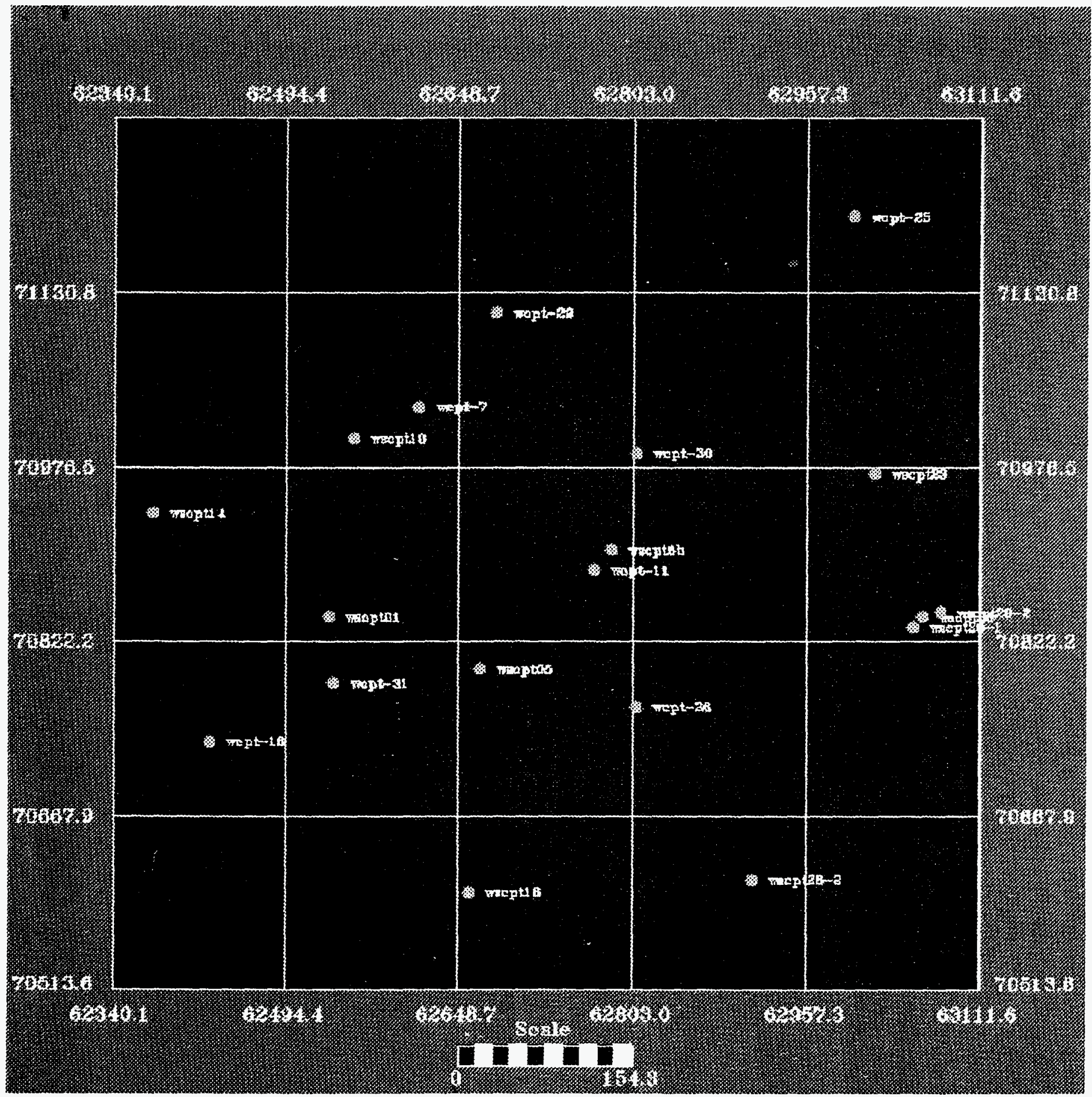

Figure 4.0.1 Locations of Investigated CPT Boreholes 


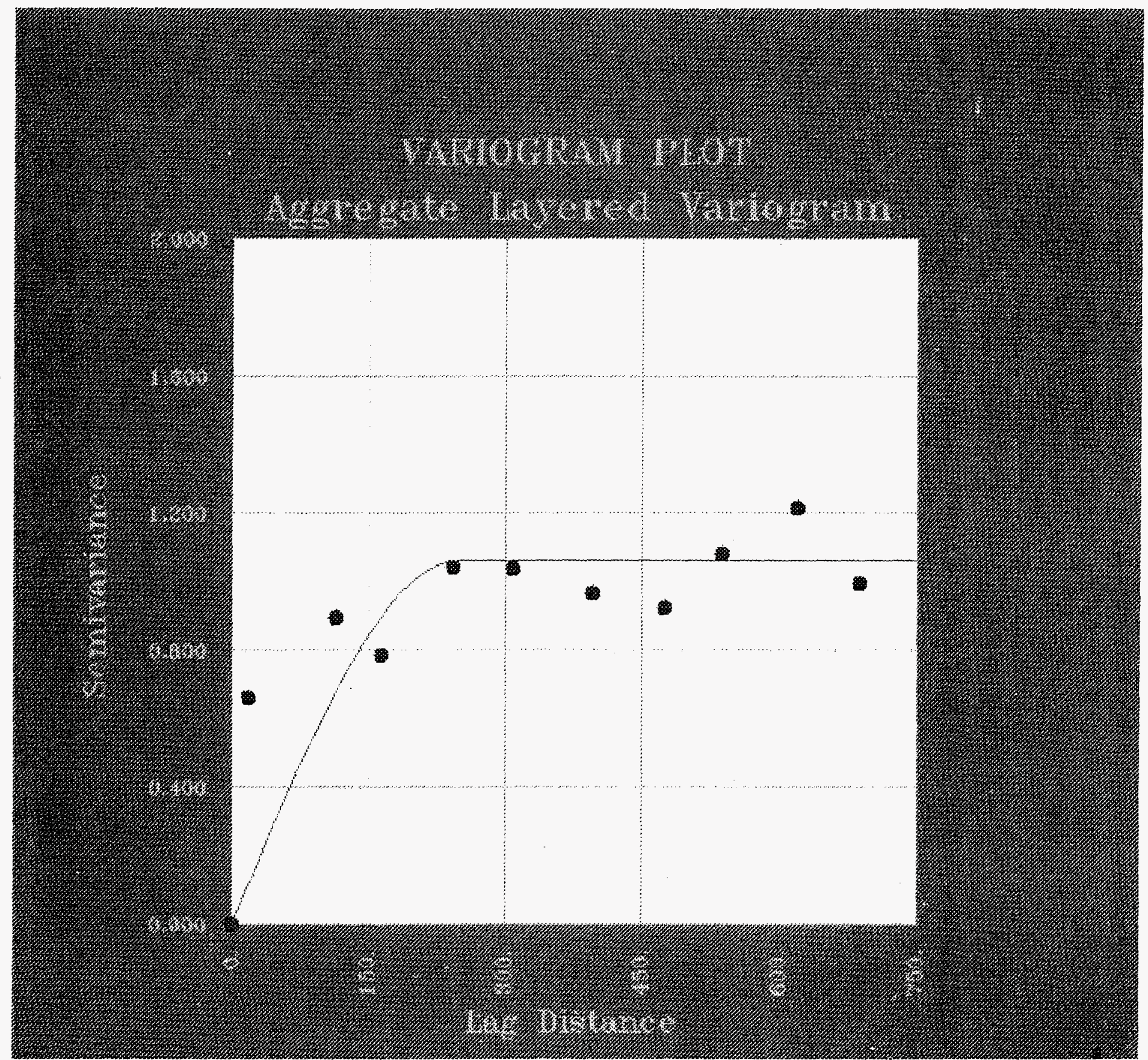

Figure 4.0.2 Omni-Directional Lateral Variogram of Shear Wave Data 


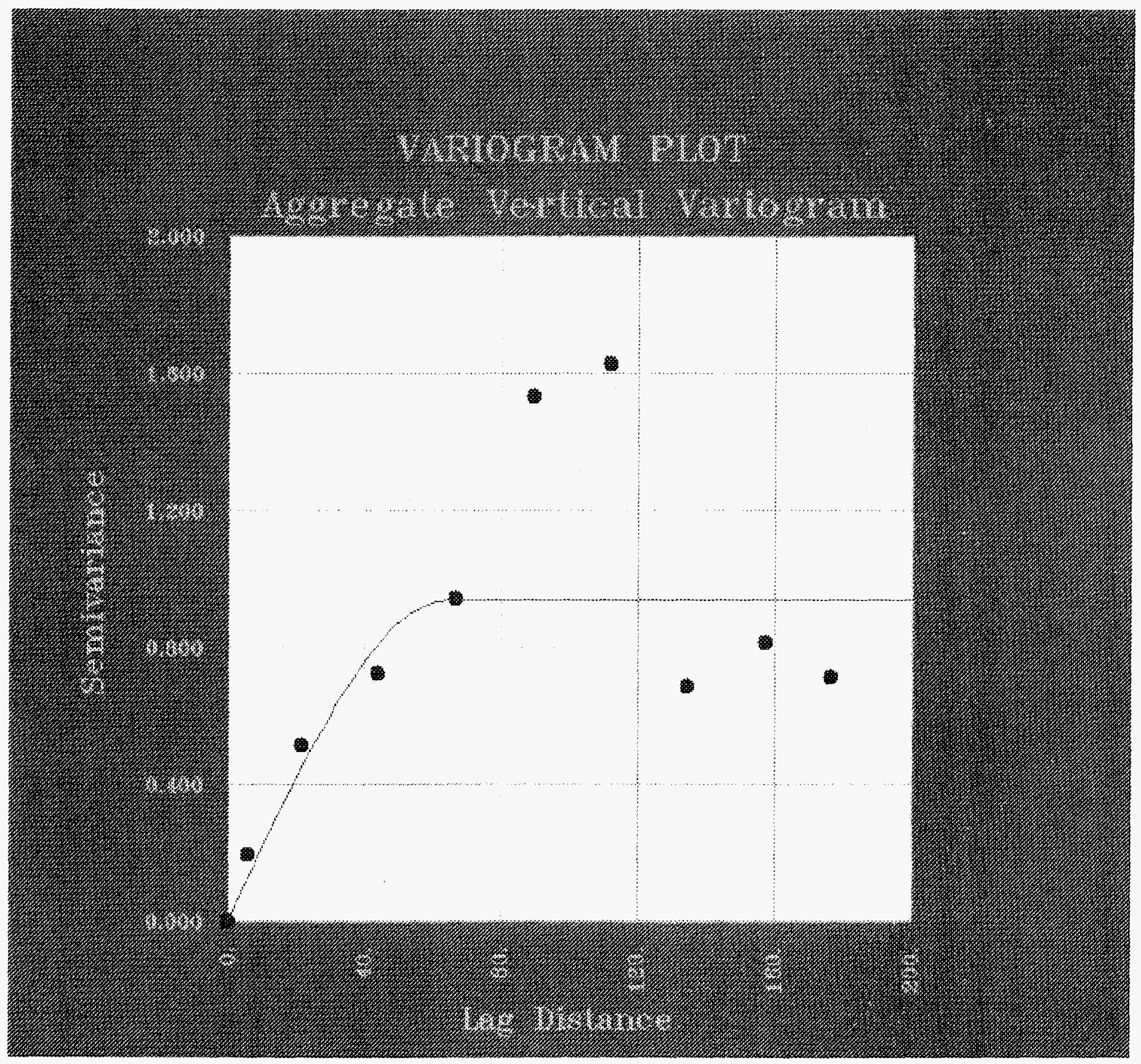

Figure 4.0.3 Omni-Directional Vertical Variogram of Shear Wave Data 


\section{Vertical Shear Wave Velocity at $(62618,70825)$}

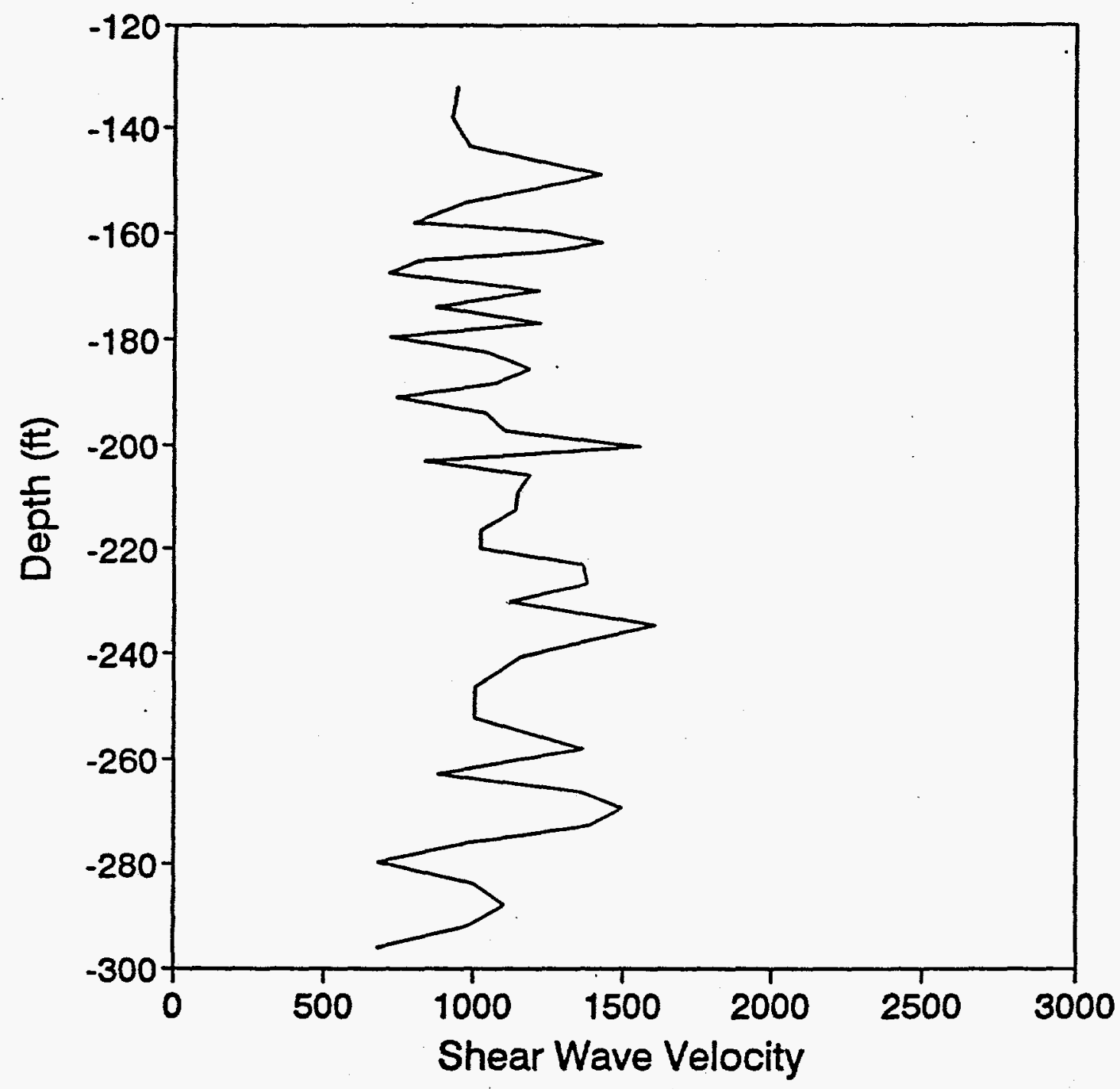

Figure 4.1.1 Simulated Shear Wave Velocity Profile using Seed \#1 at $\left(62618^{\prime}, 70825^{\prime}\right)$ 


\section{Vertical Shear Wave Velocity at $(62750,70825)$}

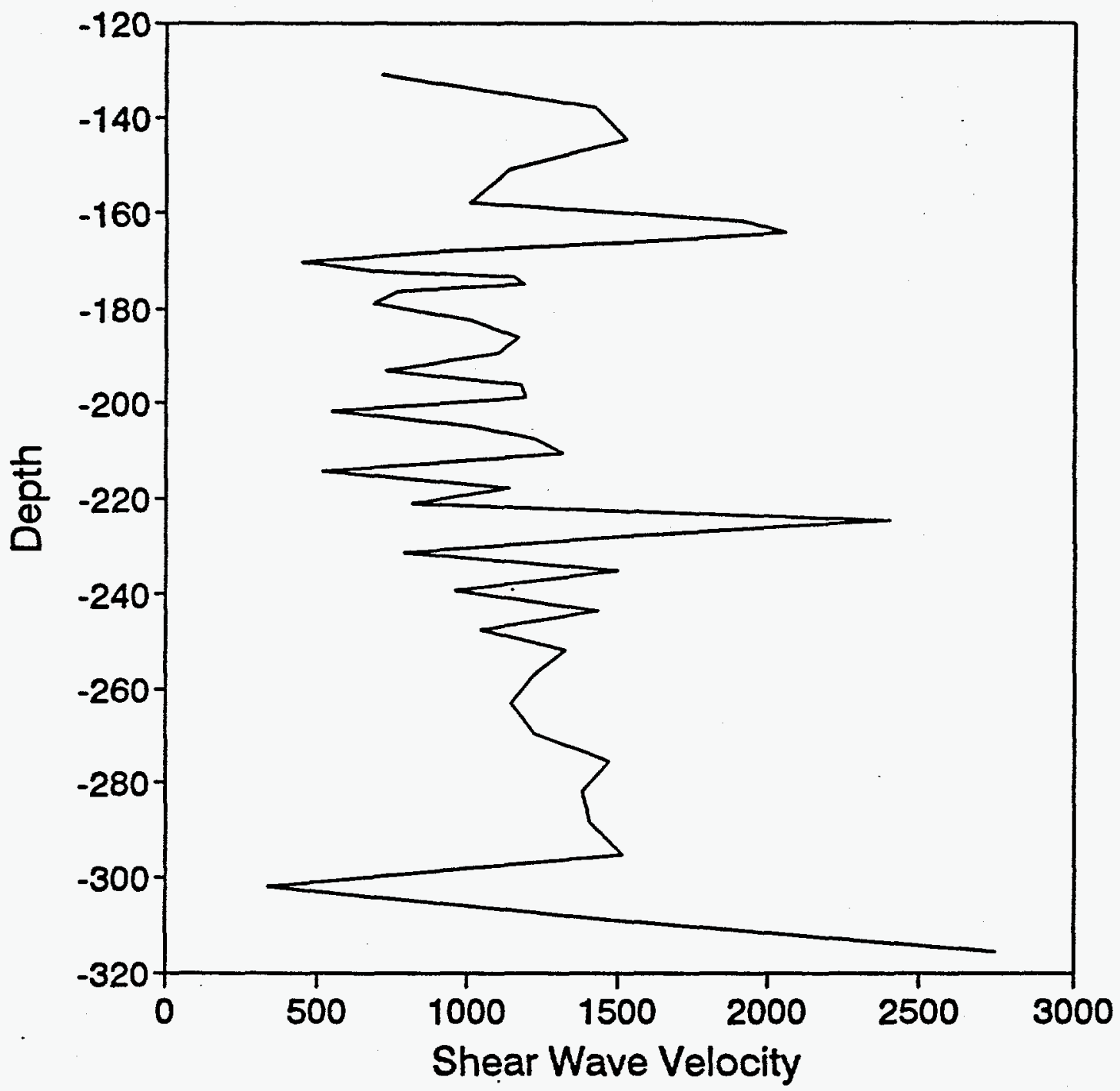

Figure 4.1.2 Simulated Shear Wave Velocity Profile using Seed \#1 at (62750', 70825') 


\section{Vertical Shear Wave Velocity at $(62618,70952)$}

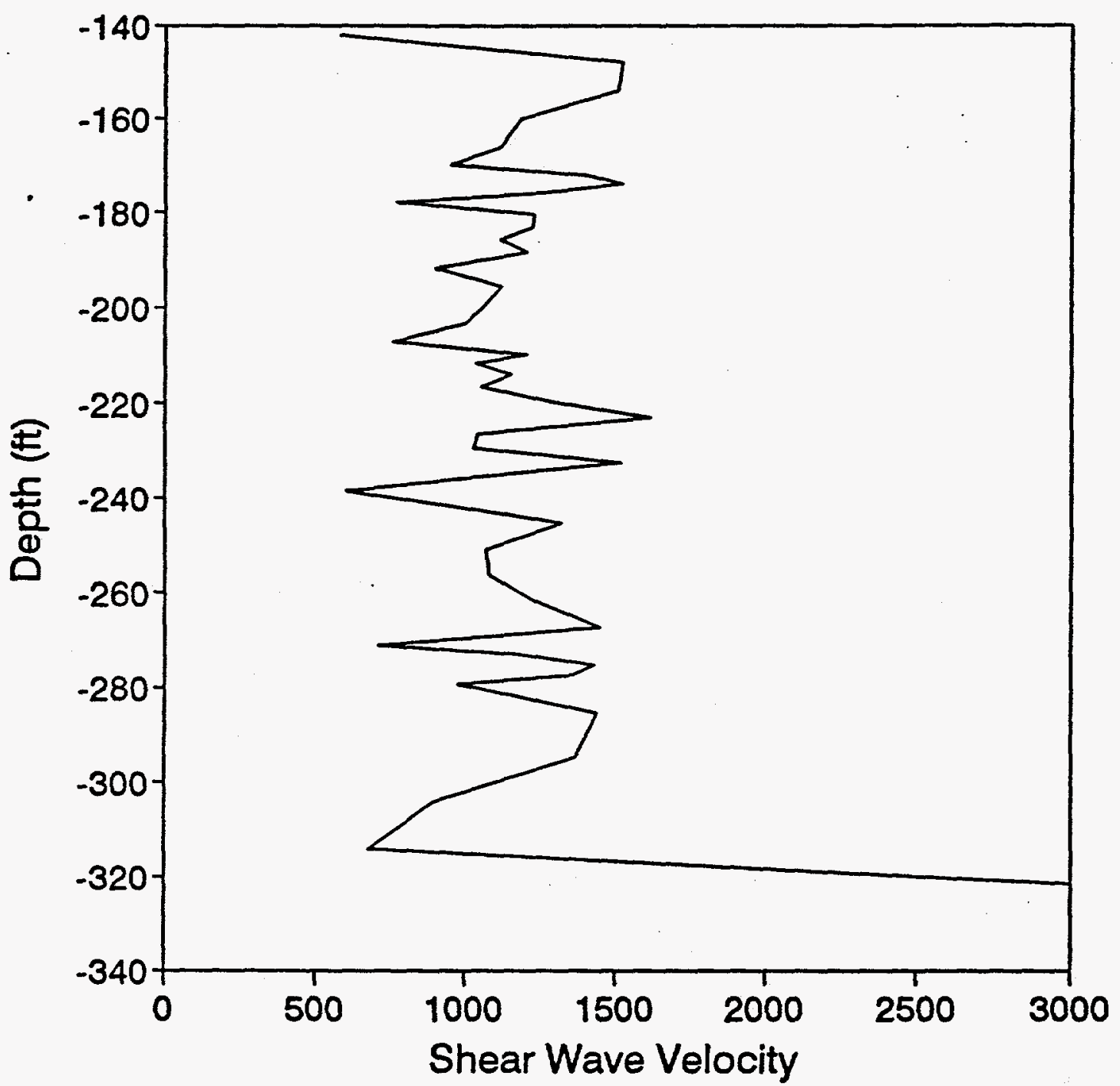

Figure 4.1.3 Simulated Shear Wave Velocity Profile using Seed \#1 at (62618', 70952') 


\section{Vertical Shear Wave Velocity at $(62750,70952)$}

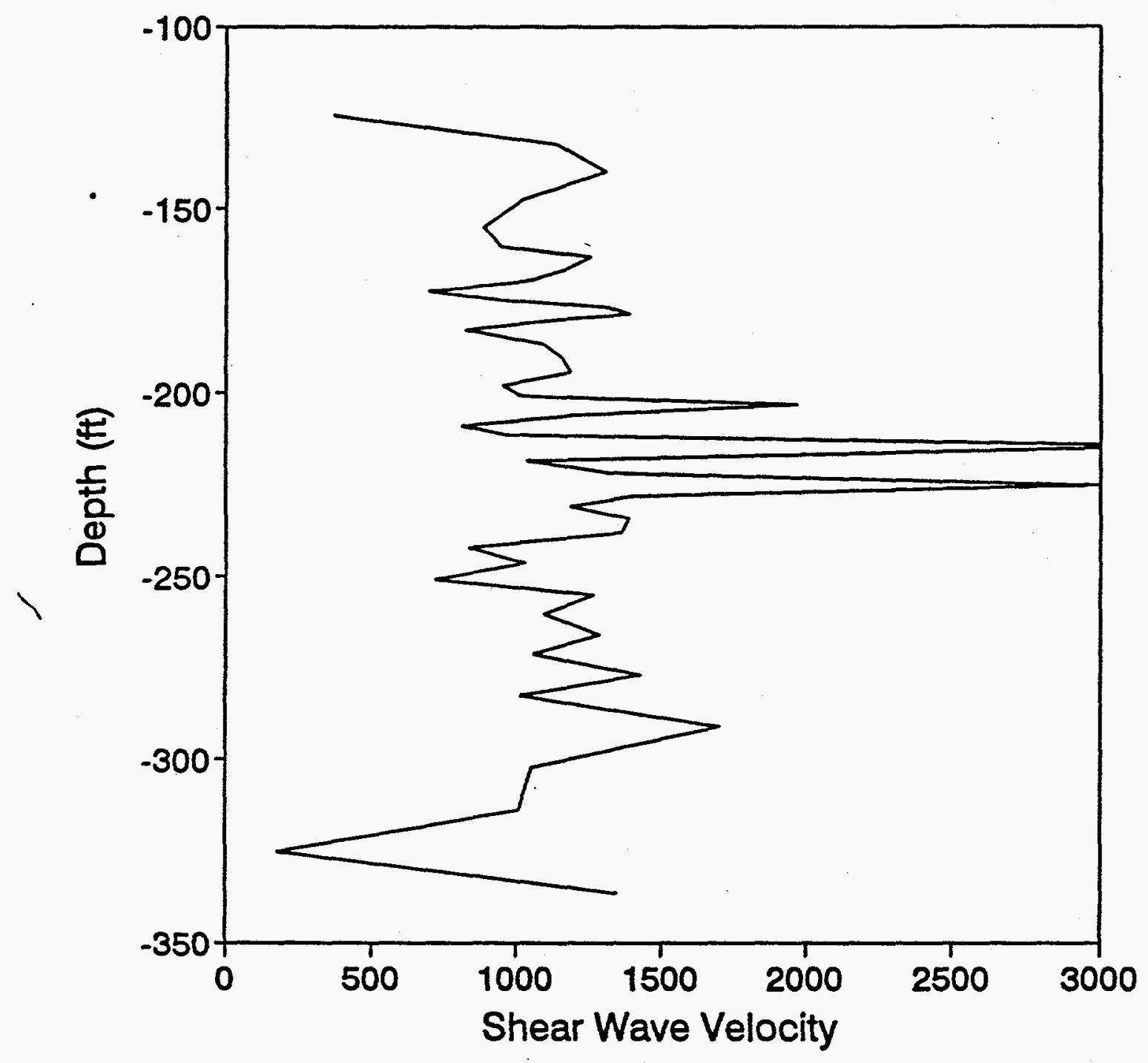

Figure 4.1.4 Simulated Shear Wave Velocity Profile using Seed \#1 at (62750', 70952') 


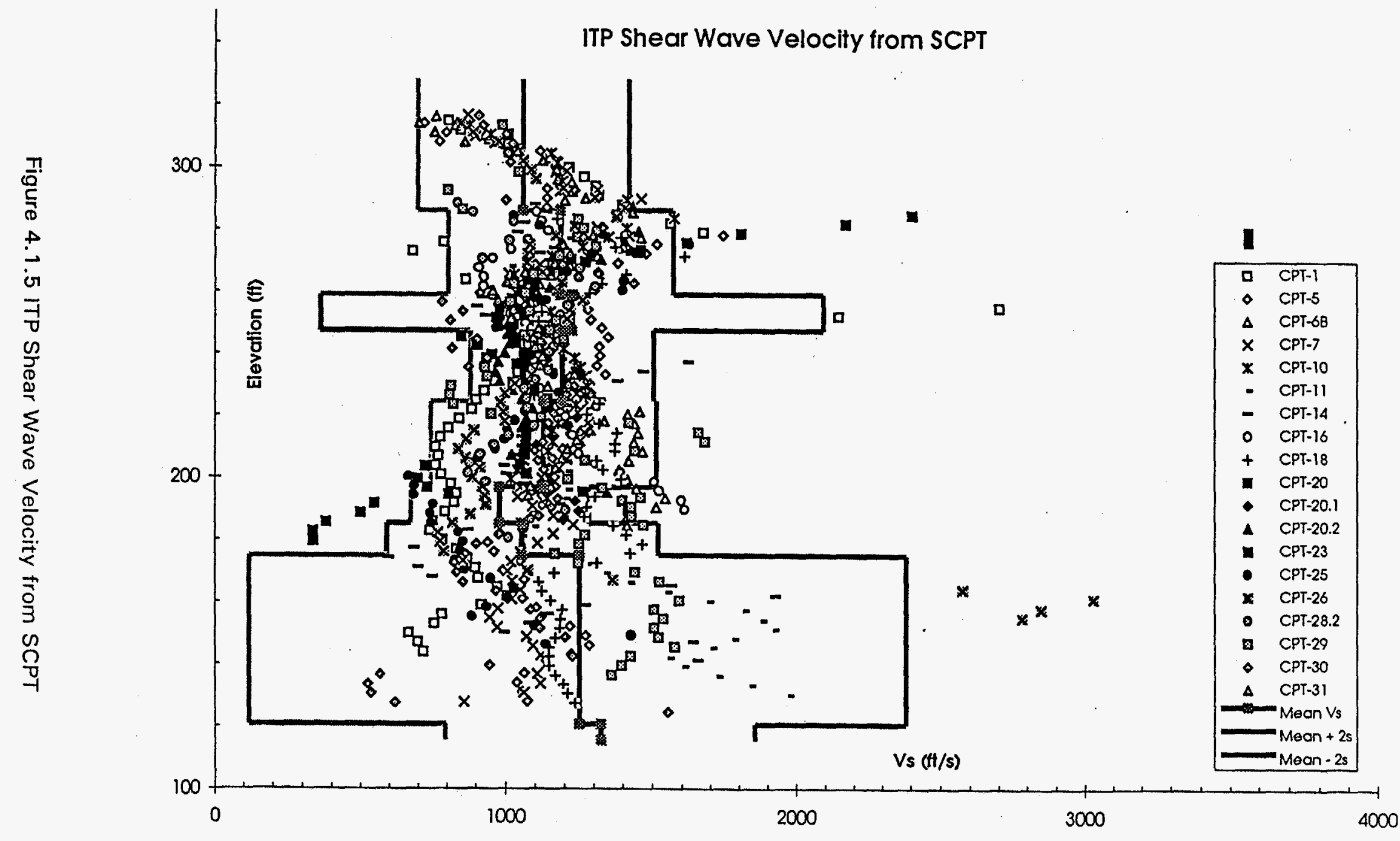




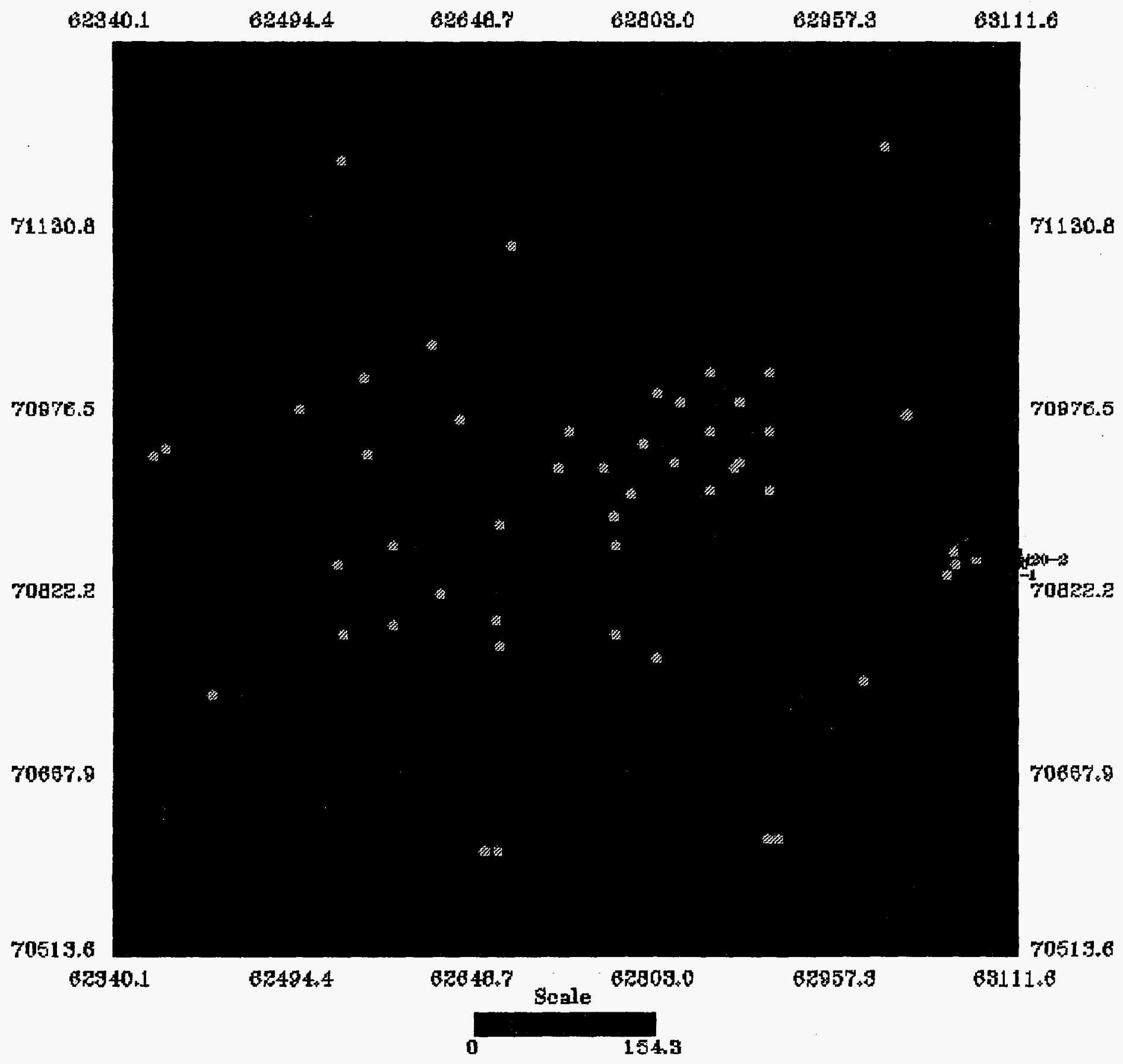

Figure 5.0.1 Locations of Combined SPT and CPT-Based Boreholes 
Cross-section Display

$$
\text { Kriging } 3 \text { of } \quad 30
$$

Figure 5.1.1 Kriging Map along the East-West Cross-Section at Northing $=70590^{\circ}$ 


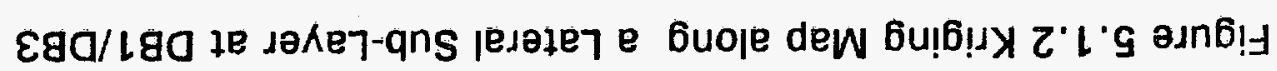
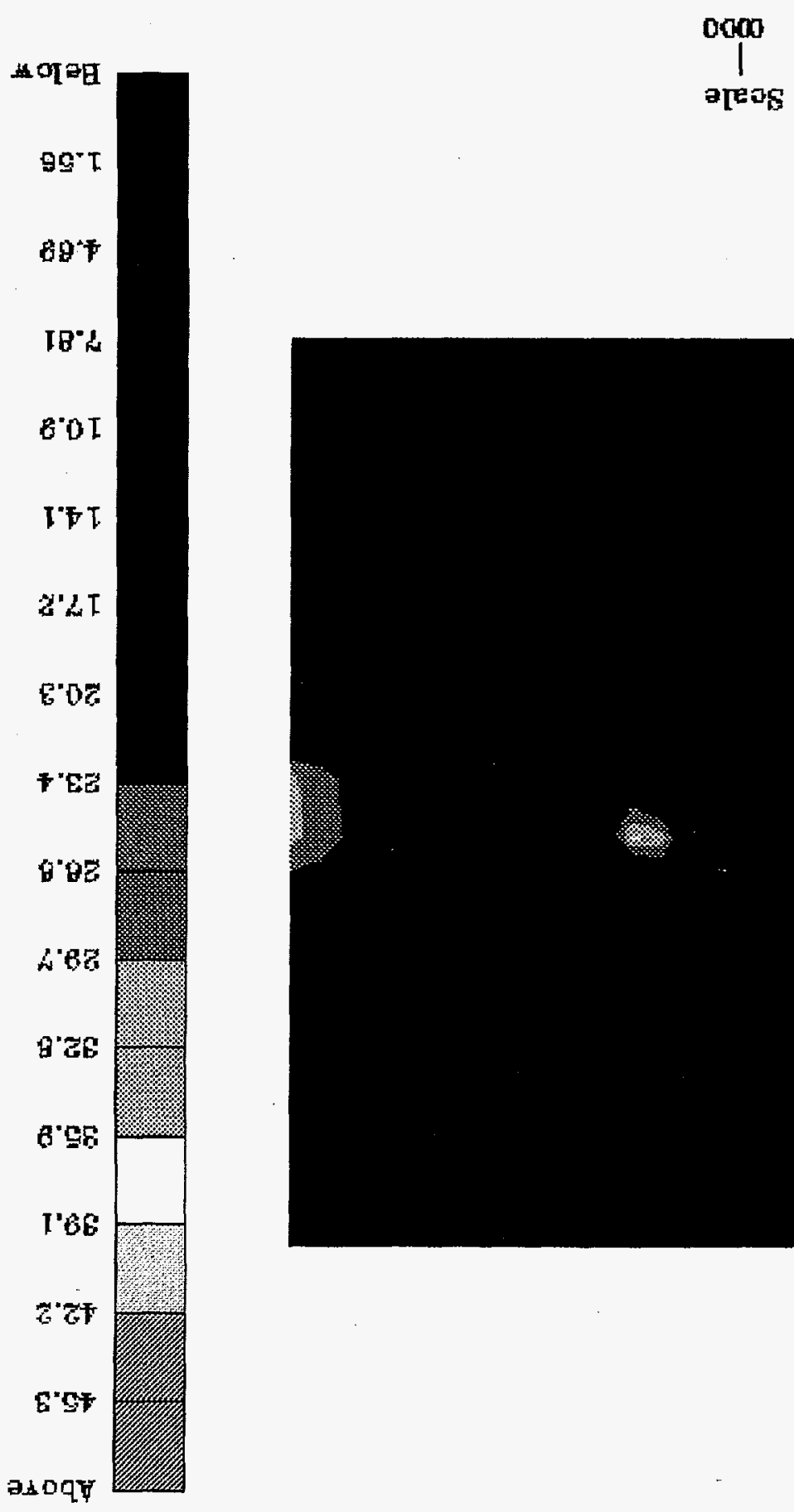


\section{Cross-section Display}

sGs 3 of 30

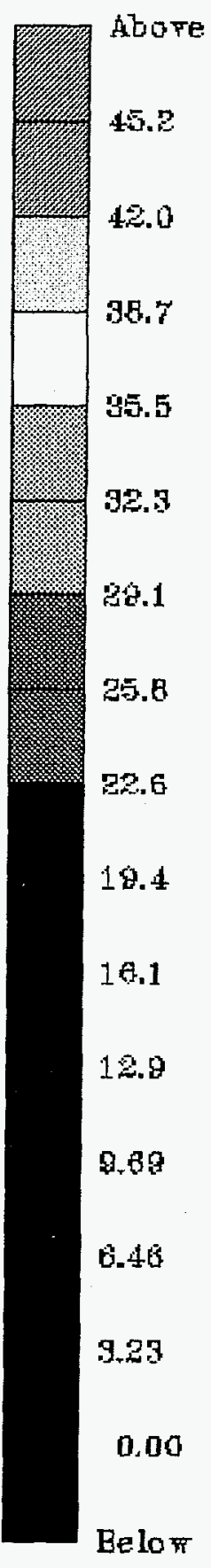

Figure 5.1.3 Simulated Map along the East-West Cross-Section at Northing $=70590^{\prime}$ 


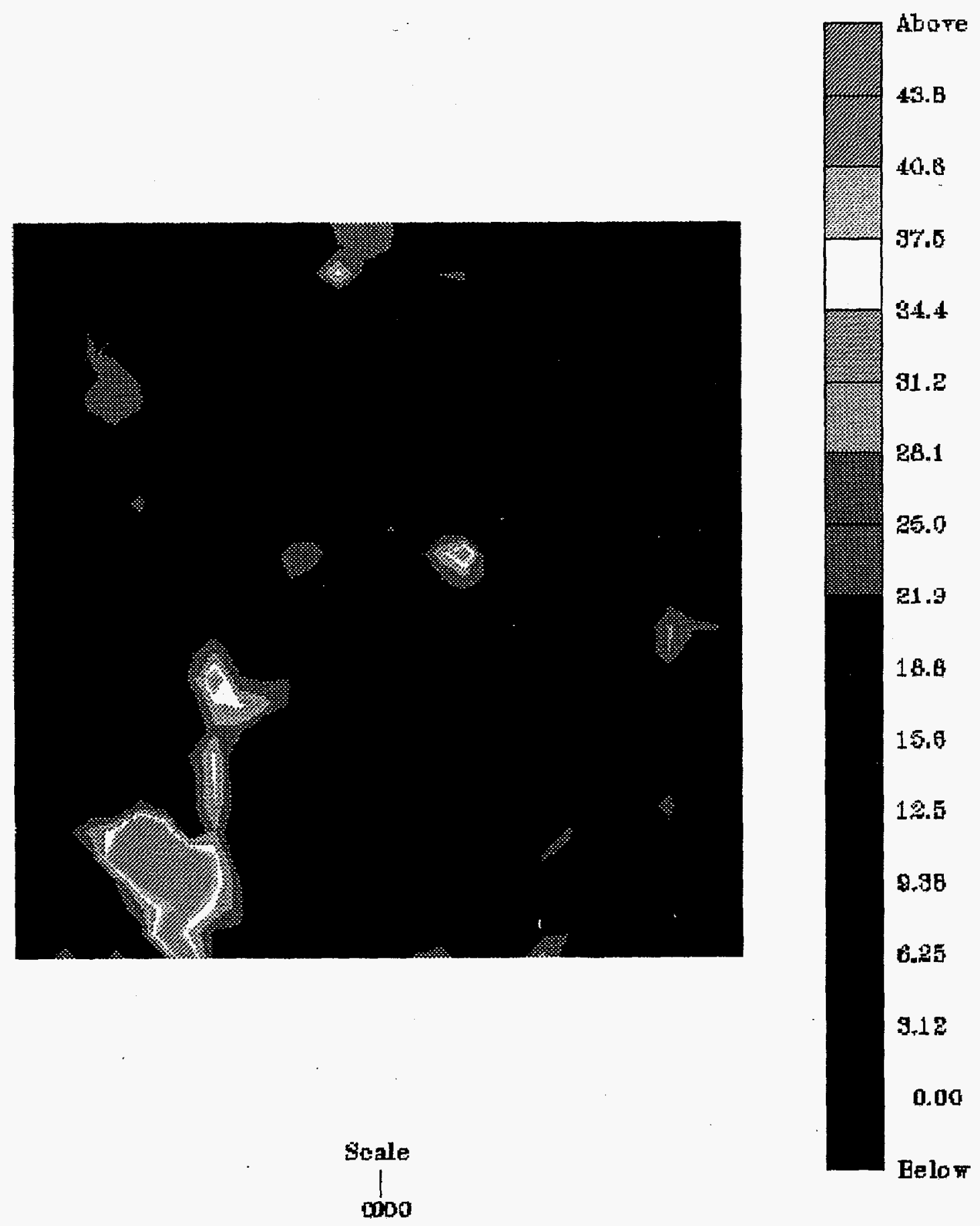

Figure 5.1.4 Simulated Map along a Lateral Sub-Layer at DB1/DB3 
ITP Real and Simulated Data

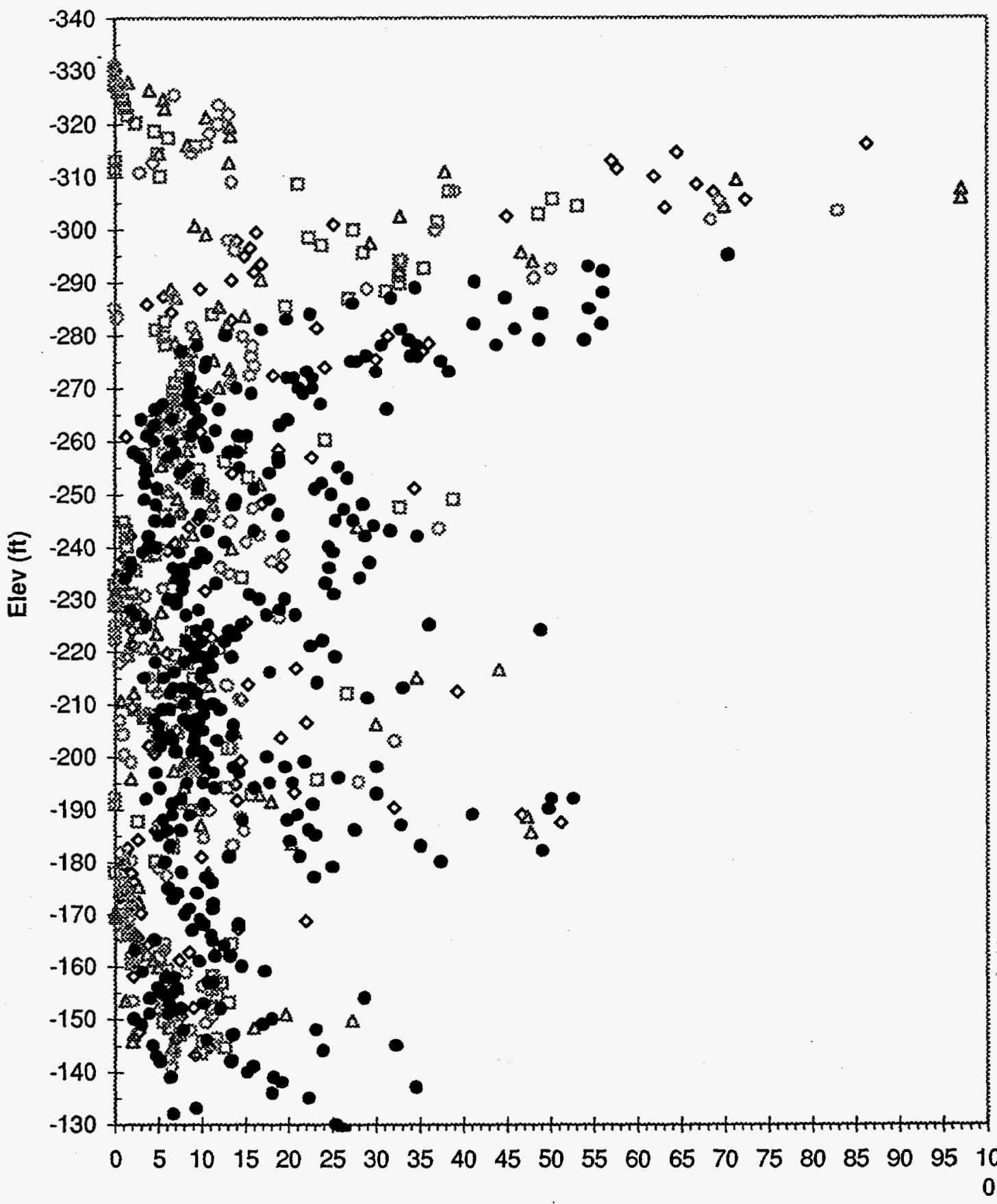

- Tank 50

c. Tank 51

$\triangle$ Tank 48

- Tank 49

- SPT N1

SPT (N1)60

Figure 5.1.5 ITP Real and Simulated Data 
Appendix III

Preliminary Evaluation of OCR from SCPT Data by

P. W. Mayne 
Georgia Institute of Technology

School of Civil Engineering

Geotechnical Engineering Laboratories

Atlanta, GA 30332-0355

(404) 894-6226 or FAXs at (404) 894-2281

\section{FAX Memorandum}

Date: $\quad$ April 15, 1994

To: $\quad$ Mike Lewis

Geotechnical Engineering Manager

SRS/Bechtel, Savannah River Inc.

802 E. Martintown Road, BTC-416

North Augusta, SC 29841

FAX: $\quad 7$ pages to $803-952-5183$

From: $\quad$ Paul W. Mayne, Associate Professor, CE

Re: Preliminary Evaluation of OCR from Piezocone SCPT-18 at SRS-H Area ITP

Dear Mike,

Enclosed is a preliminary assessment of OCR solely using the piezocone data from one of the soundings at the ITP site. This particular sounding was chosen at random as representative of site conditions, however, it is located downhill and south of the tank area. Using pre-established analysis procedures, we evaluated the OCR profiles in this manner:

1. Initially, the sounding was divided into (a) clay and (b) sand layers based on visual examination of the $q_{c}, f_{b}$, and $u_{b c}$ data. We understand that $q_{c}$ is supposed to represent the corrected cone tip resistance, $q_{T}$.

2. For clay layers, we evaluated the effective preconsolidation stress using the following relationship (Mayne and Holtz, 1988; Kulhawy and Mayne, 1990):

$$
\sigma_{\mathrm{p}}{ }^{\prime}=0.54 \Delta \mathrm{u}_{2}
$$

where $\Delta u_{2}=\Delta u_{b c}=$ measured excess pore pressure behind the cone tip.

The OCR for clay layers was then calculated as $\mathrm{OCR}=\sigma_{\mathrm{p}}{ }^{\prime} / \sigma_{\mathrm{vo}}$ ' where the effective overburden pressure $\left(\sigma_{\mathrm{vo}}{ }^{\prime}\right)$ was preliminarily evaluated assuming a total unit weight $\gamma=115$ pcf throughout the profile and groundwater taken to be hydrostatic below a depth of 25 feet.

3. Values of $\mathrm{K}_{\mathrm{o}}$ in the clay were evaluated according to an expression derived from regression analysis of self-boring pressuremeter test (SBPMT) data compiled from 56 different clays (Mayne and Kulhawy, 1990): 
4. In the sand layer, the estimate of OCR is more difficult because of the paucity of stress history measurements in natural sands. A methodology based on CPT-calibration chamber data on clean sands has therefore been used (Mayne and Kulhawy, 1991). For this procedure, it is necessary to solve two simultaneous equations or iterate to find both $\mathrm{K}_{\mathrm{o}}$ and OCR:

[3]

$$
\mathrm{K}_{\mathrm{o}}=\left(\sigma_{\mathrm{bo}}{ }^{\prime} / \sigma_{\mathrm{vo}}{ }^{\prime}\right)=\frac{\left(\mathrm{p}_{\mathrm{s}} / \sigma_{\mathrm{vo}}{ }^{\prime}\right)\left(\mathrm{q}_{\mathrm{c}} / \mathrm{p}_{\mathrm{p}}\right)^{1.6}}{145 \exp \left\{\left[\frac{\left(\mathrm{q}_{\mathrm{c}} / \mathrm{p}_{\mathrm{J}}\right) /\left(\sigma_{\mathrm{vo}} / \mathrm{p}\right)^{0.5}}{12.2 \mathrm{OCR}^{0.18}}\right]^{0.5}\right\}}
$$

$$
\mathrm{K}_{\mathrm{o}}=\left(1-\sin \phi^{\prime}\right) O C \mathrm{R}^{\sin \phi^{\prime}}
$$

Equation [3] is derived from a statistical analysis of corrected CPT data from 24 different sets of calibration chamber tests on unaged, uncemented, quartzitic sands. It is noted that the data are primarily from clean sands. Equation [4] is based on laboratory triaxial and oedometer measurements on 171 different soils, including sands, gravels, silts, and clays (Mayne and Kulhawy, 1982). The use of [4] also requires an assessment of the effective friction angle of the material ( $\left.\phi^{\prime}\right)$ for which the relationship proposed by Robertson and Campanella (1983) has been adopted:

$$
\phi^{\prime}=\arctan \left[0.10+0.38 \log \left(\mathrm{q}_{\mathrm{e}} / \sigma_{\mathrm{vo}}{ }^{\prime}\right)\right]
$$

Derived profiles of OCR, $K_{o}, \sigma_{p}{ }^{\prime}$, and $\phi^{\prime}($ sand) are shown on the enclosed figures. The magnitudes of stress history (OCR and $\sigma_{\mathrm{p}}{ }^{\prime}$ ) appear to be generally consistent with the results of laboratory oedometer tests on clay and sandy clay layers conducted by Law Engineering and recently provided to us in summarized tables and graphs. In the vicinity of SCPT-18, only a few OCR estimates from DMT soundings were available and these also appear compatible with the preliminary interpretations of piezocone data.

We should like to further discuss these preliminary evaluations with at your convenience. In particular, we are curious to know more details on the correction of $\mathrm{q}_{\mathrm{T}}$ values, since this data may also be used to derive profiles of $\sigma_{\mathrm{p}}{ }^{\prime}, \mathrm{OCR}, \mathrm{K}_{\mathrm{o}}$, and effective stress angle $\left(\phi^{\prime}\right)$ in clays. In addition, while the sand strata at the ITP site appear to have only about 10 to 15 percent fines, the fines content appears gap-graded with high-plasticity clay-size particles. This may affect the interpretation of CPT data in the sand strata.

Sincerely,

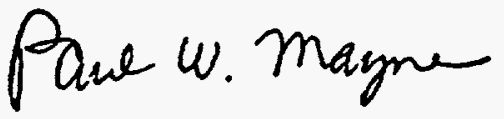

Paul W. Mayne, PhD, P.E. Associate Professor

(404) $894-6226$ 
Kulhawy, F.H. and Mayne, P.W. (1990). Manual on Estimating Soil Properties for Foundation Design. Report EL-6800, Electric Power Research Institute, Palo Alto, 306 p.

Mayne, P.W. (1991). Tentative Method for Estimating $\sigma_{b o}$ 'From $\mathrm{q}_{\mathrm{c}}$ Data in Sands. Calibration Chamber Testing, Elsevier Publishing, New York, 249-256.

Mayne, P.W. and Holtz, R.D. (1988). Profiling Stress History from Piezocone Soundings. Soils and Foundations 28 (1), 16-28.

Mayne, P.W. and Kulhawy, F.H. (1982). Ko-OCR Relationships in Soil. Journal of the Geotechnical Engineering Division, ASCE, 108 (GT6), 851-872.

Mayne, P.W. and Kulhawy, F.H. (1990). Direct and Indirect Determinations of In-Situ $\mathrm{K}_{\mathrm{o}}$ in Clays. Transportation Research Record 1278, National Research Council, Washington, D.C., 141-149.

Mayne, P.W. and Kulhawy, F.H. (1991). Calibration Chamber Database and Boundary Effects Correction for CPT Data. Calibration Chamber Testing, Elsevier Publishing, New York, 257264.

Robertson, P.K. and Campanella, R.G. (1983). Interpretation of Cone Penetration Tests. Part 1: Sands. Canadian Geotechnical Journal 20 (4), 718-733. 
SRS-H Area-ITP-SCPT 18

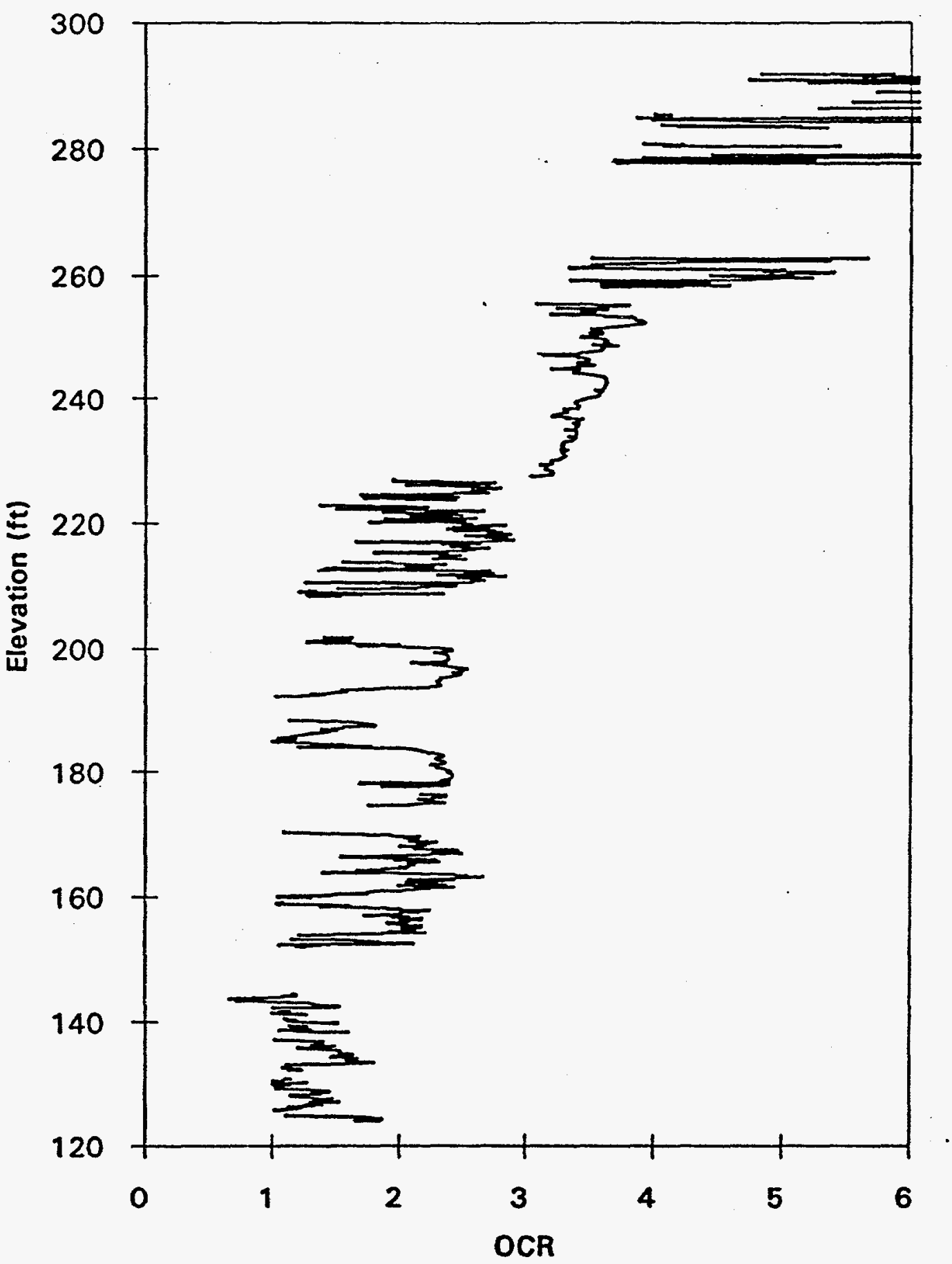


SRS-H Area-ITP-SCPT18

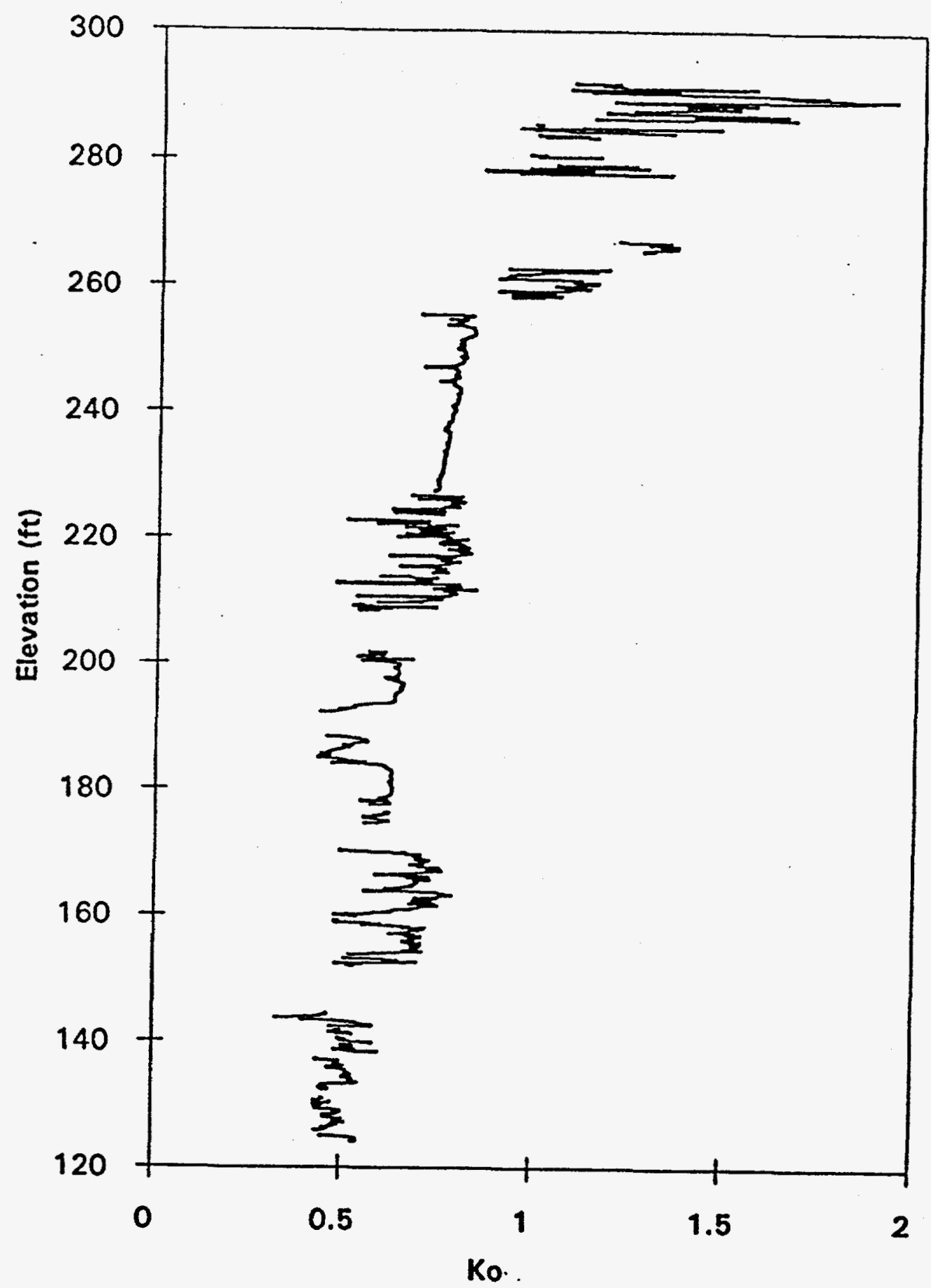


SRS-H Area-ITP-SCPT 18

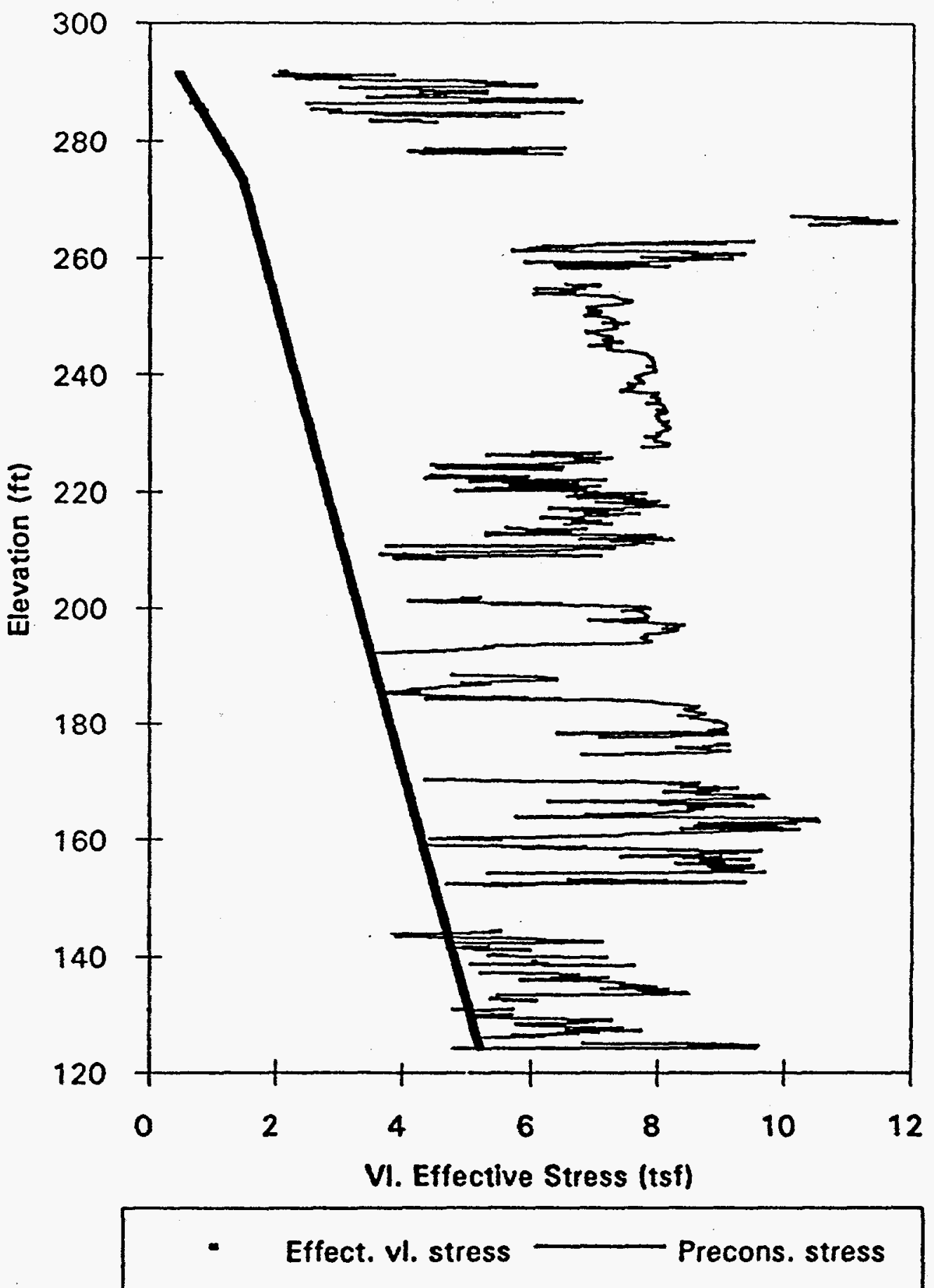


SRS-H Area-ITP-SCPT 18

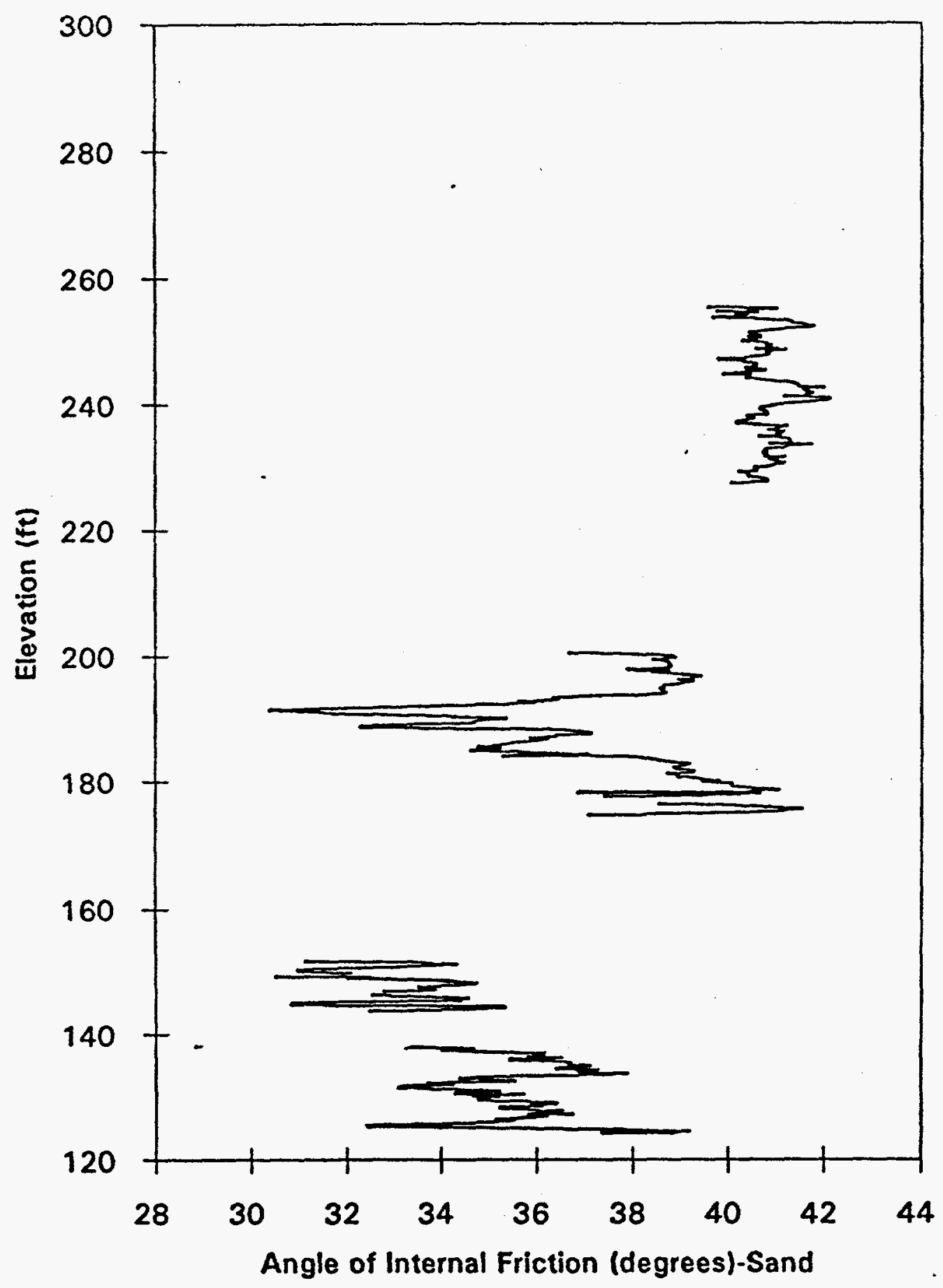


May 6, 1994

Mike Lewis

Geotechnical Engineering Manager

SRS/Bechtel, Savannah River Inc.

802 E. Martintown Road, BTC-416

North Augusta, SC 29841

Re: (1) Excel File with $\mathrm{K}_{0}-$ OCR Data Reduction from SCPT-18

(2) Correlative Estimate of $V_{s}$ from CPT $-23-q_{c}$ Profile

Dear Mike,

Here is the floppy disk file of the reduced OCR data. I believe Yasser Hegazy left the file unfiltered; that is, there are spikes in the transition zones between alternating clay and sand strata. The procedures for the OCR and $\mathrm{K}_{0}$ evaluations were provided to you in a previous memo. We also attempted an estimate of shear wave velocity $\left(V_{2}\right)$ and low-amplitude shear modulus $\left(G_{\text {max }}\right)$ from the cone tip resistance measurements at CPT-23. These were made using the following:

Sands: $\quad \mathrm{V}_{\mathrm{s}}=277\left(\mathrm{q}_{\mathrm{c}}\right)^{0.13}\left(\sigma_{\mathrm{vo}}\right)^{0.27}$

(Baldi et al., 1989)

where $V_{t}$ is in $\mathrm{m} / \mathrm{sec}$ and $\mathrm{q}_{\mathrm{c}}$ and $\sigma_{\mathrm{vo}}$ ' are in $\mathrm{MPa}$.

Sands: $\quad \mathrm{G}_{\max }=1634\left(\mathrm{q}_{\mathrm{c}}\right)^{0.250}\left(\sigma_{\mathrm{vo}}{ }^{\prime}\right)^{0.375}$

(Rix and Stokoe, 1991)

where all stresses are in units of $\mathrm{kPa}$.

Clays: $\quad V_{1}=126\left[\log \left[q_{c} /\left(p_{a} \sqrt{P I}\right)\right]+1\right]$

(Mayne \& Rix, 1993)

where $\mathrm{V}_{\mathrm{s}}$ is in $\mathrm{m} / \mathrm{sec}, \mathrm{PI}=$ plasticity index in percent, $\mathrm{q}_{\mathrm{c}}$ and $\mathrm{p}_{\mathrm{a}}$ are in same units, and $\mathrm{p}_{\mathrm{z}}=1 \mathrm{~atm} \approx 100 \mathrm{kPa}$.

Clays: $\quad G_{\max }=406\left(q_{c}\right)^{0.695}\left(e_{a}\right)^{-1.130}$

(Mayne \& Rix, 1993)

with $G_{\max }$ and $q_{c}$ in $\mathrm{kPa}$ and $\mathrm{e}_{\mathrm{o}}$ is dimensionless.

Should you have any questions regarding these items, please call.

Sincerely,

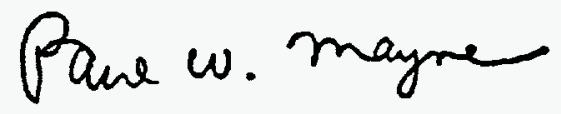

Paul W. Mayne, PhD, P.E.

Associate Professor

OFF: (404) 894-6226

FAX: (404) 894-2281

xc: S. Rouhani 
SRS-H Area-ITP-SCPT-23

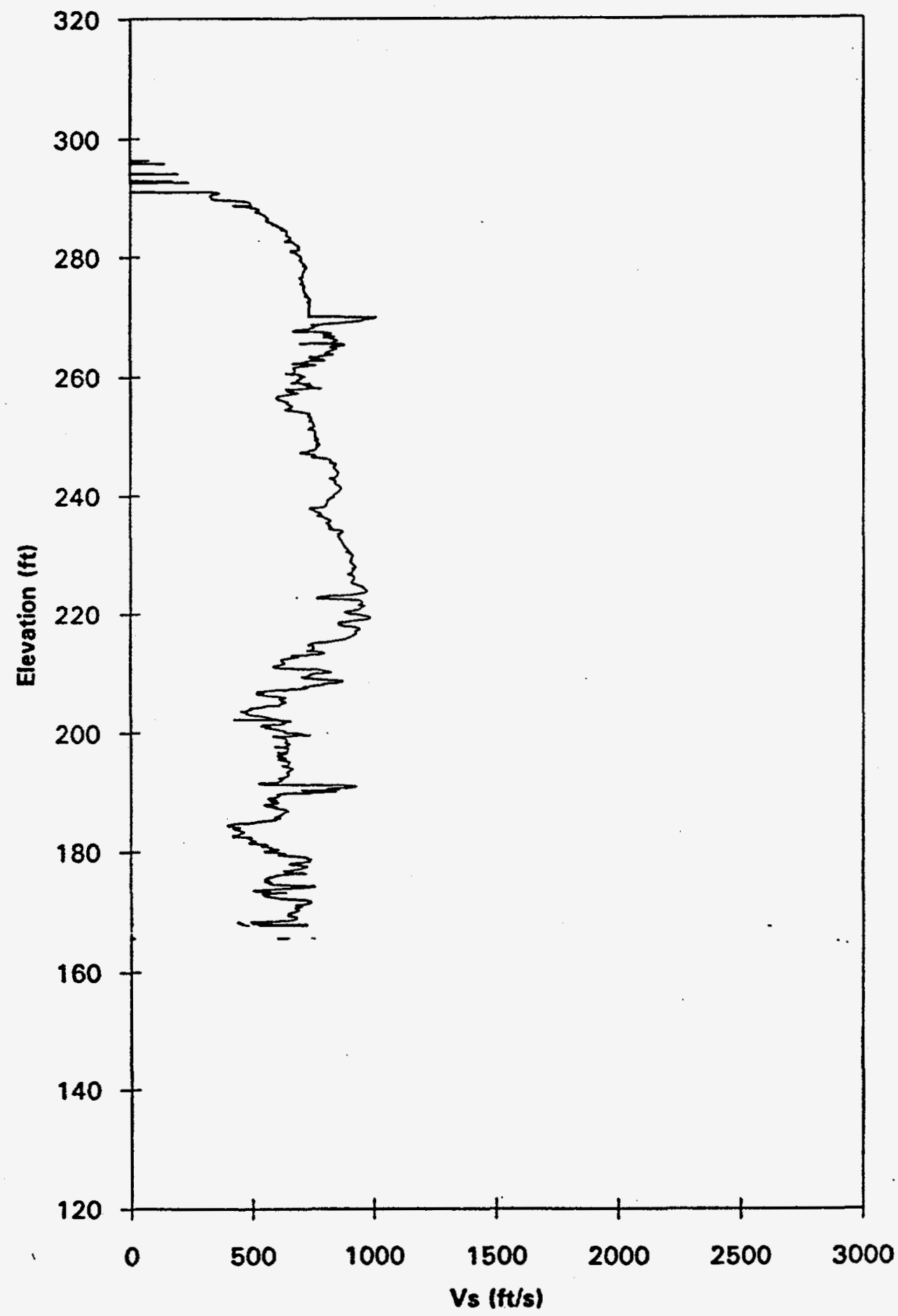


SRS-H Area-ITP-SCPT-23

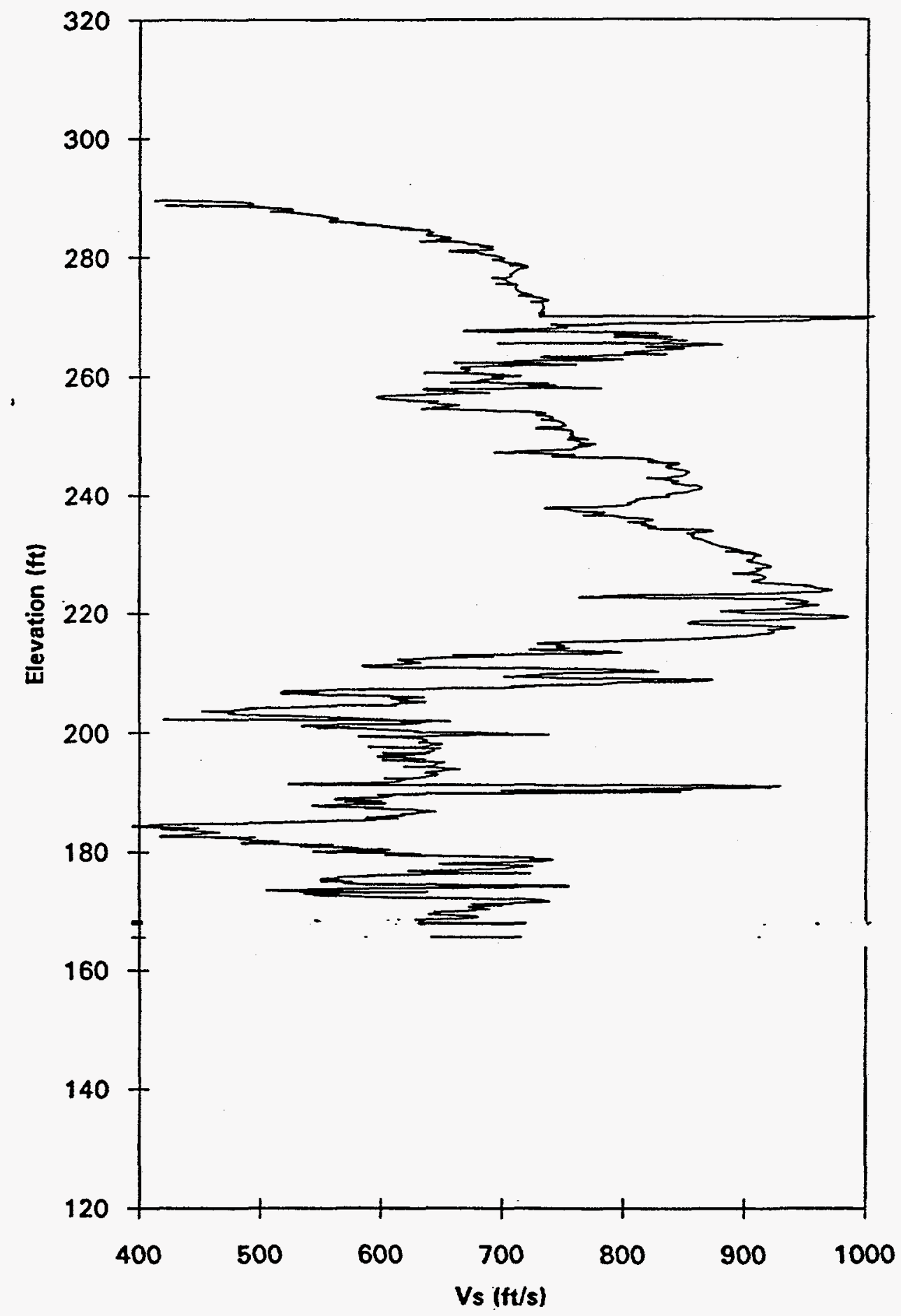


SRS-H Area-ITP-SCPT-23

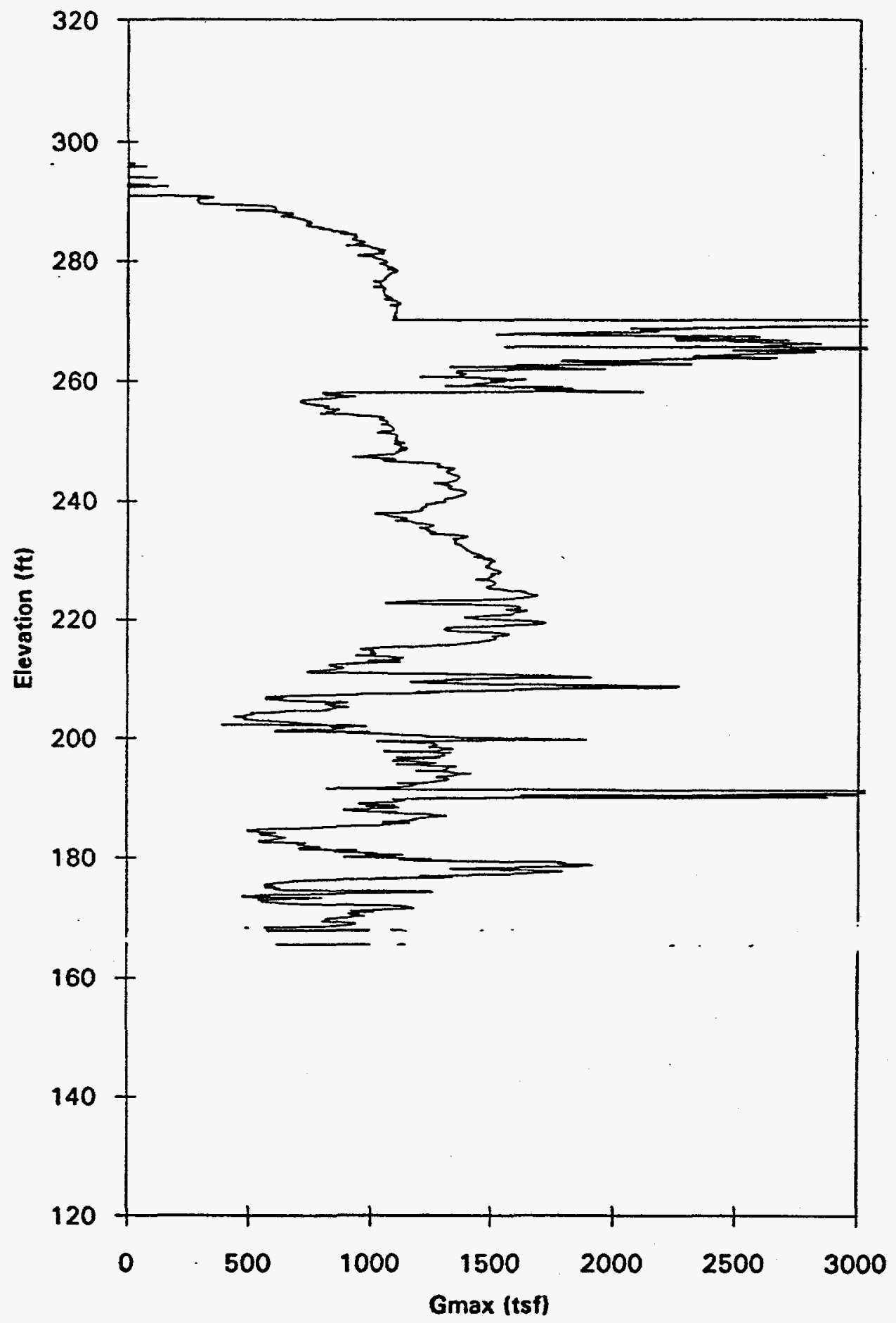


Appendix IV

List of SCPT Borehole Logs 
SCPT-01 APPLIED RESSEARCH ASSOCLATES, DNC.

$01 / 30 / 93$

North 70843.97 East 62532.00 Elevation 326.83
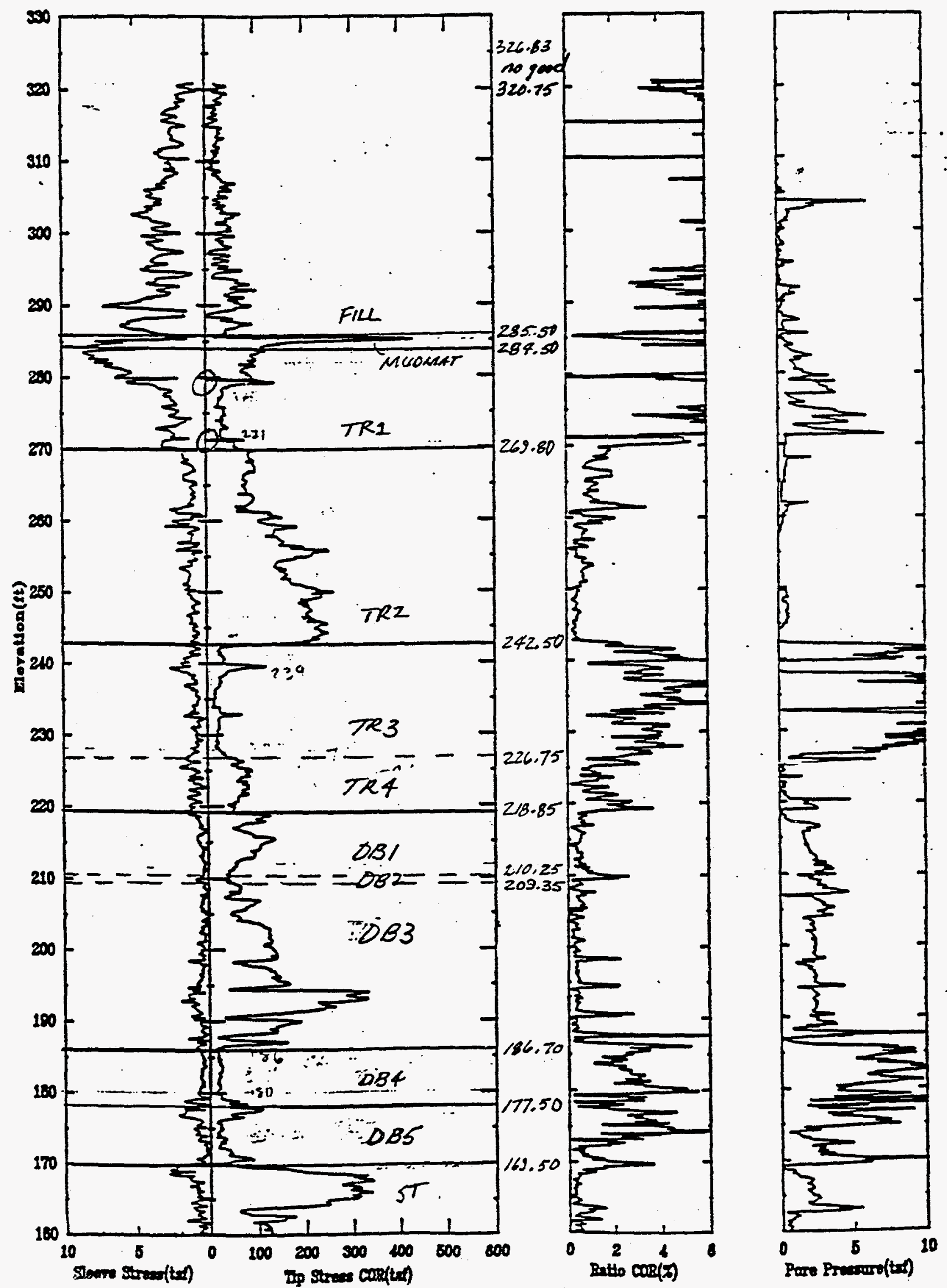

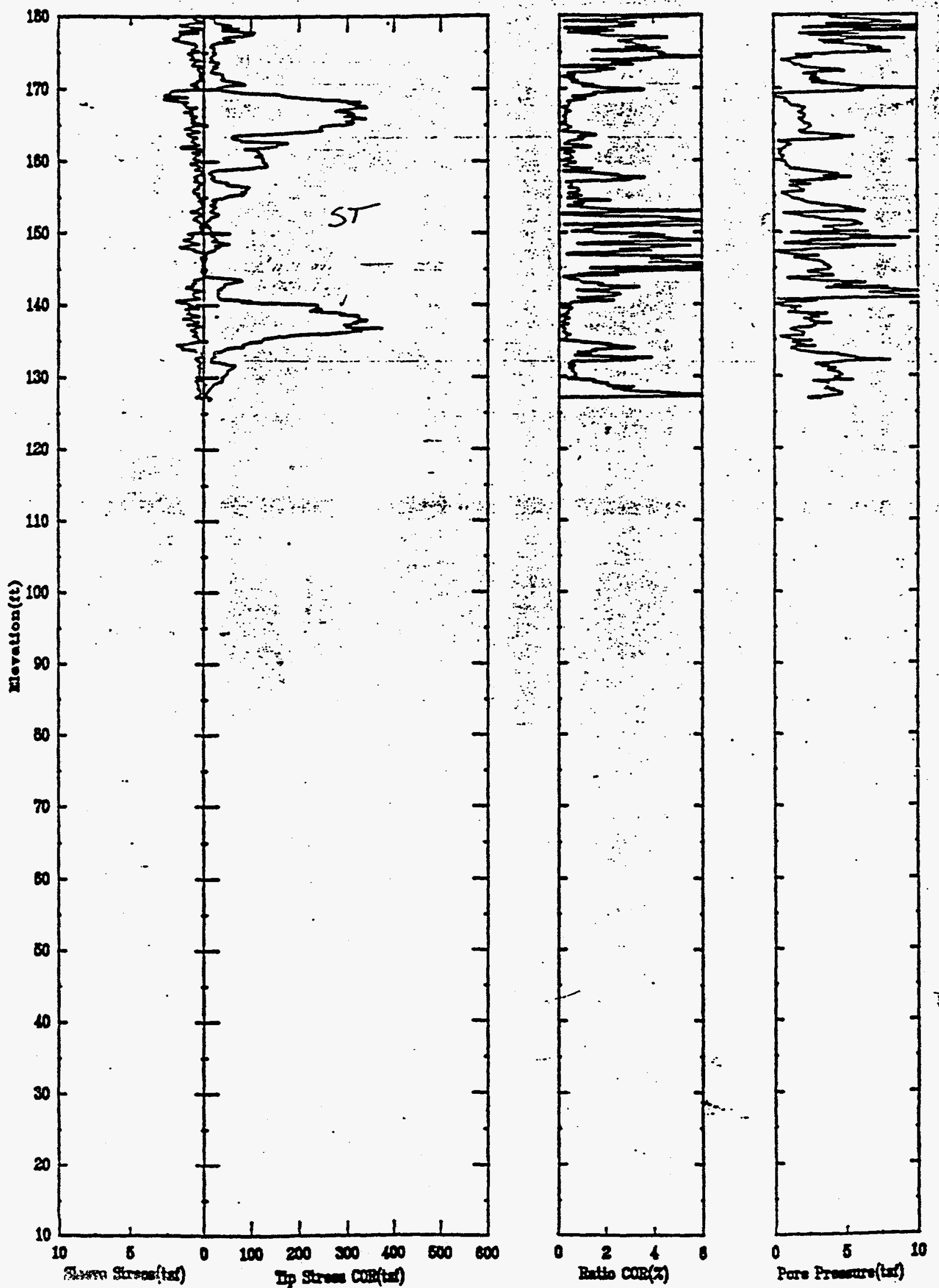

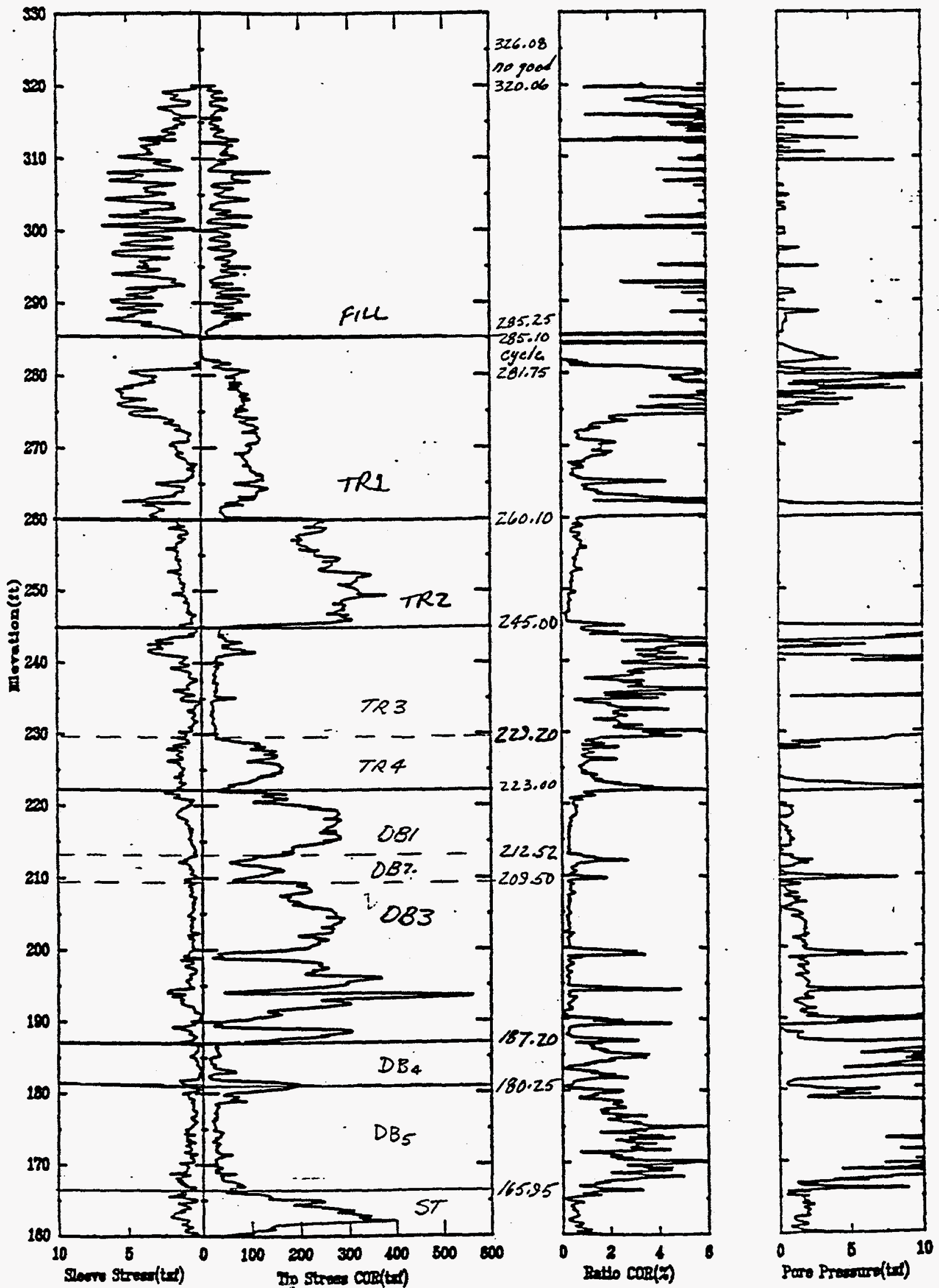
SCTP-5

North 70797.30
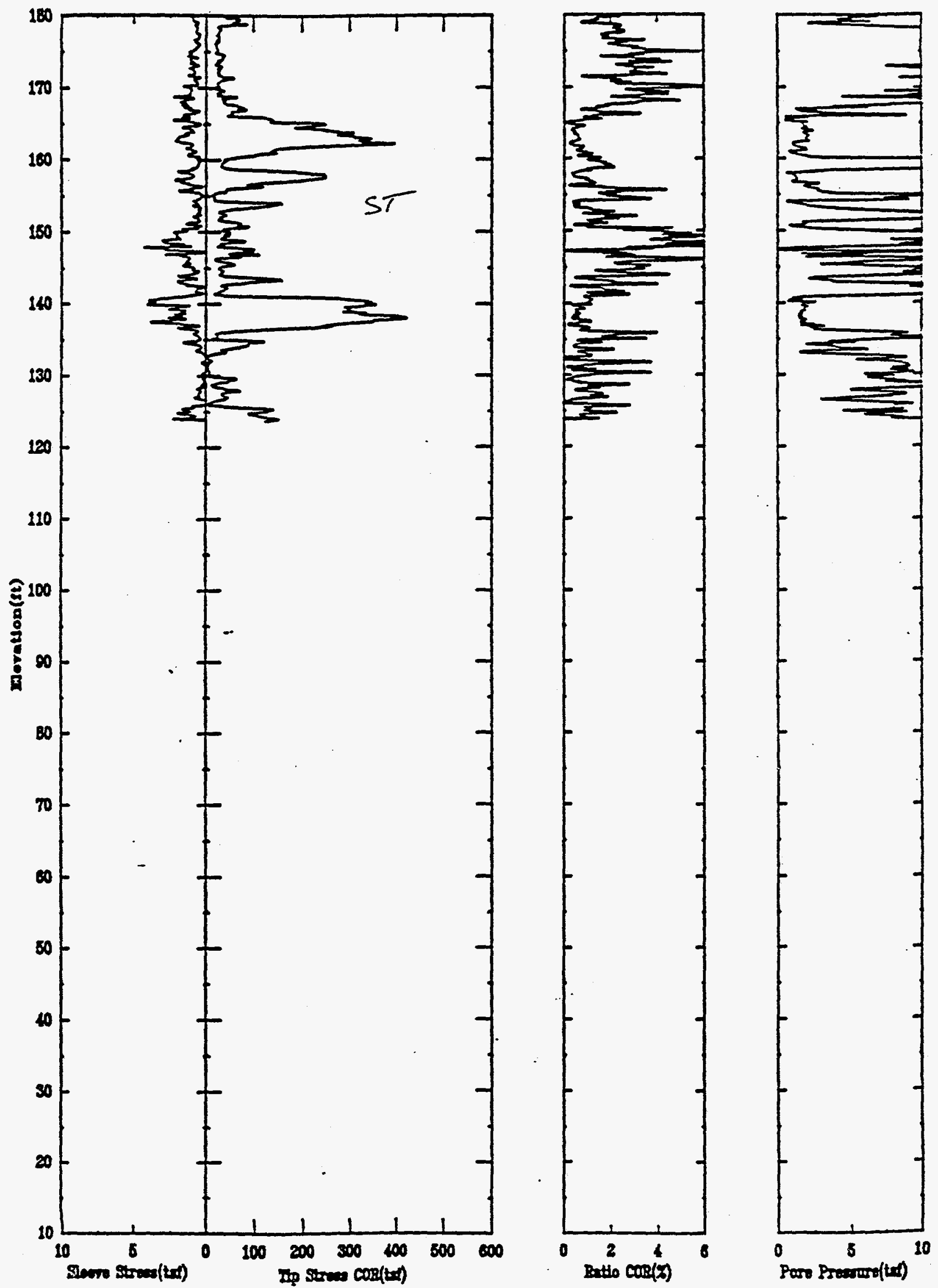

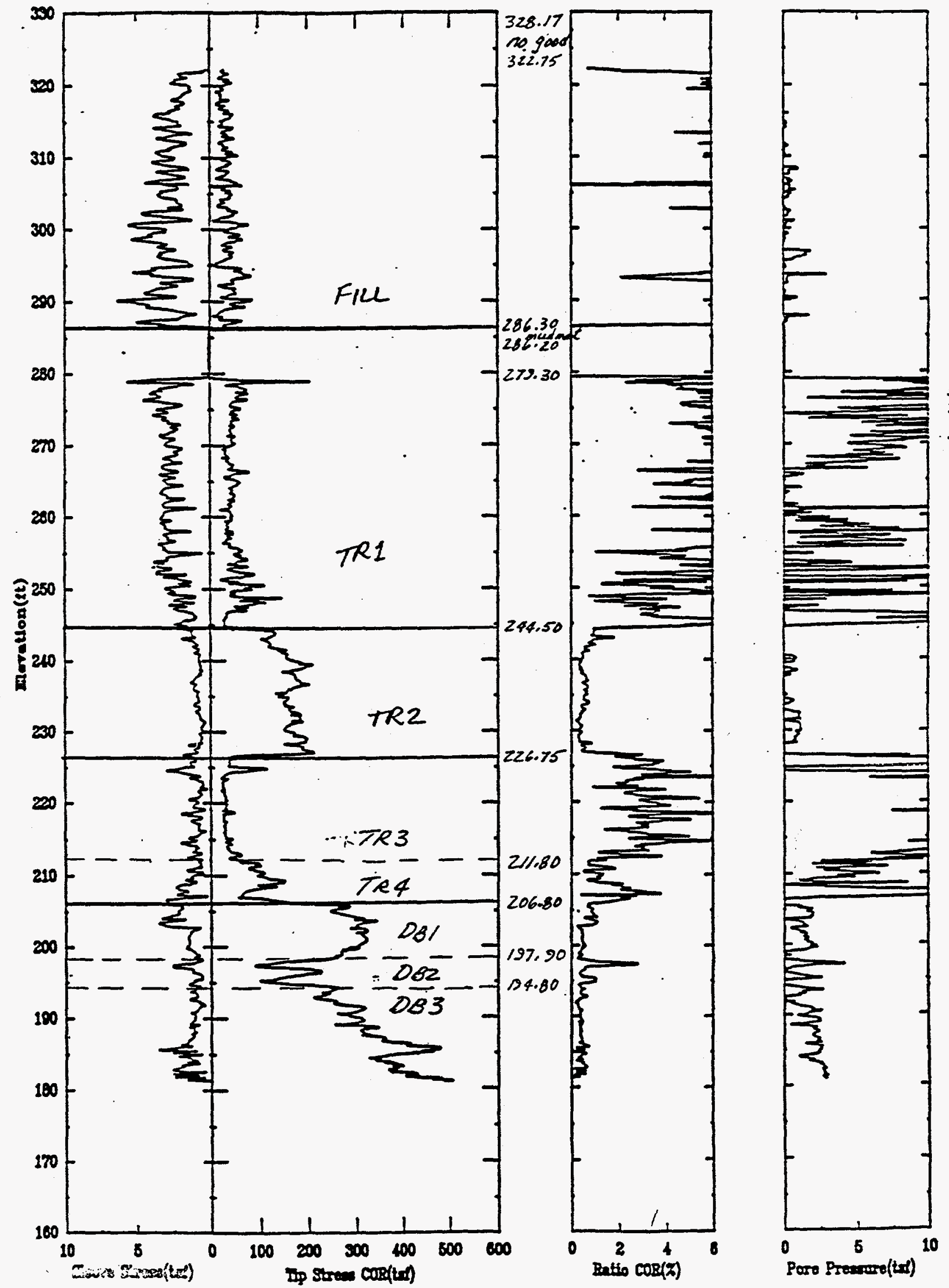
CPT-7 APPLIED RESEARCH ASSOCLATES, INC.

$04 / 15 / 93$

North $71030.17 \quad$ East 62612.85 - Elevation 328.76
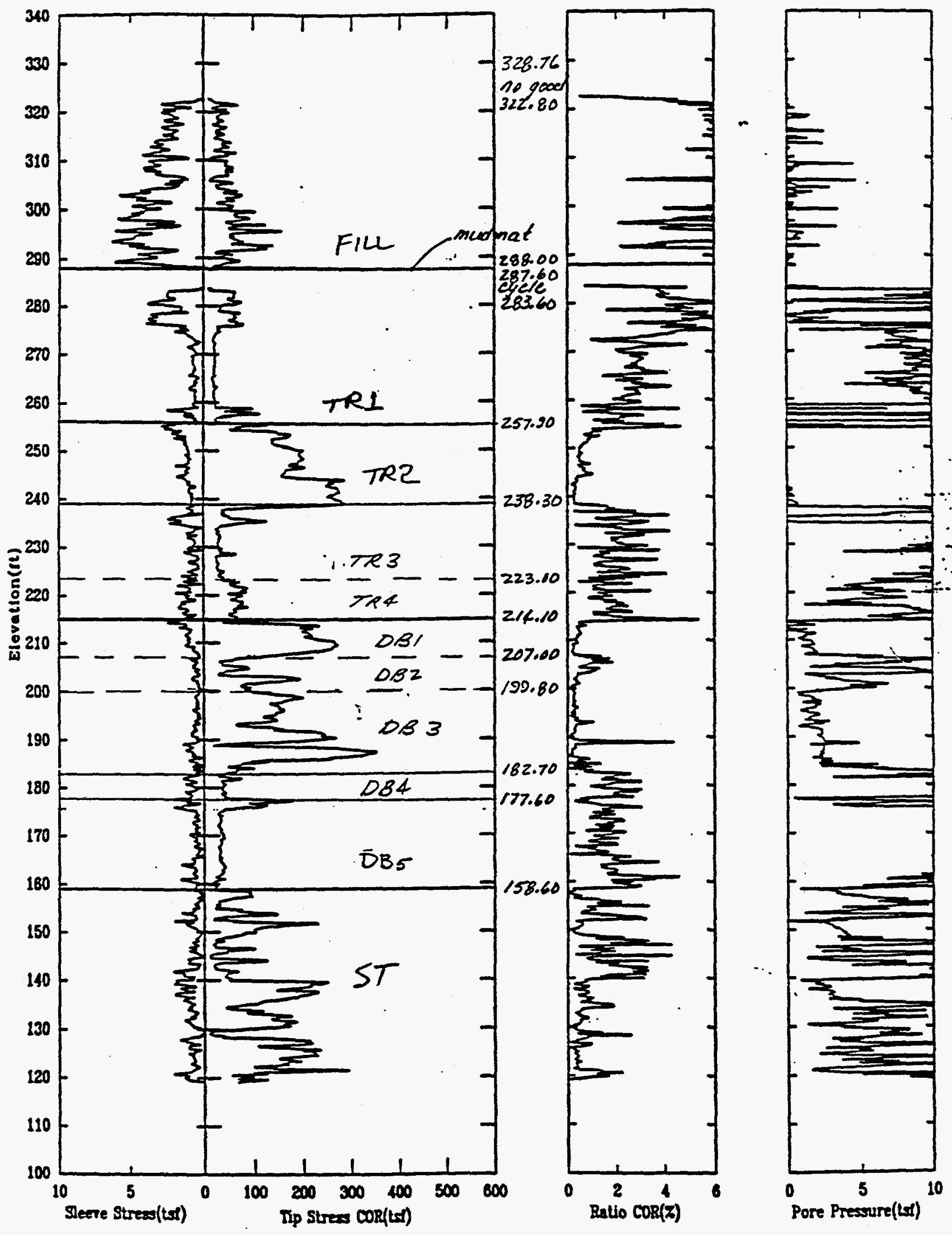
SCPT-10 LPPIED RESTARCZ LSSOCATIES, RNC. 02/01/93 North 71002.02 Dest 62554.29 Elevation 328.41
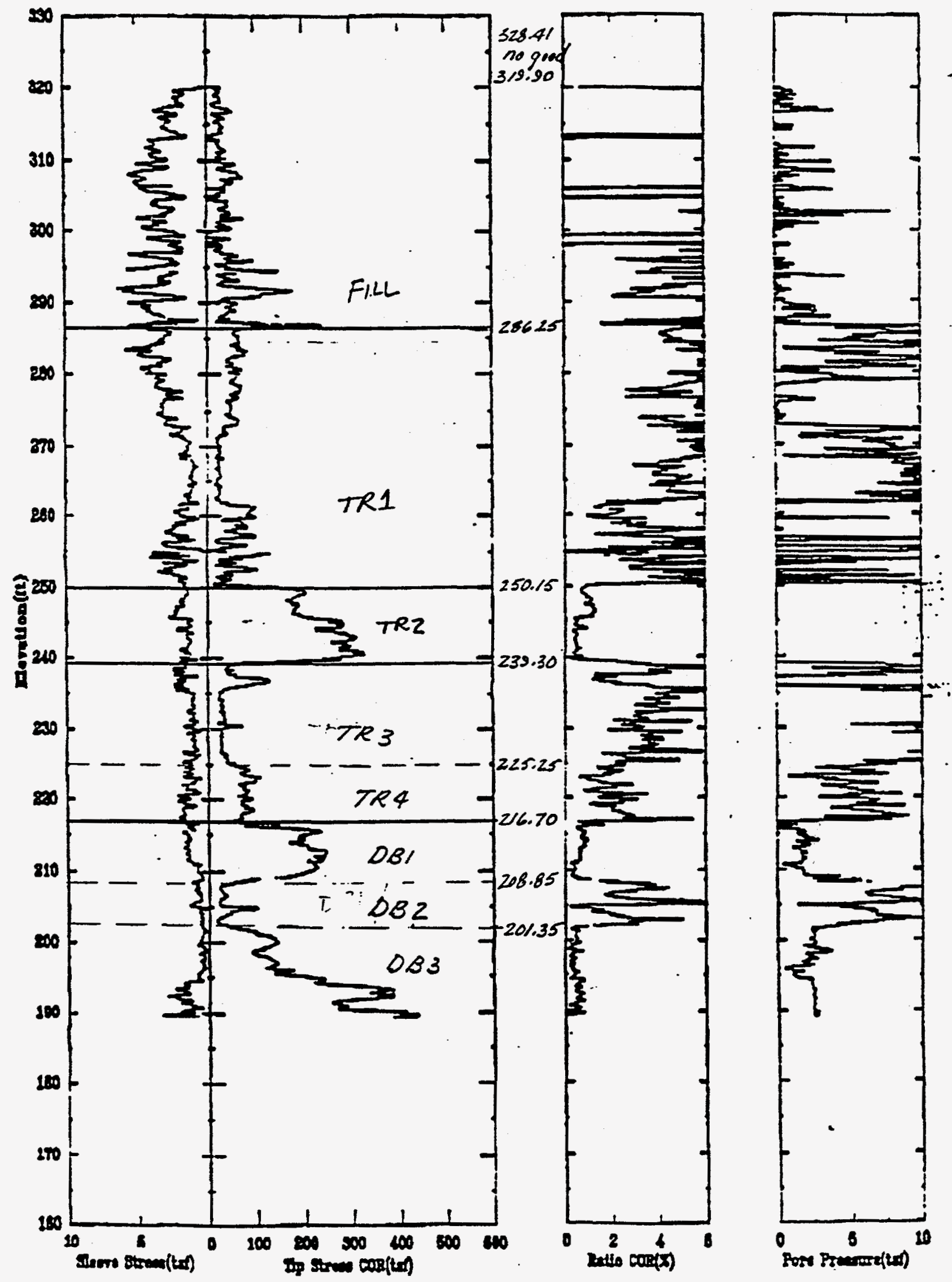
CPT-11

APPLIED RESEARCH ASSOCLATES, INC.

$04 / 16 / 93$

North 70885.10 East 62767.43 - Elevation 328.03
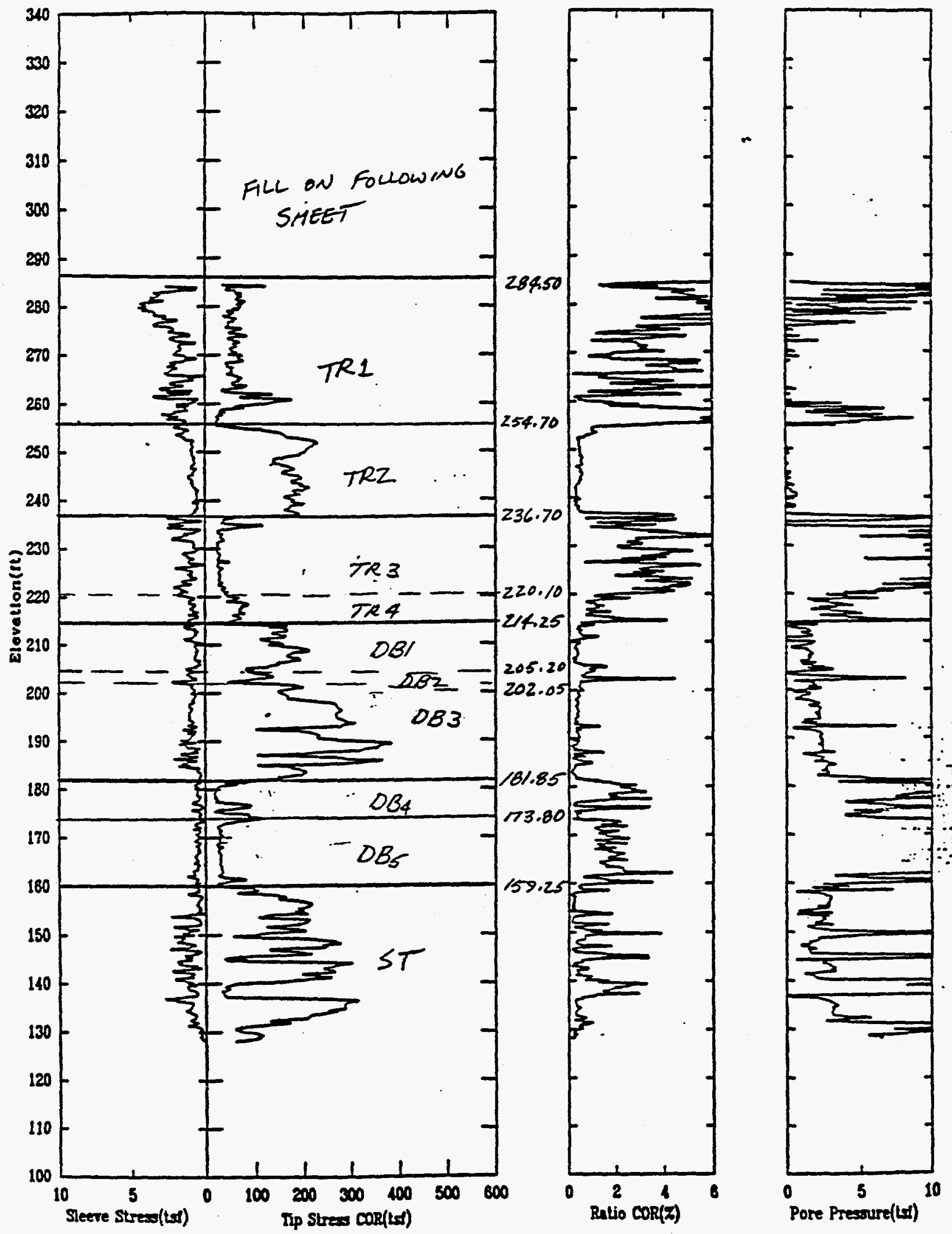

North 70885.10 East 62767.43 Eleration 327.87
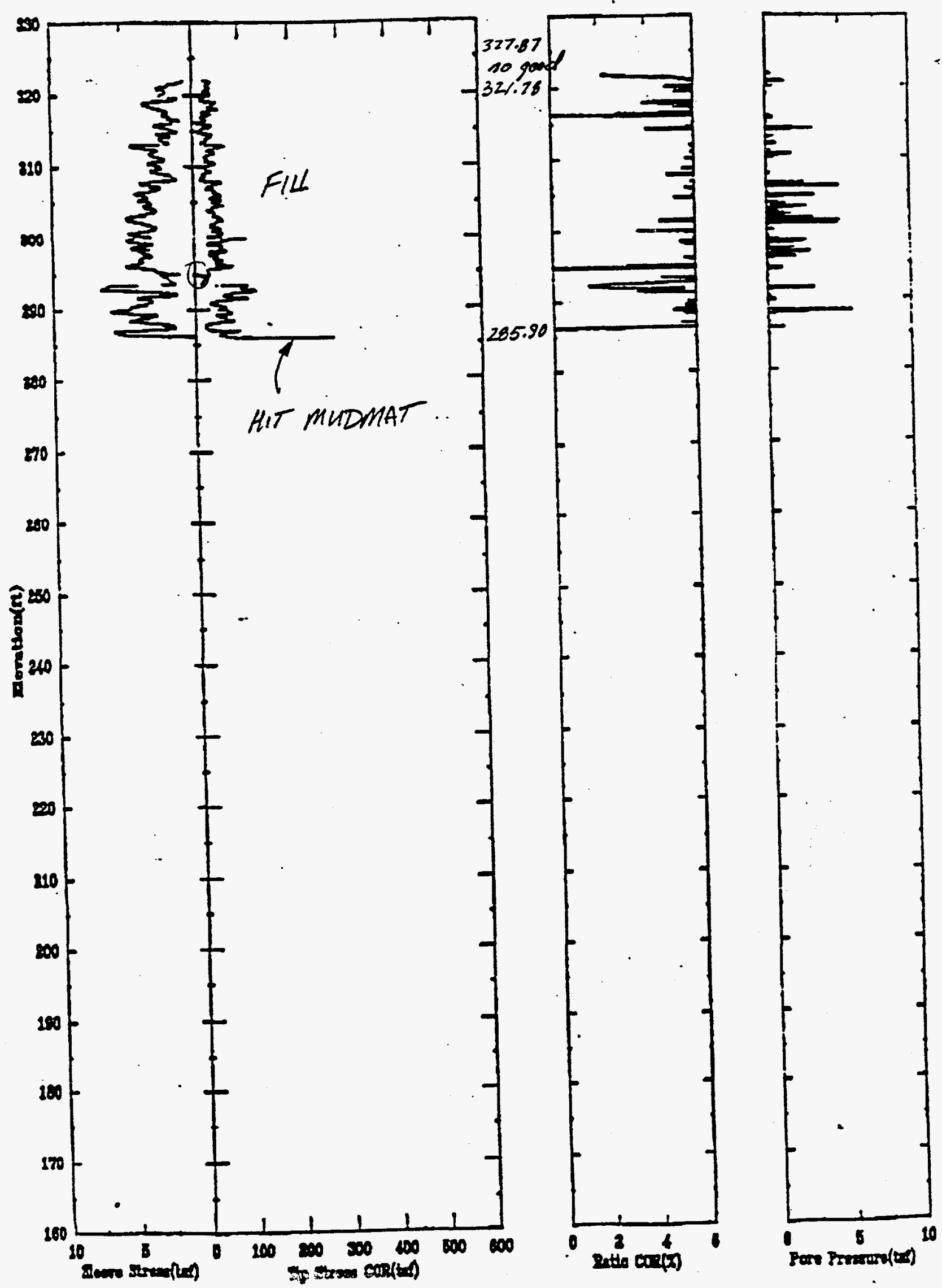


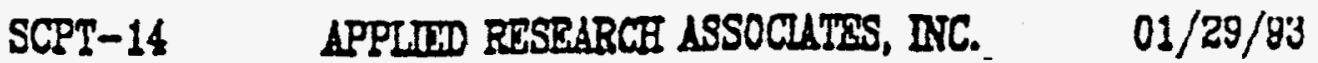
North 70035.88 East 82375.16 Eleration 300.08
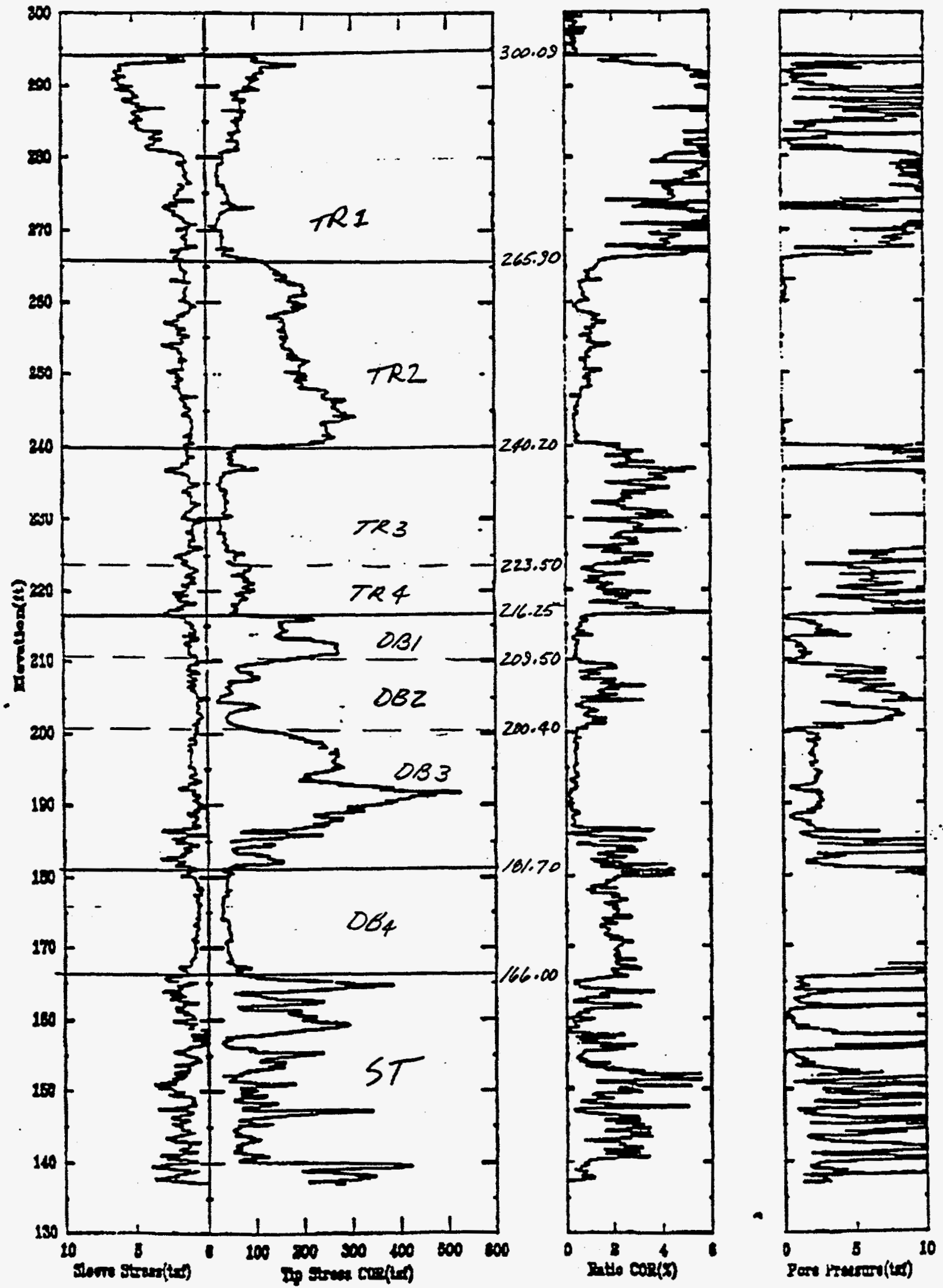
CPT-16 APPLIED RESEARCH ASSOCIATES, DNC.

$04 / 21 / 93$

North $70733.84 \quad$ East 62426.06 - Mevation 297.57
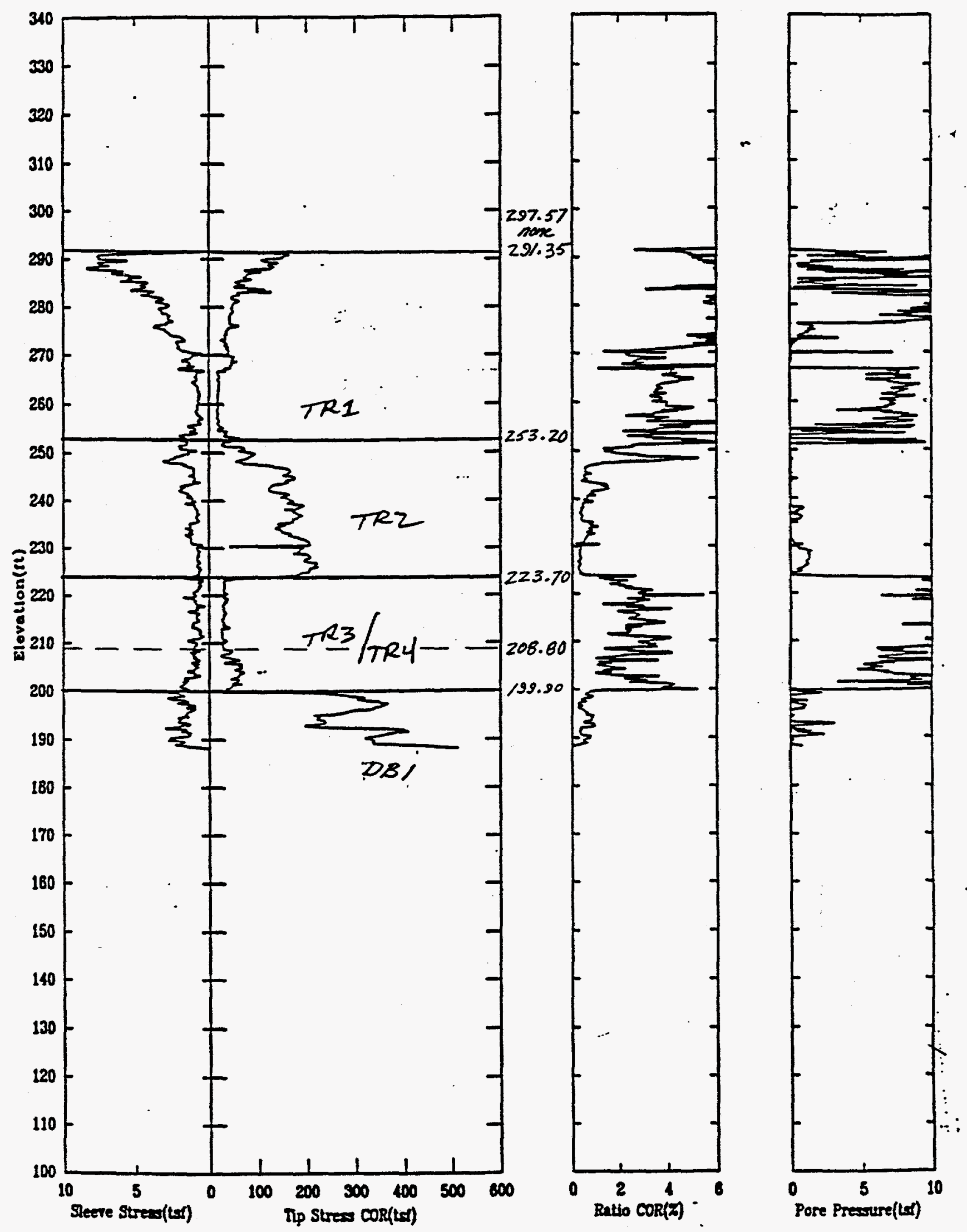
SCPT-18

APPIITD RESRARCE ASSOCHATES, INC.

$01 / 27 / 93$

North 70601.00 East 62657.50 Eleration 298.32
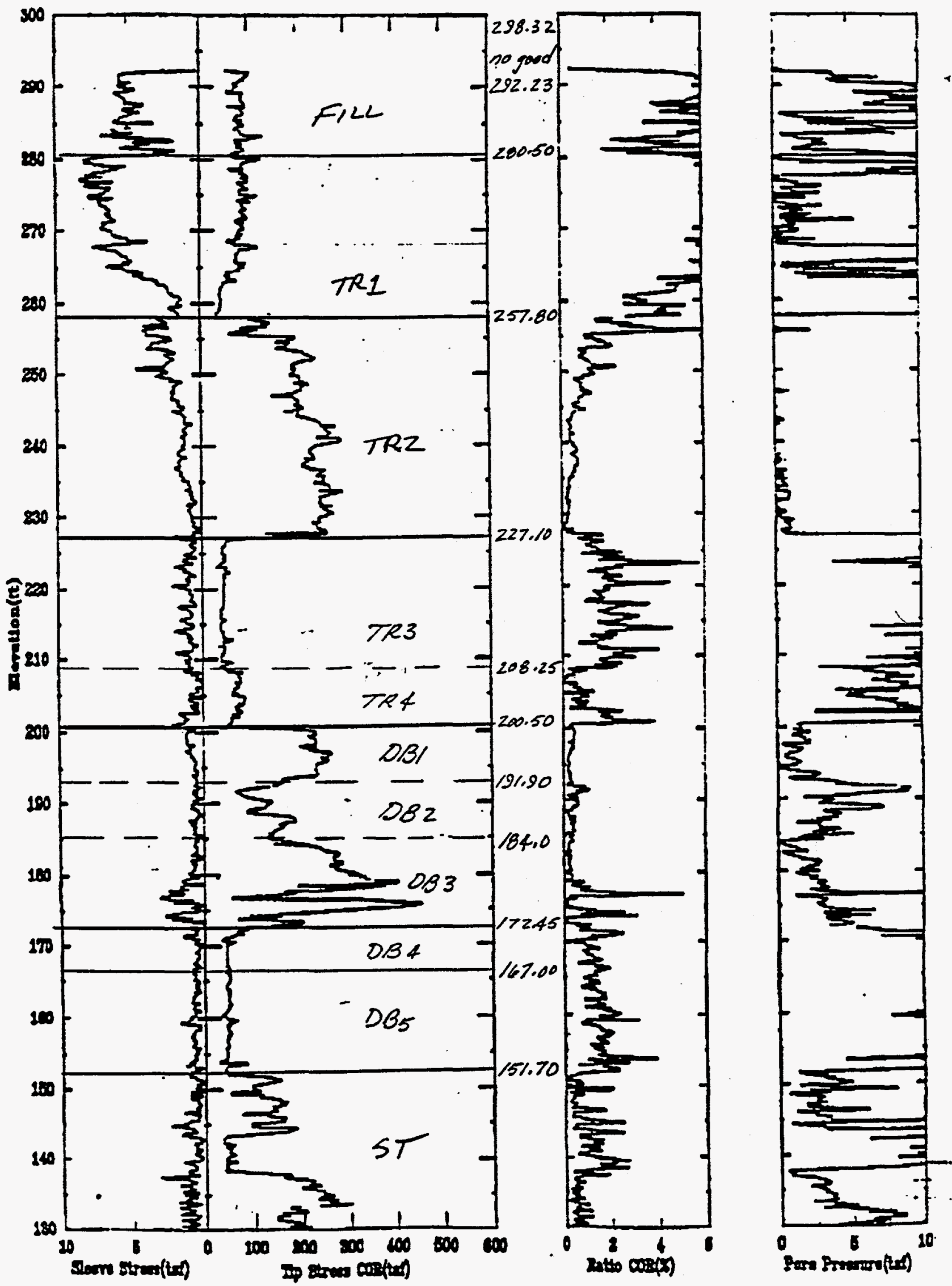
SCPT -20

LPPLTED BESTEARCE ASSOCUTTES, DNC.

$01 / 26 / 83$

North 70843.86 Fest 63059.62 Iforation 204.29
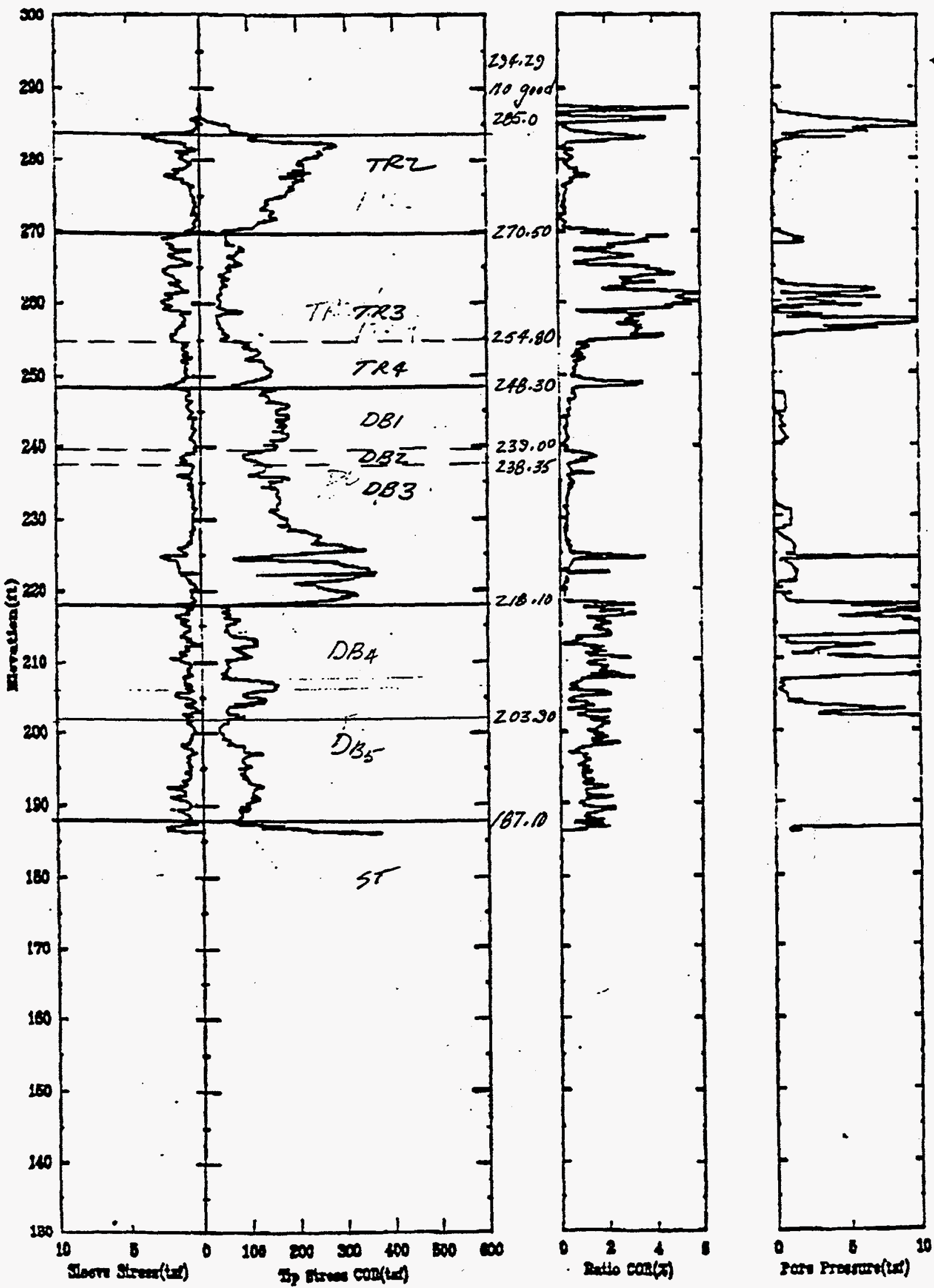

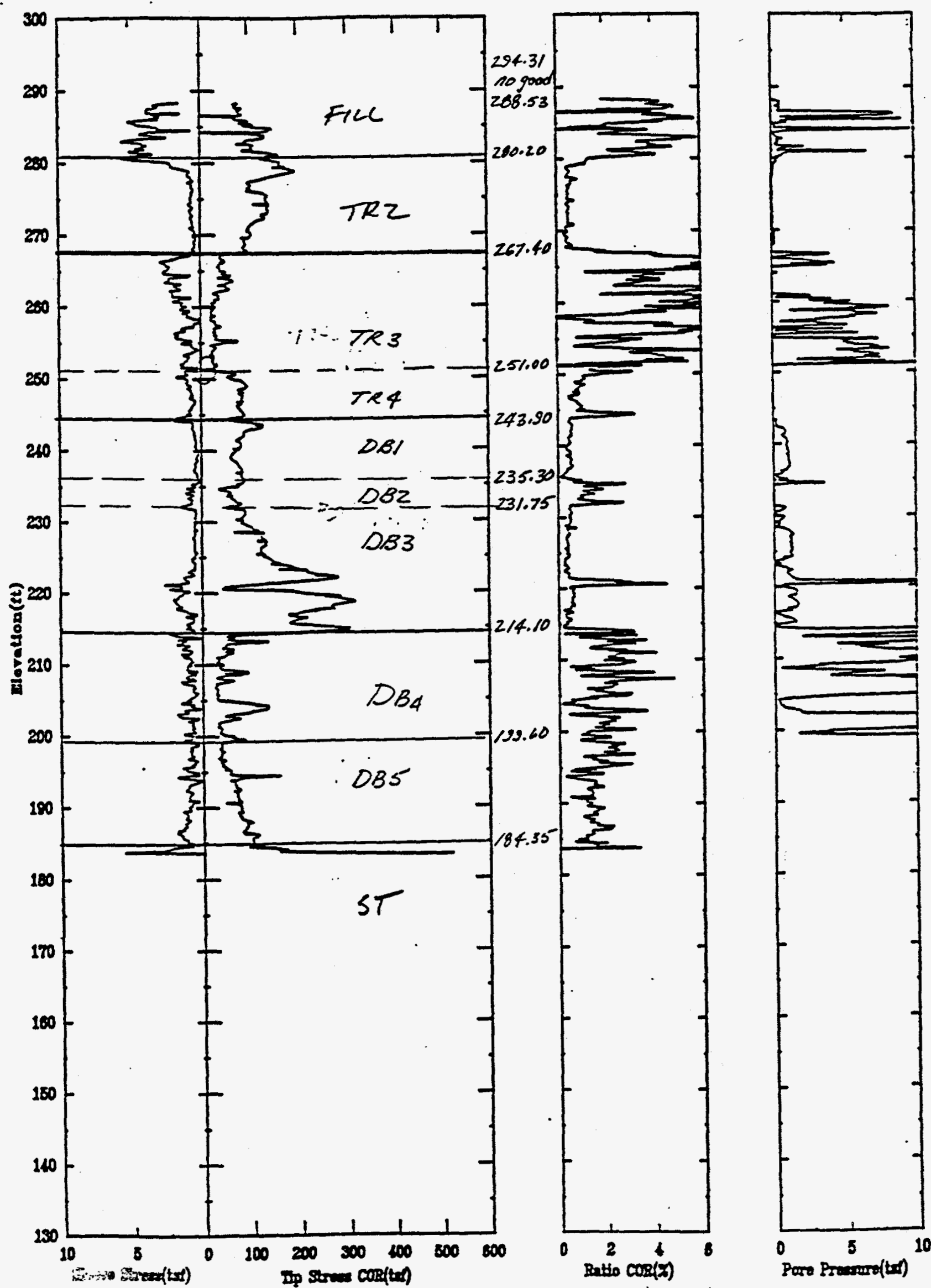

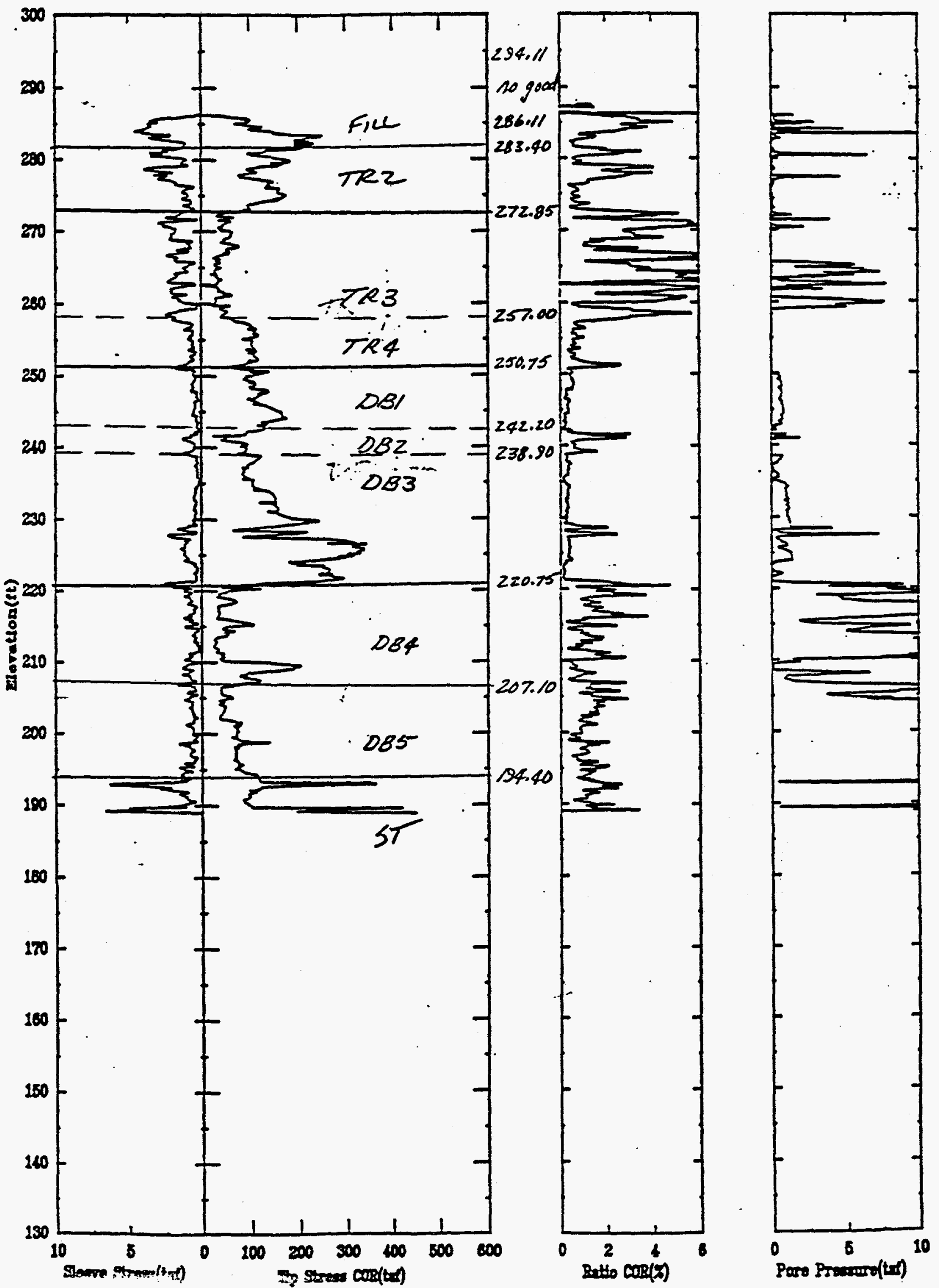
North 70970.68 East 63017.30 Elevation 296.59
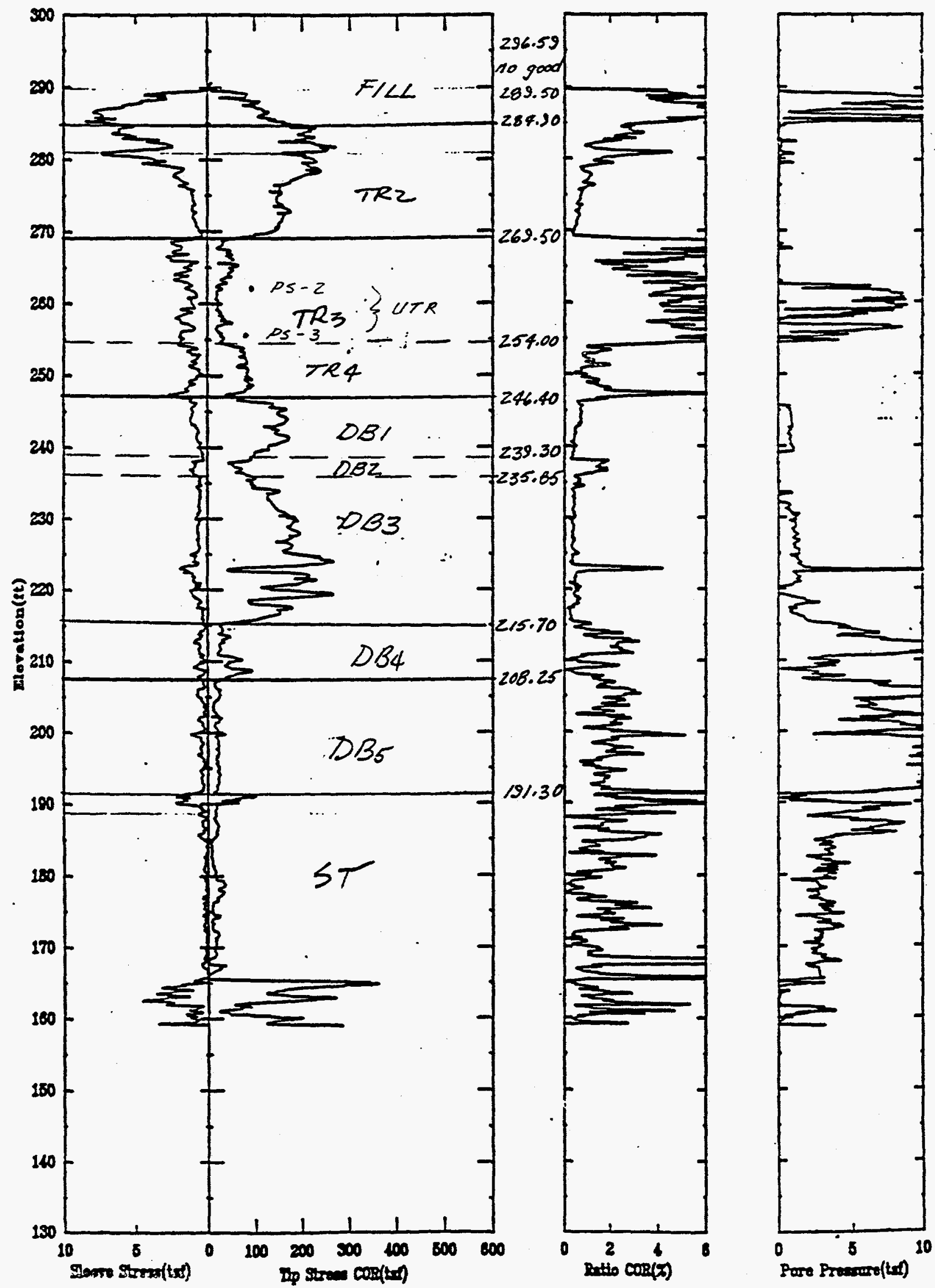
CPT-25

APPLIED RESEARCH ASSOCIATES, INC.

$05 / 24 / 92$

North $71197.74 \quad$ East $62998.40-$ Elevation $296.20^{-}$
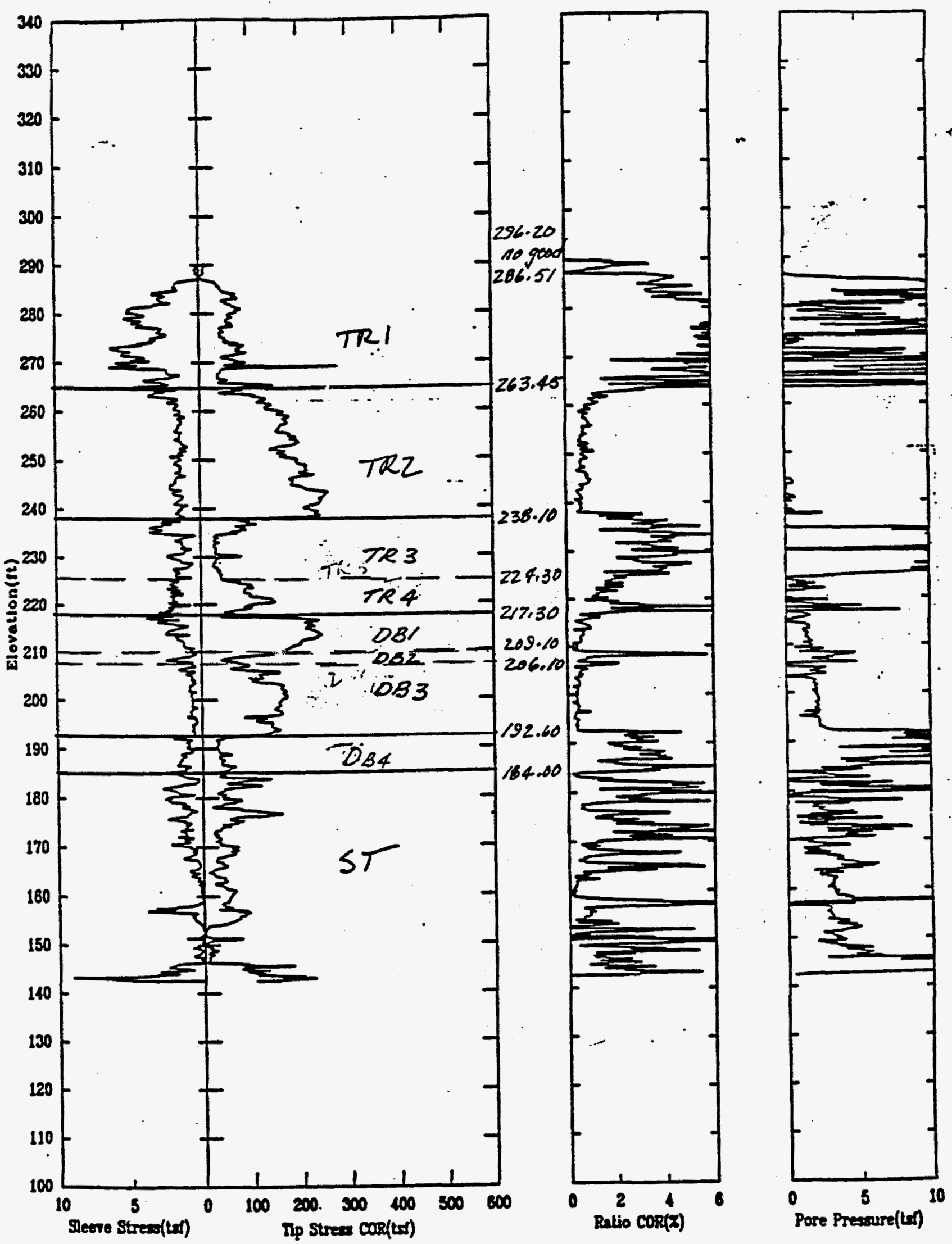
CPT-26 - APPLIED RESEARCH ASSOCLATES, DNC.
North $70764.00 \quad$ East 62805.00 - Elevation 326.13
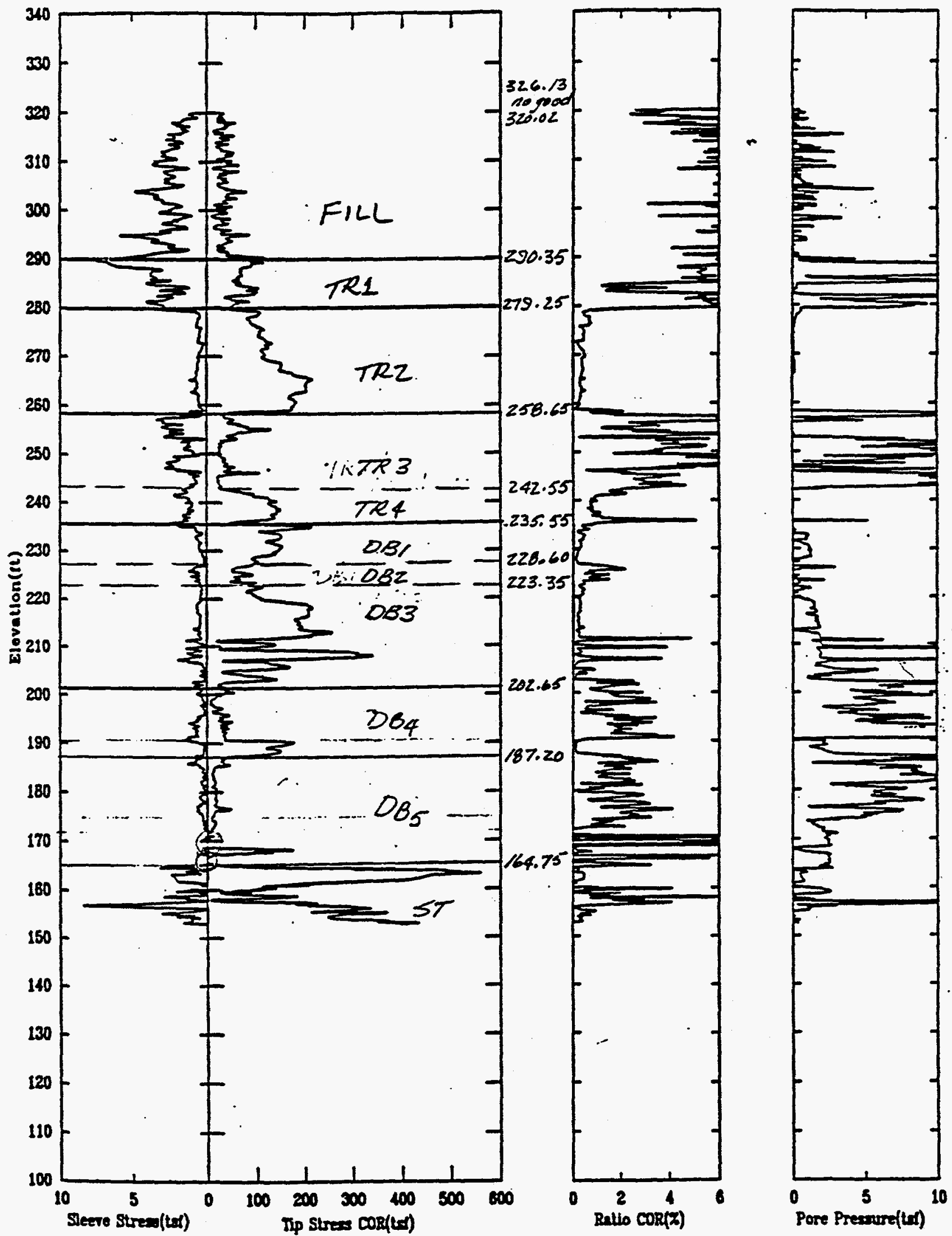
Cote:

ss af tip srstance $7 \pi 2$ $\therefore$ and

antwing
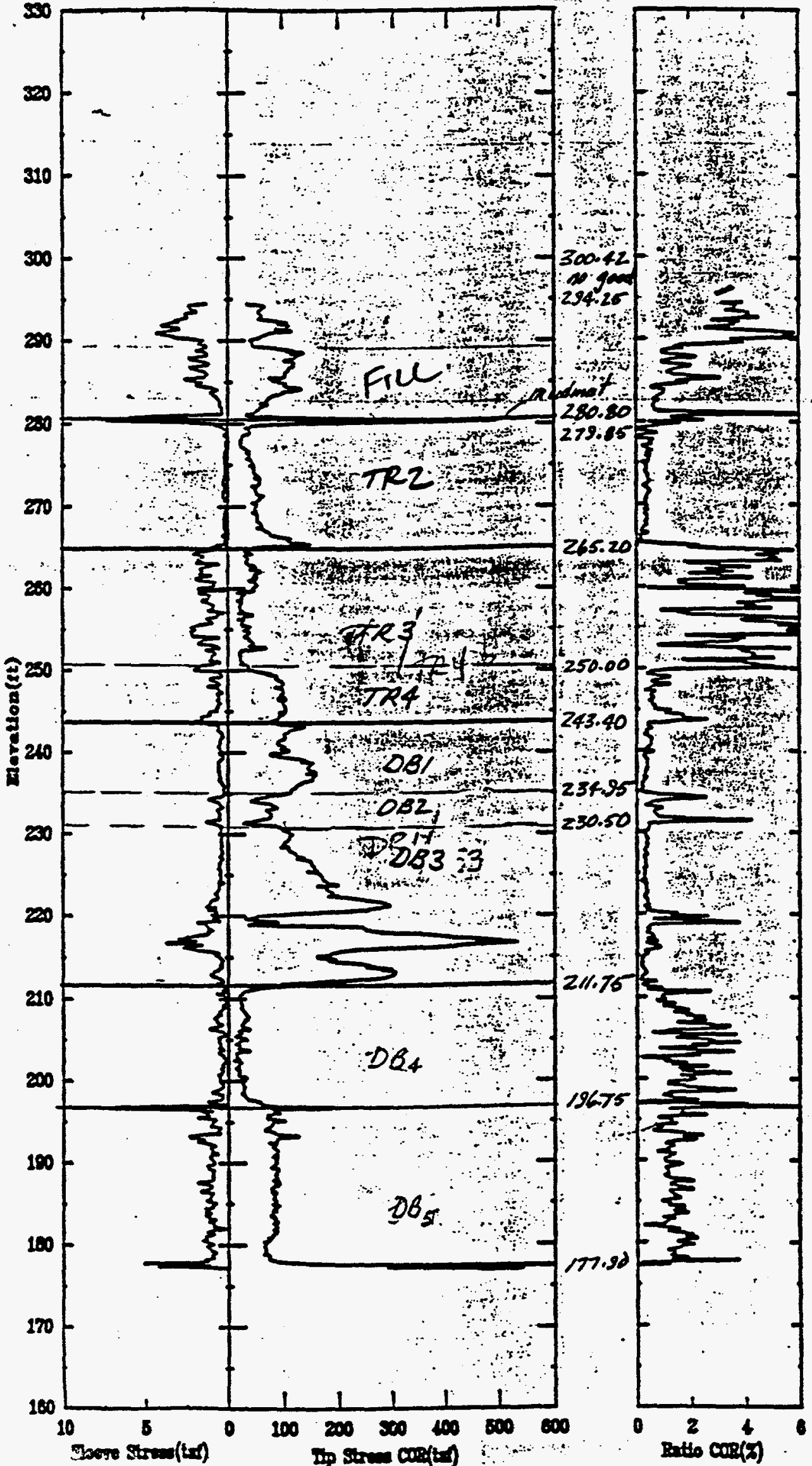

H.

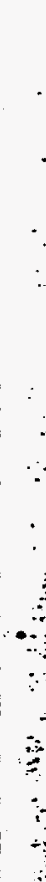

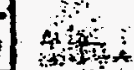

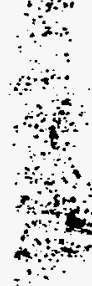

in. .

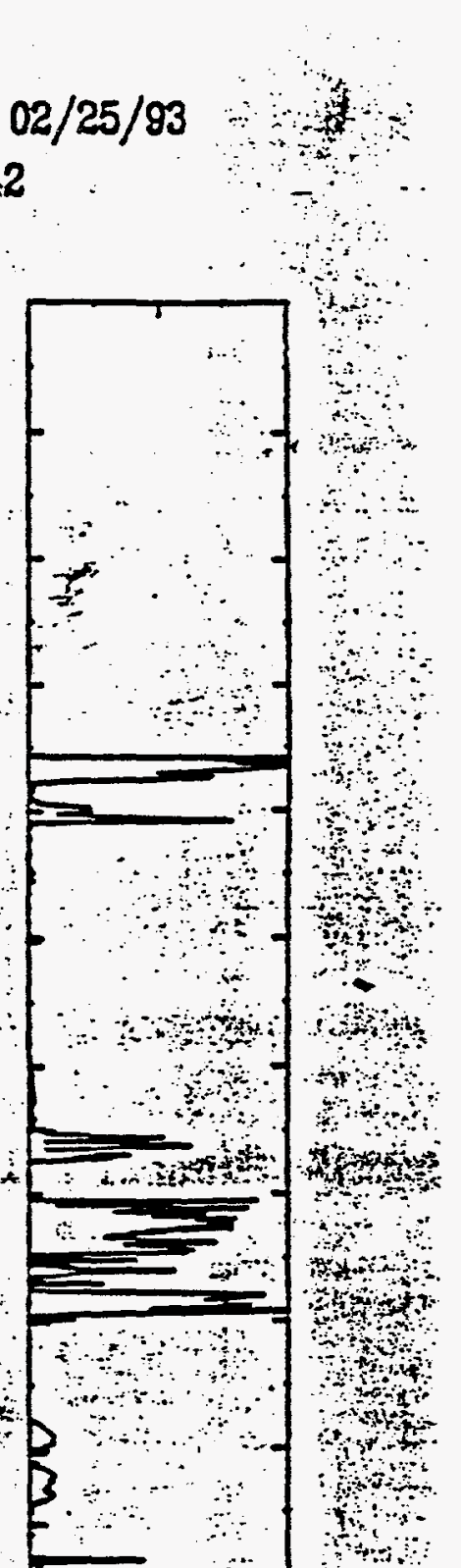

5

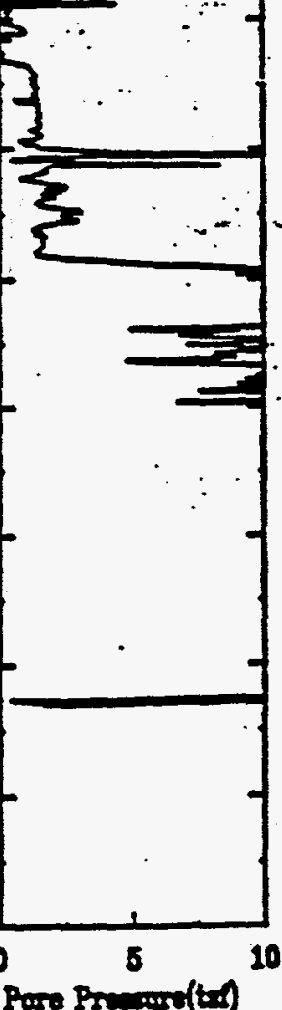



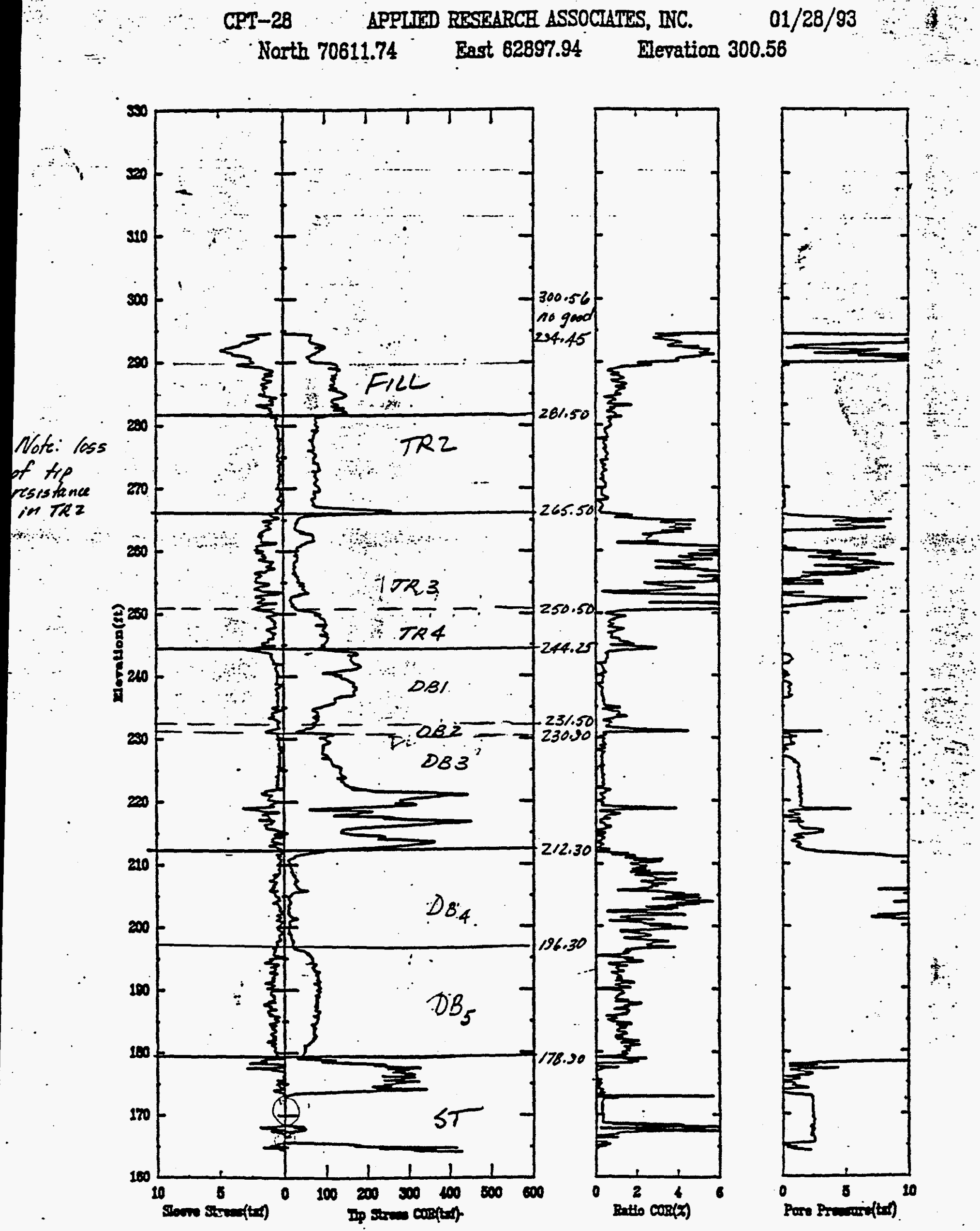
CPT-29 APPLIED RESEARCH ASSOCTATES; INC. 05/17/93 North $71113.00 \quad$ East 62681.30 Mevation 334.43
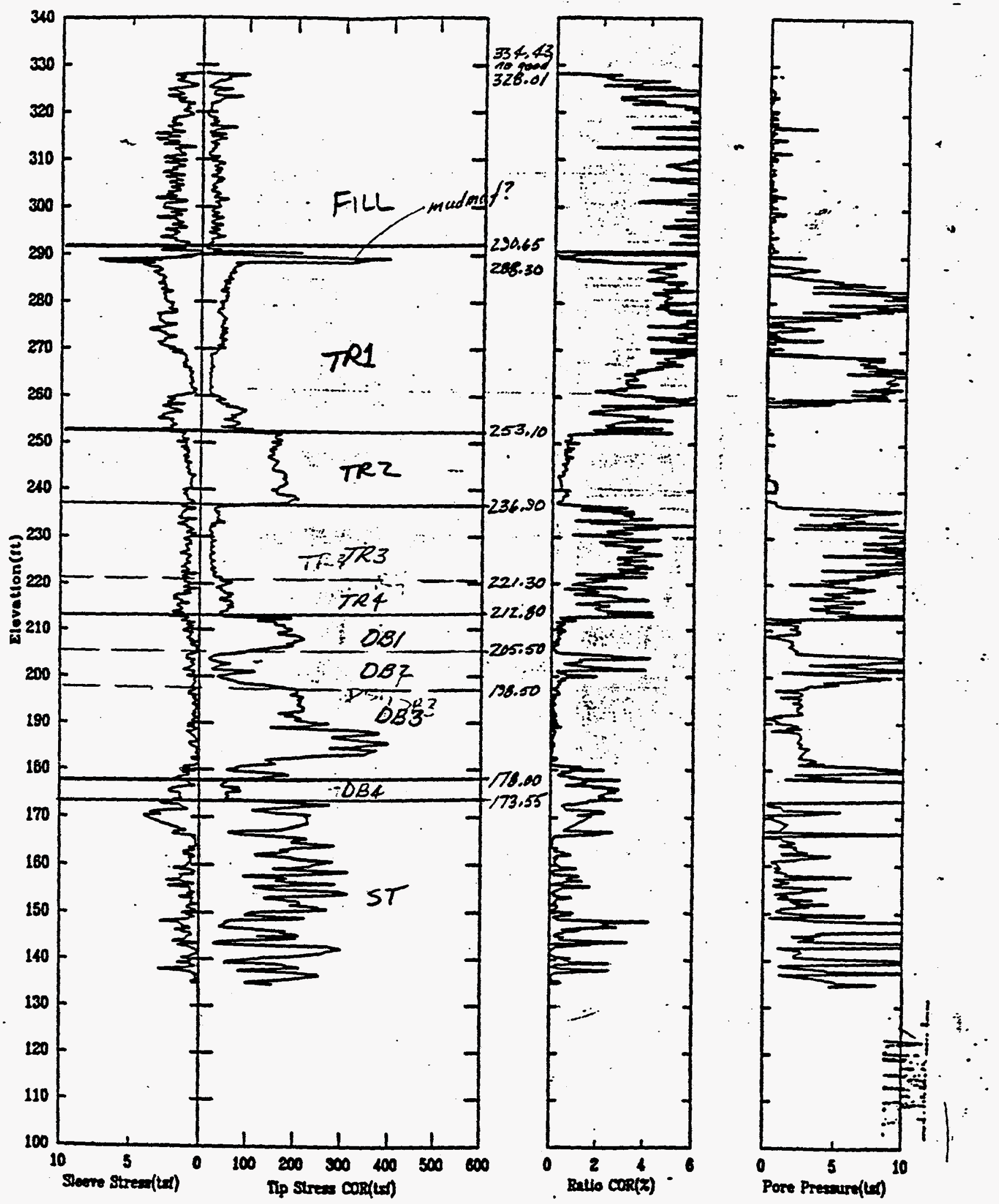
5

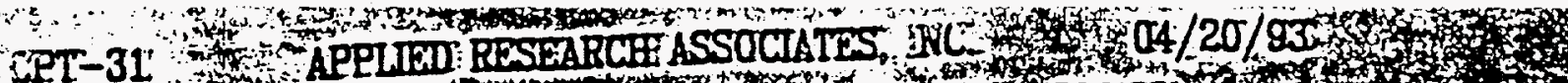

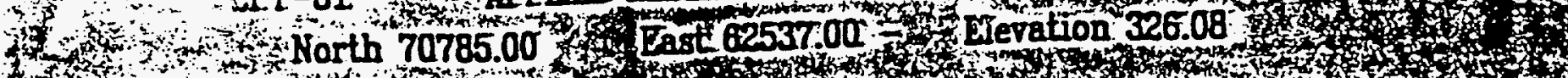

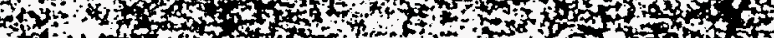
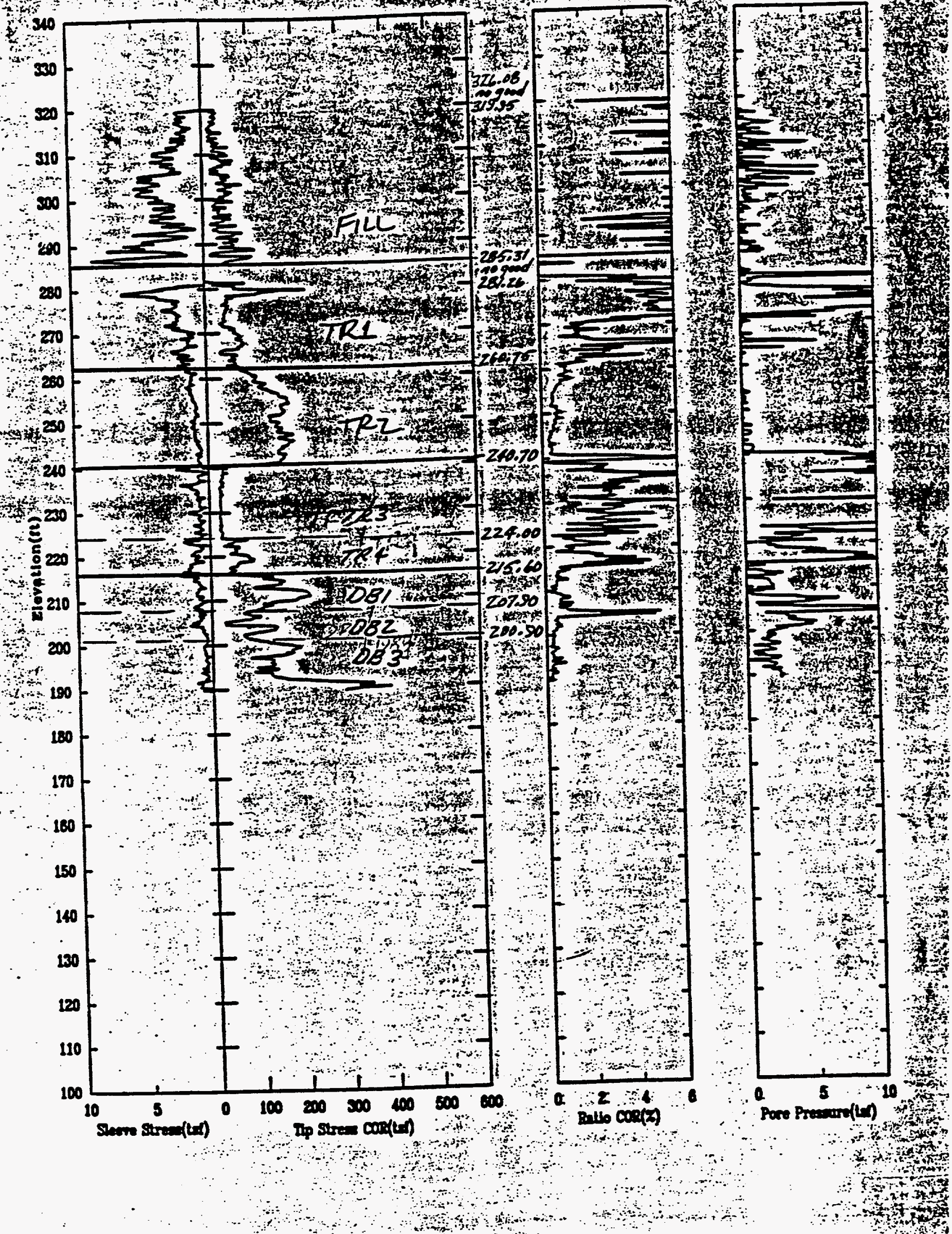


\section{Appendix V}

\section{List of Input Data Files}




\section{LIST OF INPUT DATA FILES}

(Provided by WSRC)

File name

SCPT.ZIP

CPT.ZIP

ITPCPT1.ZIP
Description

This zip-file includes 11 files which are SCPT01.ECG, SCPT05.ECG, SCPT10.ECG, SCPT14.ECG, SCPT18.ECG, SCPT20.ECG, SCPT201.ECG, SCPT202.ECG, SCPT23.ECG, SCPT282.ECG, and SCPT6B.ECG. These files includes Measurement Borehole ID, Northing, Easting, Surface Elevation, Depth, Elevation, Sleeve Stress, Tip Stress Uncorrected (UNC), Tip Stress Corrected (COR), Ratio COR, Pore Pressure, Overburden, Effective Overburden, Wet Density, Relative Density, Classification, and Blow Count.

This zip-file includes 15 files which are CPT11.ECG, CPT16.ECG, CPT25.ECG, CPT26.ECG, CPT28.ECG, CPT29.ECG, CPT30.ECG, CPT31.ECG, CPT32.ECG, CPT32B.ECG, CPT34.ECG, CPT27.ECG, CPT38.ECG, CPT7.ECG, and CPT-11.ECG. These files includes Borehole ID, Northing, Easting, Surface Elevation, Depth, Elevation, Sleeve Stress, Tip Stress UNC, Tip Stress COR, Ratio COR, Pore Pressure, Overburden, Effective Overburden, Wet Density, Relative Density, Classification, and Blow Count.

This is a zip-file of ITPCPT1.DBF. It includes Depth, Elevation, Sleeve Stress, Tip Stress UNC, Tip Stress COR, Ratio, Pore 
Pressure, Total Pressure, Effective Overburden, Wet Density, Relative Density, Classification, Blow Count, and Borehole ID Number.

ITPCPT2.ZIP

This is a zip-file of ITPCPT2.DBF. It includes Depth, Elevation, Sleeve Stress, Tip Stress UNC, Tip Stress COR, Ratio, Pore Pressure, Total Pressure, Effective Overburden, Wet Density, Relative Density, Classification, Blow Count, and Borehole ID Number.

ITPCPT3.ZIP

This is a zip-file of ITPCPT3.DBF. It includes Depth, Elevation, Sleeve Stress, Tip Stress UNC, Tip Stress COR, Ratio, Pore Pressure, Total Pressure, Effective Overburden, Wet Density, Relative Density, Classification, Blow Count, and Borehole ID Number.

ITPSPT.DAT Borehole ID Number, Easting, Northing, Elevation, and Layer markers are listed in this file.

ITPA.ECG

This file includes the coordinates of FLAC element centers of A$A^{\prime}$ section.

ITPB.ECG

This file includes the coordinates of FLAC element centers of B$B^{\prime}$ section.

SWAVE.DAT This file includes Borehole ID Number, Elevation, Shear Wave, and Layer.

SWAVE.COR This file includes Northing, Easting, and Borehole ID Number. SWAVE.STA The Shear Wave Velocity statistics is listed in this file. 
The Layer Shear Wave Velocity statistics is listed in this file.

ITPSPT.DAT This file includes Borehole ID Number, Easting, Northing, Elevation, Blow Count, Layer, and Category.

SR_ITP.DAT This file includes Borehole ID Number, Elevation, Blow Count, and Layer.

N1SIM.DAT

This file includes Easting, Northing, Elevation, Computed Blow Count, Layer, and Borehole ID Number. 
Appendix VI

Regression Analyses and Analysis of Variance 
NTB > READ 'TRI.DAT' C1-C5

38 ROWS READ

$\begin{array}{llllll}\text { ROW } & \mathrm{C} 1 & \mathrm{C} 2 & \mathrm{C} 3 & \mathrm{C} 4 & \mathrm{C} 5\end{array}$

$\begin{array}{rrrrrr}1 & 70.40 & 164.40 & 2.25 & 15.65 & 0.30 \\ 2 & 54.40 & 199.02 & 4.17 & 6.39 & 0.42 \\ 3 & 56.00 & 168.94 & 5.70 & 1.75 & 0.48 \\ 4 & 41.31 & 121.87 & 6.70 & 5.43 & 0.60\end{array}$

MTB > EXEC 'NAMES.PRG'

$M T B$ > NAME $\mathrm{Cl}$ 'N1'

$M T B$ > NAME C2 ' $\mathrm{QC1}$ '

$M T B$ > NAME C3 'FR'

MTB > NAME C4 'PP'

MTB > NAME C5 ' $\mathrm{PO}$ '

MTB > LET C6 $=\mathrm{C} 2 * \mathrm{C} 3$

MTB > LET C7 $=\mathrm{C} 2 * \mathrm{C} 4$

MTB > LET C8 $=\mathrm{C} 2 * \mathrm{C} 5$

MTB > LET C9 $=\mathrm{C} 3 * \mathrm{C} 4$

$\mathrm{MTB}>\mathrm{LET} \mathrm{C} 10=\mathrm{C} 3 * \mathrm{C} 5$

$\mathrm{MTB}>\mathrm{LET} \mathrm{C} 11=\mathrm{C} 4 * \mathrm{C} 5$

$\mathrm{MTB}>\mathrm{LET} \mathrm{C} 12=\mathrm{C} 2 / \mathrm{CI}$

$M T B$ > NAME C6 'QC1XFR'

$M T B$ > NAME C7 'QC1XPP'

MTB > NAME C8 'QCIXPO'

ITB > NAME C9 'FRXPP'

ITB > NAME C10 'FRXPO'

ITB > NAME C11 'PPXPO'

ITB > NAME C12 'QC1/N1'

ITB > NOCONSTANT

ITB > REGRESS C12 ON $10 \mathrm{C} 2-\mathrm{C} 11$ C98 C99

NOTE * FR is highly correlated with other

NOTE * PP is highly correlated with other

NOTE * QC1xFR is highly correlated with other

NOTE * FRXPO is highly correlated with other

NOTE * PPXPO is highly correlated with other

predictor variables predictor variables predictor variables predictor variables predictor variables

The regression equation is

$\mathrm{C} I / \mathrm{NI}=0.0194 \mathrm{QC1}+0.654 \mathrm{FR}-0.206 \mathrm{PP}+2.41 \mathrm{PO}-0.00454 \mathrm{QC1} 1 \times \mathrm{FR}$

+0.00031 QC1XPP + $0.0103 \mathrm{QC1XPO}+0.0165$ FRXPP -0.557 FRXPO

+0.031 PPXPO 


$\begin{array}{lrrrr}\text { Predictor } & \text { Coef } & \text { Stdev } & \text { t-ratio } & p \\ \text { Noconstant } & & & & \\ \text { QCI } & 0.019391 & 0.008288 & 2.34 & 0.027 \\ \text { FR } & 0.6535 & 0.3062 & 2.13 & 0.042 \\ \text { PP } & -0.2063 & 0.2221 & -0.93 & 0.361 \\ \text { PO } & 2.4058 & 0.5065 & 4.75 & 0.000 \\ \text { QC1XFR } & -0.004543 & 0.002283 & -1.99 & 0.056 \\ \text { QC1XPP } & 0.000314 & 0.001111 & 0.28 & 0.780 \\ \text { QC1XPO } & 0.010255 & 0.006897 & 1.49 & 0.148 \\ \text { FRXPP } & 0.01655 & 0.01171 & 1.41 & 0.169 \\ \text { FRXPO } & -0.5565 & 0.1421 & -3.92 & 0.001 \\ \text { PPXPO } & 0.0308 & 0.1075 & 0.29 & 0.776\end{array}$

$s=0.5138$

Analysis of Variance

$\begin{array}{lrrrrr}\text { SOURCE } & \text { DF } & \text { SS } & \text { MS } & \text { F } \\ \text { Regression } & 10 & 279.012 & 27.901 & 105.69 & 0.000 \\ \text { Error } & 28 & 7.392 & 0.264 & & \\ \text { Total } & 38 & 286.404 & & \\ \text { SOURCE } & \text { DF } & \text { SEQ SS } & & \\ \text { DC1 } & 1 & 198.009 & & \\ \text { FR } & 1 & 37.602 & & \\ \text { P } & 1 & 2.241 & & \\ \text { PO } & 1 & 30.525 & & \\ \text { D } 1 \times F R & 1 & 0.306 & & \\ \text { D } 1 \times P P & 1 & 0.719 & & \\ \text { DCIXPO } & 1 & 0.110 & & \\ \text { RXPP } & 1 & 0.621 & & \\ \text { RXPO } & 1 & 8.857 & & \\ \text { PXPO } & 1 & 0.022 & & \end{array}$

Inusual Observations bs.
QC1 QC1/N1
Fit stdev.Fit Residual
St.Resid
1642.3352
0.4807
0.2002
$1.10 \mathrm{X}$
$3 \frac{1}{7}$
0.0000
0.2127
$-1.0104$
2.1351
1.0104
0.4025
$-2.16 R$
116
2.1288
3.0233
$-0.8945$
$-2.80 R$

denotes an obs. with a large st. resid.

denotes an obs. whose $x$ value gives it large influence. 
MTB > DOTPLOT C12

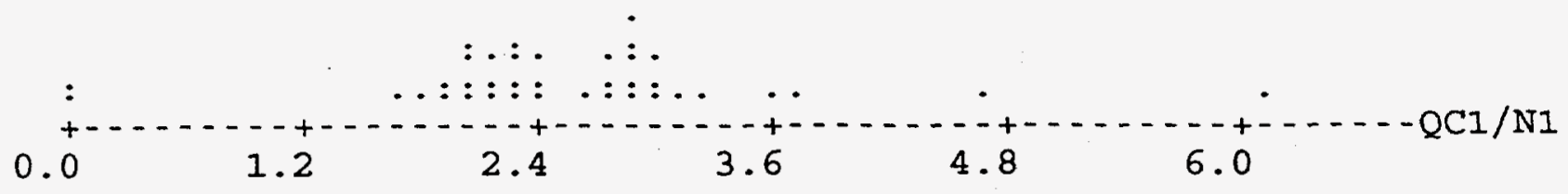

MTB > DOTPLOT C99

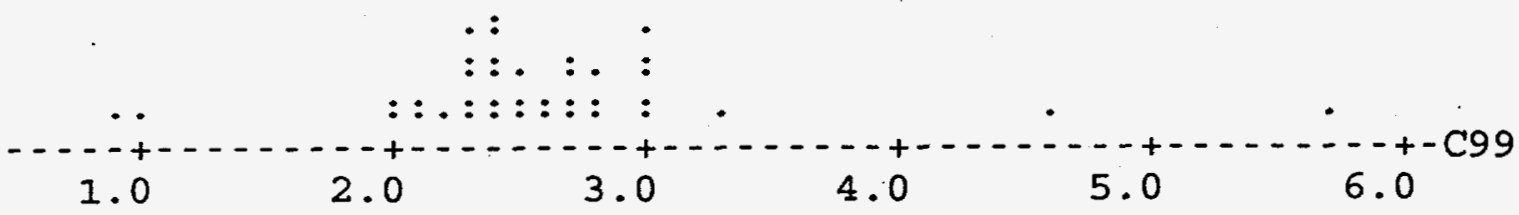

MTB > CORR C12 C99

Correlation of $\mathrm{QC1} / \mathrm{N} 1$ and $\mathrm{C} 99=0.912$

MTB > WRITE 'TR1.OUT' C12 C99

MTB > READ 'TR2A.DAT' C1-C5

12 ROWS READ

$\begin{array}{rrrrrr}\text { ROW } & \text { NI } & \text { QCI } & \text { FR } & \text { PP } & \text { PO } \\ & & & & & \\ 1 & 49.06 & 158.25 & 1.81 & 3.41 & 0.60 \\ 2 & 41.25 & 325.51 & 0.36 & 0.29 & 0.72 \\ 3 & 32.84 & 277.73 & 0.45 & 0.24 & 0.78 \\ 4 & 33.73 & 223.62 & 0.71 & 0.08 & 0.90\end{array}$

ITB > EXEC 'NAMES.PRG'

ITB > NAME C1 'N1'

$\mathrm{ITB}>\mathrm{NAME} \mathrm{C} 2$ ' $\mathrm{QC} 1$ '

ITB > NAME C3 ' $F R$ '

ITB > NAME C4 ' $\mathrm{PP}$ '

ITB > NAME C5 'PO'

ITB > LET $\mathrm{C} 6=\mathrm{C} 2 * \mathrm{C} 3$

ITB > LET C7 $=\mathrm{C} 2 * \mathrm{C} 4$

ITB > LET C8 $=\mathrm{C} 2 * \mathrm{C} 5$

ITB > LET C9 $=\mathrm{C} 3 * \mathrm{C} 4$

TTB > LET $\mathrm{C} 10=\mathrm{C} 3 * \mathrm{C} 5$

ITB > LET C11 $=\mathrm{C} 4 * \mathrm{C5}$

ITB > LET C12 $=\mathrm{C} 2 / \mathrm{C} 1$

ITB > NAME C6 'QC1XFR'

ITB > NAME C7 'QC1XPP'

ITB > NAME C8 'QC1XPO'

ITB > NAME C9 'FRXPP'

ITB > NAME C10 'FRXPO'

TTB > NAME C11 'PPXPO' 
ITB > NAME C12 'QC1/N1'

ITB $>$ NOCONSTANT

ITB > REGRESS C12 ON $10 \quad \mathrm{C} 2-\mathrm{C} 11$ C98 699

FRXPO is highly correlated with other $\mathrm{X}$ variables

FRxPO has been removed from the equation

$\begin{array}{lr}\text { NOTE * } & \text { QC1 is highly correlated with other predictor variables } \\ \text { NOTE * } & \text { FR is highly correlated with other predictor variables } \\ \text { NOTE * } & \text { PP is highly correlated with other predictor variables } \\ \text { NOTE * } & \text { PO is highly correlated with other predictor variables } \\ \text { NOTE * } & \text { QClXFR is highly correlated with other predictor variables } \\ \text { NOTE * } & \text { QCIXPP is highly correlated with other predictor variables } \\ \text { NOTE * } & \text { QClXPO is highly correlated with other predictor variables } \\ \text { NOTE * } & \text { FRXPP is highly correlated with other predictor variables } \\ \text { NOTE * } & \text { PPXPO is highly correlated with other predictor variables }\end{array}$

he regression equation is

$\mathrm{C} 1 / \mathrm{N} 1=-0.111 \mathrm{QC} 1+4.32 \mathrm{FR}-14.7 \mathrm{PP}+3.73 \mathrm{PO}-0.02 \varepsilon 6 \mathrm{QC} 1 \mathrm{xFR}$

- 0.0918 QC1XPP - 0.0929 QC1XPO + 6.45 FRXPP + 25.7 PPXPO

redictor

oconstant

C1

$\mathrm{R}$

Coef

Stdev

$t$-ratio

$\mathrm{p}$

0.11058

4.325

$-14.74$

0.05069

2.18

0.117

5.664

13.91

0.76

0.501

3.732

8.239

CIXFR

$-0.02856$

0.02508

C1XPP

$-0.09184$

0.05911

$-0.09294$

6.449

$\mathrm{RxPP}$

25.75

0.08576

5.323

34.82

$-1.06$

0.367

0.45

0.681

$-1.14$

0.338

$-1.55$

0.218

$-1.08$

0.358

PXPO

1.21

0.312

$=0.8570$

nalysis of Variance

OURCE

egression rror

otal
DF

9

3

12
SS

389.156

2.203

391.359 $\begin{array}{rrr}\text { MS } & F & p \\ 43.240 & 58.87 & 0.003 \\ 0.734 & & \end{array}$ 

$1 / 11 / 95$
Page 5

$\begin{array}{lrr}\text { SOURCE } & \text { DF } & \text { SEQ SS } \\ \text { QC1 } & 1 & 375.065 \\ \text { FR } & 1 & 6.995 \\ \text { PP } & 1 & 0.011 \\ \text { PO } & 1 & 2.204 \\ \text { QCIXFR } & 1 & 0.007 \\ \text { QC1XPP } & 1 & 2.175 \\ \text { QCIXPO } & 1 & 0.413 \\ \text { FR XPP } & 1 & 1.884 \\ \text { PPXPO } & 1 & 0.402\end{array}$

Unusual Observations
bbs.
QC1 $\mathrm{QC1} / \mathrm{N} 1$
Fit Stdev.Fit Residual
St.Resid
$1 \quad 158$
3.226
0.857
0.857
$-0.005$
$-0.013$
$-1.69 X$
5.087
$-1.11 X$

$x$ denotes an obs. whose $x$ value gives it large influence.

MTB > DOTPLOT $\mathrm{C} 12$

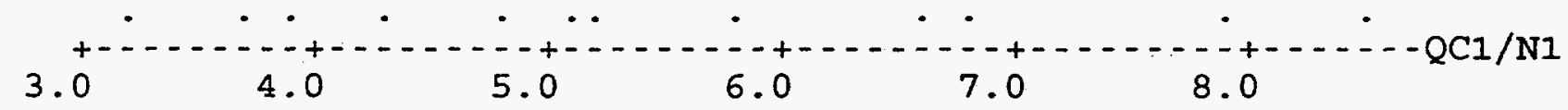

MTB > DOTPLOT C99

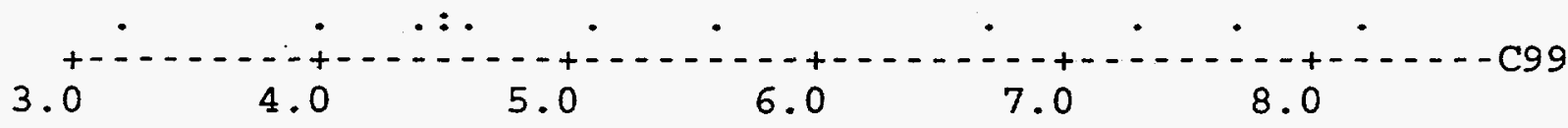

ITB > CORR C12 C99

forrelation of $\mathrm{QC} 1 / \mathrm{N} 1$ and $\mathrm{C} 99=0.964$

ITB > WRITE 'TR2A.OUT' C12 C99 

$1 / 11 / 95$
Page 6

MTB > READ 'TR2B.DAT' CI-C5

63 ROWS READ

$\begin{array}{rrrrrr}\text { ROW } & \text { N1 } & \text { QCI } & \text { FR } & \text { PP } & \text { PO } \\ & & & & & \\ 1 & 6.67 & 104.34 & 1.00 & 0.12 & 1.82 \\ 2 & 11.70 & 126.25 & 0.72 & 0.27 & 1.87 \\ 3 & 15.24 & 120.76 & 0.73 & 0.10 & 1.90 \\ 4 & 10.71 & 103.33 & 0.88 & -0.42 & 1.96\end{array}$

TTB > EXEC 'NAMES.PRG'

ITB > NAME $\mathrm{Cl}$ ' $\mathrm{N} 1$ '

TTB > NAME C2 ' $\mathrm{QC1}$ '

ITB > NAME C3 'FR'

ITB > NAME C4 'PP'

ITB > NAME C5 'PO'

TTB > LET C6 $=\mathrm{C} 2 * \mathrm{C} 3$

$\mathrm{ATB}>\mathrm{LET} \mathrm{C7}=\mathrm{C} 2 * \mathrm{C} 4$

ITB $>$ LET C8 $=\mathrm{C} 2 * \mathrm{C} 5$

ITB $>$ LET C9 $=\mathrm{C} 3 * \mathrm{C} 4$

$\mathrm{TTB}>\mathrm{LET} \mathrm{C} 10=\mathrm{C} 3 * \mathrm{C} 5$

IT'B $>$ LET C11 $=\mathrm{C} 4 * \mathrm{C} 5$

$\mathrm{ITB}>\mathrm{LET} \mathrm{C} 12=\mathrm{C} 2 / \mathrm{Cl}$

$\mathrm{TB}>$ NAME C6 'QC1XFR'

$\mathrm{TB}>$ NAME C7 'QC1XPP'

$\mathrm{TB}>\mathrm{NAME} \mathrm{C} 8$ ' $^{\mathrm{Q}} \mathrm{QCIXPO}$

TB > NAME C9 'FRXPP'

$\mathrm{TB}>\mathrm{NAME} \mathrm{C} 10$ 'ERXPO'

$\mathrm{TB}>\mathrm{NAME} \mathrm{C} 11$ 'PPXPO'

$\mathrm{TB}>\mathrm{NAME} \mathrm{C} 12$ ' $\mathrm{QC} 1 / \mathrm{N1}$ '

$\mathrm{TB}>$ NOCONSTANT

TB > REGRESS C12 ON 10 C2-C11 C98 C99

NOTE *

NOTE *

FR is highly correlated with other

$P P$ is highly correlated with other

NOTE * FRXPO is highly correlated with other

NOTE * PPXPO is highly correlated with other predictor variables

predictor variables

predictor variables

predictor variables

he regression equation is

$\mathrm{C} 1 / \mathrm{N} 1=0.0496 \mathrm{QC} 1-3.69 \mathrm{FR}-2.27 \mathrm{PP}+4.06 \mathrm{PO}+0.0215 \mathrm{QC} 1 \times \mathrm{FR}$

+0.0351 QClXPP - 0.0357 QC1XPO + 1.04 FRXPP + 1.09 FRXPO

-0.3 .97 PPXPO 

$1 / 11 / 95$
Page 7

Predictor

Noconstant

QC1

FR

$\mathrm{PP}$

PO

QC1XFR

QC1XPP

QC1XPO

FRXPP

FRXPO

PPXPO

$$
\begin{array}{r}
\text { Coef } \\
0.04955 \\
-3.693 \\
-2.270 \\
4.061 \\
0.021475 \\
0.03508 \\
-0.03565 \\
1.0414 \\
1.090 \\
-0.3974
\end{array}
$$

$$
\begin{array}{r}
\text { Stdev } \\
0.01284 \\
1.918 \\
2.926 \\
1.031 \\
0.007148 \\
0.01143 \\
0.01066 \\
0.7062 \\
1.162 \\
0.7705
\end{array}
$$

t-ratio

$$
\begin{array}{r}
3.86 \\
-1.93 \\
-0.78 \\
3.94 \\
3.00 \\
3.07 \\
-3.34 \\
1.47 \\
0.94 \\
-0.52
\end{array}
$$$$
0.000
$$$$
0.060
$$$$
0.441
$$$$
0.000
$$$$
0.004
$$$$
0.003
$$$$
0.002
$$$$
0.146
$$$$
0.352
$$$$
0.608
$$

$s=2.155$

Analysis of Variance

$\begin{array}{lrrrrr}\text { SOURCE } & \text { DF } & \text { SS } & \text { MS } & \text { F } & \text { p } \\ \text { Regression } & 10 & 2358.26 & 235.83 & 50.80 & 0.000 \\ \text { Error } & 53 & 246.02 & 4.64 & & \\ \text { Total } & 63 & 2604.28 & & \\ \text { SOURCE } & \text { DF } & \text { SEQ SS } & & \\ \text { QC1 } & 1 & 2182.18 & & \\ \text { FR } & 1 & 46.43 & & \\ \text { PP } & 1 & 4.94 & & \\ \text { PO } & 1 & 18.19 & & \\ \text { DC1XFR } & 1 & 24.31 & & \\ \text { DC1XPP } & 1 & 21.52 & & \\ \text { DC1XPO } & 1 & 34.88 & & \\ \text { FRXPP } & 1 & 20.85 & & \\ \text { FRXPO } & 1 & 3.72 & & \\ \text { PPXPO } & 1 & 1.23 & & & \\ \end{array}$

Inusual Observations

$\begin{array}{crrrrrr}\text { Dbs. } & \text { QC1 } & \text { QC1/N1 } & \text { Fit } & \text { Stdev.Fit } & \text { Residual } & \text { St.Resid } \\ 1 & 104 & 15.643 & 6.527 & 0.379 & 9.117 & 4.30 \mathrm{R} \\ 37 & 40 & 2.280 & 2.279 & 2.106 & 0.002 & 0.00 \mathrm{X} \\ 47 & 82 & 11.268 & 5.705 & 0.487 & 5.564 & 2.65 \mathrm{R} \\ 53 & 24 & 3.707 & 3.800 & 2.006 & -0.094 & -0.12 \mathrm{X} \\ 54 & 242 & 4.993 & 8.881 & 0.951 & -3.888 & -2.01 \mathrm{R} \\ 56 & 351 & 14.403 & 12.530 & 1.588 & 1.873 & 1.29 \mathrm{X} \\ 57 & 262 & 13.914 & 15.012 & 1.975 & -1.099 & -1.27 \mathrm{X} \\ 61 & 24 & 2.335 & 2.365 & 1.820 & -0.030 & -0.03 \mathrm{X}\end{array}$


$R$ denotes an obs. with a large st. resid.

$X$ denotes an obs. whose $X$ value gives it large influence.

MTB > DOTPLOT C12

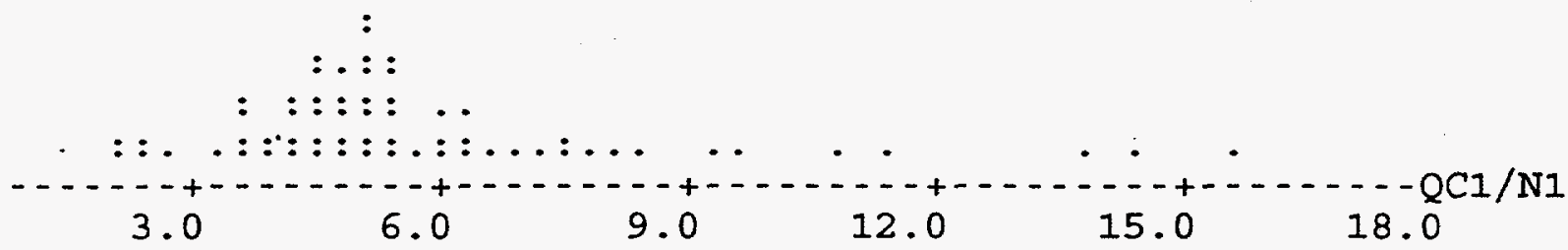

MTB > DOTPLOT C99

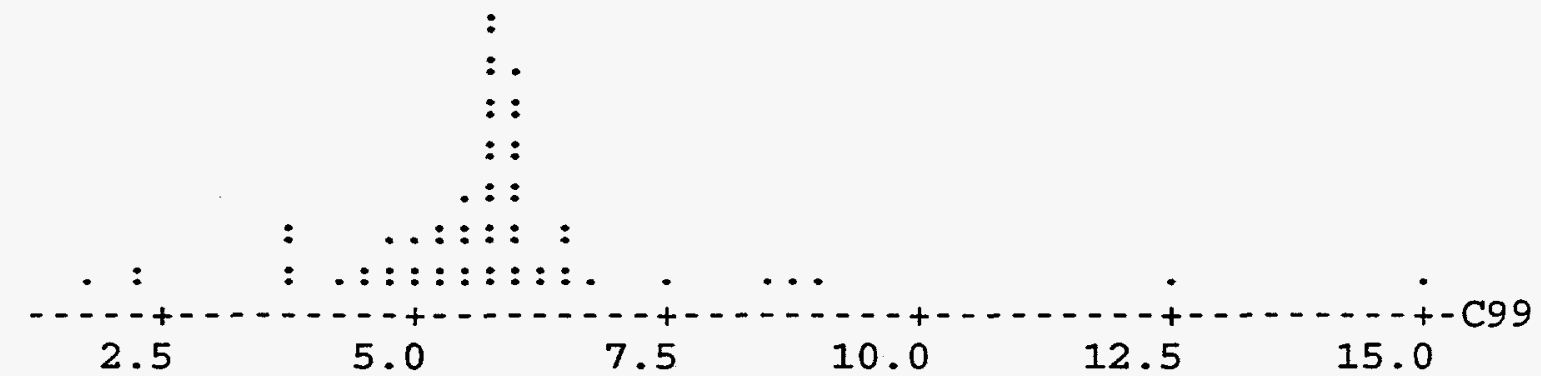

MTB > CORR C12 C99

Forrelation of $\mathrm{QC1} / \mathrm{N} 1$ and $\mathrm{C} 99=0.691$

ITB > WRITE 'TR2B.OUT' C12 C99

ITB > READ 'TR34.DAT' C1-C5

137 ROWS READ

$\begin{array}{llllll}\text { ROW } & \text { N1 } & \text { QC1 } & \text { FR } & \text { PP } & \text { PO }\end{array}$

$\begin{array}{rrrrrr}1 & 10.04 & 26.67 & 2.62 & 9.94 & 2.54 \\ 2 & 10.60 & 34.28 & 2.84 & 5.95 & 2.57 \\ 3 & 6.80 & 16.01 & 3.51 & 11.26 & 2.62 \\ 4 & 7.99 & 16.23 & 3.25 & 13.29 & 2.65\end{array}$



REGRESS . TXT
$1 / 11 / 95$
Page 9

MTB > EXEC 'NAMES.PRG'

$M T B$ > NAME C1 'N1'

$M T B$ > NAME C2 ' $\mathrm{QC1}$ '

$M T B$ > NAME C3 ' $F R '$

MTB > NAME C4 'PP'

$\mathrm{MTB}>$ NAME C5 ' $\mathrm{PO}$ '

$\mathrm{MTB}>\mathrm{LET} \mathrm{C} 6=\mathrm{C} 2 * \mathrm{C} 3$

$\mathrm{MTB}>\mathrm{LET} \mathrm{C7}=\mathrm{C} 2 * \mathrm{C} 4$

$\mathrm{MTB}>\mathrm{LET} \mathrm{C} 8=\mathrm{C} 2 * \mathrm{C} 5$

$\mathrm{MTB}>\mathrm{LET}$ C9 $=\mathrm{C} 3 * \mathrm{C} 4$

MTB > LET C10 = C $3 * \mathrm{C} 5$

MTB > LET C11 $=\mathrm{C} 4 * \mathrm{C} 5$

MTB > LET C12 = C2 $/ \mathrm{C} 1$

$M T B$ > NAME C6 'QCIXFR'

$M T B$ > NAME C7 'QCIXPP'

$M T B>$ NAME C8 'QCIXPO'

MTB > NAME C9 'ERXPP'

MTB > NAME C10 'FRXPO'

MTB > NAME C11 'PPXPO'

$\mathrm{MTB}>\mathrm{NAME} \mathrm{C} 12$ ' $\mathrm{QC} 1 / \mathrm{N1}$ '

MTB > NOCONSTANT

MTB > REGRESS C12 ON $10 \mathrm{C} 2-\mathrm{C} 11 \mathrm{C} 98 \mathrm{C} 99$

* NOTE * FR is highly correlated with other predictor variables NOTE * PP is highly correlated with other predictor variables NOTE * QC1XPO is highly correlated with other predictor variables NOTE * PPXPO is highly correlated with other predictor variables

The regression equation is

$\mathrm{QC} 1 / \mathrm{N} 1=-0.0410 \mathrm{QC1}+0.380 \mathrm{FR}+0.211 \mathrm{PP}+2.33 \mathrm{PO}+0.0108 \mathrm{QCIXFR}$

-0.0297 QC1XPP + 0.0423 QC1XPO + 0.0714 FRXPP -0.398 FRXPO

-0.060 PPXPO

$\begin{array}{lrrrr}\text { Predictor } & \text { Coef } & \text { Stdev } & \text { t-ratio } & p \\ \text { Joconstant } & & & & \\ \text { DC1 } & -0.04099 & 0.04533 & -0.90 & 0.368 \\ \text { R } & 0.3796 & 0.5950 & 0.64 & 0.525 \\ \text { P } & 0.2110 & 0.4509 & 0.47 & 0.641 \\ \text { P } & 2.3289 & 0.4961 & 4.69 & 0.000 \\ \text { C1XFR } & 0.01077 & 0.01439 & 0.75 & 0.456 \\ \text { C1XPP } & -0.029725 & 0.006858 & -4.33 & 0.000 \\ \text { CIXPO } & 0.04231 & 0.02301 & 1.84 & 0.068 \\ \text { RXPP } & 0.07138 & 0.05186 & 1.38 & 0.171 \\ \text { RXPO } & -0.3980 & 0.2434 & -1.64 & 0.104 \\ \text { PXPO } & -0.0605 & 0.1172 & -0.52 & 0.607\end{array}$

$=2.243$

nalysis of Variance

$\begin{array}{lrrrrr}\text { OURCE } & \text { DF } & \text { SS } & \text { MS } & \text { F } & \text { p } \\ \text { egression } & 10 & 4226.02 & 422.60 & 84.04 & 0.000 \\ \text { rror } & 127 & 638.66 & 5.03 & & \\ \text { otal } & 137 & 4864.68 & & & \end{array}$



$1 / 11 / 95$
Page 10

$\begin{array}{lrr}\text { SOURCE } & \text { DF } & \text { SEQ SS } \\ \text { QC1 } & 1 & 3828.96 \\ \text { FR } & 1 & 20.05 \\ \text { PP } & 1 & 17.72 \\ \text { PO } & 1 & 180.46 \\ \text { QC1XFR } & 1 & 36.32 \\ \text { QC1XPP } & 1 & 97.02 \\ \text { QC1XPO } & 1 & 2.07 \\ \text { FRXPP } & 1 & 22.61 \\ \text { PRXPO } & 1 & 19.46 \\ \text { PPXPO } & 1 & 1.34\end{array}$

Inusual Observations

bbs. $\quad \mathrm{QC1} \quad \mathrm{QC} 1 / \mathrm{N} 1$

16

69.8

3.902

Fit Stdev.Fit Residual

St.Resid

$57.2 \quad 5.636$

8.879

$-4.976$

2.372

$-2.69 R X$

$32.7 \quad 5.258$

1.218

$1.26 \mathrm{X}$

$43 \quad 32.7$

3.264

4.311

2. $08 \mathrm{R}$

9.439

0.863

5.435

2. 48R

$43.6 \quad 12.089$

$4.004 \quad 0.484$

5.140

2. 3IR

$49.7 \quad 14.003$

0.298

6.416

2. $89 \mathrm{R}$

$51.0 \quad 14.655$

7.587

6.610

$2.98 \mathrm{R}$

23.7

1.783

0.343

0.255

$0.31 \mathrm{X}$

1.528

2.088

$-1.515$

$\begin{array}{ll}10.0 & 2.209 \\ 12.4 & 2.557\end{array}$

1.094

$-0.845$

$-0.77 x$

$44.6 \quad 3.799$

3.402

1.140

$-5.050$

$-0.44 X$

$58.7 \quad 15.000$

0.611

$-2.34 R$

9.590

0.546

5.410

$2.49 \mathrm{R}$

$39.5 \quad 15.449$

0.428

7.230

$3.28 R$

denotes an obs. with a large st. resid.

denotes an obs. whose $x$ value gives it large influence.

TTB > DOTPLOT C12

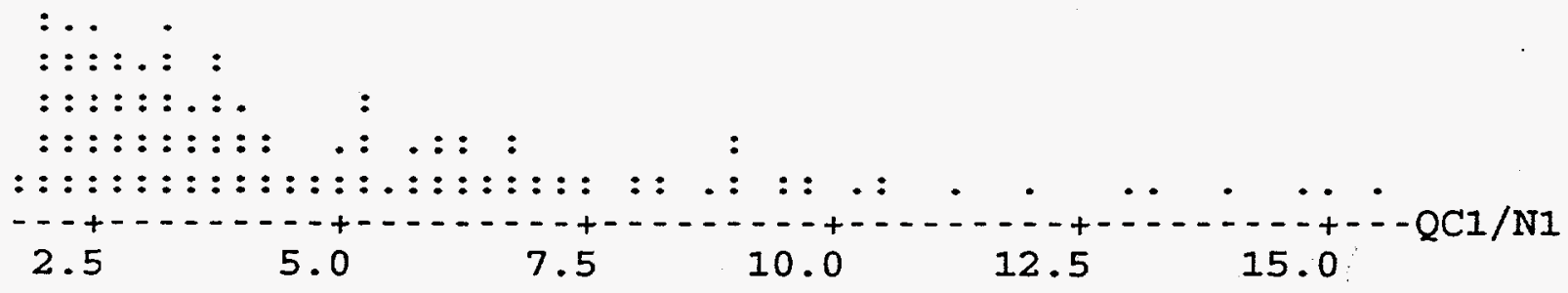


MTB > DOTPLOT C99

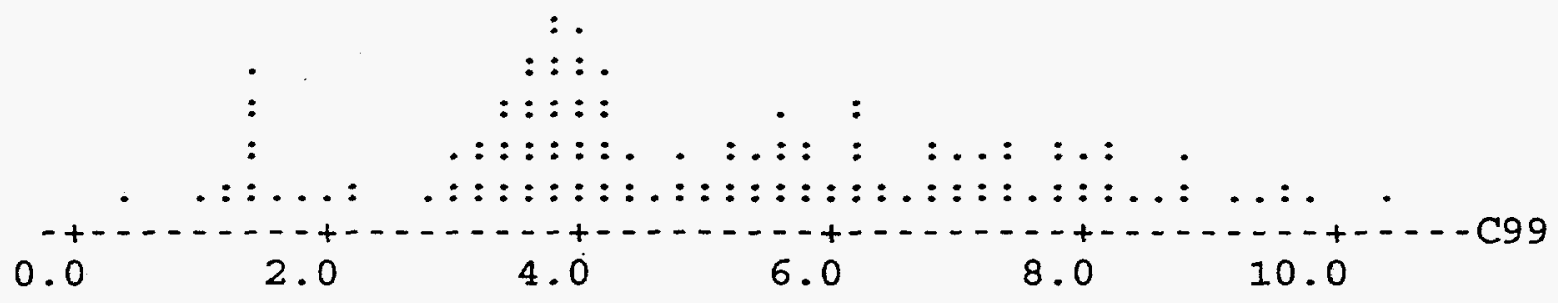

MTB > CORR C12 C99

Correlation of $\mathrm{QC1} / \mathrm{N} 1$ and $\mathrm{C} 99=0.716$

MTB > WRITE 'TR34.OUT' C12 C99

$M T B>$ READ 'DB13.DAT' C1-C5

128 ROWS READ

$\begin{array}{llllll}\text { ROW } & -\mathrm{N} 1 & \text { QC1 } & \text { FR } & \text { PP } & \text { PO }\end{array}$

$\begin{array}{rrrrrr}1 & 23.26 & 80.37 & 0.55 & 2.23 & 3.26 \\ 2 & 33.08 & 105.37 & 0.50 & 1.34 & 3.29 \\ 3 & 29.00 & 85.98 & 0.46 & 1.26 & 3.34 \\ 4 & 11.44 & 47.53 & 1.06 & 2.54 & 3.37\end{array}$

ITB > EXEC 'NAMES.PRG'

ITB > NAME $\mathrm{Cl}$ ' $\mathrm{N} 1$ '

ITB > NAME C2 ' $\mathrm{QC1}$ '

ITB > NAME C3 'FR'

ITB > NAME C4 'PP'

ITB > NAME C5 'PO'

$\mathrm{ATB}>\mathrm{LET} \mathrm{C} 6=\mathrm{C} 2 * \mathrm{C} 3$

$\mathrm{ITB}>\mathrm{LET} \mathrm{C} 7=\mathrm{C} 2 * \mathrm{C} 4$

ITB $>$ LET C8 $=\mathrm{C} 2 * \mathrm{C} 5$

ITB > LET C9 = C3*C4

ITB > LET C10 = C3*C5

ITB > LET C11 $=\mathrm{C} 4 * \mathrm{C} 5$

$\mathrm{ITB}>\mathrm{LET} \mathrm{C} 12=\mathrm{C} 2 / \mathrm{C} 1$

ITB > NAME C6 'OC1XFR'

ITB > NAME C7 'OC1XPP'

TTB > NAME C8 'QC1XPO'

TTB > NAME C9 'FRXPP'

ITB > NAME C10 'FRXPO'

TB > NAME C11 'PPXPO' 
$\mathrm{TB}>\mathrm{NAME} \mathrm{Cl2}$ ' $\mathrm{QCl} / \mathrm{NI}$ '

TTB $>$ NOCONSTANT

TTB > REGRESS C12 ON 10 C2-C11 C98 C99

NOTE * QC1 is highly correlated with other predictor variables NOTE * PP is highly correlated with other predictor variables NOTE * QClxPO is highly correlated with other predictor variables NOTE * FRXPO is highly correlated with other predictor variables NOTE * PPXPO is highly correlated with other predictor variables

he regression equation is

$\mathrm{C} 1 / \mathrm{N} 1=0.225 \mathrm{QC} 1+7.77 \mathrm{FR}-7.73 \mathrm{PP}+7.36 \mathrm{PO}-0.0780 \mathrm{QC} 1 \times \mathrm{FR}$ +0.0573 QC1XPP - 0.106 QC1XPO + 1.82 FRXPP - 4.098 FRXPO

+0.685 PPXPO

$\begin{array}{lrrrr}\text { redictor } & \text { Coef } & \text { Stdev } & \text { t-ratio } & p \\ \text { Oconstant } & & & & \\ \text { C1 } & 0.22459 & 0.08566 & 2.62 & 0.010 \\ \text { R } & 7.766 & 9.826 & 0.79 & 0.431 \\ \text { P } & -7.734 & 4.338 & -1.78 & 0.077 \\ \text { O } & 7.360 & 1.972 & 3.73 & 0.000 \\ \text { C1XFR } & -0.07795 & 0.09740 & -0.80 & 0.425 \\ \text { C1XPP } & 0.05728 & 0.02999 & 1.91 & 0.059 \\ \text { C1XPO } & -0.10617 & 0.03031 & -3.50 & 0.001 \\ \text { RXPP } & 1.825 & 1.297 & 1.41 & 0.162 \\ \text { RXPO } & -4.076 & 4.045 & -1.01 & 0.316 \\ \text { PXPO } & 0.6852 & 0.9858 & 0.70 & 0.488\end{array}$

$=8.003$

nalysis of Variance

\begin{tabular}{|c|c|c|c|c|c|}
\hline DURCE & $\mathrm{DF}$ & SS & MS & F & \\
\hline egression & 10 & 11551.0 & 1155.1 & 18.03 & 0.000 \\
\hline rror & 118 & 7558.5 & 64.1 & & \\
\hline btal & 128 & 19109.5 & & & \\
\hline DURCE & DF & SEQ SS & & & \\
\hline $\mathrm{CI}$ & 1 & 8945.2 & & & \\
\hline R & 1 & 193.6 & & & \\
\hline p & 1 & 309.1 & & & \\
\hline p & 1 & 688.7 & & & \\
\hline C1XFR & 1 & 114.1 & & & \\
\hline $1 \times 1 \times P P$ & 1 & 207.8 & & & \\
\hline C1XPO & 1 & 960.8 & & & \\
\hline$R \times P P$ & 1 & 65.4 & & & \\
\hline $\mathrm{RxPO}$ & 1 & 35.3 & & $\ldots$ & \\
\hline PXPO & 1 & 30.9 & & & \\
\hline
\end{tabular}

husual Observations

Fit Stdev.Fit Residual 2.474

5.305

4.151

1.812

6.287

9.729

4.175

12.214

10.430
4.379

5.885

4.481

4.208

4.254

3.949

5.709

1.274

1.153
$-0.441$

$-3.636$

2.231

3. 055

$-3.382$

$-6.776$

$-0.558$

41.715

38.591
St.Resid

$-0.07 x$

$-0.67 x$

$0.34 \mathrm{X}$

$0.45 \mathrm{X}$

$-0.50 x$

$-0.97 x$

$-0.10 \mathrm{X}$

$5.28 \mathrm{R}$

$4.87 \mathrm{R}$ 


$\begin{array}{rr}86 & 35.449 \\ 108 & 29.975 \\ 31 & 3.371 \\ 90 & 26.735\end{array}$
10.524
9.475
10.155

1.126

24.925

$3.15 R$

80

91

90

1.370

20.500

2. $60 \mathrm{R}$

4.248

$-6.784$

1.408

16.016

$-1.00 \mathrm{X}$

2.03R

$R$ denotes an obs. with a large st. resid.

$X$ denotes an obs. whose $X$ value gives it large influence.

MTB > DOTPLOT C12

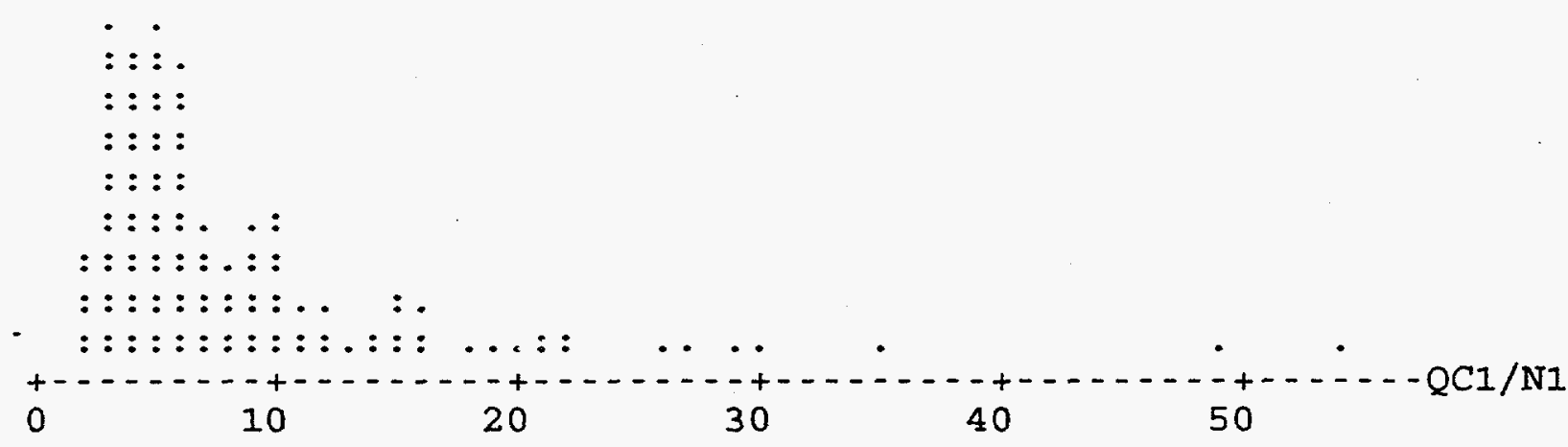

ITB > DOTPLOT C99

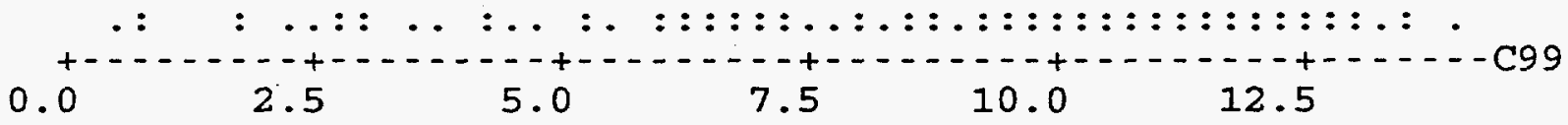

$\mathrm{TB}>$ CORR C12 C99

orrelation of $\mathrm{QC} 1 / \mathrm{N} 1$ and $\mathrm{C} 99=0.377$

TB > NOTE REMOVE ALL OBSERVATIONS WITH QCI/N1 > 25

OTE $\star \star \star$ Data Editor entered at this point.

TB > REGRESS C12 ON 10 C2-C11 C98 C99

NOTE * QC1 is highly correlated with other predictor variables NOTE * PP is highly correlated with other NOTE * QC1XPO is highly correlated with other NOTE * FRxPO is highly correlated with other NOTE * PPXPO is highly correlated with other predictor variables predictor variables predictor variables predictor variables

he regression equation is

$\mathrm{C} 1 / \mathrm{N} 1=0.140 \mathrm{QC1}+8.03 \mathrm{FR}-5.76 \mathrm{PP}+5.29 \mathrm{PO}-0.0233 \mathrm{QC} 1 \times \mathrm{XFR}$

+0.0269 QC1XPP - 0.0658 QC1XPO + 1.24 FRXPP - 4.17 FRXPO

+0.795 PPXPO

cedictor

constant

1

s

IXFR

$\operatorname{IXPP}$

$1 \times P O$

\section{Coef}

0.13976

8.029

$-5.761$

5.289

$-0.02332$

0.02689

$-0.06576$

\section{Stdev}

0.04858

5.532

2.478

1.130

0.05503

0.01697

0.01718 t-ratio

2.88

1.45

$-2.33$

4.68

$-0.42$

1.58

$-3.83$ $\mathrm{p}$

0.005

0.150

0.022

0.000

0.673

0.116

0.000 
FR $\times P P$

FRXPO
1. 2438

$-4.172$
0.7364

1.69

$-1.82$

0.094

0.071 

$1 / 11 / 95$
Page 14
$\mathrm{PPxPO}$
0.7952
0.5587
1.42
0.157

$=4.474$

Analysis of Variance

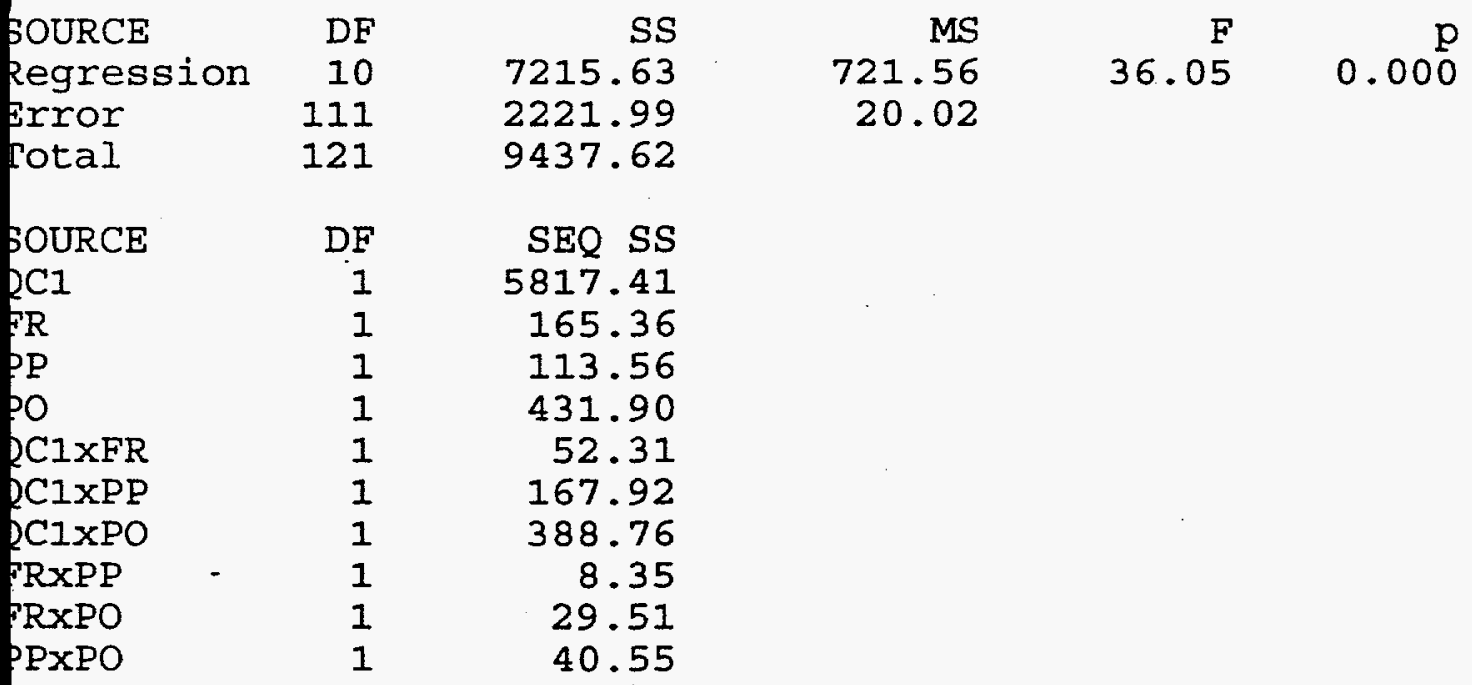

Inusual Observations

\begin{tabular}{lrrrrrr} 
bbs. & QCI & QC1/N1 & \multicolumn{1}{c}{ Fit } & Stdev.Fit & Residual & St.Resid \\
20 & 45 & 2.033 & 1.863 & 2.451 & 0.170 & $0.05 \mathrm{X}$ \\
21 & 34 & 1.669 & 5.289 & 3.310 & -3.619 & $-1.20 \mathrm{X}$ \\
22 & 41 & 6.382 & 3.307 & 2.509 & 3.075 & $0.83 \mathrm{X}$ \\
25 & 101 & 21.487 & 6.449 & 1.033 & 15.038 & $3.45 \mathrm{R}$ \\
28 & 38 & 4.867 & 3.883 & 2.367 & 0.984 & $0.26 \mathrm{X}$ \\
56 & 105 & 2.906 & 5.792 & 2.382 & -2.886 & $-0.76 \mathrm{X}$ \\
57 & 144 & 2.953 & 7.184 & 2.230 & -4.232 & $-1.09 \mathrm{X}$ \\
61 & 39 & 3.617 & 3.526 & 3.192 & 0.090 & $0.03 \mathrm{X}$ \\
62 & 93 & 19.584 & 8.371 & 1.015 & 11.213 & $2.57 \mathrm{R}$ \\
64 & 89 & 22.425 & 8.800 & 0.762 & 13.624 & $3.09 \mathrm{R}$ \\
67 & 41 & 21.497 & 8.804 & 1.547 & 12.693 & $3.02 \mathrm{R}$ \\
75 & 31 & 3.371 & 8.344 & 2.395 & -4.973 & $-1.32 \mathrm{X}$ \\
90 & 81 & 19.097 & 9.637 & 0.729 & 9.460 & $2.14 \mathrm{R}$ \\
99 & 68 & 21.732 & 8.242 & 0.828 & 13.491 & $3.07 \mathrm{R}$ \\
20 & 105 & 18.243 & 7.323 & 0.652 & 10.921 & $2.47 \mathrm{R}$
\end{tabular}

denotes an obs. with a large st. resid.

denotes an obs. whose $x$ value gives it large influence. 
MTB > DOTPLOT C12

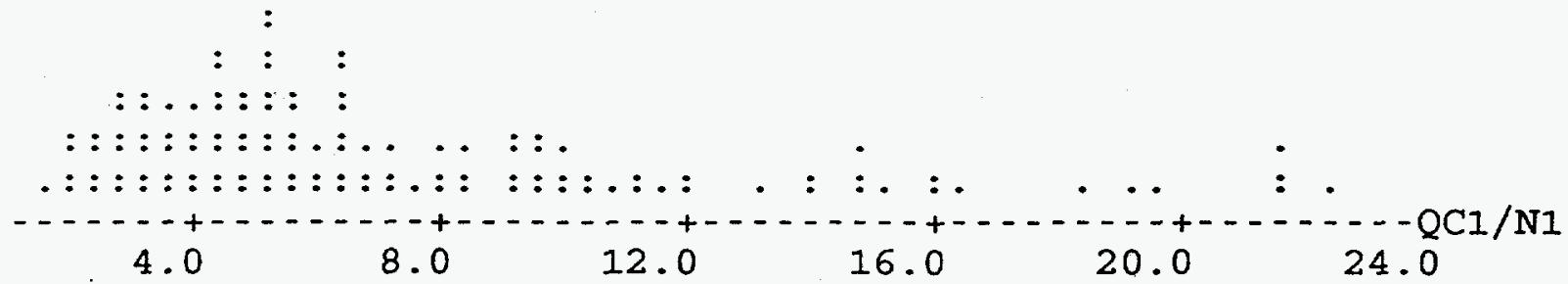

MTB > DOTPLOT C99

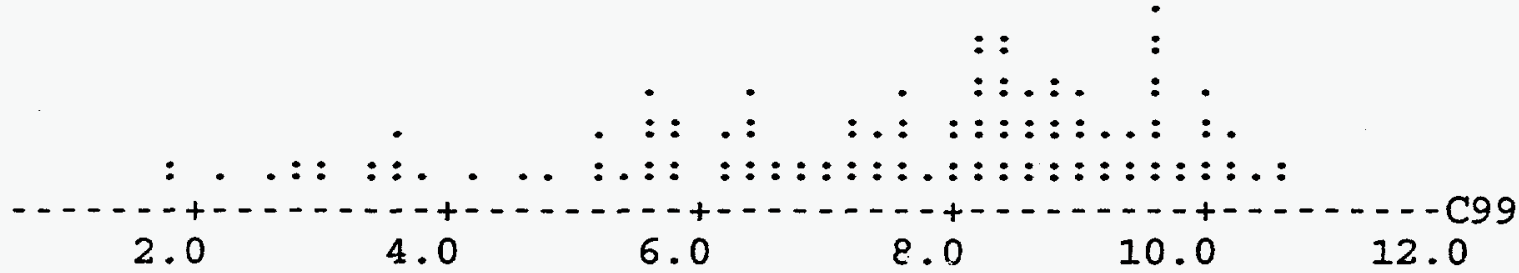

ITB > CORR C12 C99

forrelation of $Q C 1 / \mathrm{N} 1$ and $\mathrm{C} 99=0.443$

TRB > NOTE: RESTART AGAIN

TB > READ 'DB13.DAT' C1-C5 128 ROWS READ

$\begin{array}{llllll}\text { ROW } & \text { N1 } & \text { QC1 } & \text { FR } & \text { PP } & \text { PO }\end{array}$

$\begin{array}{rrrrrr}1 & 23.26 & 80.37 & 0.55 & 2.23 & 3.26 \\ 2 & 33.08 & 105.37 & 0.50 & 1.34 & 3.29 \\ 3 & 29.00 & 85.98 & 0.46 & 1.26 & 3.34 \\ 4 & 11.44 & 47.53 & 1.06 & 2.54 & 3.37\end{array}$

$T B>$ EXEC 'NAMES.PRG'

$\mathrm{TB}>\mathrm{NAME} \mathrm{Cl}$ ' $\mathrm{N} 1$ '

$\mathrm{TB}>\mathrm{NAME} \mathrm{C} 2$ ' $\mathrm{OC} 1$ '

$\mathrm{TB}>\mathrm{NAME} \mathrm{C} 3$ ' $\mathrm{FR}$ '

$\mathrm{TB}>\mathrm{NAME} \mathrm{C} 4$ ' $\mathrm{PP}$ '

$\mathrm{TB}>\mathrm{NAME} \mathrm{C} 5$ ' $^{\mathrm{PO}}$ '

$\mathrm{TB}>\mathrm{LET} \mathrm{C} 6=\mathrm{C} 2 * \mathrm{C} 3$

$\mathrm{TB}>\mathrm{LET} \mathrm{C} 7=\mathrm{C} 2 * \mathrm{C} 4$

$\mathrm{IB}>\mathrm{LET} \mathrm{C} 8=\mathrm{C} 2 * \mathrm{C} 5$

$\mathrm{TB}>\mathrm{LET} \mathrm{C} 9=\mathrm{C} 3 * \mathrm{C} 4$

$\mathrm{IB}>\mathrm{IET} \mathrm{C} 10=\mathrm{C} 3 * \mathrm{C} 5$

$\mathrm{TB}>\mathrm{LET} \mathrm{C} 11=\mathrm{C} 4 * \mathrm{C} 5$

$\mathrm{IB}>\mathrm{LET} \mathrm{C} 12=\mathrm{C} 2 / \mathrm{C} 1$

$\mathrm{IB}>$ NAME $\mathrm{C} 6$ 'QC1XFR'

$\mathrm{PB}>$ NAME C7 'QCIXPP'

$\mathrm{TB}>$ NAME C8 'QC1XPO'

$\Gamma B>$ NAME C9 'FRXPP'

$\mathrm{TB}>$ N NAME C10 'FRXPO'

$\mathrm{PB}>$ NAME C11 'PPXPO' 
$M T B>$ NAME C12 'QC1/N1'

$M T B>$ NOCONSTANT

MTB > REGRESS C12 ON 10 C2-C11 C98 C99
* NOTE *
QC1 is highly correlated with other
predictor variables
PP is highly correlated with other
predictor variables
NOTE *
QC1xPO is highly correlated with other
predictor variables
NOTE *
FRxPO is highly correlated with other
predictor variables
NOTE *
PPXPO is highly correlated with other
predictor variables

The regression equation is

$\mathrm{QC} 1 / \mathrm{N} 1=0.225 \mathrm{QCI}+7.77 \mathrm{FR}-7.73 \mathrm{PP}+7.36 \mathrm{PO}-0.0780 \mathrm{QC} 1 \mathrm{XFR}$

+0.0573 QC1XPP - 0.106 QC1XPO + 1.82 FRXPP - 4.08 FRXPO

$+0.685 \mathrm{PPXPO}$

$\begin{array}{lrrrr}\text { Predictor } & \text { Coef } & \text { Stdev } & \text { t-ratio } & p \\ \text { Joconstant } & & & & \\ \text { CC1 } & 0.22459 & 0.08566 & 2.62 & 0.010 \\ \text { R } & 7.766 & 9.826 & 0.79 & 0.431 \\ \text { P } & -7.734 & 4.338 & -1.78 & 0.077 \\ \text { P } & 7.360 & 1.972 & 3.73 & 0.000 \\ \text { C1XFR } & -0.07795 & 0.09740 & -0.80 & 0.425 \\ \text { C1XPP } & 0.05728 & 0.02999 & 1.91 & 0.059 \\ \text { C1XPO } & -0.10617 & 0.03031 & -3.50 & 0.001 \\ \text { RXPP } & 1.825 & 1.297 & 1.41 & 0.162 \\ \text { RXPO } & -4.076 & 4.045 & -1.01 & 0.316 \\ \text { PXPO } & 0.6852 & 0.9858 & 0.70 & 0.488\end{array}$

$=8.003$

nalysis of variance

$\begin{array}{lrrrrr}\text { OURCE } & \text { DF } & \text { SS } & \text { MS } & \text { F } & \text { p } \\ \text { egression } & 10 & 11551.0 & 1155.1 & 18.03 & 0.000 \\ \text { rror } & 118 & 7558.5 & 64.1 & & \\ \text { otal } & 128 & 19109.5 & & & \\ \text { OURCE } & D F & \text { SEQ SS } & & \\ \text { C1 } & 1 & 8945.2 & & \\ \text { R } & 1 & 193.6 & & \\ \text { P } & 1 & 309.1 & & \\ \text { D } & 1 & 688.7 & & \\ \text { CIXFR } & 1 & 114.1 & & \\ \text { CIXPP } & 1 & 207.8 & & \\ \text { CIXPO } & 1 & 960.8 & & \\ \text { RXPP } & 1 & 65.4 & & \\ \text { RXPO } & 1 & 35.3 & & \\ \text { PXPO } & 1 & 30.9 & & & \end{array}$

husual Observations

2

$\begin{array}{rr}\text { QCI } & \text { QC1/N1 } \\ 45 & 2.033 \\ 34 & 1.669 \\ 41 & 6.382 \\ 38 & 4.867 \\ 105 & 2.906 \\ 144 & 2.953 \\ 39 & 3.617 \\ 68 & 53.929 \\ 90 & 49.022\end{array}$

Fit Stdev.Fit Residual

St.Resid

$\begin{array}{lll}2.474 & 4.379 & -0.441 \\ 5.305 & 5.885 & -3.636\end{array}$

5.305

2.231

4.481

1.812

3.055

6.287

4.208

4.254

$-3.382$

3.949

9.729

$-6.776$

4.175

5.709

$-0.558$

$1.274 \quad 41.715$

1.153

38.591

$$
\begin{array}{r}
-0.07 \mathrm{X} \\
-0.67 \mathrm{X} \\
0.34 \mathrm{X} \\
0.45 \mathrm{X} \\
-0.50 \mathrm{X} \\
-0.97 \mathrm{X} \\
-0.10 \mathrm{X} \\
5.28 \mathrm{R} \\
4.87 \mathrm{R}
\end{array}
$$




$\begin{array}{rrrrrrc}72 & 86 & 35.449 & 10.524 & 1.126 & 24.925 & 3.15 \mathrm{R} \\ 73 & 108 & 29.975 & 9.475 & 1.370 & 20.500 & 2.60 \mathrm{R} \\ 80 & 31 & 3.371 & 10.155 & 4.248 & -6.784 & -1.00 \mathrm{X} \\ 91 & 90 & 26.735 & 10.719 & 1.408 & 16.016 & 2.03 \mathrm{R}\end{array}$

denotes an obs. with a large st. resid.

denotes an obs. whose $x$ value gives it large influence.

ITB > CORR C12 C99

forrelation of $\mathrm{QC1} / \mathrm{N} 1$ and $\mathrm{C} 99=0.377$

$\mathrm{ITB}>\mathrm{PLOT} \mathrm{C} 12 \mathrm{C} 1$

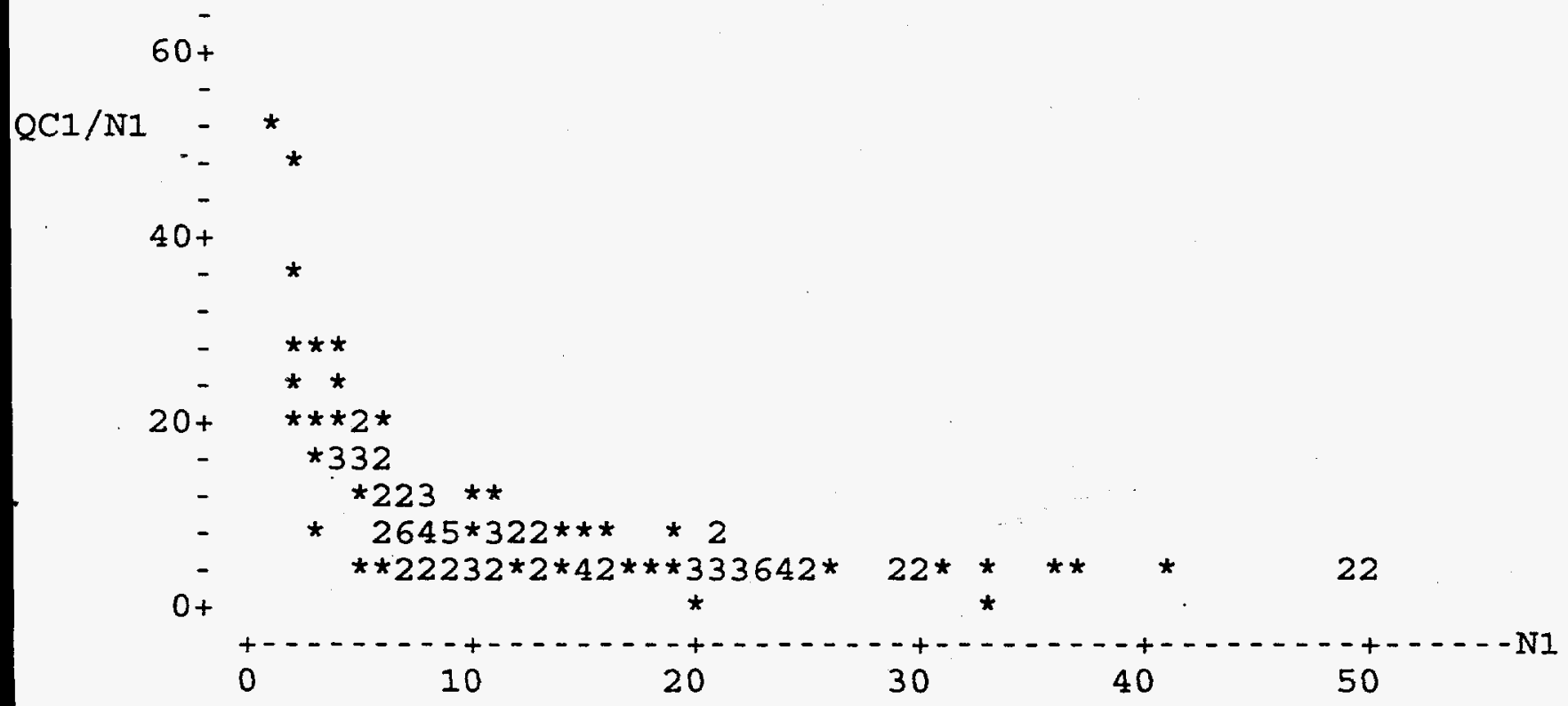

$\mathrm{TB}>\mathrm{PLOT} \mathrm{C} 12 \mathrm{C} 2$

$60+$

$\mathrm{QC} 1 / \mathrm{N} 1$

$40+$

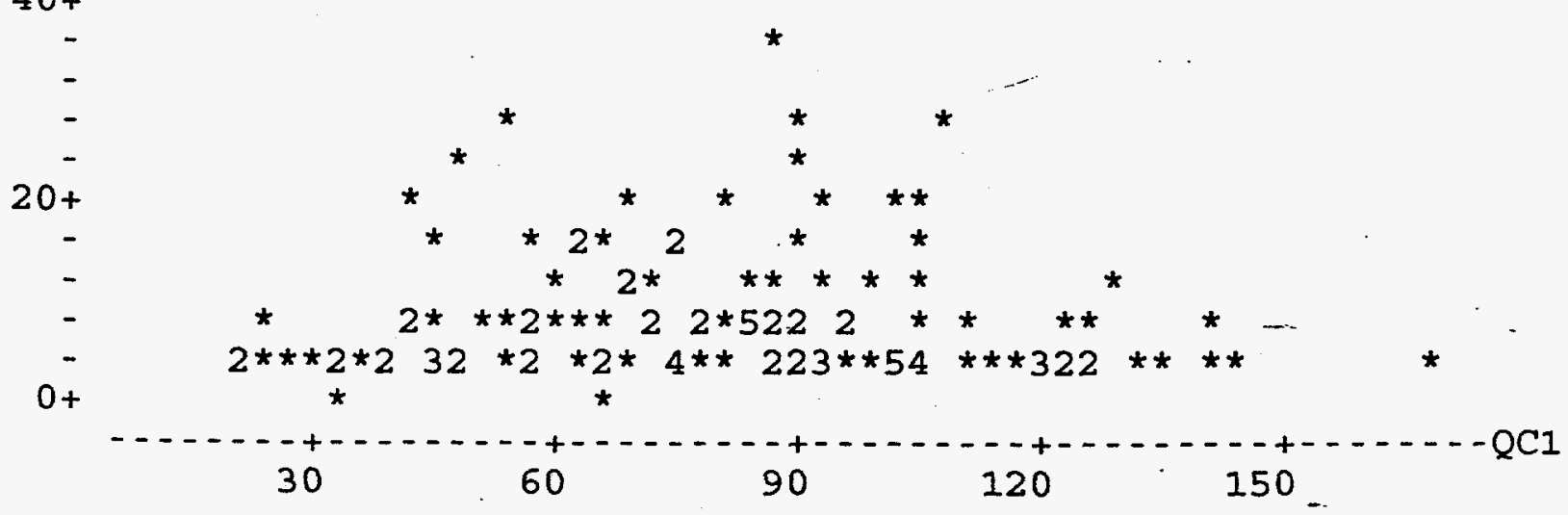


MTB > PLOT C12 C3

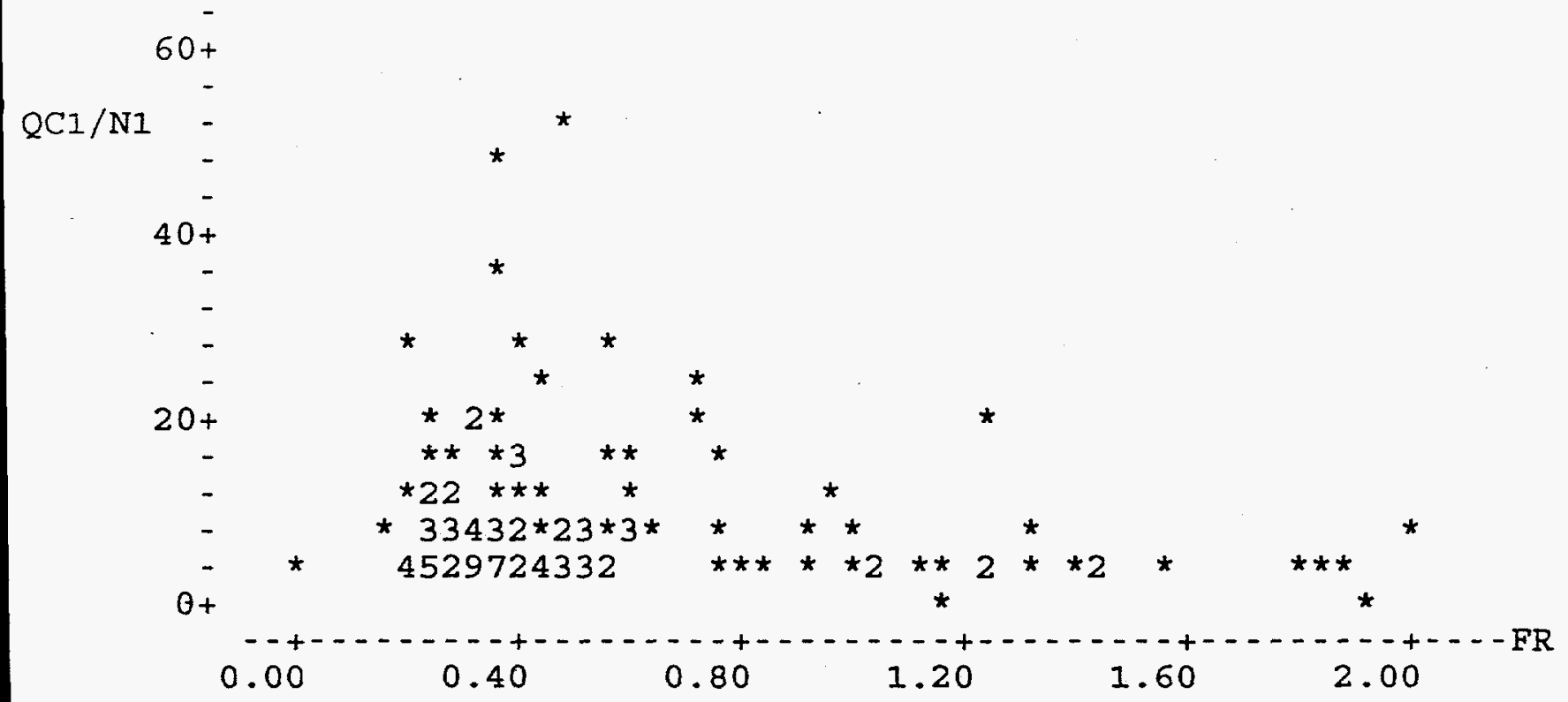

ITB > PLOT C12 C4

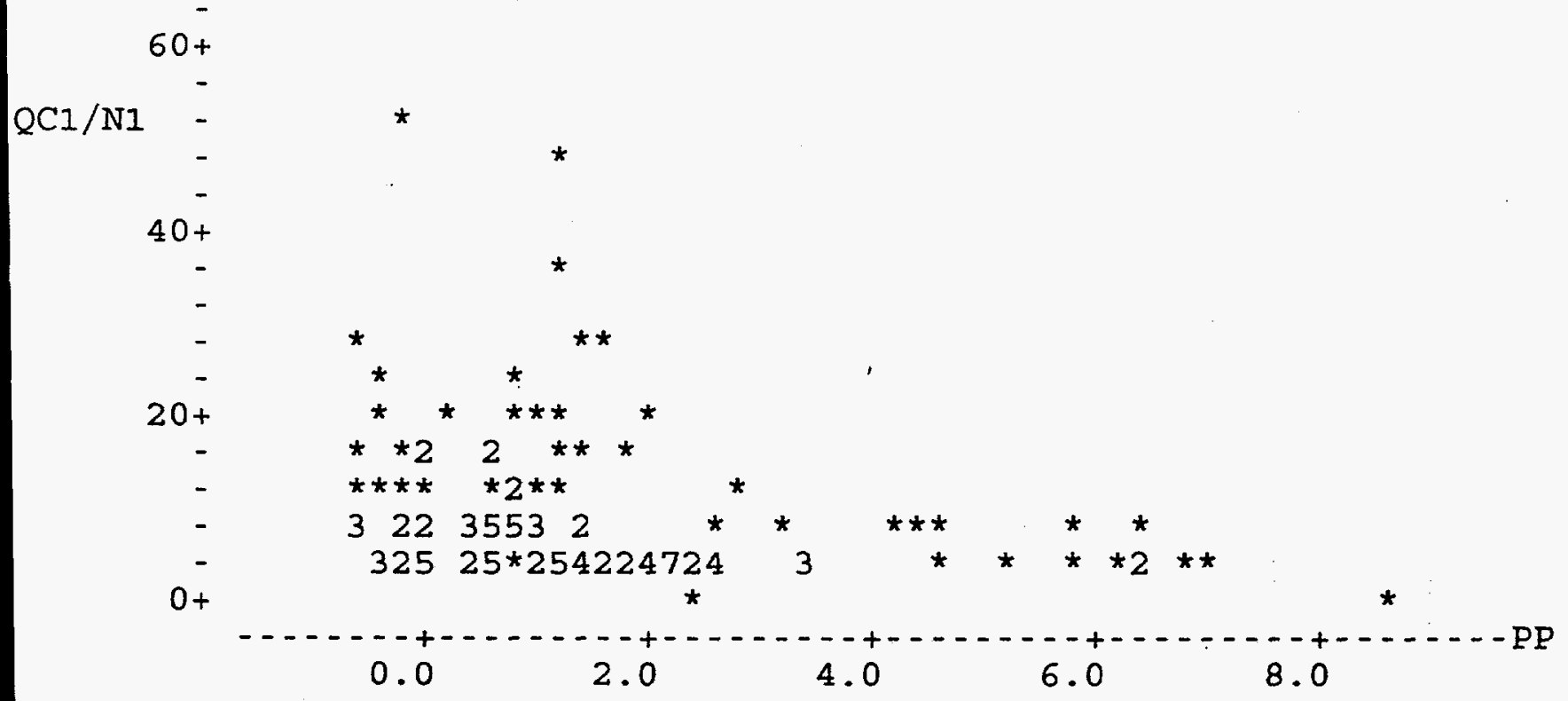


$\mathrm{MTB}>\mathrm{PLOT} \mathrm{C} 12 \mathrm{C} 5$

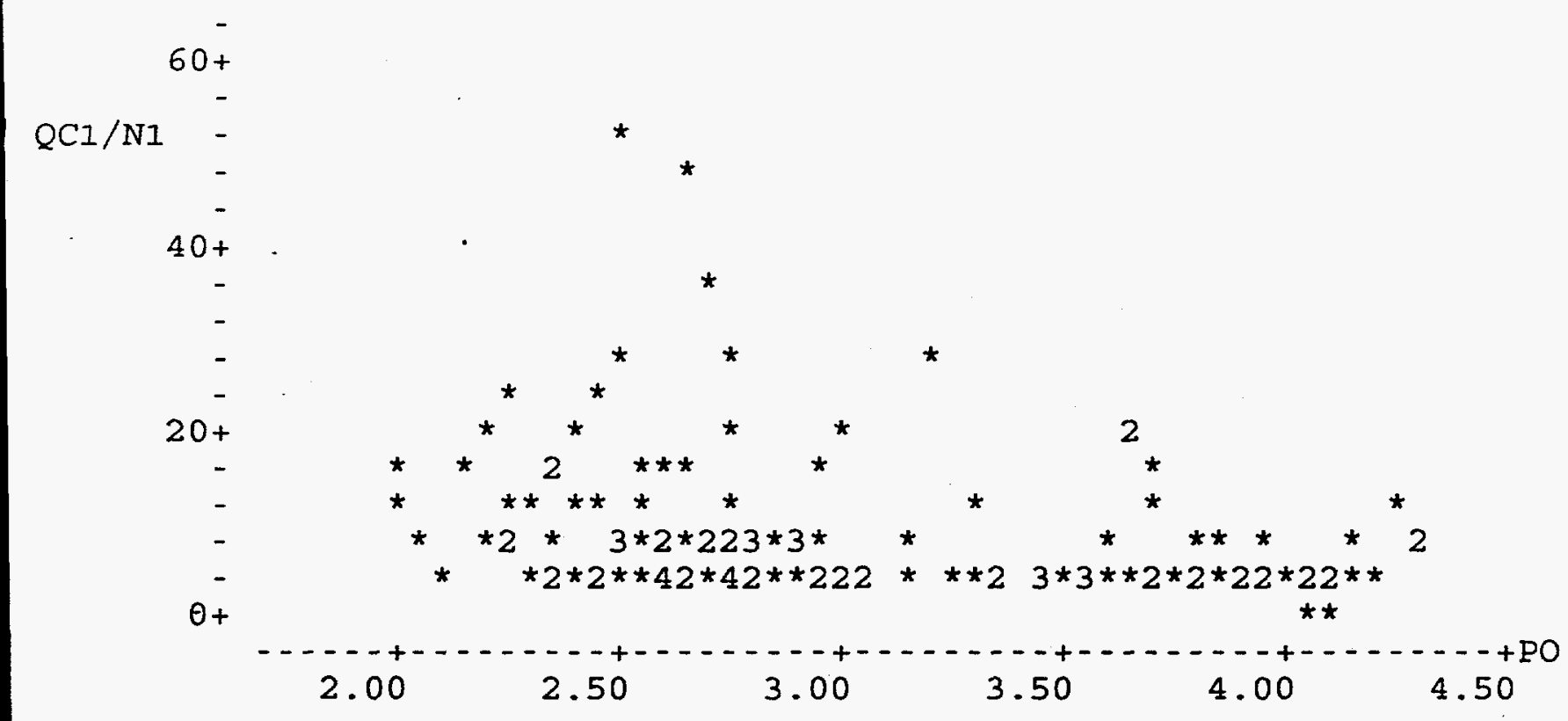

MTB > LET C13 = LOGTEN (C1)

MTB > PLOT $\mathrm{C} 12 \quad \mathrm{C} 13$

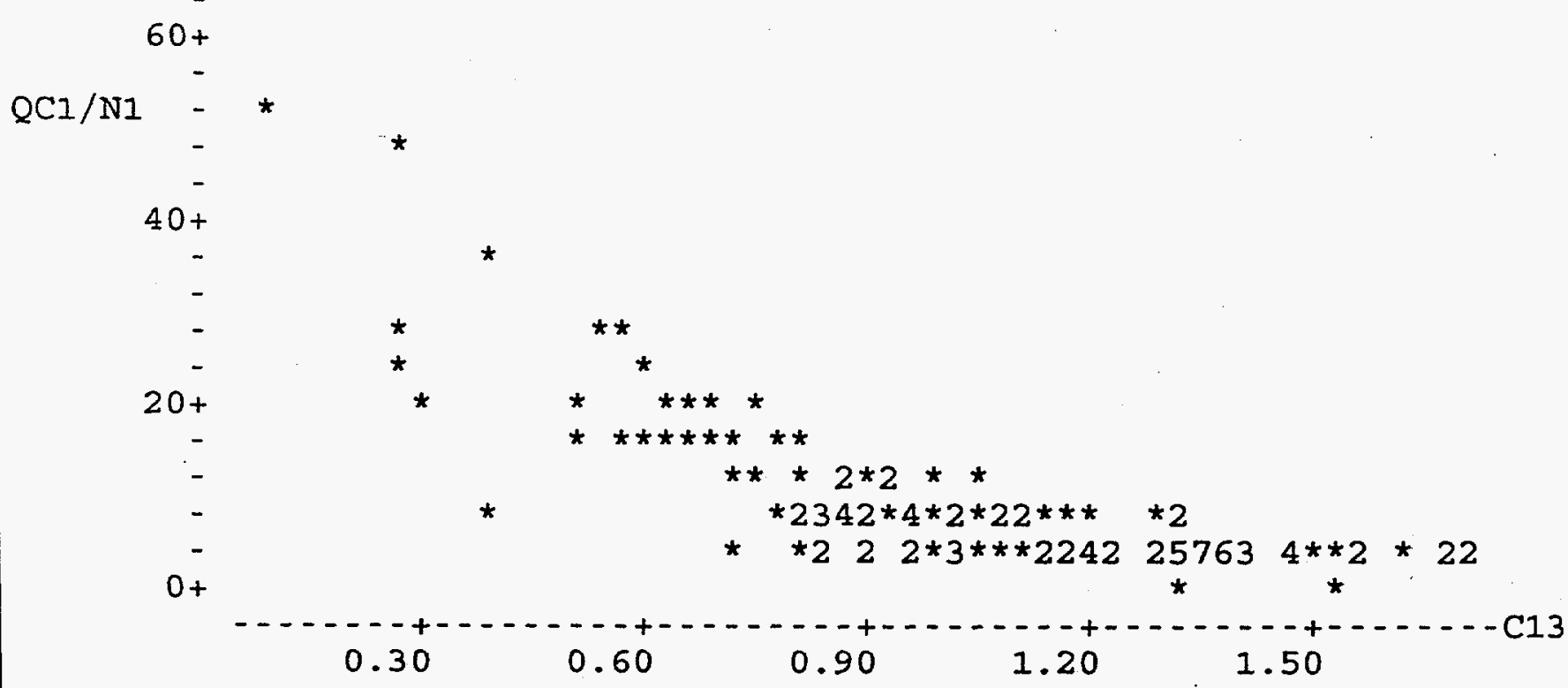




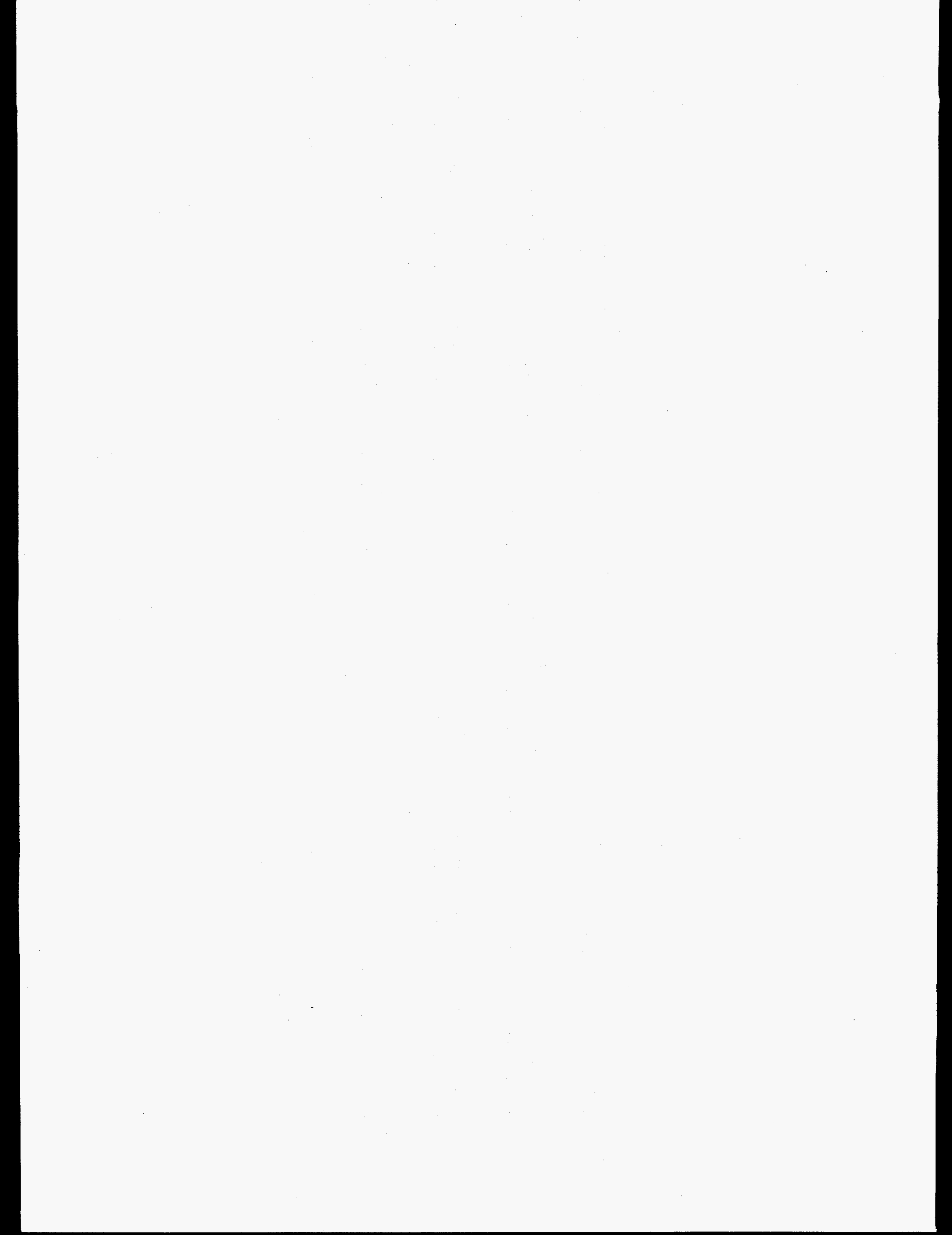


MTB > LET CI3 = SQRT (C1)

MTB > PLOT C12 Cl

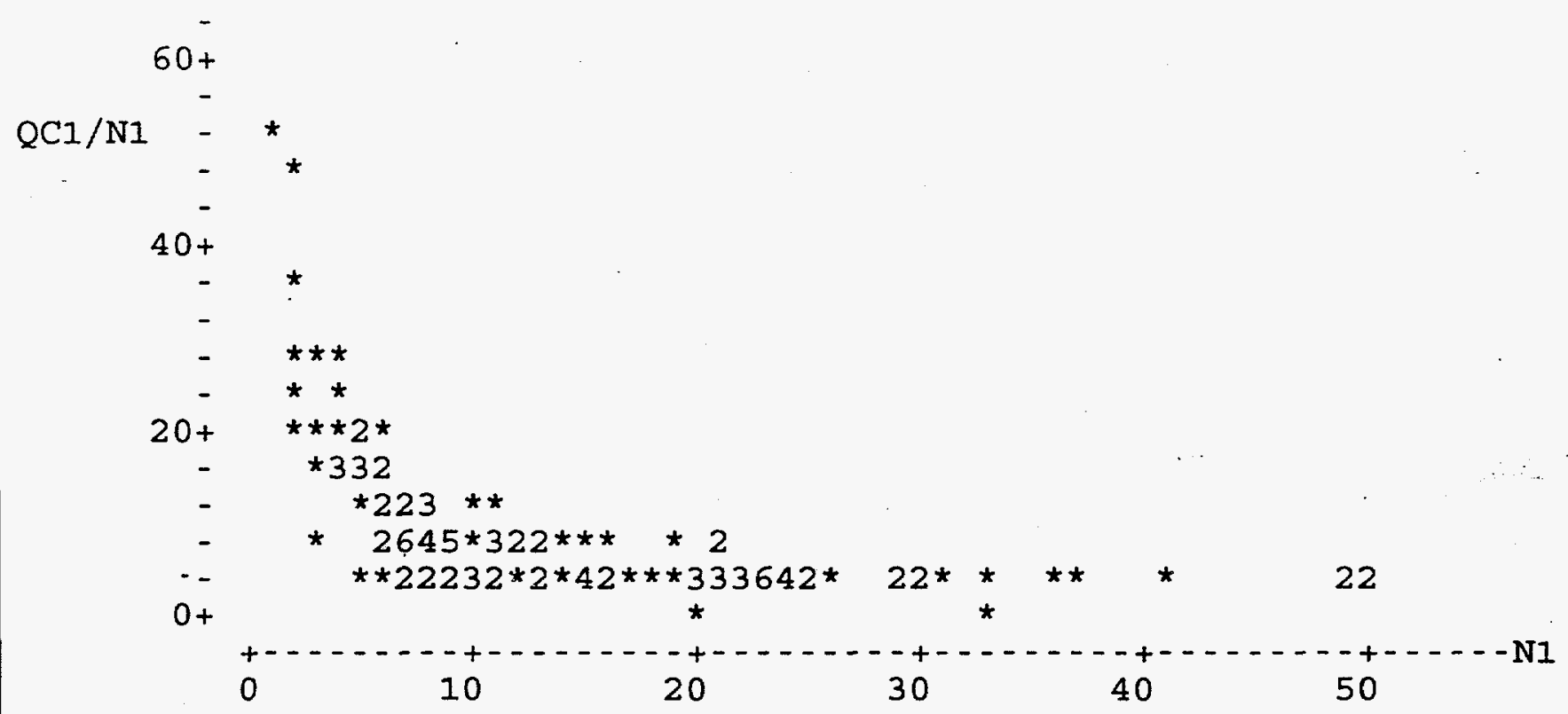

$\mathrm{MTB}>\mathrm{PLOT} \mathrm{C} 12 \mathrm{C} 2$

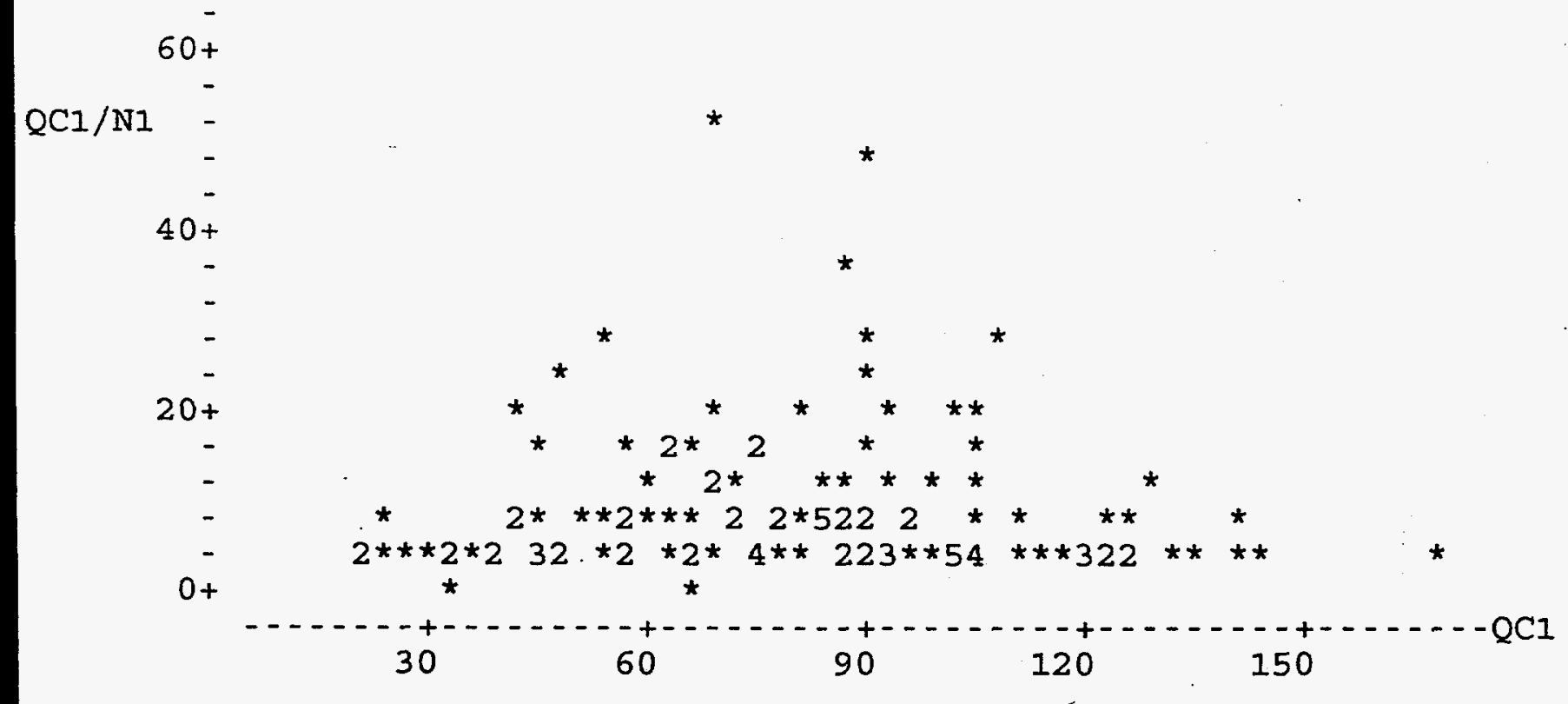


ITB > PLOT C12 C3

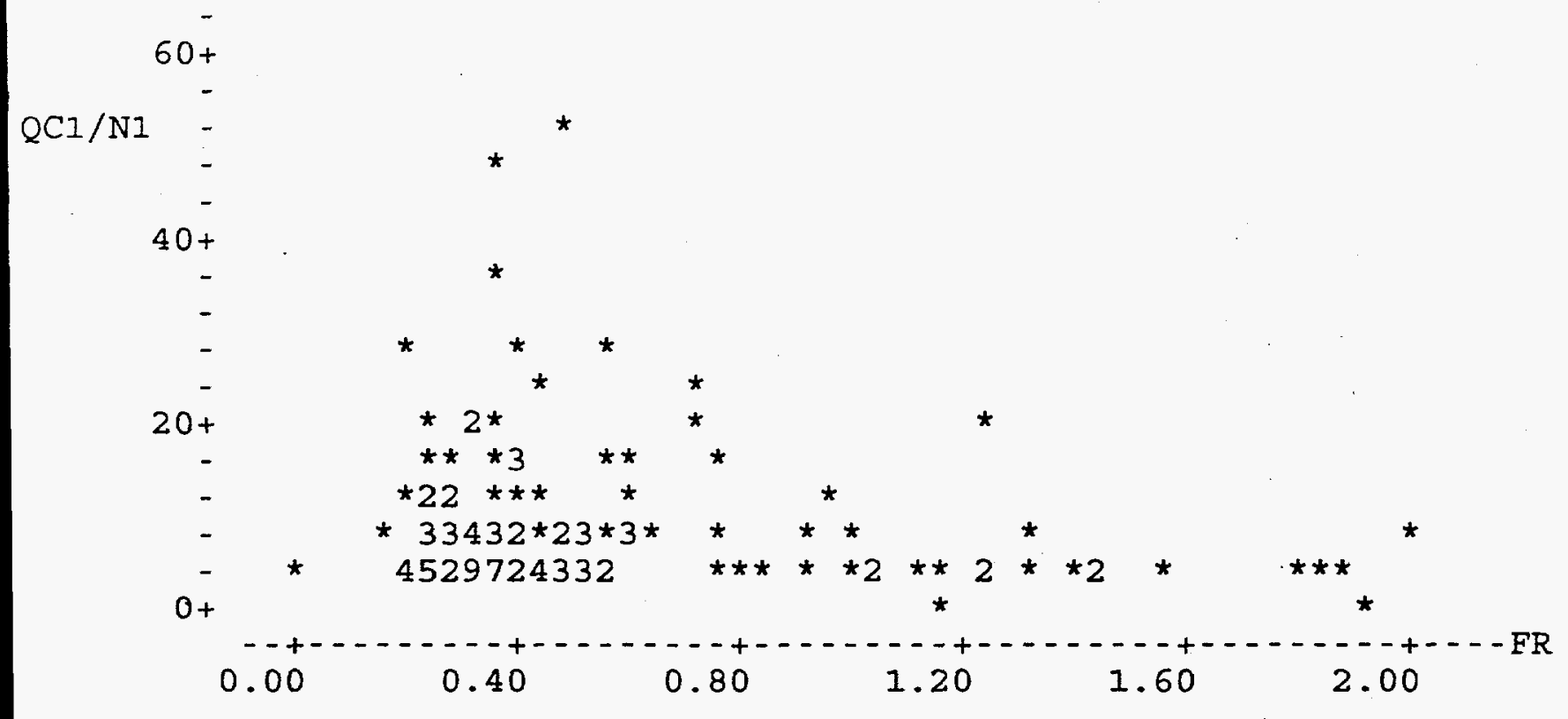

$\mathrm{PB}>\mathrm{PLOT} \mathrm{C} 12 \mathrm{C} 4$

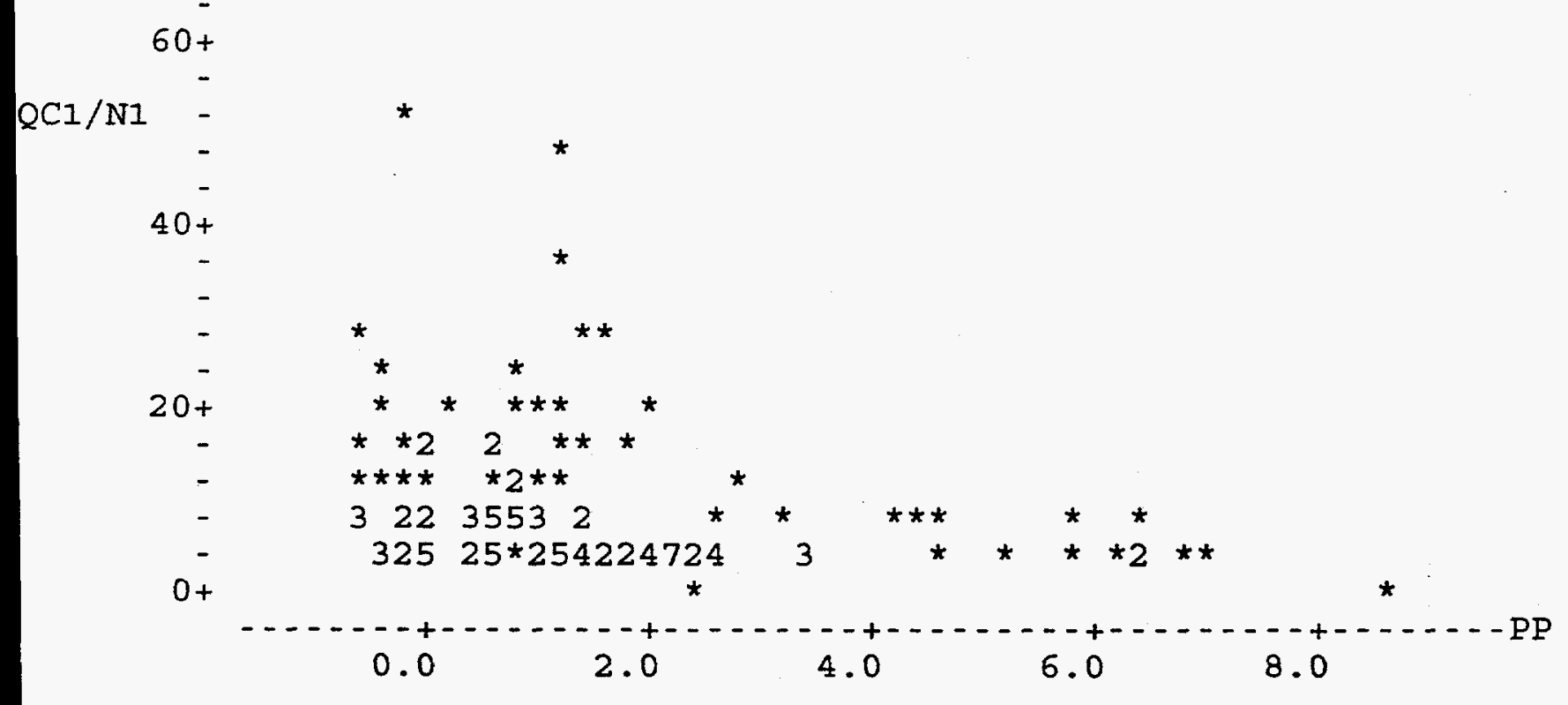


MTB > PLOT C12 C5

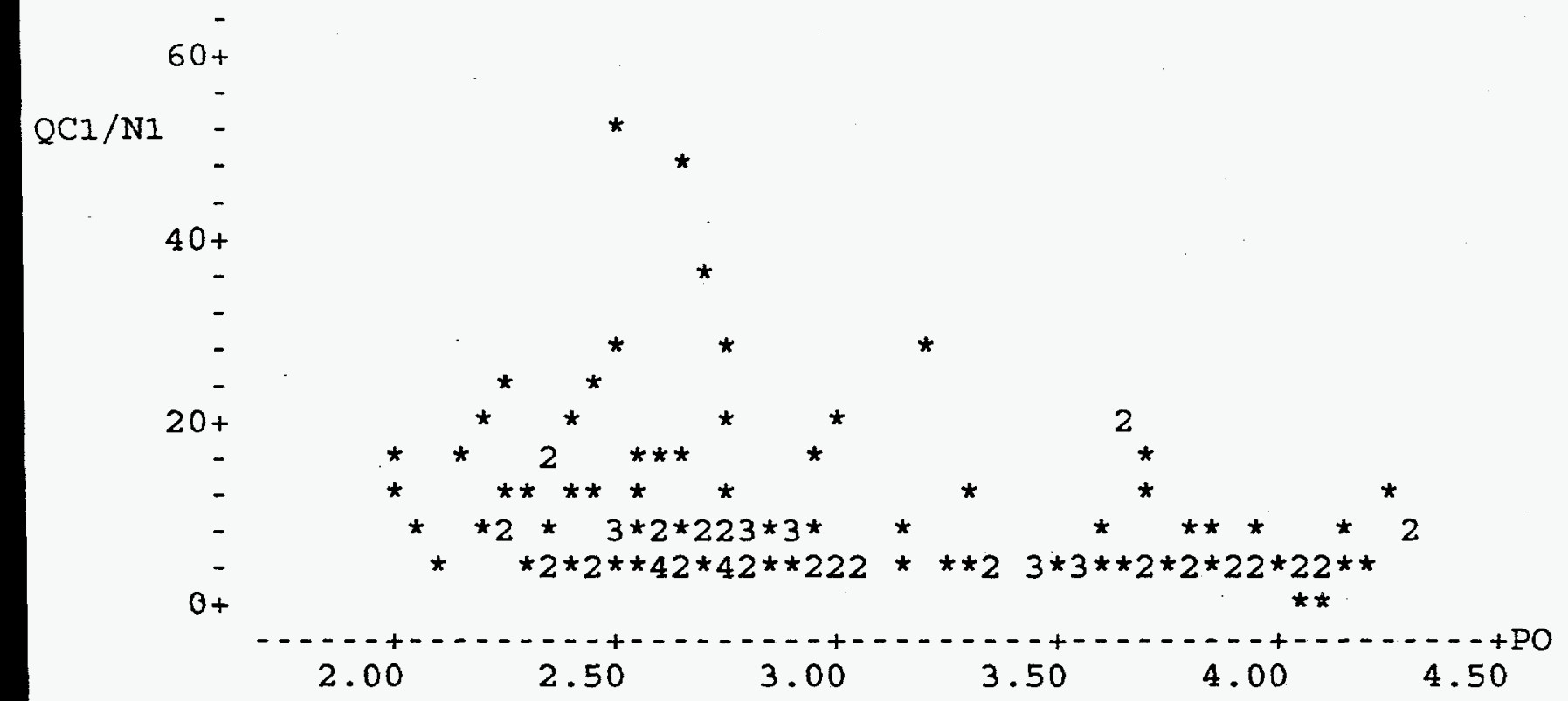

$\mathrm{TTB}>$ DOTPLOT $\mathrm{CI2}$

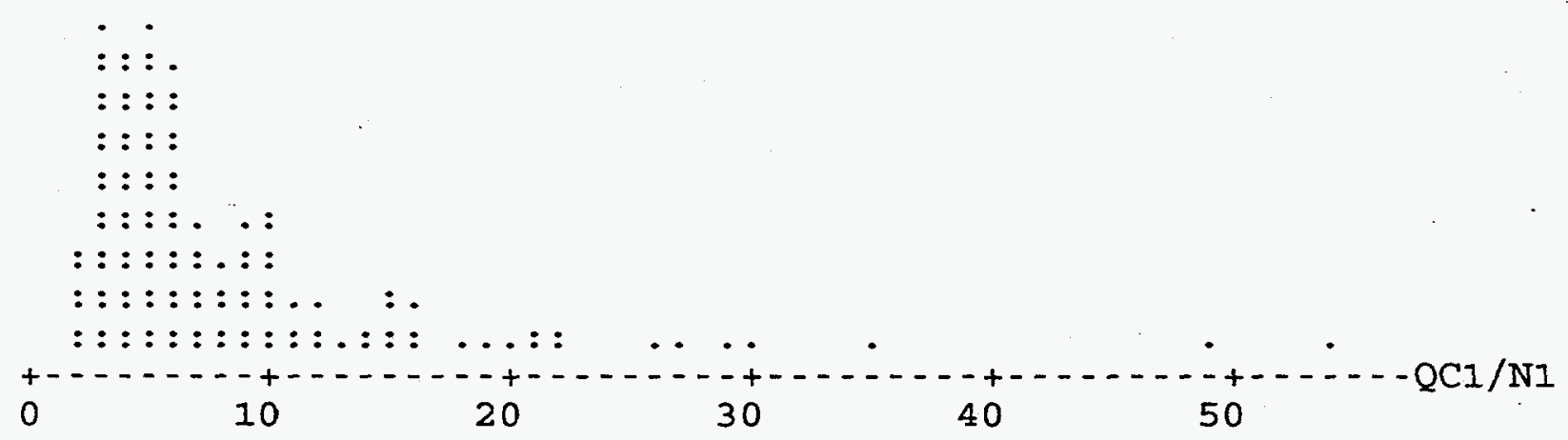

TB > NOTE REMOVE ALL OBSERVATIONS WITH QCI/N1 > 16 
NOTE *** Data Editor entered at this point.

MTB > REGRESS C12 ON $10 \mathrm{C} 2-\mathrm{C} 11$ C98 C99

* NOTE * QC1 is highly correlated with other predictor variables

* NOTE * PP is highly correlated with other predictor variables

* NOTE * QCIXPO is highly correlated with other predictor variables

* NOTE * FRxPO is highly correlated with other predictor variables

* NOTE * PPXPO is highly correlated with other predictor variables

The regression equation is

$\mathrm{QCI} / \mathrm{N1}=0.116 \mathrm{QC1}+6.13 \mathrm{FR}-5.62 \mathrm{PP}+5.06 \mathrm{PO}-0.0071 \mathrm{QCIXFR}$

+0.0232 QC1XPP - 0.0586 QCIXPO + 1.34 FRXPP - 3.90 FRXPO

+0.809 PPXPO

$\begin{array}{lrrrr}\text { Predictor } & \text { Coef } & \text { Stdev } & \text { t-ratio } & \text { p } \\ \text { Noconstant } & & & & \\ \text { QC1 } & 0.11568 & 0.03549 & 3.26 & 0.002 \\ \text { FR } & 6.132 & 3.916 & 1.57 & 0.120 \\ \text { PP } & -5.625 & 1.736 & -3.24 & 0.002 \\ \text { PO } & 5.0553 & 0.7980 & 5.34 & 0.000 \\ \text { QC1XFR } & -0.00706 & 0.03916 & -0.18 & 0.857 \\ \text { QC1XPP } & 0.02322 & 0.01199 & 1.94 & 0.055 \\ \text { QC1XPO } & -0.05859 & 0.01235 & -4.74 & 0.000 \\ \text { FRXPP } & 1.3389 & 0.5153 & 2.60 & 0.011 \\ \text { FRXPO } & -3.903 & 1.599 & -2.44 & 0.016 \\ \text { PPXPO } & 0.8090 & 0.3921 & 2.06 & 0.042\end{array}$

$s=3.104$

Analysis of Variance

$\begin{array}{lrr}\text { SOURCE } & \text { DF } & \text { SS } \\ \text { Regression } & 10 & 5198.47 \\ \text { Error } & 103 & 992.26 \\ \text { Total } & 113 & 6190.73 \\ & & \\ \text { SOURCE } & \text { DF } & \text { SEQ SS } \\ \text { DC1 } & 1 & 4129.49 \\ \text { R } & 1 & 125.97 \\ \text { PP } & 1 & 50.78 \\ \text { P } & 1 & 384.03 \\ \text { RC1XFR } & 1 & 33.40 \\ \text { DC1XPP } & 1 & 139.08 \\ \text { RC1XPO } & 1 & 253.90 \\ \text { RXPP } & 1 & 18.58 \\ \text { RRXPO } & 1 & 22.24 \\ \text { PPXPO } & 1 & 41.01\end{array}$

$\begin{array}{rrr}\text { MS } & F & p \\ 519.85 & 53.96 & 0.000\end{array}$

9.63 
nusual Observations

bs
20
21
22
26
27
38
44
54
59
61
63
68
70
79
QC1 QCI/NI $45 \quad 2.033$

$34 \quad 1.669$

$41 \quad 6.382$

$76 \quad 14.703$

$38 \quad 4.867$

$130 \quad 11.657$

$\begin{array}{ll}76 & 15.839\end{array}$

105

39

63

90

66

31

75
2.906

3.617

15.926

14.617

14.086

3.371

2.566
Fit Stdev.Fit Residual

1.944

6.231

3. 845

7.609

3. 671

4.367

8.781

4.984

3.058

7.976

6.992

7.254

6.359

8.672
1. 706

2.303

1.745

0.599

1.652

1. 319

0.647

1. 678

2.220

0.488

0.501

0.529

1.767

0.586
0.089
-4.561

2.538

7.095

1.196

7.291

7.058

$-2.079$

0.559

7.951

7.625

6.832

$-2.988$

$-6.106$
St. Resid

$0.03 \mathrm{X}$

$-2.19 R X$

$0.99 \mathrm{X}$

2. $33 \mathrm{R}$

$0.46 \mathrm{X}$

2. $59 \mathrm{R}$

$2.32 \mathrm{R}$

$-0.80 \mathrm{X}$

$0.26 \mathrm{X}$

2. $59 \mathrm{R}$

2. 49R

2. 23R

$-1.17 \mathrm{X}$

$-2.00 R$

denotes an obs. with a large st. resid.

denotes an obs. whose $x$ value gives it large influence.

$\mathrm{TB}>$ DOTPLOT $\mathrm{C} 12$

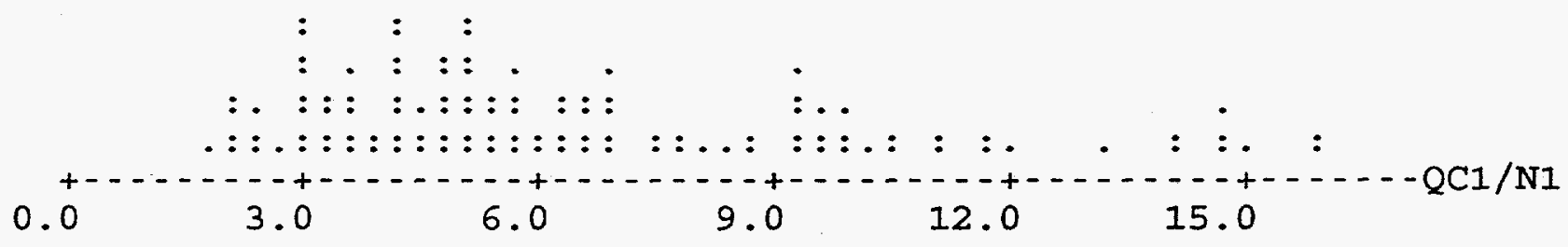

B > DOTPLOT C99

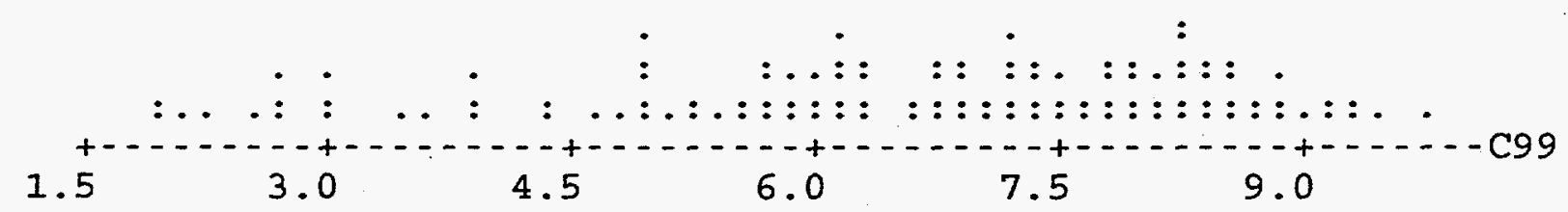


TTB > CORR C12 C99

Forrelation of $\mathrm{QC} 1 / \mathrm{N} 1$ and $\mathrm{C} 99=0.525$

ITB > READ 'DB4.DAT' C1-C5

43 ROWS READ

$\begin{array}{rrrrrr}\text { ROW } & \text { N1 } & \text { QC1 } & \text { FR } & \text { PP } & \text { PO } \\ 1 & 13.16 & 15.23 & 2.80 & 9.39 & 4.21 \\ 2 & 5.83 & 14.66 & 2.29 & 16.03 & 4.24 \\ 3 & 7.72 & 13.69 & 1.74 & 18.82 & 4.29 \\ 4 & 10.58 & 11.70 & 2.08 & 19.61 & 4.32\end{array}$

ITB > EXEC 'NAMES.PRG'

ITB > NAME $\mathrm{C} 1$ ' $\mathrm{N} 1$ '

ITB > NAME C2 ' $\mathrm{QC1}$ '

TB > NAME C3 'FR'

TTB > NAME C4 ' $\mathrm{PP}$ '

THB > NAME C5 'PO'

$\mathrm{TB}>\mathrm{LET} \mathrm{C} 6=\mathrm{C} 2 * \mathrm{C} 3$

$\mathrm{TB}>\mathrm{LET} \mathrm{C} 7=\mathrm{C} 2 * \mathrm{C} 4$

$\mathrm{TB}>\mathrm{LET} \mathrm{C} 8=\mathrm{C} 2 * \mathrm{C} 5$

$\mathrm{TB}>\mathrm{LET} \mathrm{C} 9=\mathrm{C} 3 * \mathrm{C} 4$

$\mathrm{TB}>\mathrm{LET} \mathrm{C} 10=\mathrm{C} 3 * \mathrm{C} 5$

$\mathrm{TB}>\mathrm{LET} \mathrm{C} 11=\mathrm{C} 4 * \mathrm{C} 5$

$\mathrm{TB}>\mathrm{LET} \mathrm{C} 12=\mathrm{C} 2 / \mathrm{C} 1$

TB > NAME C6 'QC1XFR'

$\mathrm{TB}>$ NAME C7 'QC1XPP'

TB > NAME C8 'QCIXPO'

$\mathrm{TB}>$ NAME C9 'FRXPP'

$\mathrm{TB}>$ NAME C10 'FRXPO'

$\mathrm{TB}>$ NAME $\mathrm{C} 11$ 'PPXPO'

$\mathrm{IB}>\mathrm{NAME} \mathrm{C} 12$ ' $\mathrm{QCl} / \mathrm{NI}$ '

$\mathrm{IB}>$ NOCONSTANT

TB > REGRESS C12 ON 10 C2-C11 C98 C99

NOTE * QCl is highly correlated with other predictor variables NOTE * FR is highly correlated with other predictor variables NOTE * PP is highly correlated with other predictor variables NOTE * PO is highly correlated with other predictor variables NOTE * QC1XPO is highly correlated with other predictor variables NOTE * FRXPP is highly correlated with other predictor variables NOTE * FRXPO is highly correlated with other predictor variables NOTE * PPXPO is highly correlated with other predictor variables

he regression equation is

$\mathrm{F} 1 / \mathrm{N} 1=0.045 \mathrm{QC1}-8.76 \mathrm{FR}-0.35 \mathrm{PP}+6.23 \mathrm{PO}+0.229 \mathrm{QC} 1 \mathrm{XFR}-0.0050 \mathrm{QC} 1 \times \mathrm{XP}$ -0.0805 QC1XPO + 0.553 FRXPP - 0.93 FRxPO - 0.181 PPXPO 


$\begin{array}{lrrrr}\text { Predictor } & \text { Coef } & \text { Stdev } & \text { t-ratio } & p \\ \text { Noconstant } & & & & 0.21 \\ \text { QC1 } & 0.0446 & 0.2147 & 0.837 \\ \text { ER } & -8.756 & 8.545 & -1.02 & 0.313 \\ \text { PP } & -0.349 & 1.305 & -0.27 & 0.791 \\ \text { PO } & 6.226 & 2.071 & 3.01 & 0.005 \\ \text { QC1XFR } & 0.2293 & 0.1157 & 1.98 & 0.056 \\ \text { QC1XPP } & -0.00499 & 0.01760 & -0.28 & 0.779 \\ \text { QC1XPO } & -0.08048 & 0.05283 & -1.52 & 0.137 \\ \text { FRXPP } & 0.5528 & 0.2899 & 1.91 & 0.065 \\ \text { FRXPO } & -0.930 & 2.420 & -0.38 & 0.703 \\ \text { PPXPO } & -0.1814 & 0.2606 & -0.70 & 0.491\end{array}$

$s=3.519$

Analysis of Variance

$\begin{array}{lrrrrr}\text { SOURCE } & \text { DF } & \text { SS } & \text { MS } & \text { P } \\ \text { Regression } & 10 & 967.99 & 96.80 & 7.82 & 0.000 \\ \text { Error } & 33 & 408.60 & 12.38 & & \\ \text { TotaI } & 43 & 1376.59 & & \\ \text { SOURCE } & \text { DF } & \text { SEQ SS } & & \\ \text { QC1 } & 1 & 799.69 & & \\ \text { FR } & 1 & 3.70 & & \\ \text { PP } & 1 & 0.55 & & \\ \text { PO } & 1 & 50.90 & & \\ \text { QC1XFR } & 1 & 0.44 & & \\ \text { QC1XPP } & 1 & 1.77 & & \\ \text { QC1XPO } & 1 & 56.35 & & \\ \text { FRXPP } & 1 & 22.59 & & \\ \text { FRXPO } & 1 & 26.00 & & \\ \text { PPXPO } & 1 & 6.00 & & & \\ \end{array}$

Unusual Observations
bbs.
QC1
$\mathrm{QC} 1 / \mathrm{N} 1$
Fit Stdev.Fit Residual
St. Resid
11
72.3
6.490
6.047
3.334
0.443
$0.39 \mathrm{X}$
42
26.9
24.917
9.449
1.839
15.467
$5.16 \mathrm{R}$

denotes an obs. with a large st. resid.

denotes an obs. whose $x$ value gives it large influence. 
MTB > DOTPLOT C12

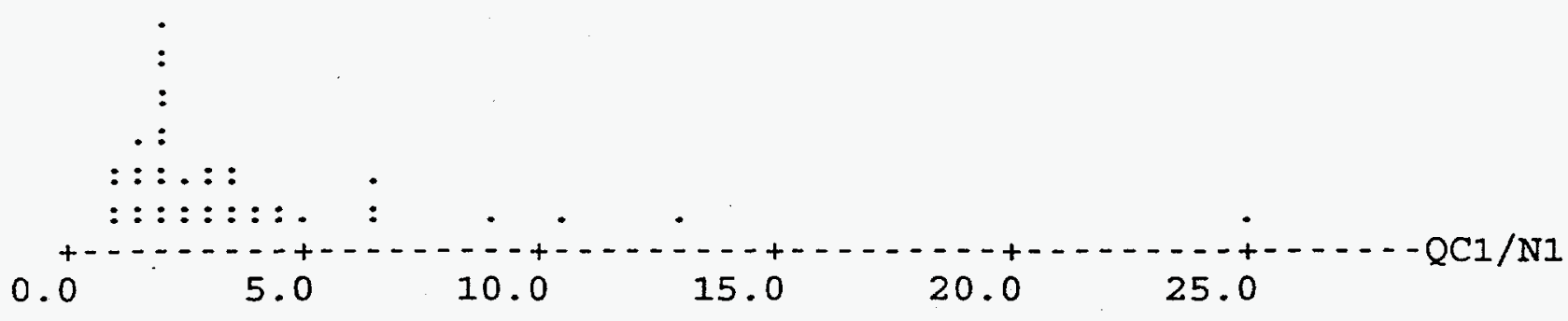

ITB > DOTPLOT C99

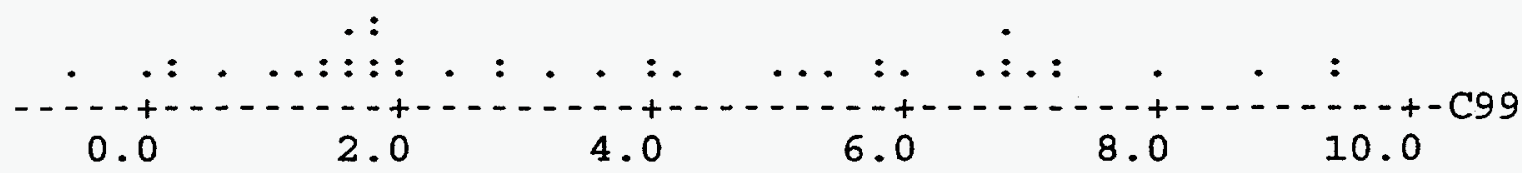

ITB > NOTE REMOVE ALL OBSERVATIONS WTTH QC1/N1 > 10

TOTE *** Data Editor entered at this point.

ITB > REGRESS C12 ON 10 C2-C11 C98 C99

NOTE * QCl is highly correlated with other predictor variables

NOTE * FR is highly correlated with other predictor variables

NOTE * $\quad P P$ is highly correlated with other predictor variables

NOTE * PO is highly correlated with other predictor variables

NOTE * QC1XPO is highly correlated with other predictor variables

NOTE * FRXPP is highly correlated with other predictor variables

NOTE * FRXPO is highly correlated with other predictor variables

NOTE * PPXPO is highly correlated with other predictor variables

he regression equation is

$\mathrm{C} 1 / \mathrm{N} 1=0.0480 \mathrm{QC1}+0.77 \mathrm{FR}-0.545 \mathrm{PP}+1.93 \mathrm{PO}+0.0450 \mathrm{QC1XFR}$ +0.00521 QC1XPP - 0.0206 QC1XPO + 0.137 FRXPP - 0.899 FRXPO +0.0284 PPXPO

$\begin{array}{lrrrr}\text { redictor } & \text { Coef } & \text { Stdev } & \text { t-ratio } & p \\ \text { oconstant } & & & & \\ \text { C1 } & 0.04800 & 0.08270 & 0.58 & 0.566 \\ \text { R } & 0.768 & 3.055 & 0.25 & 0.803 \\ \text { P } & -0.5449 & 0.4680 & -1.16 & 0.253 \\ \text { O } & 1.9331 & 0.8065 & 2.40 & 0.023 \\ \text { C1XFR } & 0.04503 & 0.04479 & 1.01 & 0.323 \\ \text { C1XPP } & 0.005214 & 0.007632 & 0.68 & 0.500 \\ \text { C1XPO } & -0.02055 & 0.01953 & -1.05 & 0.301 \\ \text { RXPP } & 0.1369 & 0.1052 & 1.30 & 0.203 \\ \text { RXPO } & -0.8990 & 0.8469 & -1.06 & 0.297 \\ \text { PXPO } & 0.02842 & 0.09112 & 0.31 & 0.757\end{array}$

$=1.217$

nalysis of Variance

OURCE

egression

rror

otal
DF

10

30

40
SS

422.844

44.419

467.263
MS

42.284

1.481
$F$
28.56

0.00 
SOURCE

DC1

$\mathrm{R}$

$P$

Po

C $1 \times F R$

C1XPP

C $1 \times P O$

$\mathrm{R} \times \mathrm{PP}$

$\mathrm{RXPO}$

PXPO
DF

1

1

1

1

1

1

1

1

1

1
SEQ SS

401.610

2.752

1.063

3.869

0.151

2.829

7.759

0.302

2.365

0.144

nusual observations

bs. $\quad \mathrm{QCl} \quad \mathrm{QCl} / \mathrm{N} 1$

$\begin{array}{lll}11 & 72.3 & 6.490\end{array}$

$29 \quad 53.3 \quad 9.029$

$\begin{array}{lll}30 & 66.3 \quad 2.935\end{array}$

Fit Stdev.Fit Residual St.Resid

$\begin{array}{rrr}5.902 & 1.154 & 0.588 \\ 5.200 & 0.616 & 3.829 \\ 5.391 & 0.814 & -2.456\end{array}$

$1.52 \mathrm{X}$

$3.65 \mathrm{R}$

$\begin{array}{lll}5.391 & 0.814 & -2.456\end{array}$

$-2.72 R$

denotes an obs. with a large st. resid.

denotes an obs. whose $\mathrm{X}$ value gives it large influence.

TB > DOTPLOT C12

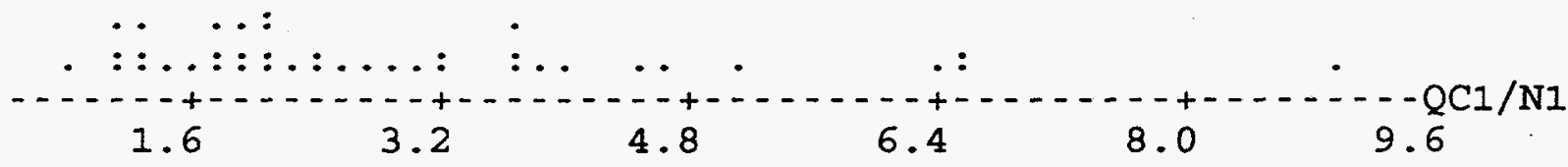

TB > DOTPLOT C99

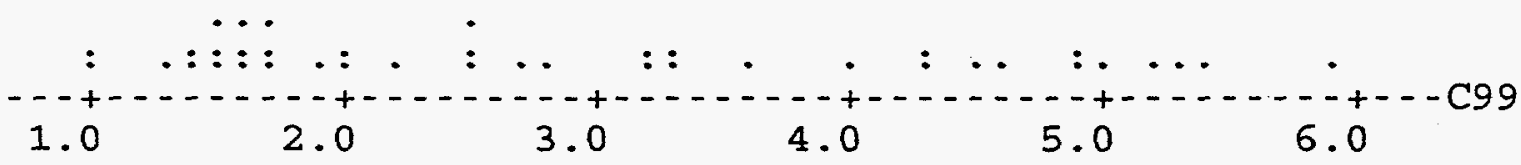

$\Gamma \mathrm{T}>\mathrm{CORR}$ C12 C99

prrelation of $\mathrm{QC1} / \mathrm{N} 1$ and $\mathrm{C} 99=0.806$ 


$\begin{array}{rrrrrr}\text { MTB > READ 'DB5.DAT' } & \text { C1-C5 } \\ & \text { 38 } & \text { ROWS } & & & \\ \text { ROW } & \text { N1 } & \text { QC1 } & \text { FR } & \text { PP } & \text { PO } \\ & & & & & \\ 1 & 11.25 & 16.92 & 1.16 & 18.55 & 4.55 \\ 2 & 12.62 & 16.68 & 1.30 & 19.84 & 4.58 \\ 3 & 11.62 & 16.71 & 1.52 & 20.03 & 4.63 \\ 4 & 9.73 & 15.73 & 1.77 & 16.00 & 4.66\end{array}$

MTB > EXEC 'NAMES.PRG

* ERROR * Missing or stray quote

* Name or file may be ignored

MTB > EXEC 'NAMES.PRG'

$M T B>$ NAME C1 'N1'

$\mathrm{MTB}>\mathrm{NAME} \mathrm{C} 2$ ' $\mathrm{QC1}$ '

MTB > NAME C3 'FR'

MTB > NAME C4 ' $\mathrm{PP}$ '

MTB > NAME C5 'PO'

$\mathrm{MTB}>\mathrm{LET} \mathrm{C} 6=\mathrm{C} 2 * \mathrm{C} 3$

$\mathrm{MTB}>\mathrm{LET} \mathrm{C} 7=\mathrm{C} 2 * \mathrm{C} 4$

MTB > LET C8 $=\mathrm{C} 2 * \mathrm{C} 5$

MTB > LET C9 $=\mathrm{C} 3 * C 4$

MTB > LET C10 = C3*C5

$\mathrm{MTB}>\mathrm{LET} \mathrm{C} 11=\mathrm{C} 4 * \mathrm{C} 5$

$\mathrm{MTB}>\mathrm{LET} \mathrm{C} 12=\mathrm{C} 2 / \mathrm{Cl}$

$M T B>$ NAME C6 'QC1XFR'

$M T B$ > NAME C7 'QCIXPP'

$M T B$ > NAME C8 'QCIXPO'

$M T B$ > NAME C9 'FRXPP'

ITB > NAME C10 'FRXPO'

ITB > NAME C11 'PPXPO'

ATB > NAME C12 'QCl/N1'

ITB > NOCONSTANT

ITB > REGRESS C12 ON 10 C2-C11 C98 C99

NOTE * QCl is highly correlated with other

NOTE * FR is highly correlated with other

NOTE * PP is highly correlated with other

NOTE * PO is highly correlated with other

NOTE * QClXFR is highly correlated with other

NOTE * QC1XPP is highly correlated with other

NOTE * QClXPO is highly correlated with other

NOTE * FRXPO is highly correlated with other

NOTE * PPXPO is highly correlated with other

predictor variables predictor variables predictor variables predictor variables predictor variables predictor variables predictor variables predictor variables predictor variables

he regression equation is

$\mathrm{CI} / \mathrm{NI}=0.501 \mathrm{QCI}-7.37 \mathrm{FR}+0.272 \mathrm{PP}-0.140 \mathrm{PO}-0.0670 \mathrm{QC1 \times FR}$

- 0.00175 QC1XPP - 0.0772 QC1XPO - 0.0006 FRXPP + 2.27 FRXPO

- 0.0824 PPXPO 

$1 / 11 / 95 \quad$ Page 30

$\begin{array}{lrrrr}\text { Predictor } & \text { Coef } & \text { Stdev } & \text { t-ratio } & p \\ \text { Noconstant } & & & & \\ \text { QC1 } & 0.5010 & 0.1604 & 3.12 & 0.004 \\ \text { FR } & -7.375 & 2.453 & -3.01 & 0.006 \\ \text { PP } & 0.2722 & 0.2361 & 1.15 & 0.259 \\ \text { PO } & -0.1399 & 0.7770 & -0.18 & 0.858 \\ \text { QC1XFR } & -0.06697 & 0.06076 & -1.10 & 0.280 \\ \text { QC1XPP } & -0.001752 & 0.001889 & -0.93 & 0.362 \\ \text { LC1XPO } & -0.07719 & 0.03331 & -2.32 & 0.028 \\ \text { FRXPP } & -0.00060 & 0.04420 & -0.01 & 0.989 \\ \text { FR PPO } & 2.2721 & 0.7150 & 3.18 & 0.004 \\ \text { PPXPO } & -0.08243 & 0.05978 & -1.38 & 0.179\end{array}$

$s=0.9100$

Analysis of Variance

\begin{tabular}{|c|c|c|c|c|}
\hline $\begin{array}{l}\text { SOURCE } \\
\text { Regression } \\
\text { Error } \\
\text { rotal }\end{array}$ & $\begin{array}{l}\text { DF } \\
10 \\
28 \\
38\end{array}$ & $\begin{array}{r}S S \\
214.208 \\
23.186 \\
237.394\end{array}$ & $\begin{array}{r}\text { MS } \\
21.421 \\
0.828\end{array}$ & $\begin{array}{r}F \\
25.87\end{array}$ \\
\hline $\begin{array}{l}\text { POURCE } \\
\text { CI } \\
R \\
\mathrm{P} \\
\mathrm{O} \\
\mathrm{C} 1 \times \mathrm{XPR} \\
\mathrm{C} 1 \times \mathrm{PP} \\
\mathrm{C} 1 \times \mathrm{PPO} \\
\mathrm{R} \times \mathrm{PP} \\
\mathrm{R} \times \mathrm{PO} \\
\mathrm{P} \times \mathrm{PO}\end{array}$ & $\begin{array}{r}\text { DF } \\
1 \\
1 \\
1 \\
1 \\
1 \\
1 \\
1 \\
1 \\
1 \\
1\end{array}$ & $\begin{array}{r}\text { SEQ SS } \\
172.501 \\
10.176 \\
5.953 \\
12.180 \\
0.218 \\
1.557 \\
1.202 \\
1.507 \\
7.340 \\
1.575\end{array}$ & & \\
\hline
\end{tabular}

nusual Observations

bs. QC1 QC1/N1

$\begin{array}{lll}5 & 17.3 & 5.376\end{array}$

Fit Stdev.Fit Residual

St.Resid

4.281

0.287

2.491

2.88R

28.7

2.885

0.809

0.064

$0.15 \mathrm{X}$

23

0.872

4.217

0.824

0.050

$0.13 \mathrm{X}$

15.4

2.458

0.381

1.784

$2.16 \mathrm{R}$

38

1.949

0.863

$-0.655$

$-2.27 R X$

denotes an obs. with a large st. resid.

denotes an obs. whose $x$ value gives it large influence. 


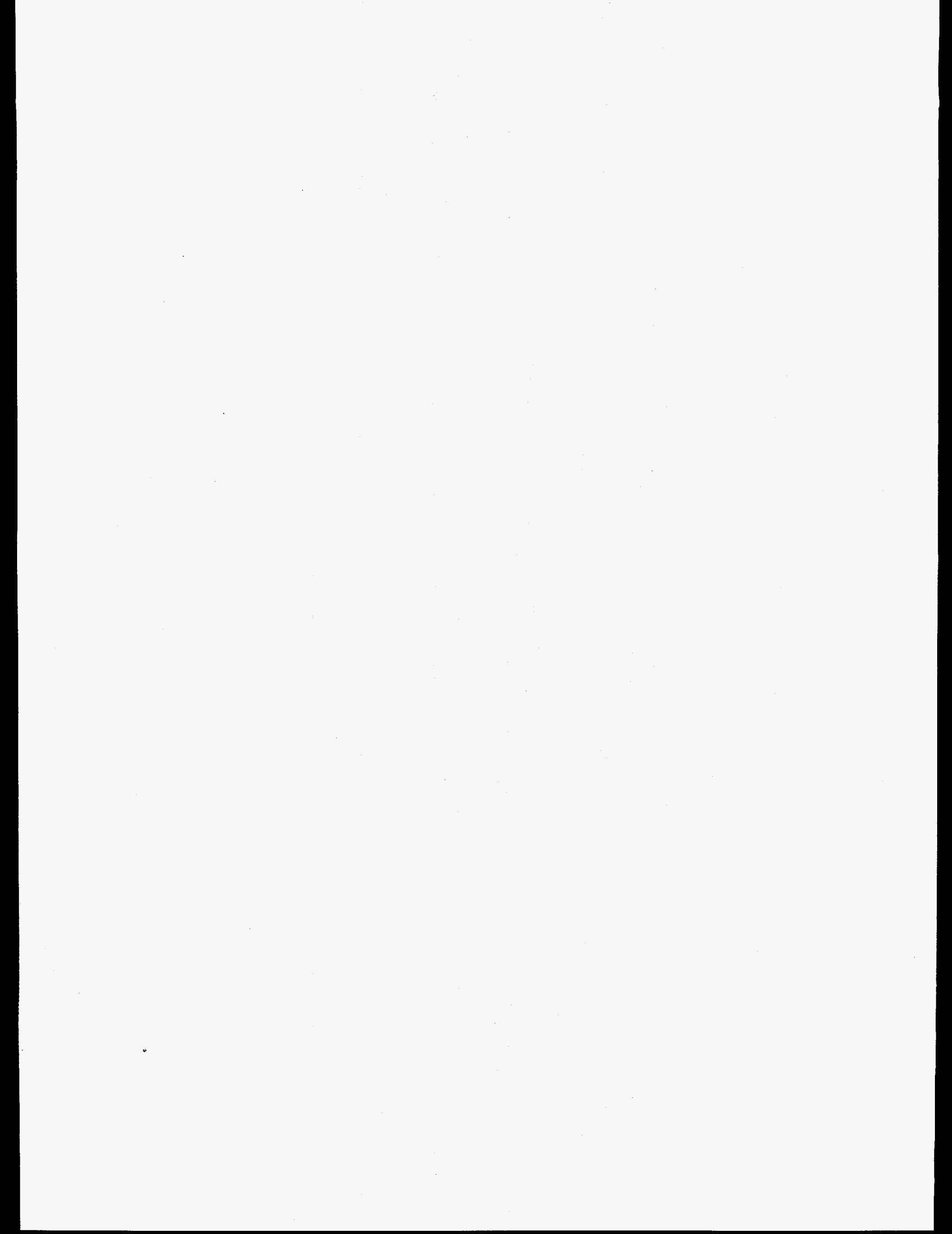


MTB > DOTPLOT C12

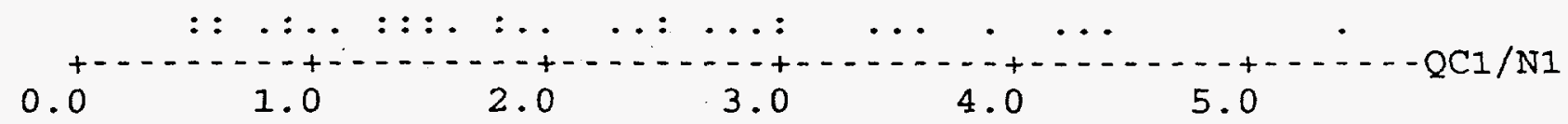

MTB > DOTPLOT C99

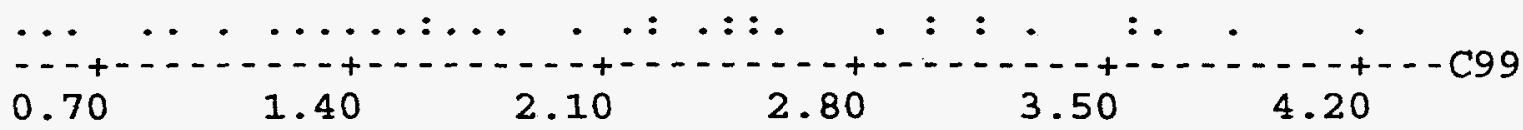

MTB > CORR C12 C99

forrelation of $\mathrm{QC1} / \mathrm{N} 1$ and $\mathrm{C} 99=0.781$

ITB > READ 'ST.DAT' C1-C5

176 ROWS READ

$\begin{array}{rrrrrr}\text { ROW } & \text { N1 } & \text { QC1 } & \text { FR } & \text { PP } & \text { PO } \\ & & & & & \\ 1 & 4.63 & 83.23 & 1.11 & 1.18 & 4.67 \\ 2 & 2.30 & 49.03 & 1.55 & 2.23 & 4.73 \\ 3 & 13.31 & 53.37 & 1.28 & 2.09 & 4.75 \\ 4 & 14.59 & 80.03 & 0.51 & 0.66 & 4.81\end{array}$

TRB > EXEC 'NAMES.PRG'

TTB > NAME C1 ' $\mathrm{N} 1$ '

$\mathrm{TB}>\mathrm{NAME} \mathrm{C} 2$ ' $\mathrm{QC1}$ '

TB > NAME C3 'FR'

TB > NAME C4 ' $\mathrm{PP}$ '

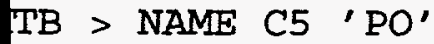

$\mathrm{TB}>\mathrm{LET} \mathrm{C} 6=\mathrm{C} 2 * \mathrm{C} 3$

$\mathrm{TB}>\mathrm{LET} \mathrm{C} 7=\mathrm{C} 2 * \mathrm{C4}$

$\mathrm{TB}>\mathrm{LET} \mathrm{C} 8=\mathrm{C} 2 * \mathrm{C} 5$

$\mathrm{TB}>\mathrm{LET}$ C9 $=\mathrm{C} 3 * \mathrm{C} 4$

$\mathrm{TB}>\mathrm{LET} \mathrm{C} 10=\mathrm{C} 3 * \mathrm{C} 5$

$\mathrm{TB}>\mathrm{LET} \mathrm{C} 11=\mathrm{C} 4 * \mathrm{C} 5$

$\mathrm{IB}>\mathrm{LET} \mathrm{C} 12=\mathrm{C} 2 / \mathrm{C} 1$

$\Gamma \mathrm{C}>$ NAME C6 'QCIXFR'

$\mathrm{IB}>$ NAME C7 'QC1XPP'

$\mathrm{TB}>$ NAME C8 'QC1XPO'

$\mathrm{IB}>$ NAME C9 'FRXPP'

$\mathrm{TB}>$ NAME $\mathrm{C} 10$ 'FRXPO'

$\mathrm{CB}>\mathrm{NAME} \mathrm{CII}$ 'PPXPO' 
$\mathrm{MTB}>\mathrm{NAME} \mathrm{C} 12^{\prime} \mathrm{QC} 1 / \mathrm{N1}$ '

$M T B>$ NOCONSTANT

MTB > REGRESS C12 ON 10 C2-C11 C98 C99

* NOTE * QC1 is highly correlated with other

* NOTE * FR is highly correlated with other

$P P$ is highly correlated with other

* NOTE *

* NOTE *

QClXPP is highly correlated with other

* NOTE *

QClXPO is highly correlated with other

FRXPO is highly correlated with other

* NOTE *

PPXPO is highly correlated with other

predictor variables predictor variables predictor variables predictor variables predictor variables predictor variables

* NOTE * predictor variables

The regression equation is

$\mathrm{QCl} / \mathrm{NI}=-0.079 \mathrm{QC1}+4.47 \mathrm{FR}-0.82 \mathrm{PP}+1.33 \mathrm{PO}+0.0223 \mathrm{QCI} \times \mathrm{FR}$ +0.000642 QC1XPP + 0.0238 QC1XPO + 0.119 FRXPP -1.34 FRXPO +0.075 PPXPO

$\begin{array}{lrrrr}\text { Predictor } & \text { Coef } & \text { Stdev } & \text { t-ratio } & \text { p } \\ \text { Noconstant } & & & & \\ \text { QC1 } & -0.0787 & 0.1394 & -0.56 & 0.573 \\ \text { FR } & 4.471 & 9.197 & 0.49 & 0.627 \\ \text { PP } & -0.820 & 2.125 & -0.39 & 0.700 \\ \text { PO } & 1.3331 & 0.6170 & 2.16 & 0.032 \\ \text { QC1XFR } & 0.02232 & 0.03382 & 0.66 & 0.510 \\ \text { QCIXPP } & 0.0006421 & 0.0004358 & 1.47 & 0.143 \\ \text { QC1XPO } & 0.02378 & 0.03082 & 0.77 & 0.441 \\ \text { FRXPP } & 0.1186 & 0.1793 & 0.66 & 0.509 \\ \text { FRXPO } & -1.341 & 1.909 & -0.70 & 0.484 \\ \text { PPXPO } & 0.0751 & 0.4111 & 0.18 & 0.855\end{array}$

$s=10.27$

Analysis of Variance

SOURCE

Regression

Error

Total

DF
10
166
176

10

166

176
SS

17040.1

17512.9

34553.0
MS

1704.0

105.5 $\mathrm{p}$

$$
0.573
$$

0.700

0.032

0.510

0.143

0.441

0.484

0.855 
SOURCE

QC1

FR

PP

PO

QCIXFR

$\mathrm{QCIXPP}$

$\mathrm{QC} 1 \times \mathrm{PO}$

$\mathrm{FRPPP}$

$\mathrm{F} \times \mathrm{PO}$

PXPO

$\begin{array}{rr}D F & S E Q S S \\ 1 & 16218.5 \\ 1 & 25.4 \\ 1 & 2.0 \\ 1 & 211.1 \\ 1 & 6.2 \\ 1 & 459.8 \\ 1 & 23.7 \\ 1 & 33.3 \\ 1 & 56.5 \\ 1 & 3.5\end{array}$

Inusual Observations

$\begin{array}{rrrrrrr}\text { Pbs. } & \text { QC1 } & \text { QC1/N1 } & \text { Fit } & \text { Stdev.Fit } & \text { Residual } & \text { St.Resid } \\ 40 & 105 & 7.820 & 12.642 & 4.288 & -4.822 & -0.52 \mathrm{X} \\ 68 & 54 & 1.425 & 5.997 & 5.225 & -4.572 & -0.52 \mathrm{X} \\ 87 & 63 & 41.500 & 5.545 & 1.566 & 35.955 & 3.54 \mathrm{R} \\ 94 & 1178 & 105.112 & 105.102 & 10.271 & 0.010 & 0.19 \mathrm{X} \\ 96 & -362 & 20.652 & 18.317 & 7.947 & 2.336 & 0.36 \mathrm{X} \\ 03 & 39 & 1.470 & 1.285 & 4.668 & 0.185 & 0.02 \mathrm{X} \\ 27 & 25 & 1.226 & -2.502 & 6.970 & 3.728 & 0.49 \mathrm{X} \\ 46 & 78 & 56.304 & 8.715 & 1.390 & 47.590 & 4.68 \mathrm{R} \\ 47 & 54 & 117.261 & 7.233 & 1.206 & 110.028 & 10.79 \mathrm{R} \\ 67 & 16 & 1.340 & -1.178 & 5.578 & 2.518 & 0.29 \mathrm{X}\end{array}$

denotes an obs. with a large st. resid.

denotes an obs. whose $X$ value gives it large influence.

TRB > DOTPLOT C12

ach dot represents 5 points

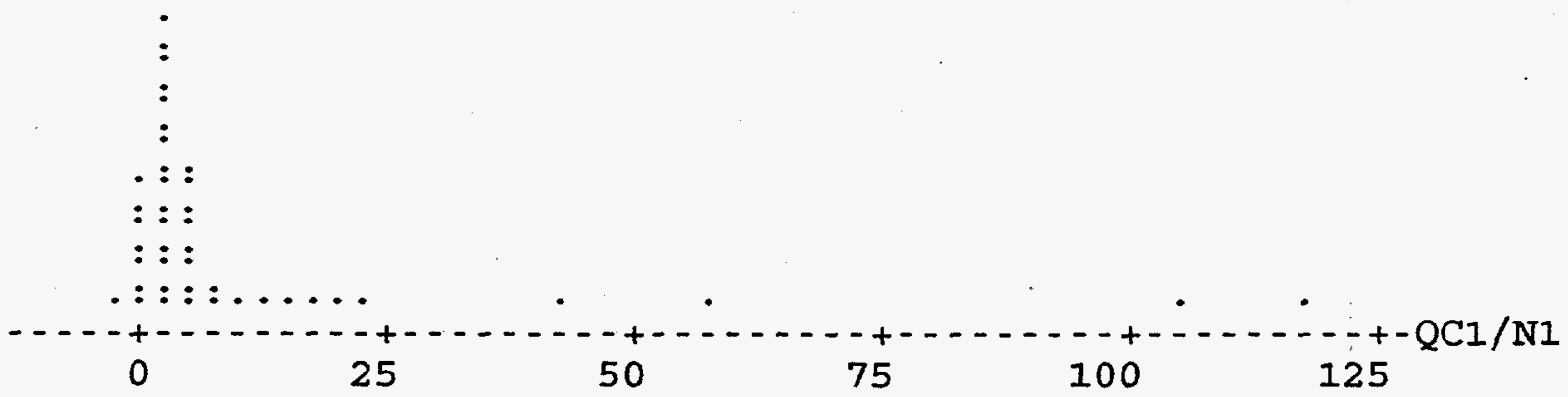




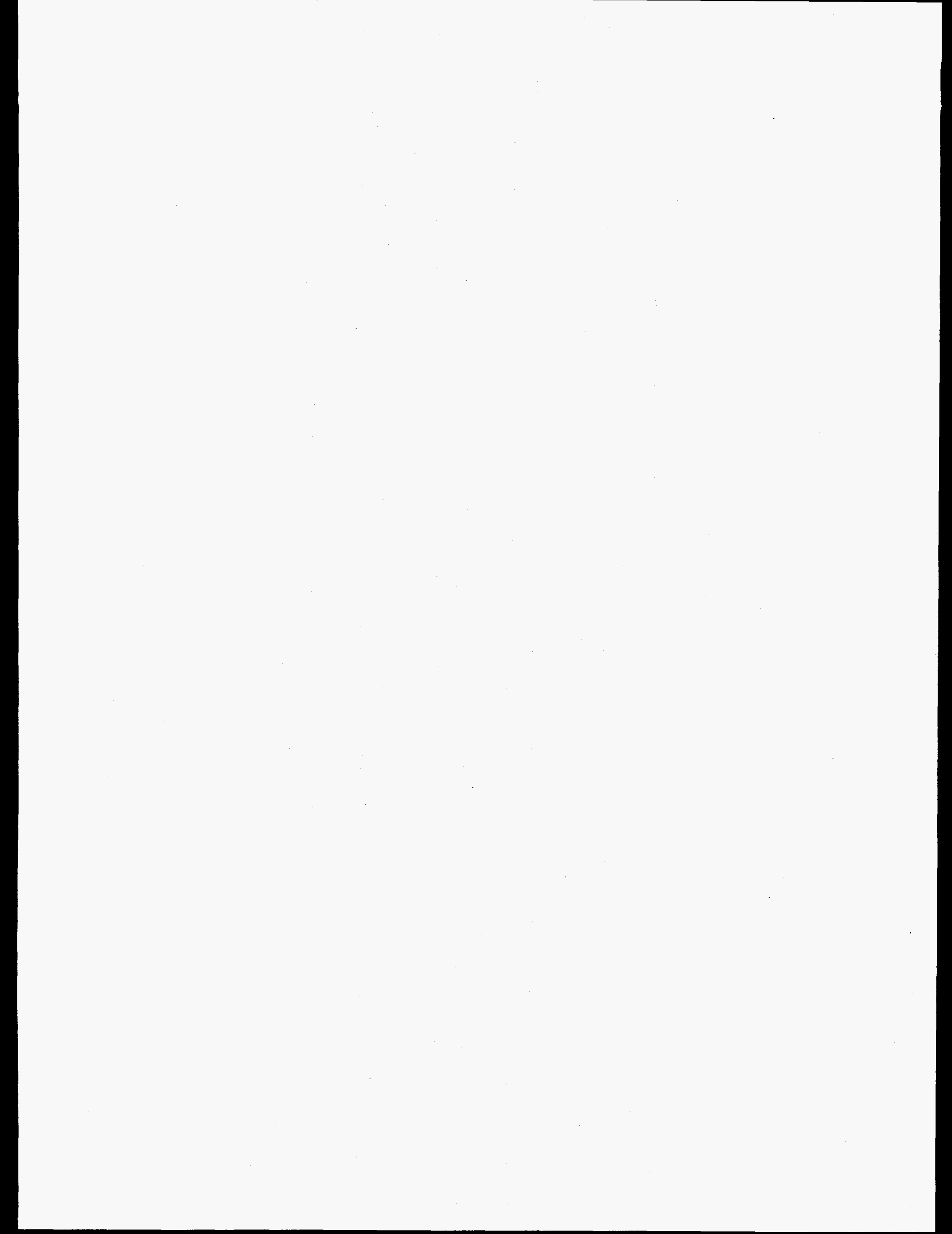


MTB > DOTPLOT C99

Each dot represents 3 points

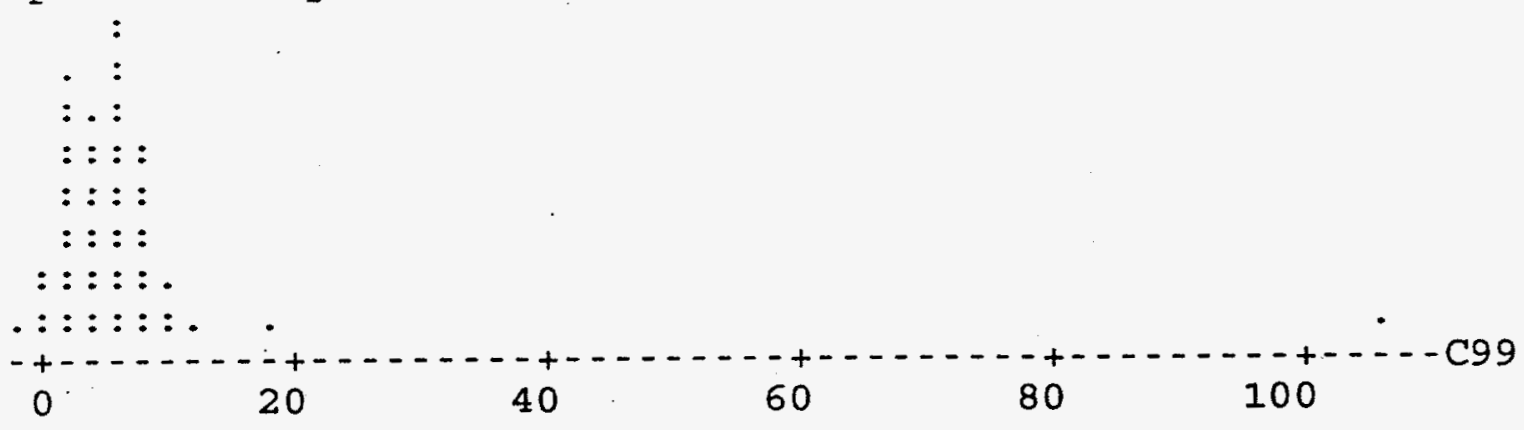

TTB > NOTE REMOVE ALI QCI/NI > 25

TOTE $* * *$ Data Editor entered at this point.

ITB > REGRESS C12 ON 10 C2-C11 C98 C99

NOTE * QC1 is highly correlated with other

NOTE * - FR is highly correlated with other

NOTE * PP is highly correlated with other

NOTE * QCIXPO is highly correlated with other

NOTE * FRXPO is highly correlated with other

NOTE *

PPXPO is highly correlated with other

predictor variables

predictor variables

predictor variables

predictor variables

predictor variables

predictor variables

he regression equation is

$\mathrm{Cl} / \mathrm{N} 1=-0.0651 \mathrm{QCI}+3.34 \mathrm{FR}-0.215 \mathrm{PP}+0.697 \mathrm{PO}+0.0195 \mathrm{QCIXFR}$ +0.00220 QC1XPP + 0.0196 QC1XPO + 0.0062 FRXPP -0.918 FRXPO $+0.017 \mathrm{PPXPO}$

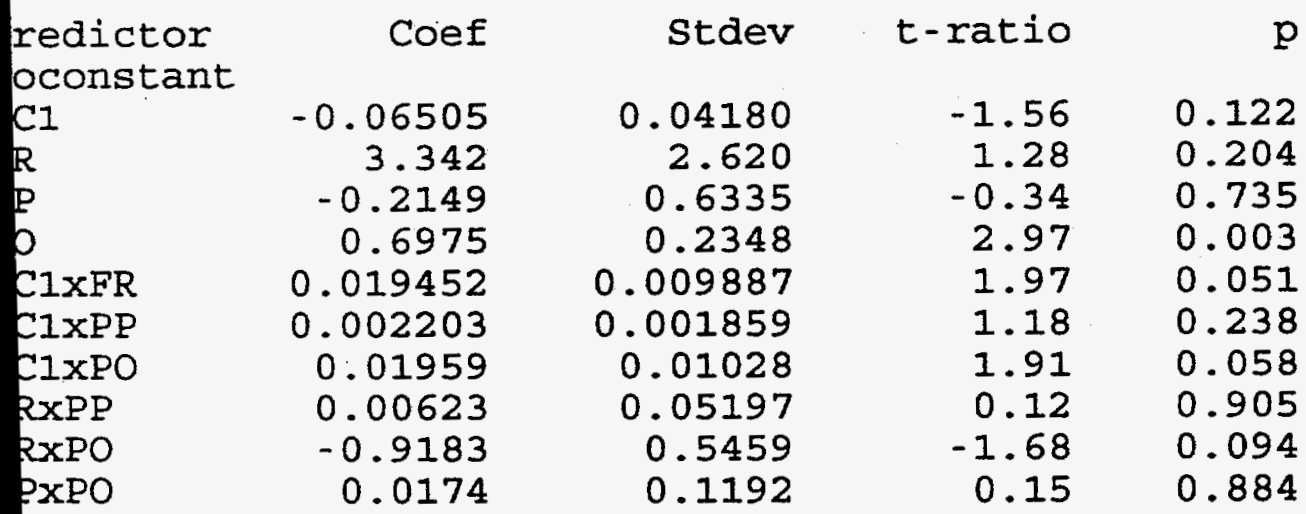

$=2.919$

halysis of Variance

DURCE DF

gression 10

rror

btal
161

171
SS

3486.01

1372.10

4858.11
MS

348.60

8.52
$40.90 \quad 0.000$ 


$\begin{array}{lrr}\text { SOURCE } & \text { DF } & \text { SEQ SS } \\ \text { QC1 } & 1 & 3186.08 \\ \text { FR } & 1 & 38.02 \\ \text { PP } & 1 & 1.20 \\ \text { PO } & 1 & 146.69 \\ \text { QC1XFR } & 1 & 24.43 \\ \text { QC1XPP } & 1 & 43.65 \\ \text { QC1XPO } & 1 & 12.52 \\ \text { FRXPP } & 1 & 0.23 \\ \text { FRXPO } & 1 & 33.01 \\ \text { PPXPO } & 1 & 0.18\end{array}$

Unusual Observations

\begin{tabular}{|c|c|c|c|c|c|c|}
\hline Obs. & QC1 & $\mathrm{QCl} / \mathrm{NI}$ & Fit & stdev. Fit & Residual & St.Resid \\
\hline 1 & 83 & 17.976 & 6.272 & 0.455 & 11.704 & $4.06 \mathrm{R}$ \\
\hline 2 & 49 & 21.317 & 4.546 & 0.345 & 16.771 & $5.79 R$ \\
\hline 18 & 90 & 14.030 & 7.849 & 0.736 & 6.180 & $2.19 \mathrm{R}$ \\
\hline 21 & 33 & 14.705 & 3.935 & 0.418 & 10.770 & $3.73 R$ \\
\hline 22 & 43 & 13.850 & 4.608 & 0.416 & 9.242 & $3.20 R$ \\
\hline 40 & 105 & 7.820 & 9.295 & 1.358 & -1.475 & $-0.57 x$ \\
\hline 68 & 54 & 1.425 & 4.816 & 1.586 & -3.391 & $-1.38 x$ \\
\hline 75 & 153 & 2.973 & 8.606 & 1.083 & -5.633 & $-2.08 R$ \\
\hline 79 & 139 & 17.029 & 9.315 & 1.143 & 7.714 & $2.87 R$ \\
\hline 93 & 362 & 20.652 & 20.243 & 2.722 & 0.409 & $0.39 \mathrm{x}$ \\
\hline 100 & 39 & 1.470 & 1.869 & 1.345 & -0.398 & $-0.15 x$ \\
\hline 112 & 21 & 8.824 & 2.379 & 0.439 & 6.445 & $2.23 R$ \\
\hline 12 & 25 & 1.226 & 0.745 & 1.990 & 0.481 & 0.2 \\
\hline 6 & 16 & 1.340 & -0.421 & 1.616 & 1.761 & 0.7 \\
\hline
\end{tabular}

$R$ denotes an obs. with a large st. resid.

denotes an obs. whose $x$ value gives it large influence.

MTB > DOTPLOT $\mathrm{C} 12$

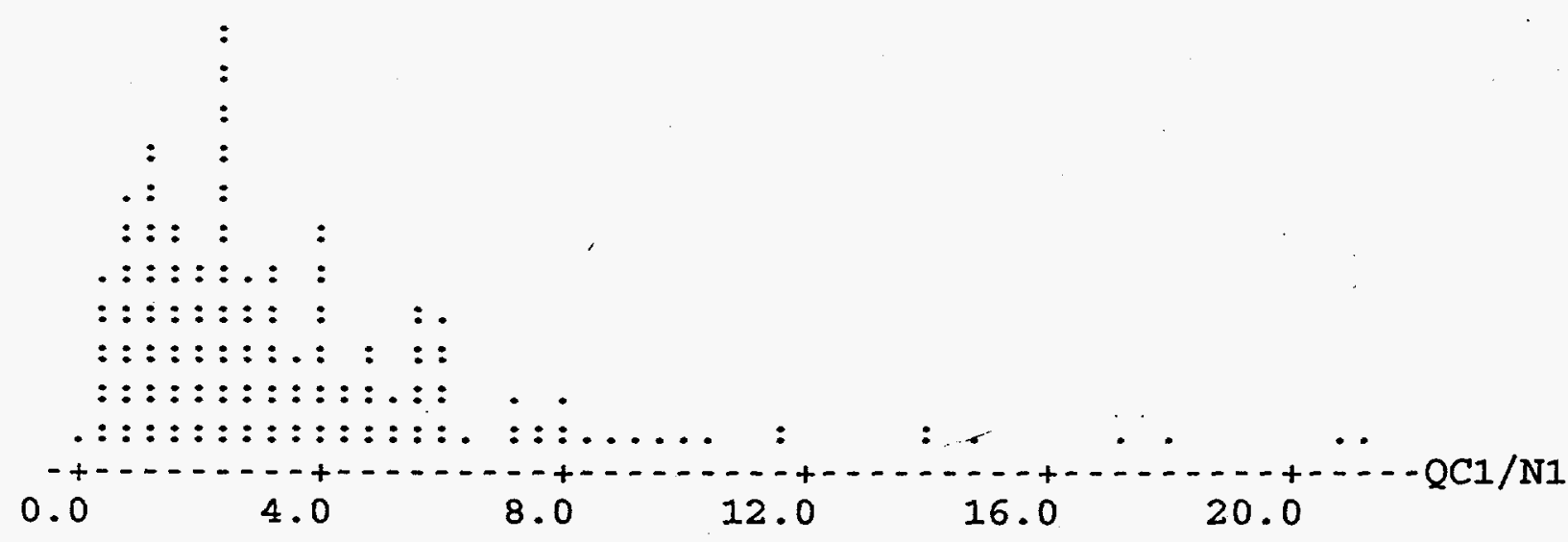

